\title{
Modelling vegetation-climate interactions in South and Southeast Asia using a trait-based dynamic vegetation model
}

\author{
Dissertation \\ zur Erlangung des Doktorgrades \\ der Naturwissenschaften \\ vorgelegt beim Fachbereich Geowissenschaften / Geographie \\ der Johann Wolfgang Goethe -Universität \\ in Frankfurt am Main
}

Von

Dushyant Kumar

aus Tawang, India

Frankfurt (2020)

(D 30) 
Vom Fachbereich Geowissenschaften / Geographie der

Johann Wolfgang Goethe - Universität als Dissertation angenommen.

\section{Dekan:}

Prof. Dr. Georg Rümpker

Johan Wolfgang Goethe Universität

Institut für Geowissenschaftenen

Altenhöferallee 1, D-60438 Frankfurt am Main

\section{Gutachter:}

Dr. Simon Scheiter

Senckenberg Biodiversität und Klima Forschungszentrum

Senckenberganlage 25, D- 60325 Frankfurt am Main

Prof. Dr. Thomas Hickler

Johann Wolfgang Goethe Universität

Institut für Physische Geographie

Altenhöferallee 1, D-60438 Frankfurt am Main

Datum der Disputation: 20 $0^{\text {th }}$ July, 2021 


\section{TABLE OF CONTENTS}

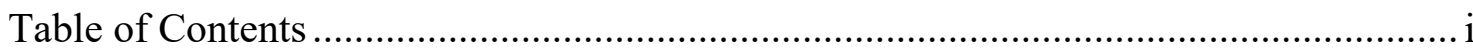

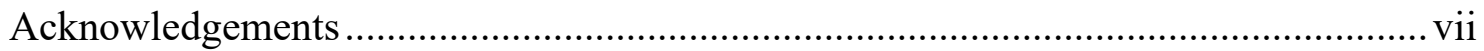

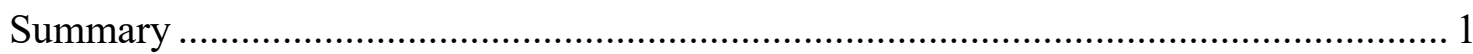

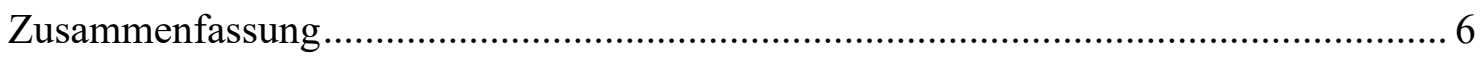

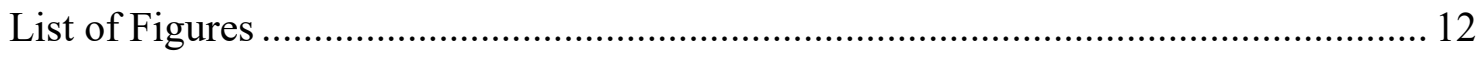

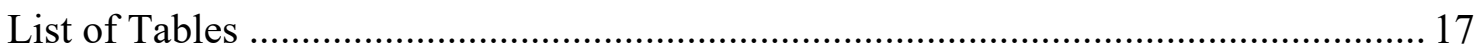

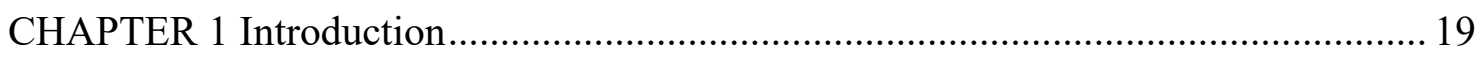

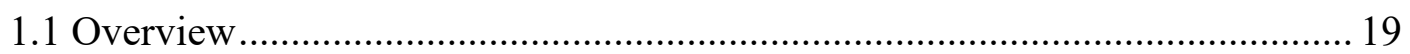

1.1.1 Role of climate in vegetation distribution ...................................... 20

1.1.2 South and Southeast Asia - Phytogeography .................................. 21

1.1.3 South and Southeast Asia - Climatology ......................................... 22

1.1.4 Biodiversity of South and Southeast Asia ........................................... 24

1.1.5 Anthropogenic impacts on the ecosystem .......................................... 25

1.1.6 Climate-vegetation interaction in tropical Asia: review .....................226

1.1.7 Biodiversity conservation in protected areas under climate change.......28

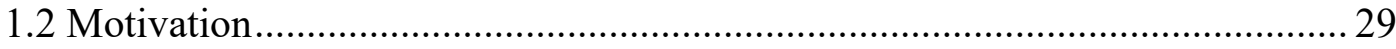

1.2.1 Dynamic Global Vegetation Models (DGVMs)....................................3 34

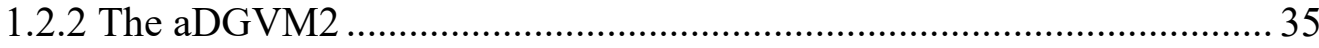

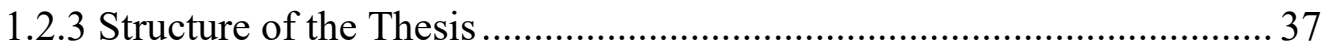

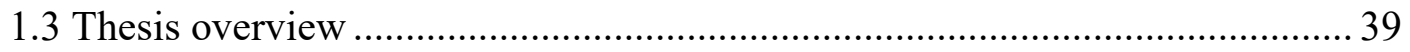

CHAPTER 2 Biome diversity in South Asia - How can we improve vegetation models to understand global change impact at regional level? ............................... 41

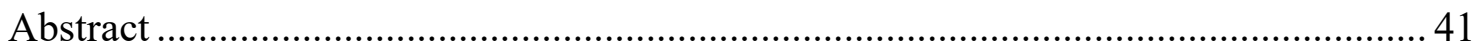

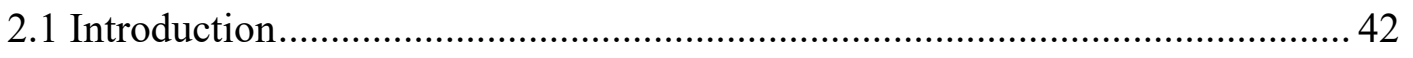

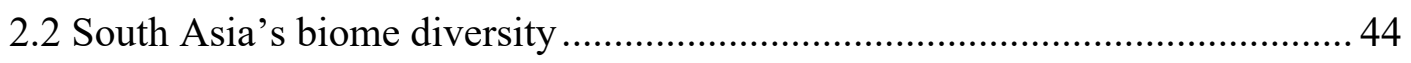


2.3 South Asia's contribution to global carbon cycle ......................................... 45

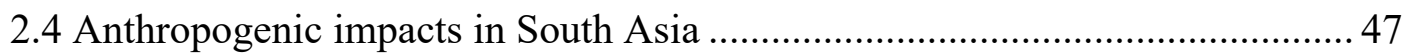

2.5 Dynamic global vegetation models (DGVMs) ............................................ 48

2.6 Current status of vegetation modelling in South Asia ................................... 49

2.7 Current challenges in vegetation modelling .............................................. 50

2.8 Potential of developing DGVMs in South Asia............................................... 53

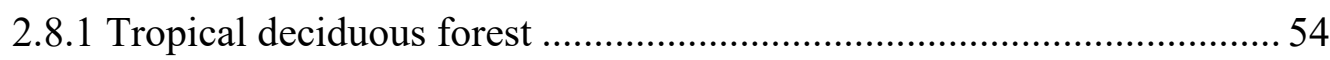

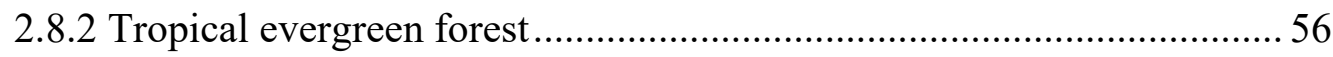

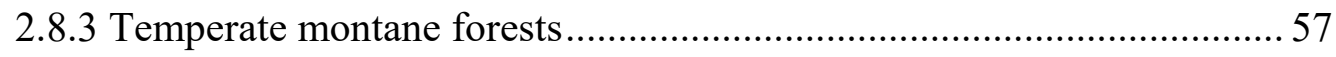

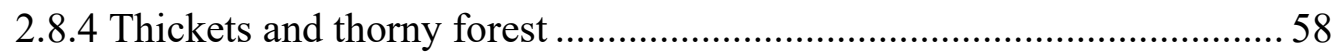

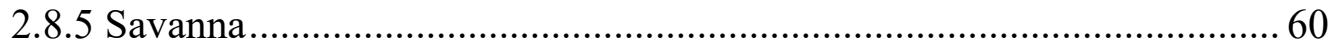

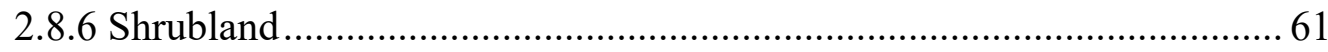

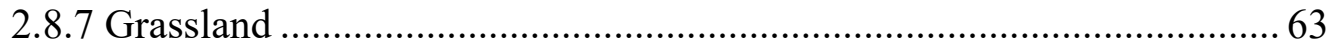

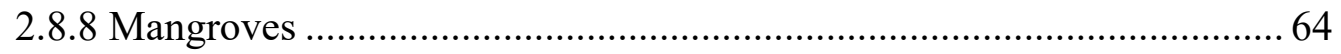

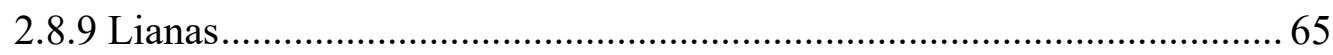

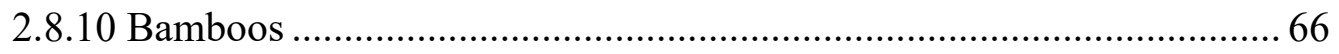

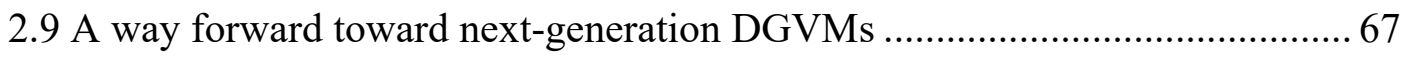

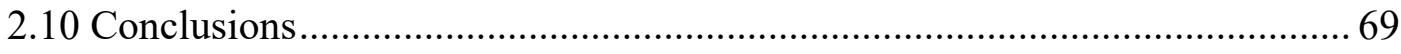

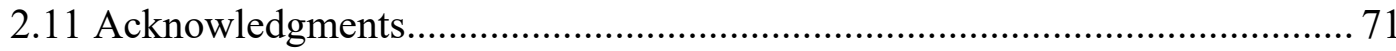

CHAPTER 3 Climate change and elevated $\mathrm{CO}_{2}$ favor forest over savanna under different future scenarios in South Asia ....................................................................... 73

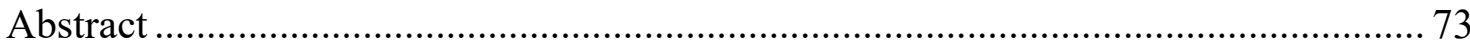

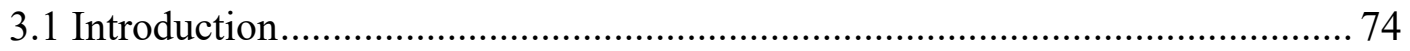

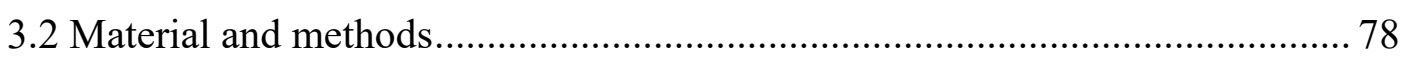

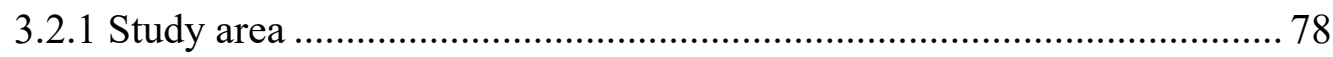

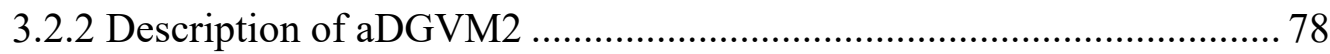

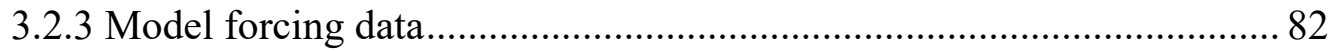




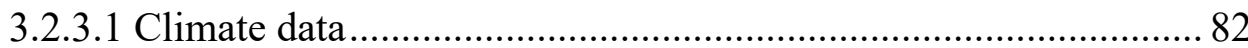

3.2.3.2 Projected changes in temperature and precipitation.................... 82

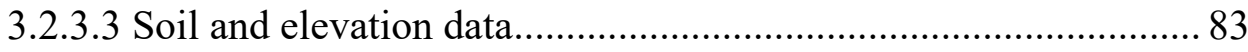

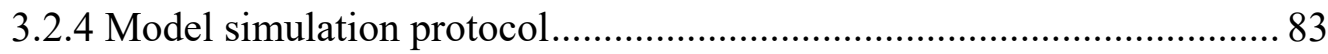

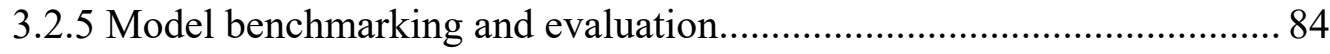

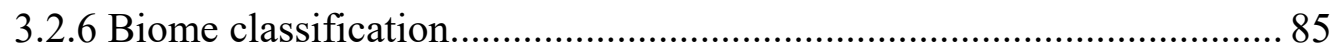

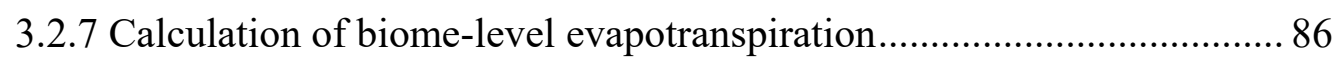

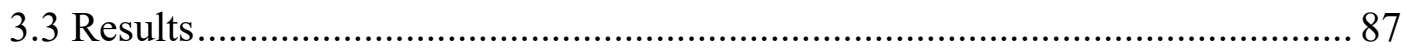

3.3.1 Model performance and contemporary vegetation patterns ..................8 87

3.3.2 Projected changes in biome distribution pattern.................................. 89

3.3.3 Projected changes in biomass at biome level ...................................... 91

3.3.4 Projected changes in evapotranspiration at biome level ....................... 94

3.3.5 Response of mean ET and mean above ground biomass to climate

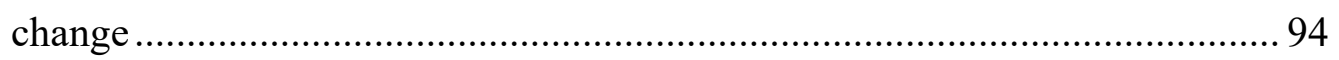

3.3.6 Impact of climate change on climatic niches of biomes ...................... 96

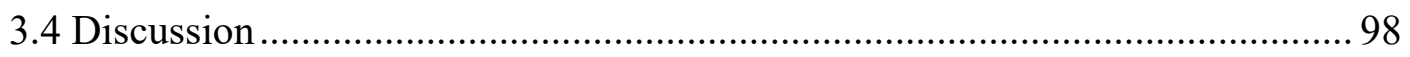

3.4.1 Impact of climate change and elevated $\mathrm{CO}_{2}$ on biomes and biomass .... 98

3.4.2 Impact of climate change and fixed $\mathrm{CO}_{2}$ on biomes and biomass ....... 100

3.4.3 Impact of climate change and $\mathrm{CO}_{2}$ change on climatic niches of

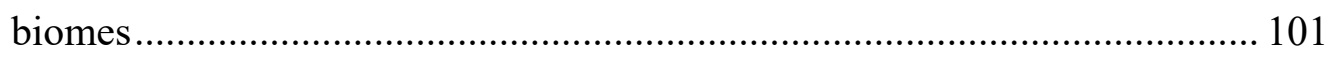

3.4.4 Effect of $\mathrm{CO}_{2}$ on ET and its interaction with climate change.............. 102

3.4.5 Implication of the projected change for conservation ....................... 103

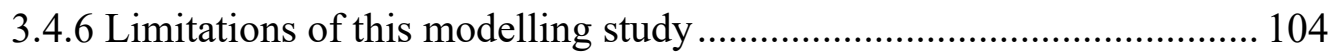

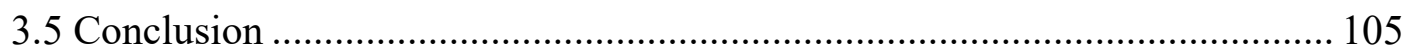

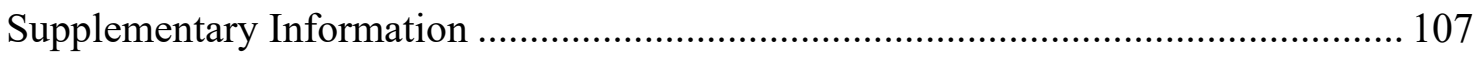

CHAPTER 4 Climate change promotes transitions to tall evergreen vegetation in tropical Asia 


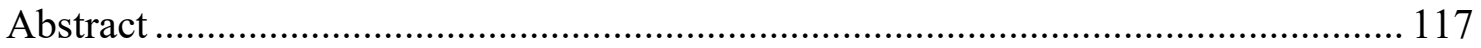

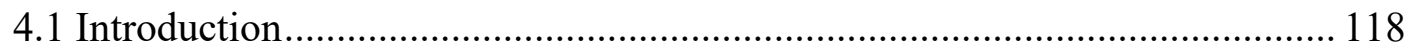

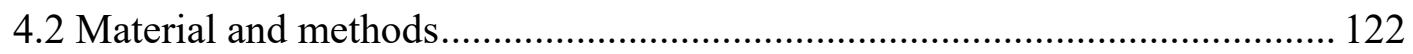

4.2.1 Description of aDGVM2 _.......................................................... 122

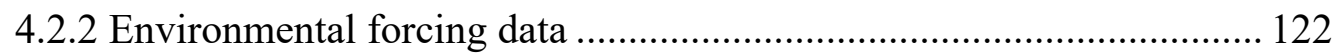

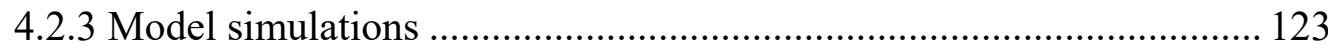

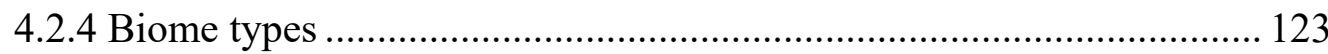

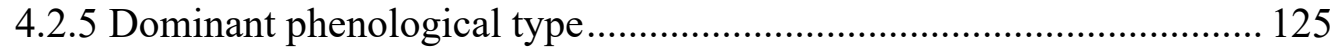

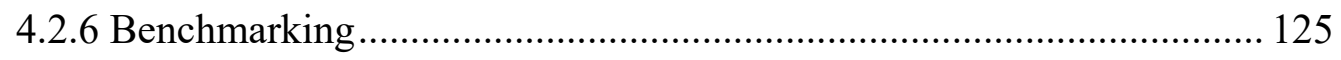

4.2.7 Biomass and height changes ................................................... 126

4.2.8 Cultivated and managed vegetation............................................... 126

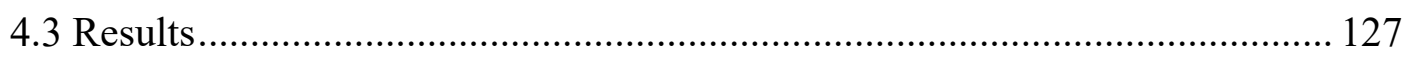

4.3.1 Vegetation state under current climate conditions........................... 127

4.3.2 Climate change impacts on biomass and height ............................... 129

4.3.3 Climate change impacts on phenology and biomes.......................... 135

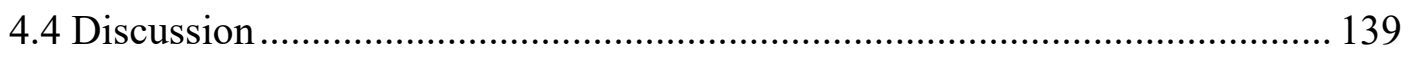

4.4.1 Biomass increase and $\mathrm{CO}_{2}$ fertilization ........................................ 139

4.4.2 Ecological strategies, biomes and ecosystem functions .................... 142

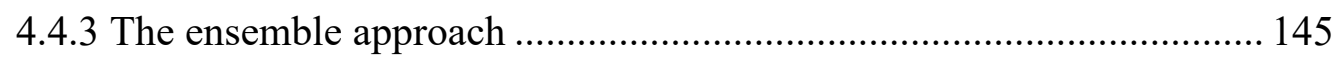

4.4.4 Anthropogenic impacts and implications for management ................ 145

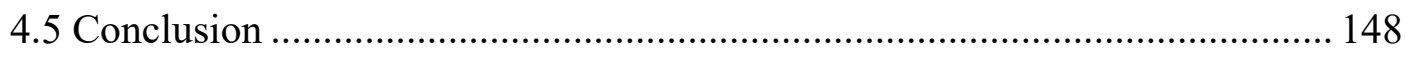

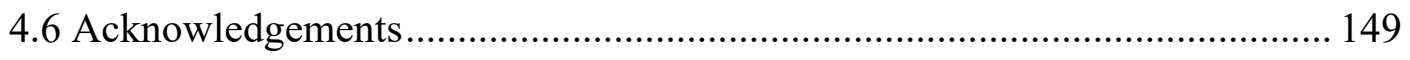

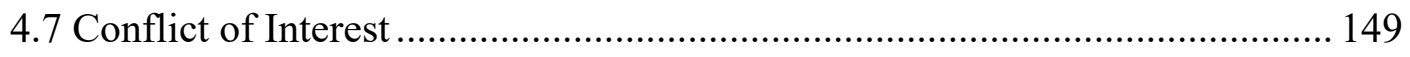

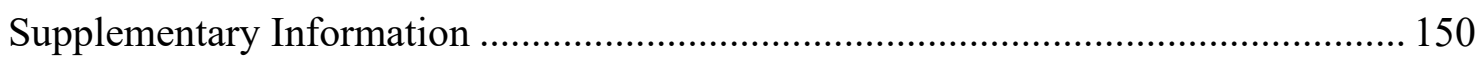

CHAPTER 5 Misinterpretation of Asian savannas as degraded forest can mislead management and conservation policy under climate change .................................. 163

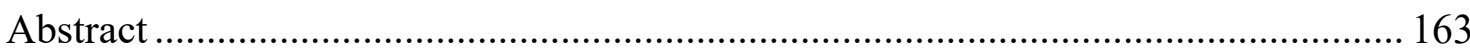




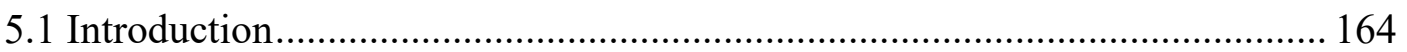

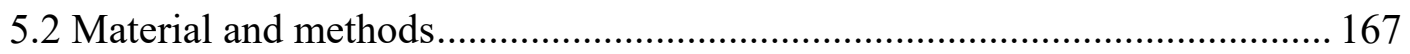

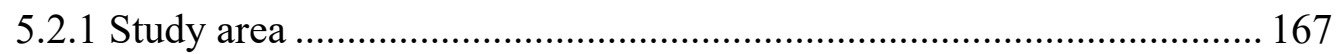

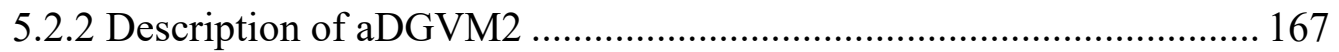

5.2.3 Environmental drivers and experimental model setup ...................... 168

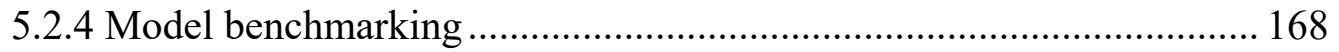

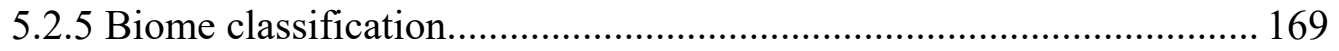

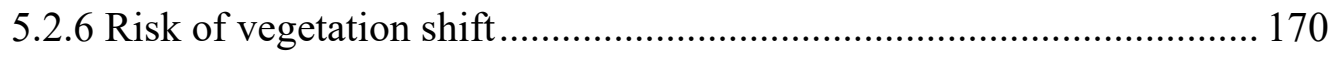

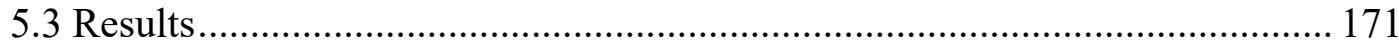

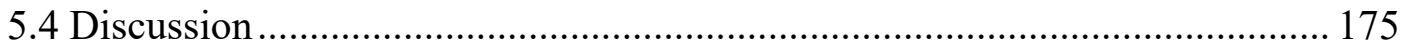

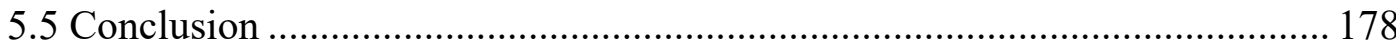

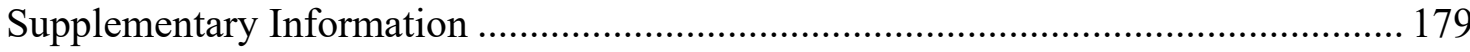

CHAPTER 6 General overview, outlook and conclusion....................................... 183

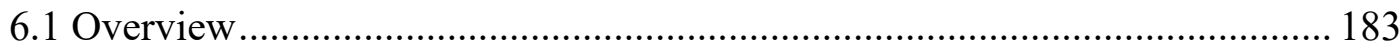

6.1.1 Improving the representation of regional vegetation in DGVMs ......... 184

6.1.2 Modelling the potential vegetation dynamics in South Asia, using traitbased vegetation model-aDGVM2 …..................................................... 186

6.1.3 Modelling the impact climate on vegetation structure and phenology. 188

6.1.4 Conservation of threatened Asian savanna under climate change....... 189

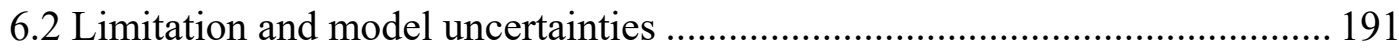

6.2.1 Inclusion of anthropogenic factors .................................................. 191

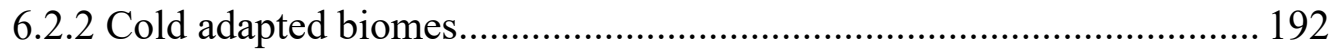

6.2.3 Detailed representation of various carbon pools ............................... 193

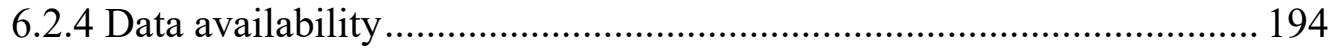

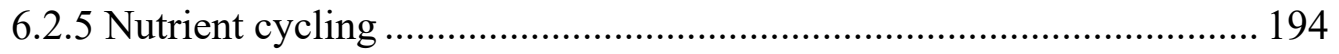

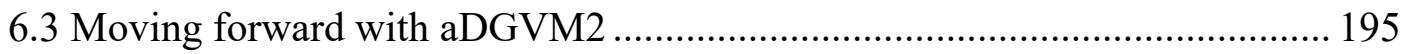

6.3.1 Building the way forward for biome-trait spectrum with aDGVM2 ... 195 
6.3.2 Investigating lag-effects on diversity with aDGVM2 ...................... 196

6.4 Expansion of aDGVM2 for global scale.................................................... 197

6.4.1 Including temperate and boreal vegetation communities .................... 198

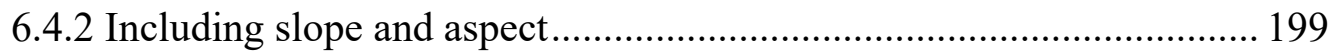

6.4.3 Including temperature triggered phenology...................................... 200

6.5 Significance of presented research............................................................. 201

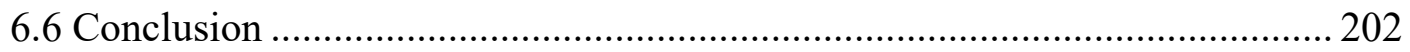

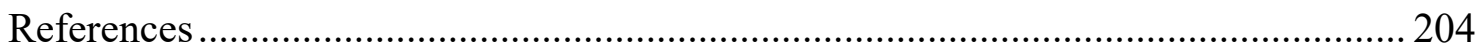

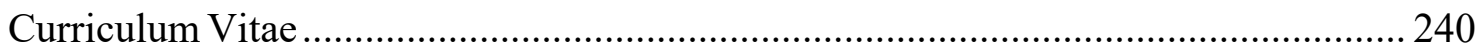




\section{ACKNOWLEDGEMENTS}

In pursuit of this academic endeavor, I was advised, encouraged, and guided by several individuals who were instrumental in one way or another in shaping my academic career. This thesis would not have been possible without the guidance and the help of several individuals who, contributed and extended their valuable assistance in the preparation and completion of this study. So, I avail of this opportunity to express my sincere sense of gratitude and heartfelt thanks by acknowledging all of them.

First and foremost, I would like to express my sincere gratitude and regards to my Ph.D. supervisor, Dr. Simon Scheiter, for his continuous guidance, motivation, and fruitful discussions. I have learned a great deal about critical thinking, ethics, and integrity in the research environment from my association with him. He encouraged me to not only grow as a researcher but also as an independent thinker. Admittedly, the lessons learned from him will hold me well in my future professional endeavors. I am incredibly grateful to him for his contributions towards making my $\mathrm{Ph} . \mathrm{D}$. experience productive and transforming me into a confident researcher.

I would like to gratefully acknowledge the Senckenberg Biodiversity \& Climate Research Center (SBiK-F) in Frankfurt am Main for providing the required facilities and technical support for conducting my research work. I am also thankful to the DFG, which funded my research. I would also like to acknowledge my teammates and friends (Carola, Mirjam, Liam and Camille) for their cooperation and supports throughout this journey.

I shall fail in my duty if I could not express the feelings and indebtedness lying in the tender core of my heart towards my father Shri Kalpnath Prasad, mother Smt. Meena Devi, my brother Parmanand, and my sister Anshu for their blessings and wellwishes, who have shouldered innumerable difficulties, allowing me to be as ambitious as I wanted. I would not have been here in the first place without their faith in me. 



\section{SUMMARY}

Climate controls the broad-scale distributions of plant species and vegetation more than any other factor. Rapid climate change associated with increasing greenhouse gas emissions influences current and future vegetation patterns. Change in the global climate will alter ecosystems, biome boundaries, biodiversity patterns, and the supply of relevant ecosystem services. The important drivers of change other than climate include airborne nitrogen deposition, biotic interactions (invasive species), and atmospheric carbon dioxide $\left(\mathrm{CO}_{2}\right)$ (fertilizing or water use efficiency effects). The relative importance of these drivers in causing ecological change is critical to predicting future ecological dynamics, and depends on different spatial scales. The impacts of climate change on vegetation are complex, and our understanding of these interactions is complicated by these other factors. A better understanding of the consequences of climate change is required, particularly in under-investigated regions such as tropical Asia, i.e., South and South-east Asia. Tropical Asia is host to 7 of the 36 global biodiversity hotspots, and therefore effective management strategies would require an in-depth understanding of the response of vegetation to climate change.

The projected climate changes have been shown to have negative impacts on nature, thus representing a threat to human well-being. However, many effects caused by climate change and rising atmospheric $\mathrm{CO}_{2}$ are poorly understood in the region. This demands timely action to identify and protect the most vulnerable ecosystems. Management strategies also need to be informed with the recent knowledge of the ecosystem, especially from the biodiversity perspective. For example, Asian savannas have been treated as degraded forests and managed from the forestry point of view, but this endangers the endemic diversity and wildlife dependent on savannas. The main objective of this thesis was to investigate the impact of climate change and rising $\mathrm{CO}_{2}$ on biome patterns, biome boundaries, biome productivity, and phenology in Tropical Asia. I explored how rising temperature and changing precipitation regimes affect the biome boundaries and ecosystem functions by altering vegetation structure and productivity. This study also identified the vulnerability of biomes to these changes, especially the most threatened Asian savannas. The findings help improve our understanding of the effects of environmental change on ecosystems, conservation of threatened and most vulnerable biomes, and human well-being. All the objectives were explored using a 
complex trait-based dynamic global vegetation model (DGVM) called adaptive dynamic vegetation model version 2 (aDGVM2).

DGVMs are the well-known tools to investigate climate change impacts on ecosystems and vegetation-climate interactions. However, most DGVMs do not explicitly represent the heterogeneous vegetation types of Tropical Asia. Previous DGVM-based studies in the region have many limitations, for example, they do not explicitly represent Asian savanna and observed boundaries between the deciduous and evergreen forest. Most of these studies have used few plant functional traits (PFTs) for the entire regions and used fixed values to represent plant traits for model parameterization. I argue that improving the representation of distinct vegetation types via improved ecophysiological and biological processes would increase the realism of model predictions in the region. Therefore, in Chapter 2, I proposed using either the functional trait (FT) approach or the PFTs approach with variable traits derived as a function of environmental condition in DGVMs, to move away from the paradigm of fixed PFTs. I made the case to develop region-specific DGVMs capable of representation and simulation of regional vegetation dynamics. These models can be used to explore the impacts of climate change and management scenarios on ecosystems. Region specific DGVM would help integrate model results at the policy level to prioritize the management of conservation practices in a more justified scientific way, and can advance our ecological understanding of ecosystems function and community structure in the region and beyond.

In the presented chapters, I have used the aDGVM2. The advantage of aDGVM2 is that vegetation types are not predefined in the model but are inferred from the simulated results. This characteristic makes it unique as it increases realism and ability to improve simulations' reliability under future climate scenarios. In aDGVM2, only plant communities with successful strategies, i.e., trait-combinations, are dynamically assembled and emerge based on the prevailing environmental conditions. The spatial extent of vegetation type is not constraint by using bioclimatic limits in aDGVM2. The model has been already used for other tropical region for example Amazonia and Africa. This is the first time it was used for tropical Asia. I added a new vegetation type i.e., $\mathrm{C}_{3}$ grasses and modified the sub module to simulate photosynthesis for each individual plants. In chapter 3, I used this updated version of aDGVM2 to simulate the current and future vegetation distribution in South Asia under RCP4.5 and RCP8.5 (RCP: 
representative concentration pathway). I explored how the presence or absence of $\mathrm{CO}_{2}$ fertilization influences vegetation responses to climate change. The model predicted an increase in biomass, canopy cover, and tree height under the presence of $\mathrm{CO}_{2}$ fertilization, which triggered transitions towards tree-dominated biomes by the end of the 21 st century under both RCPs. This woody encroachment threatens open biomes such as savannas and grasslands, and put biodiversity at risk. At the same time, woody encroachment due to $\mathrm{CO}_{2}$ fertilization indicates that the region can remain a carbon sink given there is no other resource limitation. However, nutrient limitations on $\mathrm{CO}_{2}$ fertilization effects were not included in the study, and carbon sink potential has to be seen with caution. In addition, model simulations show that savanna vegetation and vegetation in the Himalayas and the Western Ghats are vulnerable and susceptible to change. The projected biome transitions due to changing climate and rising $\mathrm{CO}_{2}$ imply that ecosystem management and mitigation strategies should be framed to target longterm management for conserving the protected areas and threatened biomes. Proper management strategies for biomes would also require investigating the impact of landuse change and fire disturbance, in addition to climate change.

In Chapter 4, the study domain was extended to include South-east Asia to verify if the model configuration used in Chapter 3 can also simulate vegetation patterns in tropical Asia. Climate change has been found to modify plant phenology and vegetation structure, altering vegetation distribution, carbon storage, and biodiversity. An ensemble of climate change scenarios was used to investigate its influences on biomass, vegetation height and phenology in tropical Asia until the end of the $21^{\text {st }}$ century. The aDGVM2 simulations show a robust trend of increasing vegetation biomass and transitions from small deciduous vegetation to taller evergreen vegetation across most of tropical Asia. Model simulations revealed substantial variation within the ensemble, both in biomass increases and in distributions of different biome types. Therefore, it is required to consider various climate models when assessing future vegetation trends for more robust prediction, as the results were found to vary across individual ensemble members. As shown in Chapter 3, this study also showed that open ecosystems with deciduous vegetation such as grasslands and savannas are most vulnerable to climate change. Understanding the mechanisms of plant phenology responses to climate warming is still very limited. Therefore, it is important to predict the future impact of phenological changes on ecosystems. Shifts in plant phenology also affect ecosystem carbon cycles 
and ecosystem feedback to climate, yet the quantification of such impacts remains challenging. Filling such knowledge gaps will enhance our capacity to understand and predict plant phenological changes and better represent carbon storage potential with elevated $\mathrm{CO}_{2}$ under ongoing anthropogenic climate change.

In Chapter 5, I focused on Asian savannas, which have been mismanaged since the colonial era due to misinterpretation as a degraded forest. Management has led to the loss of savanna's biodiversity. This study shows that large areas in South Asia can be interpreted as woodland, degraded forest, or savanna. I propose a biome classification scheme to distinguish between degraded forest or woodland and savanna based on the abundance of grass biomass and canopy cover. I emphasize that adopting a grass-centric perspective for biome classification accounting for the grassy component and the woody component is necessary to recognize savannas for conservation correctly. I found that considering vegetation systems as woodland or degraded forest could easily be mistaken as a potential for forest restoration within a tree-centric perspective. This would put approximately $35 \%$ to $40 \%$ of a unique savanna biome at risk. This will lead to a decrease in spatial coverage of savannas, and associated biodiversity losses are likely to happen. I argue that a proper monitoring system is needed to detect an early sign for the actual encroachment in Asian savannas, as used in the African savannas. Although projected woody encroachments may imply a transition toward the forest that benefits climate mitigation, it also presents major conservation and management challenges because this transition might also threaten the biodiversity of savannas. This raises potential conflicts of interest between biodiversity conservation in open ecosystems, i.e., savanna and active afforestation, to enhance carbon sequestration. The fire suppression policy and exclusion of large grazers in Asian savannas have done more harm than benefit. In African savannas, the role of herbivores in driving community and ecosystem dynamics has been extensively studied and documented, whereas, in Asian savanna, current knowledge of the functional role of herbivores is limited and needs exploration. As is the case with savannas elsewhere, Asian savannas are threatened by land-use changes, including conversion to agriculture and tree plantations. A major concern is that government-led afforestation efforts for promoting carbon sequestration programs are a significant challenge to these unique ancient mixed tree-grass biomes. Sometimes afforestation initiatives introduced exotic woody species, which later become invasive. Therefore, the inappropriate fire and herbivore management due to a lack of understanding of their 
functional roles demands timely conservation efforts and call for more future research with an explicit focus on Asian savannas. Proper management strategies should be taken into account for carbon sequestration in climate change adaptation without affecting the biodiversity and conservation in the open ecosystem. The aDGVM2 can serve as a tool to inform decision making for climate adaptation and mitigation for savannas.

In conclusion, the results presented in this thesis suggest that the aDGVM2 satisfactorily reproduced a broad pattern of biomes and biomass in tropical Asia. Using aDGVM2, I investigated the impact of climate change and rising atmospheric $\mathrm{CO}_{2}$ concentration to understand the potential vegetation-climate interactions in the study region. The model predicted that vegetation in South and South-East Asia would significantly shift towards tree-dominated biomes due to $\mathrm{CO}_{2}$-induced fertilization of $\mathrm{C}_{3}$ photosynthesis. The simulation under fixed $\mathrm{CO}_{2}$ and rising $\mathrm{CO}_{2}$ scenarios clearly shows that rising level of atmospheric $\mathrm{CO}_{2}$ is responsible for most of the predicted change in biome properties. This transition toward forest would threaten savanna biomes. However, the study also shows that the region has the potential to remain a carbon sink in the 21 st century. I also demonstrated that Asian savannas could be distinguished from forests with the proposed grass-centric biome classifications schemes. These results will encourage sustainable management strategies for the conservation of threatened savanna biomes to protect it from woody encroachment by regulating fire management and limiting afforestation. The aDGVM2 can be used to explore these strategies for savannas and other threatened biomes. Future research should consider the interactive effects of climate variables, i.e., rainfall and temperature, fire, herbivory, and land-use. Improving vegetation models should also include slope and aspect to represent mountainous regions such as the Himalayas, seed dispersal, and migration. Representation of these details in the model will be critical for forecasting the dynamics of Asian ecosystems. This study is an important step towards understanding ecosystems of South and Southeast Asia, specifically savannas. It thus contributes to our ability to improve conservation strategies to mitigate the consequences of climate change. 


\section{ZUSAMMENFASSUNG}

Mehr als jeder andere Faktor bestimmt das Klima großräumig das Vorkommen von Pflanzenarten und Vegetation. Dabei beeinflusst der rasche Klimawandel zusammen mit steigenden Treibhausgasemissionen die gegenwärtige und zukünftige Vegetationsverbreitung. Der globale Klimawandel wird Ökosysteme, Biomgrenzen, Biodiversitätsmuster und die Bereitstellung wichtiger Ökosystemdienstleistungen verändern. Neben dem Klima gehören die Stickstoffdeposition aus der Luft, biotische Interaktionen (invasive Arten) und atmosphärisches Kohlendioxid $\left(\mathrm{CO}_{2}\right)\left(\mathrm{CO}_{2}\right.$-Düngung oder erhöhte Wassernutzungseffizienz) zu wichtigen Triebkräften des Wandels. Die relative Bedeutung dieser Triebkräfte für ökologischer Veränderungen ist entscheidend für die Vorhersage zukünftiger ökologischer Dynamiken und hängt von verschiedenen räumlichen Skalen ab. Auswirkungen des Klimawandels auf die Vegetation sind komplex und unser Verständnis dieser Wechselwirkungen wird durch die genannten zusätzlichen Einflussfaktoren erschwert. Ein besseres Verständnis der Folgen des Klimawandels ist erforderlich, insbesondere in weniger gut untersuchten Regionen wie dem tropischen Asien, d.h. Süd- und Südostasien. Das tropische Asien beherbergt 7 der 36 globalen Biodiversitäts-Hotspots. Daher erfordern wirksame Managementstrategien ein tiefgehendes Verständnis der Auswirkungen des Klimawandels auf die Vegetation.

Es hat sich gezeigt, dass die prognostizierten Klimaveränderungen negative Auswirkungen auf die Natur haben und somit eine Bedrohung für das menschliche Wohlergehen darstellen. Viele Auswirkungen, die durch den Klimawandel und den Anstieg des atmosphärischen $\mathrm{CO}_{2}$-Ausstoßes verursacht werden, sind jedoch für das tropische Asien nur unzureichend verstanden. Zeitnahes Handeln ist erforderlich, um die empfindlichsten Ökosysteme $\mathrm{zu}$ identifizieren und $\mathrm{zu}$ schützen. Auch Managementstrategien müssen basierend auf neuesten Erkenntnisse zu Ökosystemen angepasst werden, insbesondere in Bezug auf Biodiversität. Beispielsweise wurden asiatische Savannen in der Vergangenheit als degradierte Wälder behandelt und entsprechend forstwirtschaftlich genutzt, was jedoch eine Gefahr für die endemische Diversität und die von Savannen abhängige Tierwelt darstellt. Das Hauptziel dieser Arbeit war die Auswirkungen des Klimawandels und des steigenden $\mathrm{CO}_{2}$-Ausstosses auf Biomverteilung, -grenzen und -produktivität sowie die Phänologie im tropischen Asien zu untersuchen. Dabei steht im Fokus, wie sich steigende Temperatur und ein verändertes Niederschlagsregime über Veränderungen in Struktur und Produktivität der Vegetation 
auf Biomgrenzen und Ökosystemfunktionen auswirken. Die Vulnerabilität der Biome, insbesondere der besonders gefährdeten asiatischen Savannen, gegenüber diesen Veränderungen, wird in dieser Arbeit untersucht. Damit wird dazu beigetragen, unser Verständnis der Auswirkungen von Umweltveränderungen auf Ökosysteme, den Schutz bedrohter und besonders gefährdeter Biome sowie das menschliche Wohlergehen zu verbessern. Diese Forschungsziele wurden mithilfe eines komplexen, dynamischen globalen Vegetationsmodells (dynamic global vegetation model, DGVM), dem auf Pflanzenmerkmalen (plant traits) basierten adaptive dynamic vegetation model Version 2 (aDGVM2), untersucht.

DGVMs sind ein bekanntes Instruments bei der Untersuchung der Auswirkungen des Klimawandels auf Ökosysteme und der Wechselwirkungen zwischen Vegetation und Klima. Die heterogenen Vegetationstypen im tropischen Asien werden in den meisten DGVMs jedoch nicht explizit simuliert. Bisherige DGVM-basierte Untersuchungen für die Region haben verschiedene Einschränkungen, da z.B. die asiatische Savanne und die beobachteten Übergänge zwischen Laub- und immergrünen Wäldern nicht umgesetzt sind. Die meisten dieser Studien verwenden für die gesamte Region nur wenige funktionelle Pflanzentypen (plant functionsl types, PFTs) und arbeiten mit festen Werten für Pflanzenmerkmalen in der Modellparametrisierung. In dieser Arbeit argumentiere ich, dass Modellvorhersagen für die Region durch die Verbesserung der Darstellung verschiedener Vegetationstypen über verbesserte ökophysiologische und biologische Prozesse realitätsnäher werden. Um vom Paradigma der festen PFTs wegzukommen, schlage ich daher in Kapitel 2 einen Ansatz basierend auf funktionellen Merkmalen (functional traits, FTs) sowie den PFT-Ansatz mit variablen Pflanzenmerkmalen, die als Funktion der Umweltbedingungen in DGVMs abgeleitet werden, vor. Um regionale Vegetationsdynamiken darzustellen und simulieren $\mathrm{zu}$ können, müssen regionsspezifische DGVMs entwickelt werden. Diese Modelle können dazu verwendet werden, die Auswirkungen des Klimawandels und von Managementszenarien auf Ökosysteme zu untersuchen. Regionsspezifische DGVMs tragen dazu bei, dass Modellergebnisse auf politischer Ebene besser angenommen und Maßnahmen des Umweltschutzs auf eine gut begründete wissenschaftliche Basis gestellt werden. Diese Modelle können unser ökologisches Verständnis zur Funktion von Ökosystemen und der Struktur von Pflanzengesellschaften in der Region und über diese hinaus verbessern. 
In dieser Arbeit habe ich das aDGVM2 verwendet. Der Vorteil des aDGVM2s besteht darin, dass Vegetationstypen nicht im Modell vordefiniert sind, sondern aus den simulierten Ergebnissen abgeleitet werden. Mit dieser Eigenschaft ist das aDGVM2 einzigartig und Simulationsergebnisse werden realitätsnäher. Die Zuverlässigkeit der Simulationen unter zukünftigen Klimaszenarien wird verbessert. In aDGVM2 bilden und entwickeln sich basierend auf vorherrschenden Umweltbedingungen nur Pflanzengesellschaften mit erfolgreichen Strategien, d.h. Merkmalskombinationen, heraus. Die räumliche Verbreitung eines Vegetationstyps wird in aDGVM2 nicht durch bioklimatische Grenzen vorgegeben. Das Modell wurde bereits für andere tropische Regionen wie z.B. Amazonien und Afrika verwendet. Dies ist das erste Mal, dass es für das tropische Asien verwendet wurde. Für diese Arbeit, habe ich das aDGVM2 erweitert, indem ich C3-Gräser als neuen Vegetationstyp hinzugefügt habe und Photosynthese für einzelne Pflanzen individuell simuliert wird. Diese aktualisierte Version des aDGVM2 wird in Kapitel 3 verwendet, um die aktuelle und zukünftige Vegetationsverteilung in Südasien unter RCP4.5 und RCP8.5 zu simulieren (RCP - representative concentration pathway, repräsentativer Konzentrationspfad). Dabei lag ein Fokus auf der Untersuchung des Einflusses von $\mathrm{CO}_{2}$-Düngung auf klimawandelgetriebene Vegetationsveränderungen. Unter $\mathrm{CO}_{2}$-Düngung wird eine Zunahme der Biomasse, der Kronenbedeckung und der Baumhöhe simuliert. Für beide RCPs bedeutet dies einen Übergang zu baumdominierten Biomen bis zum Ende des 21. Jahrhunderts. Offene Biome wie Savannen und Grasland und ihre biologische Vielfalt werden durch diese Verbuschung und Verwaldung gefährdet. Gleichzeitig bedeutet die zunehmende Verbreitung holziger Vegetation unter $\mathrm{CO}_{2}$-Düngung, dass, solange andere Ressourcen nicht limitierend sind, die Region eine Kohlenstoffsenke bleibt. Da der Einfluss eingeschränkter Nährstoffverfügbarkeit auf den Effekt der $\mathrm{CO}_{2}$-Düngung in diese Studie nicht mit einbezogen wurde, ist das Potenzial als Kohlenstoffsenke vorbehaltlich weiterer Untersuchungen zu sehen. Darüber hinaus zeigen die Simulationen, dass die Vegetation in den Savannen, im Himalaya und in den Westghats gefährdet und anfällig für Veränderungen ist. Die aufgrund des Klimawandels und steigender $\mathrm{CO}_{2}$-Emissionen projizierten Biomveränderungen implizieren, dass Strategien zum Management von Ökosystemen und zur Eindämmung des Klimawandels auf ein langfristiges Management zur Erhaltung von Schutzgebieten und bedrohter Biome abzielen sollten. Angemessene Managementstrategien für Biome müssen zusätzlich zu den Folgen des Klimawandels Auswirkungen von Landnutzungsänderungen und Feuer einbeziehen. 
In Kapitel 4 wurde die Untersuchungsregion auf Südostasien ausgeweitet und überprüft, ob die in Kapitel 3 verwendete Modellkonfiguration auch die Vegetationsmuster im tropischen Asien reproduzieren kann. Dabei zeigte sich, dass der Klimawandel Pflanzenphänologie und die Struktur der Vegetation verändert und so die Verbreitung der Vegetation, Kohlenstoffspeicherung und Biodiversität beeinflusst. Ein Ensemble von Klimawandelszenarien wurde verwendet, um seine Einflüsse auf Biomasse, Vegetationshöhe und Phänologie im tropischen Asien bis Ende des 21. Jahrhunderts zu untersuchen. Die aDGVM2-Simulationen zeigen einen robusten Trend zunehmender Vegetationsbiomasse und Wechsel von kleinen laubabwerfenden Pflanzen hin zu größeren immergrünen Pflanzen im größten Teil des tropischen Asiens. Die Modellsimulationen zeigten erhebliche Variationen innerhalb des Ensembles, sowohl in der Biomassezunahme als auch in der Verteilung verschiedener Biomtypen. Aufgrund dieser Variabilität ist es für eine robuste Vorhersage und Beurteilung künftiger Vegetationstrends daher erforderlich verschiedene Klimamodelle zu berücksichtigen. Diese Studie bestätigt darüber hinaus die Ergebnisse aus Kapitel 3, dass offene Ökosysteme mit laubabwerfender Vegetation wie Grasland und Savannen besonders anfällig für den Klimawandel sind. Das Verständnis von Mechanismen der Pflanzenphänologie und ihre Reaktion auf die Klimaerwärmung ist noch sehr begrenzt. Daher ist es wichtig, zukünftige Auswirkungen phänologischer Veränderungen auf Ökosysteme vorherzusagen. Veränderungen der Pflanzenphänologie wirken sich auf den Kohlenstoffkreislauf und Rückkopplungseffekte zwischen Ökosystemen und dem Klima aus, jedoch bleibt die Quantifizierung solcher Auswirkungen eine Herausforderung. Die Schliessung dieser Wissenslücken wird dazu beitragen, phänologische Veränderungen bei Pflanzen besser $\mathrm{zu}$ verstehen und vorherzusagen und das Kohlenstoffspeicherpotenzial unter erhöhten $\mathrm{CO}_{2}$-Konzentrationen im anthropogenen Klimawandel besser abzubilden.

Kapitel 5 liegt der Fokus auf den asiatischen Savannen, die seit der Kolonialzeit aufgrund einer Fehlinterpretation als degradierter Wald unangemessen bewirtschaftet wurden. Die Bewirtschaftung hat zum Verlust der Artenvielfalt der Savanne geführt. Diese Studie zeigt, dass große Gebiete in Südasien sowohl als Wald, degradierter Wald oder Savanne interpretiert werden können. Hier wird ein Schema zur Biomklassifizierung vorgeschlagen, das basierend auf der Menge an Grasbiomasse und der Kronenbedeckung zwischen degradiertem Wald oder Waldland und Savanne 
unterscheidet. Es wird dabei betont, dass für die richtige Bestimmung und den Schutz von Savannen eine graszentrierten Perspektive der Biomklassifizierung, die sowohl die Gras- als auch die Holzkomponente berücksichtigt, notwendig ist. Aus einer baumzentrierten Perspektive heraus kann die Interpretation von Vegetationssystemen als Waldland oder degradierter Wald leicht als ein Potenzial für Wiederaufforstung missverstanden werden. Dies würde ungefähr $35 \%$ bis $40 \%$ des einzigartigen Savannenbioms gefährden. Die räumliche Verbreitung von Savannen würde abnehmen und damit verbunden sind Biodiversitätsverluste wahrscheinlich. Ich halte daher ein angepasstes Monitoringsystem, vergleichbar mit dem afrikanischer Savannen, für notwendig, um frühe Anzeichen von Verbuschung und Verwaldung erkennen zu können. Obwohl ein Übergang zu Wald, der mit der Verbuschung einhergehen kann, dem Klimaschutz zugute kommen würde, stellt dies den Naturschutz und Manangement vor große Herausforderungen, da dies die Biodiversität der Savannen bedrohen könnte. Daraus ergeben sich potentielle Interessenkonflikte zwischen dem Schutz der Biodiversität offener Ökosystemen, d.h. Savannen, und der aktiven Aufforstung zur Stärkung der Kohlenstoffsequestrierung. Die Strategie Feuer zu unterdrücken und große Weidetiere auszuschließen haben im tropischen Asien mehr Schaden als Nutzen angerichtet. In afrikanischen Savannen wurde die Rolle der Pflanzenfresser als treibende Kraft für die Dynamik von Pflanzengesellschaften und Ökosystemen eingehend untersucht und dokumentiert. In den asiatischen Savannen hingegen ist das derzeitige Wissen über die funktionelle Rolle der Pflanzenfresser begrenzt und muss weiter erforscht werden. Ähnlich wie Savannen weltweit sind die asiatischen Savannen von Landnutzungsänderungen, einschließlich der Umwandlung in landwirtschaftliche Flächen und Baumplantagen, bedroht. Die von der Regierung angeführten Aufforstungsbemühungen mit der Förderung von Programmen zur Kohlenstoffsequestrierung sind eine große Herausforderung für diese einzigartigen sehr alten Baum-Gras-Biome. In manchen Fällen wurden bei Aufforstungsinitiativen exotische Baumarten eingesetzt, die mit der Zeit invasiv wurden. Das mangelnde Verständnis der Rolle von Feuer und Weidetieren in diesen Ökosystemen führt zu unangemessenen Managementstrategien und erfordert daher zeitnah verstärkte Maßnahmen zum Schutz von Savannen sowie zukünftig verstärkte Forschung mit einem ausdrücklichen Schwerpunkt auf asiatischen Savannen. Bei der Anpassung an den Klimawandel sollten geeignete Bewirtschaftungsstrategien zur Kohlenstoffbindung berücksichtigt werden, ohne jedoch die Biodiversität und den Schutz offener 
Ökosysteme zu beeinträchtigen. Das aDGVM2 kann als Hilfsmittel für die Entscheidungsfindung bei der Klimaanpassung und -minderung für Savannen dienen.

Zusammenfassend zeigen die in dieser Arbeit vorgestellten Ergebnisse, dass das aDGVM2 ein breites Muster von Biomen und Biomasse im tropischen Asien zufriedenstellend reproduziert. Mithilfe des aDGVM2s wurden die Auswirkungen des Klimawandels und der steigenden atmosphärischen $\mathrm{CO}_{2}$-Konzentrationen untersucht, um mögliche Interaktionen zwischen Vegetation und Klima in der Untersuchungsregion zu verstehen. Das Modell sagt vorher, dass sich die Vegetation in Süd- und Südostasien aufgrund der $\mathrm{CO}_{2}$-induzierten Düngung der $\mathrm{C}_{3}$-Photosynthese signifikant in Richtung baumdominierter Biome verschieben wird. Die Simulationen für die Szenarien mit festen $\mathrm{CO}_{2-}$ und steigenden $\mathrm{CO}_{2}$-Konzentrationen zeigten deutlich, dass steigende atmosphärische $\mathrm{CO}_{2}$-Konzentrationen für den Großteil der vorhergesagten Veränderungen der Biomeigenschaften verantwortlich sind. Diese Veränderung hin zu Wald würde Savannenbiome bedrohen. Die Studie zeigt aber auch, dass die Region das Potenzial hat, auch im 21. Jahrhundert eine Kohlenstoffsenke zu bleiben. In dieser Arbeit habe ich auch gezeigt, dass die asiatischen Savannen mit den vorgeschlagenen graszentrierten Biom-Klassifizierungssystemen von Wäldern unterschieden werden können. Diese Ergebnisse unterstützen nachhaltige Managementstrategien zur Erhaltung bedrohter Savannenbiome, um der Verwaldung mithilfe von Feuermanagement und der Einschränkung der Aufforstung Einhalt zu gebieten. Das aDGVM2 kann zur Erforschung dieser Strategien für Savannen und andere bedrohte Biome verwendet werden. Zukünftige Forschungsaktivitäten sollten die interaktiven Auswirkungen von Klimavariablen, wie z.B. Niederschlag und Temperatur, mit Feuer, Herbivorie und Landnutzung berücksichtigen. Verbesserungen von Vegetationsmodellen sollten Hangneigung und Exposition für die Modellierung von Bergregionen wie dem Himalaya, sowie Mechanismen der Samenausbreitung umfassen. Die Umsetzung dieser Aspekte im Modell wird für die Modellierung der Dynamiken asiatischer Ökosysteme von entscheidender Bedeutung sein. Diese Studie ist ein wichtiger Schritt hin zu einem besseren Verständnis der Ökosysteme Süd- und Südostasiens, insbesondere der Savannen. Sie trägt damit dazu bei, Naturschutzstrategien zur Abmilderung der Folgen des Klimawandels zu verbessern. 


\section{LIST OF FIGURES}

Figure 1.1 (a) Elevation zone map showing the heterogeneous topography of the study region (SRTM). (b) Biome map obtained from WWF Terrestrial Ecoregion data and depicts the vegetation biodiversity (Olson et al., 2001). Maps have Robinson projection.

Source:https://sedac.ciesin.columbia.edu/maps/gallery/search?facetsregion:asia

Figure 1.2 (a) The global extent of savanna and forest distribution, adapted from Lehmann et al. (2011). (b) The Köppen-Geiger climate classification system showing tropical region of Asia also has similar climatic setting to other savanna regions e.g., Africa, South America and Australia. 25 year of climate data were used to derive these map ( TYN SC 2.03, Mitchell et al., 2004, https://sedac.ciesin.columbia.edu/maps). (c) The fractional distribution of $\mathrm{C}_{4}$ grass adapted from NACP MsTMIP: Global and North American Driver Data for Multi-Model Intercomparison (Wei et al., 2014). 32

Figure 1.3 Conceptual model of aDGVM2 depicting the iterative process through which a community of plants assembles. Individuals are characterized by their traits that influence their carbon (C) status and phenotype. All individuals at a site form the community, which influences resources, environmental conditions and disturbances via engineering and modulating impacts. These conditions interact to influence growth of the individuals. Individuals, through reproduction, can add their traits to the community trait pool. Crossover and mutation of the community trait pool yield the community seed bank. Flow chart of aDGVM2 adapted from Langan et al.(2017). .36

Figure 2.1 (a) Major potential natural vegetation types of South Asia (Ramankutty et al., 2010) and (b) Global land cover map (GLC2000, http://forobs.jrc.ec.europa. eu/products/glc2000/glc2000.php). The ISLSCP-II data product was derived from the land cover data set of Loveland et al. (2000) following the Olson Global Ecosystems (OGE) framework (Olson, 1994) classification scheme. 46

Figure 2.2 Biomes simulated by aDGVM (Scheiter et al., 2012; Scheiter \& Higgins, 2009) without fire ( $a$ and b) and with fire ( $d$ and e) for the years 2017 (a and d) and 2100 (b and e). Sankey graph shows the biome shifts from 2017 to 2100 (c) without fire and (f) with fire. Under both scenarios, biomes are sensitive to 
climate change and biome shifts occurred. For the biome classification scheme, see Scheiter et al. (2012).

Figure 2.3 Bi-stability between $\mathrm{C}_{4}$ dominated biomes (savanna and $\mathrm{C}_{4}$ grassland) and $\mathrm{C}_{3}$ dominated biomes (forest and woodland) simulated by aDGVM (see Figure 1a, e). Vegetation in a grid cell is bi-stable if it is in a $\mathrm{C}_{4}$ biome state in the presence of fire but in a $\mathrm{C}_{3}$ biome state in the absence of fire. 62

Figure 3.1 Comparison between aDGVM2 results and data for (a) simulated biomass and Saatchi et al. (2011) biomass, (b) simulated tree height and Simard et al. (2011), (c) simulated tree cover and Friedl et al. (2011) tree cover and (d) simulated evapotranspiration and Zang et al. (2010) evapotranspiration. In the figure the first column shows the remote sensing products, the second column shows aDGVM2 results, and the third column shows the difference between simulation and data and the fourth column shows the scatter plot between simulated state variables against benchmarking data. NMSE and RMSE are normalized mean square error and root mean square error, respectively. In the fourth column, each point represents one grid cell in the study region. For results with masked land use cover, see supplementary Figure S3.4 87

Figure 3.2 Comparison between simulated and observed biome patterns. (a) Simulated dominant biome type, (b) Sankey diagram showing overlap between simulated biomes and potential natural vegetation cover (ISLSCP-II, Ramankutty et al., 2010) and (c) potential natural vegetation. The Sankey graph shows how aDGVM2 biomes and PNV classes overlap .88

Figure 3.3 Simulated biome distribution for the 2000s, 2050s and 2090s under (a) $\mathrm{RCP} 4.5+\mathrm{eCO}_{2}$ and (c) $\mathrm{RCP} 4.5+\mathrm{fCO}_{2}$. The Sankey diagrams showing the fractional cover of biomes and transitions between biomes from the 2000s to the $2050 \mathrm{~s}$ and the $2050 \mathrm{~s}$ to the $2090 \mathrm{~s}$ under (b) RCP4.5+eCO 2 and (d) RCP4.5+fCO 2 . See Figure S3.6 for simulated biome distribution under RCP8.5. 89

Figure 3.4 Projected change in biomass (t/ha), canopy area (\%) and evapotranspiration (ET, mm/year) between the 2000s and 2050s, and between the 2000s and the 2090s under (a) RCP4.5 $+\mathrm{eCO}_{2}$ and (b) RCP4.5 $+\mathrm{fCO}_{2}$. See Figure S3.7 for projected change of these variables under RCP8.5 93

Figure 3.5 Maps showing areas where $\mathrm{CO}_{2}$-fertilization compensates biomass dieback caused by climate change between the 2000s and the 2090s under (a) RCP4.5 and 
(b) RCP8.5. and (c) aboveground biomass between 1950 and 2099 for South Asia in different scenarios.

Figure 3.6 Relationship between (a) evapotranspiration (ET) and mean annual precipitation (MAP), (b) ET and mean annual temperature (MAT), (c) mean above ground biomass and MAP and (d) mean above ground biomass and MAT under RCP4.5. The lines (both solid and dotted) in all figures represent the bestfit regression line. Data points represent spatially averaged ET (a, b) and biomass (c, d) over entire South Asia for each year from 1950 to 2099. See Figure S3.8 for results under RCP8.5.

Figure 3.7 Simulated climate niches of biomes for the (a) 2000s, (b) 2050s and (c) 2090s under $\mathrm{RCP} 4.5+\mathrm{eCO}_{2}$ and (d) 2000s, (e) 2050s and (f) 2090s under $\mathrm{RCP} 4.5+\mathrm{fCO} 2$. The simulated biomes are overlaid on the climate envelopes of Whittaker's biomes and are plotted following Ricklefs (2008) and Whittaker (1975). See Figure S3.9 for projected change in climatic niches of biomes under $\mathrm{RCP} 8.5$ 97

Figure 4.1 Biomass $(\mathrm{a}-\mathrm{c})$ and tree height $(\mathrm{d}-\mathrm{f})$ derived from remote sensing $(\mathrm{a}, \mathrm{d}$; Saatchi et al., 2011; Simard et al., 2011) and simulated by adaptive dynamic global vegetation model version 2 (aDGVM2) under current conditions (b, e, year 2019). Panels (c, f) show model uncertainty, represented by the coefficient of variation. For aboveground biomass and height, we calculated mean and coefficient of variation for the ensemble of five different general circulation models for RCP8.5. Vegetation height of an ensemble member is represented by the 90th percentile of all woody plants. Results for RCP4.5 are provided in Figure S4.3. $\mathrm{RCP}$, representative concentration pathway 128

Figure 4.2 Consensus biome types (a) and dominant phenology types (c) simulated by adaptive dynamic global vegetation model version 2 under current conditions (year 2019). Panels (a, c) show consensus maps, (b, d) show uncertainty, represented by the number of ensemble members that simulate the consensus type. Simulations were conducted for RCP8.5. Results for RCP4.5 are provided in Figure S4.6. RCP, representative concentration pathway.

Figure 4.3 Aboveground vegetation biomass (a) and interannual biomass change between consecutive years (b) in model ensemble between 1950 and 2099 for tropical Asia. Thin lines in panel (a) represent mean annual aboveground biomass in simulations with different general circulation models, bold lines represent annual 
ensemble means for RCP4.5 and RCP8.5, and shaded areas represent the range (minimum and maximum) of the ensemble in both RCPs. Thin lines in panel (b) represent ensemble means, thick lines represent smoothed lines using 'lowess'. $\mathrm{RCP}$, representative concentration pathway 133

Figure 4.4 Histograms of interannual aboveground biomass change between two consecutive years for (a) RCP8.5 and (b) RCP4.5. Histograms were plotted for all years between 1950 and 2099 for all ensemble members. The solid red line indicates the average of all changes, the dashed red lines indicate standard deviation. Time series of ensemble means of these changes are provided in Figure 4.3b. RCP, representative concentration pathway 134

Figure 4.5 Areas where aboveground tree biomass and height change by more than $\pm 10 \%$ between current (year 2019) and future (year 2099) conditions in RCP8.5. For biomass, we used tree aboveground biomass (a), $\mathrm{C}_{3}$ grass biomass (c) and $\mathrm{C}_{4}$ grass biomass (d) in a grid cell, for vegetation height (b), we used the 90th percentile of all trees simulated in a grid cell. Results for RCP4.5 are provided in Figure S4.7. RCP, representative concentration pathway..... 134

Figure 4.6 Relative abundance of different phenological strategies under current (year 2019) and future (year 2099) conditions, as well as change within this time period. Phenological strategies are evergreen light-triggered $(\mathrm{a}-\mathrm{c})$, evergreen watertriggered $(\mathrm{d}-\mathrm{f})$, deciduous water-triggered $(\mathrm{g}-\mathrm{i})$ and deciduous light-triggered $(\mathrm{j}-$ 1). Simulations for current conditions ( $a, d, g, j)$, future conditions (b, e, h, k) and changes between current and future conditions (c, f, i, l) are provided. The maps show ensemble means for RCP8.5. Results for RCP4.5 are provided in Figure S4.12. RCP, representative concentration pathway 136

Figure 4.7 Consensus map of current (a, year 2019) and future (b, 2099) biome distribution in RCP8.5 for the ensemble. Areas where biome shifts between 2019 and 2099 were simulated for the consensus map (c, e) and in at least one of the ensemble members $(\mathrm{d}, \mathrm{f})$ are highlighted without land use impacts $(\mathrm{c}, \mathrm{d})$ and with land use impacts (e, f). Land use was derived from Tuanmu and Jetz (2014). Results for RCP4.5 are provided in Figure S4.13. RCP, representative concentration pathway 137

Figure 4.8 Consensus map of current (a, year 2019) and future (b, 2099) distribution of dominant phenological types in RCP8.5 for the ensemble. Areas where phenology shifts between 2019 and 2099 were simulated for the consensus map 
(c, e) and in at least one of the ensemble members (d, f) are highlighted without land use impacts (c, d) and with land use impacts (e, f). Land use was derived from Tuanmu \& Jetz, (2014). Results for RCP4.5 are provided in Figure S4.14. $\mathrm{RCP}$, representative concentration pathway .... 138

Figure 4.9 Transitions of dominant phenology in precipitationtemperature space for the RCP8.5 ensemble. Origin and end of arrows indicate location of a grid cell in climate space in 2019 and 2099; colours indicate different dominant phenological strategies and if a transition in the phenology was projected (red arrows) or not (other colours). Results for RCP4.5 are provided in Figure S4.15. MAP, mean annual precipitation; RCP, representative concentration pathway 139

Figure 5.1 Biome patterns in South Asia simulated with aDGVM2 under current climate conditions (2019). (a) Biome distribution map when savannas are considered in a grass-centric scheme. (b) Location of simulated biomes (grass-centric scheme) in Whittaker's biome graph. (c) Biome distribution map when savannas are considered as woodland or dry deciduous forest in a tree-centric scheme. (d) Sankey graph illustrating overlap between biomes in tree-centric and grasscentric classification schemes. The width of lines represents the fractional cover of each biome in the study area. 173

Figure 5.2 Simulated biome distributions under current and future conditions for RCP4.5 and RCP8.5. The figure shows current (2019, a, d) and future (2099, b, e) biomes and change in the biome distribution between 2019 and 2099 (c, f). Vegetation was classified using the grass-centric scheme, including savannas. See Figure S5.2 for simulations with tree-centric scheme. 174

Figure 5.3 Simulated change in (a) biomass, (b) basal area, (c) canopy area and (d) grass biomass under RCP4.5 and RCP8.5 between 2019 and 2099. 174

Figure 5.4 Risk of vegetation shifts until 2099 in RCP4.5 and RCP8.5. Different indicators were used to assess the risk. (a, d) Canopy cover and grass biomass (2indicators), (b, e) canopy cover, grass biomass and change in biome type (3 indicators) and (c, f) 3-indicators along with land cover mask to mask out managed land. 175

Figure 6.1 The two PCA axes represent grassy vs. woody biomes and plant size. The first two PCA axes explain $63.5 \%$ of the variation. Each point represents a simulated grid cell. 196 


\section{LIST OF TABLES}

Table 2.1 Biomes, growth forms and processes relevant for modelling South Asia's vegetation. We argue that including these key growth forms (within a PFT or a FT approach) and processes into dynamic global vegetation models (DGVMs) will allow us to better represent the biome distributions and biome boundaries of South Asia, as well as climate change and land use change impacts on vegetation.

Table 3.1 Biome cover (in \%) for the 2000s, 2050s and 2090s, and percent (\%) change in biome cover from the 2000 s to the 2050 s and the 2000 s to the 2090 s under RCP4.5 and RCP8.5 with fixed and elevated $\mathrm{CO}_{2} . \Delta$ indicates percent change in biome cover between time periods. 90

Table 3.2 Mean biomass (in t/ha) within biomes for the 2000s, 2050s and 2090s, and percent (\%) change in biomass from the 2000s to the 2050s and the 2000s to the 2090s under RCP4.5 and RCP8.5 with fixed and elevated $\mathrm{CO}_{2} . \Delta$ indicates percentual biomass changes between time periods. 92

Table 3.3 Biome-level ET normalized to biomass (Ebiomes, $\mathrm{mm} / \mathrm{kg} / \mathrm{year}$ ) for the $2000 \mathrm{~s}$, 2050s and 2090s, and percent (\%) change in Ebiomes from the 2000s to the 2050s and the 2000s to the 2090s under RCP4.5 and RCP8.5 with fixed and elevated $\mathrm{CO}_{2} . \Delta$ indicates percentual ET changes between time periods. .95

Table 4.1 Cover of different biome types for current (2019) and future (2099) climate conditions for RCP4.5 and RCP8.5. Cover is provided as percentage of grid cells covered by different biomes. Cover fractions for all ensemble members and the ensemble mean are provided. Values for current conditions are provided two times, because simulations for RCP4.5 and RCP8.5 slightly diverge due to model stochasticity and differences in the climate data sets. Models: 'M1' GFDLESM2M; 'M2' HadGEM2-ES; 'M3' IPSL-CM5A-LR; 'M4' MIROC-ESM; 'M5' NorESM1-M; 'Ens' ensemble mean. Table S1 provides cover fractions for biomes aggregated by height or phenology 130

Table 4.2 Aboveground vegetation biomass in the study region for different GCMs and RCPs and changes between different time periods (historic: 1950-1969; current: 2000-2019; future: 2080-2099). Biomass values for each ensemble member and the ensemble mean are provided. Models: 'M1' GFDL-ESM2M; 'M2' HadGEM2-ES; 'M3' IPSL-CM5A-LR; 'M4' MIROC-ESM; 'M5' NorESM1-M; 
'Ens' ensemble mean; indicates percentage aboveground biomass changes between time periods 132

Table 4.3 Percentage of simulated grid cells in tropical Asia affected by transitions in biome type and in dominant phenology type for different GCMs and RCPs. Changes represent the period between current (year 2019) and future (year 2099) conditions. Models: 'M1' GFDL-ESM2M; 'M2' HadGEM2-ES; 'M3' IPSLCM5A-LR; 'M4' MIROC-ESM; 'M5' NorESM1-M; 'Ens' ensemble mean; 'Ova' overall change of all GCMs, that is, area where at least one GCM simulates a transition. 138

Table 5.1 Proportion of area covered by each biome for present (2019) and future (2099) conditions, and percent change between 2019 and 2099 under both RCP 4.5 and RCP 8.5. Results for both the tree-centric and the grass-centric classification schemes are provided. 172 


\section{CHAPTER 1 \\ INTRODUCTION}

\subsection{Overview}

Global climate change has significant implications on ecosystems, biodiversity patterns and the supply of ecosystem services. Extreme consequences are expected for tropical Asia during the 21st century (IPCC, 2013), especially South Asia, which is the most densely populated and disaster-prone geographical region in the world (UNEP, 2003; Eckstein, Hutfils and Winges, 2018). The consequences of environmental change on ecosystems for biodiversity as well as on ecosystem services, are only partly understood and under-investigated for the regions. The impact of regional climate change is predominant than the global change, and thus its assessments are essential to evaluate the consequences on regional vegetation and their distribution (Panda, Behera and Roy, 2017; Deb et al., 2018). Climate change affects ecosystems through changes in mean temperature and rainfall, and frequency and severity of weather and climate extremes, such as wildfires, storms, cyclones and drought (Sivakumar and Stefanski, 2010; Malhi et al., 2020). Climate change can fundamentally alter species distribution, composition, phenology, and forest structure (Deb et al., 2018; Piao et al., 2019). Moreover, conservation and management practices could be a failure without considering these consequences that appeal to the assessment of ecosystem vulnerability due to climate change (Scarano, 2017).

In my thesis, I present a detailed description of the contemporary vegetation of South Asia and the impact of climate change on their future distribution with the help of a dynamic vegetation model. Here, I will give an overview of the South Asian biomes, climate, biogeography, and the known factors dominating the vegetation-climate relationships. Furthermore, I will introduce model improvements that were implemented in aDGVM2 to simulate vegetation of South Asia. Further, my thesis investigates the vegetation-climate interactions and their likely consequences for biodiversity conservation. 


\subsubsection{Role of climate in vegetation distribution}

The broad-scale distribution of vegetation and various plant species is controlled by climate (Box and Fujiwara, 2013). The observed patterns of vegetation around the world are considered as one of the important indicators of the interactions between climate and terrestrial ecosystems (Nolan et al., 2018). Vegetation-climate interactions are susceptible to global climate change, especially in the tropics of Asia (Deb et al., 2018). This interaction has been changing since the past and would keep changing in the future (Blois et al., 2013). However, the past climate still influences current vegetation patterns and ecosystem dynamics (Svenning et al., 2015). Other natural factors, such as local precipitation regime, including topography, micrometeorology, and soil influence the potential presence or absence of a plant species in a given geographical location (Blois et al., 2013). The success of any particular plant species also depends on the competition for resources such as light, water and nutrients (Craine and Dybzinski, 2013).

The rapid climate change associated with increasing greenhouse gas emissions influences current and future vegetation patterns (IPCC, 2013). Other factors that influence vegetation patterns are land-use change, airborne nitrogen deposition, biotic interactions (invasive species) and atmospheric $\mathrm{CO}_{2}$ (direct fertilization or water use efficiency effects). The relative importance and intensity of these drivers differ at a different scale (Aber et al., 2001). For example, for ecosystems in the Himalayan regions, climate change is substantially more likely to affect biodiversity than any of the other drivers (Chettri et al., 2010). However, in the Deccan's ecosystems, both land-use change and biotic interactions were considered most important (Ratnam et al., 2016). Therefore, understanding the interactions among the different elements of global climate change, vegetation distribution, vegetation dynamics and the ecosystems services provided to humankind are the significant research challenges of the twenty-first century (IPBES, 2019; Kubiszewski et al., 2020).

The impacts of climate change on vegetation are complex and anthropogenic activities in natural ecosystems have made our understanding of these interactions more complicated especially in a region such as South Asia, where a large proportion of the area is under cultivation (Bellard et al., 2012). This thesis concentrates on the role of climate change, exploring the potential impacts of climate change on vegetation distribution, structure, productivity, phenology and diversity. Additionally, climate- 
vegetation interactions in the past are briefly discussed along with the consequences of climate change and its implication for regional ecosystems.

\subsubsection{South and Southeast Asia - Phytogeography}

South and Southeast Asia is a unique geographical region with heterogeneous vegetation types and climatic conditions. It covers countries such as Afghanistan, Bangladesh, Bhutan, India, Nepal, Pakistan, Sri Lanka and Myanmar. These regions constitute the most densely populated region of the world. South Asia comprises the world's highest mountain range, the Himalayas, the alluvial plains of the Indus and Ganga-Brahmaputra river systems, and the uplands of the Deccan Plateau in India, together with the two coastal ecosystems -the Western Ghats and the Eastern Ghats. The Himalayas, the world's highest mountain range, stretches along the entire northern border of the region (Figure 1.1a). Three major marine ecosystems, the Arabian Sea, the Indian Ocean, and the Bay of Bengal, surround the region in the south (Figure 1.1b). The seasonal patterns of atmospheric circulation between the landmass and sea bring most of the precipitation in the form of monsoons in South Asia (Kaskaoutis et al., 2018).

The diversity in the climate and topography has resulted in a wide range of plant species in the region, ranging from temperate and tropical to desert vegetation (Spicer, 2017). About $18.6 \%$ of the region's overall land is still covered by the forest and makes up $2.73 \%$ of the total global forest area (Kumar et al., 2018). In India, 21\% of the area is classified as forest, with tropical forests comprising about $86 \%$ of the forested area (FSI, 2017). Forest areas are categorized as broadleaf evergreen, broadleaf deciduous, and mixed coniferous and constitute 0.11 million $\mathrm{km}^{2}, 0.10$ million $\mathrm{km}^{2}$, and 0.05 million $\mathrm{km}^{2}$, respectively (Kumar and Scheiter, 2019). The non-forested areas include grassland, savanna, barren, and shrubland, accounting for 0.35 million $\mathrm{km}^{2}, 0.22$ million $\mathrm{km}^{2}, 1.5$ million $\mathrm{km}^{2}$ and 0.89 million $\mathrm{km}^{2}$, respectively (FSI, 2011). In South Asia, forest biomes are well documented due to the groundwork laid by early foresters like Champion and Seth, (1968) and Brandis, (1906). The region is divided into many biogeographic zones to identify and focus explicitly on the protection and conservation of the threatened biomes or ecosystems (Rodgers and Panwar, 1988). However, the regional forest has been identified into 35 different categories and 17 vegetation types using the life-zone with very high spatial resolutions of satellite imagery. The terrestrial ecoregion compiled 
by Olson et al. (2001) shows the different dominant biomes of the region (Figure 1.1b). More detailed on distinct vegetation types are discussed in Chapter 2.

\subsubsection{South and Southeast Asia - Climatology}

The climate over South and South-east Asia has been divided into different climatic zones, which include arid, semiarid, humid, temperate, tundra, boreal, and alpine. The climate pattern of South Asia is mostly driven by its topography i.e., the Himalayas in the northern boundary and the Indian Ocean in the south. Rainfall over the region is brought mainly by the monsoon wind which enters the region from the Western Ghats, then moves northward along the Himalayan regions (Overpeck et al., 1996). Rainfall weakens as it moves toward North West of the regions. This is the reason why most parts of the western region are arid and dry. Orographic precipitation is also prominent in the mountainous regions (Wang et al., 2012), e.g., Western Ghats. The climatic variability is reflected by average temperature, the length of the dry periods, and the amount and timing of rainfall i.e., arriving and retreating of the monsoon (Overpeck et al., 1996; Annamalai and Liu, 2005). The higher Himalayas have the coldest climate, where snow exists year-round whereas, the Himalayas foothill, which includes valleys of Nepal, Bhutan, and northern India, are much warmer and humid with a subtropical climate. The humid subtropical zone stretches across South Asia including much of the Indo-Gangetic Plain. The western end of the Plain and the Deccan Plateau have regions with high temperatures and light rainfall with a semiarid climate. The driest part of this area, the Thar Desert, gets very little average annual rain ranges from less than 100 to $400 \mathrm{~mm}$ (Sharma and Mehra, 2009). The tropical wet zone is found along the western and eastern coasts of India and in Bangladesh where temperatures are high and receive very heavy rainfall. Sri Lanka and Myanmar have a tropical wet climate condition, while the southern part of Myanmar has a dry climate (Naveendrakumar et al., 2019).

The evidence for rapid climate change now seems overwhelming. Global temperatures are predicted to rise by up to $4{ }^{\circ} \mathrm{C}$ by 2100 , with associated alterations in precipitation patterns (IPCC, 2013). The climate scenarios show a relatively mild increase in global temperature i.e., $2.7^{\circ} \mathrm{C}$ by 2100 from present, when the emission of GHGs are controlled i.e., in the RCP4.5 scenario, and higher increase of 4 to $5.8^{\circ} \mathrm{C}$, when the emission of GHGs is uncontrolled i.e., in the RCP8.5 scenario (Parry et al., 2007). For South Asia, $0.5-1.2^{\circ} \mathrm{C}$ rise in temperature is projected by $2020,0.88-3.16^{\circ} \mathrm{C}$ by 
2050 , and $1.56-5.44^{\circ} \mathrm{C}$ by 2080 , with the variation depending on the scenario of future development (IPCC, 2014). Overall, the temperature increases are likely to be much higher in the winter season than in the rainy season. At the same time, precipitation is expected to increase in all time scales in all the months except during DecemberFebruary when it is likely to decrease (Kumar et al., 2013). The warming trend in India over the past 100 years (1901-2007) was observed to be $0.51^{\circ} \mathrm{C}$ with accelerated warming of $0.21^{\circ} \mathrm{C}$ every 10 years since 1970 (Kumar et al., 2011, 2013). The spatial distribution of temperature changes indicates a significant warming trend along the west coast, central India, the interior Peninsula, and over northeast India. However, a cooling trend has been observed in the northwest and some parts in southern regions (Kumar et al., 2009).

Climate change projections to 2100 indicate an overall increase in temperature with no substantial change in precipitation (Kumar, Jain and Singh, 2010). However, there are some regional patterns in precipitation which show areas with an increasing trend in monsoon rainfall along the west coast, north Andhra Pradesh and adjoining regions, north-east India and parts of Gujarat and Kerala (6 to 8\% of normal over 100 years (Kumar, 2009). Climate projections show that summer precipitation is likely to increase in South Asia, and droughts associated with summer drying could result in regional vegetation die-offs (Breshears et al., 2005). However, there is considerable uncertainty in future precipitation projections as well as in temperature (Bhowmick, Sahany and Mishra, 2019). The magnitude of the impact of climate change is likely to vary in different parts of the region. Some regions such as parts of western Rajasthan, Southern Gujarat, Madhya Pradesh, Maharashtra, Northern Karnataka, Northern Andhra Pradesh, and Southern Bihar are likely to be more vulnerable in terms of extreme events (Mall et al., 2006). I have used data from ISIMIPs project for two RCPs i.e., RCP4.5 and RCP8.5 (RCP: Representative concentration pathways), to investigate the impact of climate change vegetation dynamics of tropical Asia i.e., both South and South-east Asia, which I have discussed in detail in the following chapters. 


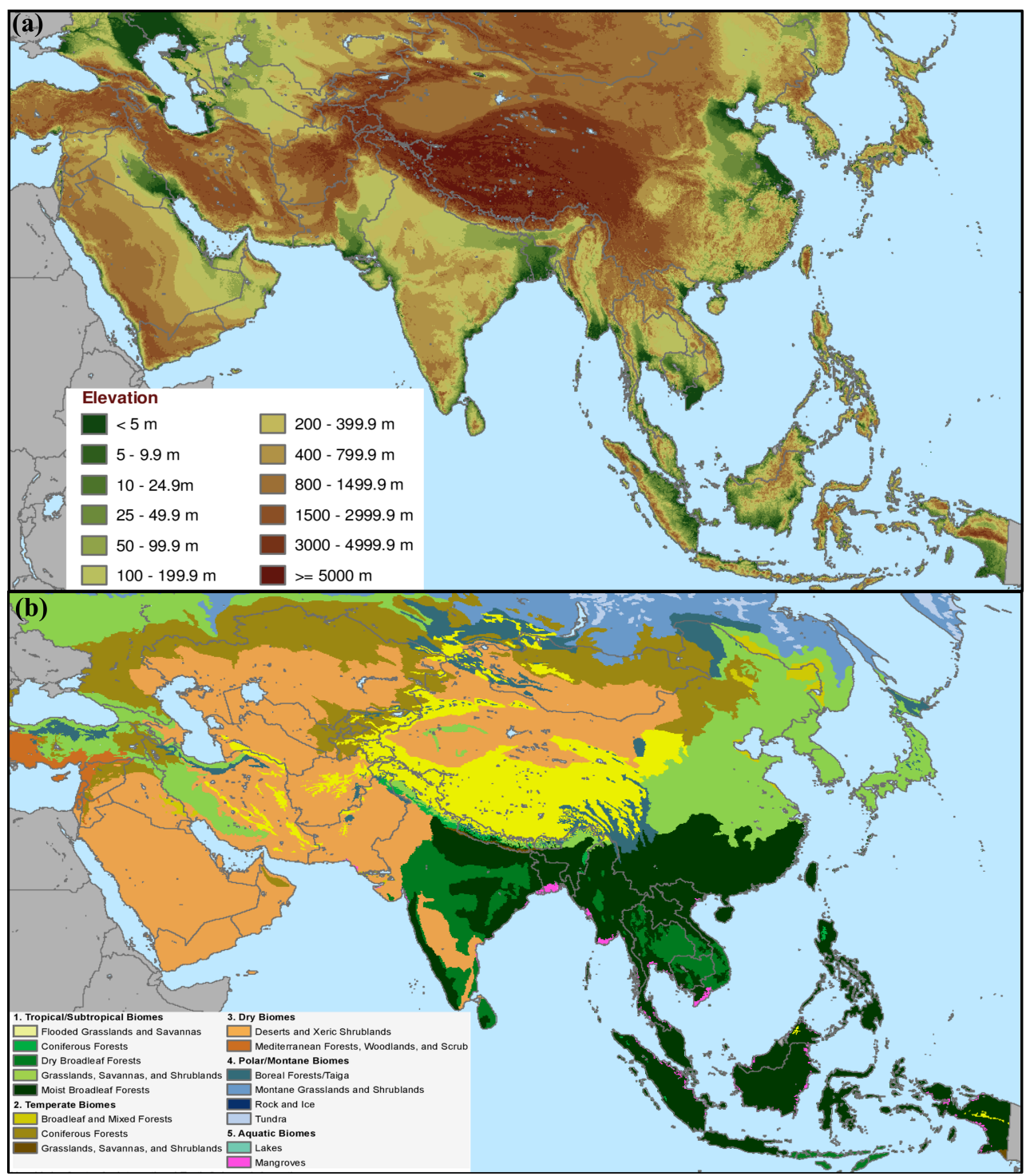

Figure 1.1 (a) Elevation zone map showing the heterogeneous topography of the study region (SRTM). (b) Biome map obtained from WWF Terrestrial Ecoregion data and depicts the vegetation biodiversity (Olson et al., 2001). Maps have Robinson projection. Source:https://sedac.ciesin.columbia.edu/maps/gallery/search?fac ets=region:asia

\subsubsection{Biodiversity of South and Southeast Asia}

Vegetation is connected to the atmosphere, hydrosphere and pedosphere, comprising the core of the land surface in the earth's ecosystem. Since the climate is the primary determinant of the vegetation cover, climate change will influence the properties of the land surface, soil and water conservation, climate regulation, and stability of the ecosystem (Cramer et al., 2001; Dawson et al., 2011). The region occupies a significant portion of the Indo-Malayan realm and a smaller portion of the Palearctic domain and represents five of the fourteen major ecological regions (Mani, 1974). These ecological 
regions demonstrate a wide range of endemic plants in different ecosystems and unique biodiversity. This diversity is determined by the inherent complexity of heterogeneous climate, geology and diverse topography of the region (Stein, Gerstner and Kreft, 2014; Stein, 2015). The variation in climatic condition provides a wide range of biomes and ecosystems (Lundholm, 2009; Yahara et al., 2012). However, the limits between biomes are difficult to delineate due to strong climatic gradients maintained by parameters such as temperature, soil, light, and water that contrast different ecosystems within short distances. I have discussed in details about the dominant biome of South Asia in Chapter 2.

South Asia is known as global hotspots of biodiversity and endemism and contains some of the most critical biodiversity hotspots in the world. The hotspots cover the entire region of the Himalayan countries, the Western Ghats, Indo-Burma, the Sundaland and Sri Lanka (Mittermeier et al., 2004). Biodiversity in Sri Lanka is considered to be the richest per unit area in the Asian region (Gunatilleke, Pethiyagoda and Gunatilleke, 2017). It has exceptionally high biodiversity due to the broad range of ecosystem it carries and the diverse species those ecosystem harbors with regards to animal and plant species (Chitale, Behera and Roy, 2014). The rainforests of Southeast Asia contain more than 25,000 species of flowering plants, equivalent to about $10 \%$ of the flora of the world (McIntyre, 2009). South Asia houses approximately 15.5 and 12 percent of the world's flora and fauna, respectively (Sarker, Rahman and Giessen, 2018). The faunal diversity of the region comprises of 933 species of mammals, 4,494 birds, 923 reptiles, 332 amphibians and 342 freshwater fishes. The floral diversity accounts for 39,875 species of flowering plants, 66 conifers and cycads, 764 ferns and 6,652 higher plants (South Asia Co-operative Environment Programme (SACEP), 2016; Venkataraman and Sivaperuman, 2018). Conservation of these diverse ecosystems is challenging due to the inherent complexity, lack of data availability and information on some ecosystems.

\subsubsection{Anthropogenic impacts on the ecosystem}

The continental-scale vegetation patterns are dominated by the climate such that regions with similar climatic conditions and vegetation form large entities, commonly known as biomes (Hansen et al., 2001). South Asia is one of the world's most densely populated regions, accordingly, a large fraction of the area is utilized for cultivation 
accounting for nearly 1 million $\mathrm{km}^{2}$. South Asia occupies $4.8 \%$ of the world's total land area. It provides a home to $23.8 \%$ of the world's population (ca. 1.8 billion) and is growing at a rate of $1.8 \%$ per annum (SACEP, 2016). Around $5 \%$ of the region's land area is being protected under various conservation programs (SACEP, 2016). The vulnerability of the natural environment due to climate change and increasing anthropogenic activities implying competition for agricultural land, urban land and water resources, have enormous societal and ecological consequences in the region. The effect of this natural-human interaction would not be limited to South Asia but would also have a severe impact on a global scale. Humans mobilize approximately $40 \%$ of the total primary production on land per annum, exerting massive pressure on biodiversity (Marambe and Silva, 2016). Estimates show that more than $40 \%$ of the world's economy and $80 \%$ of the needs of the world's poor are derived from biodiversity (McKinnon et $a l .$, 2015).

Biodiversity of the region is increasingly threatened by the demand generated by rapid economic development. The Internation Union for Conservation of Nature (ICUN, 2009) reported that one-third of all the threatened species are found in Asia. Land-use changes such as deforestation, plantation and agriculture across the major biomes have threatened the biodiversity and endemism of plant diversity (Hansen et al., 2001; Huston, 2005). All these factors have increased the chances of extinction of endangered species in many ecosystems (Sodhi et al., 2004). This thesis contributes to better recognition and understanding of diverse biomes pattern and vegetation dynamics in the region under climate change.

\subsubsection{Climate-vegetation interaction in tropical Asia: review}

Global climate change has been a central topic of debate in recent time (Dessler and Parson, 2019). The interaction between vegetation and the climate is a critical element in the earth's system. The regional and global climates are affected by the physical and biogeochemical interactions of the tropical vegetation in climatically influential areas over the earth (Mabuchi, Sato and Kida, 2005). This makes vegetation a crucial part of terrestrial ecosystems with significant temporal and spatial variability. Variations in vegetation distribution over long period provide valuable information about ecological responses to climate changes (Vicente-Serrano et al., 2013), and land use and land cover changes (Hüttich et al., 2007). Several studies on the spatio-temporal changes 
in vegetation activity and their driving factors suggested that an extensive part of the world is experiencing dramatic changes in photosynthesis (Zhao, Dai and Dong, 2018), among which changes in the region is significant (de Jong et al., 2011; Chen et al., 2014). Despite numerous past studies such as those of Boit et al. (2016), Clark et al. (2001), Erfanian et al. (2016), Harrison and Prentice (2003), Levy et al. (2004), Liu et al. (2015), Ostendorf et al.(2001), and Scheiter and Higgins (2009), focusing on the global change impact on vegetation in the tropical region, South and Southeast Asia remain poorly explored in such studies (Scheiter, Kumar, et al., 2020).

The vegetation characteristic such as vegetation structure, canopy characteristics, and phenology influence the regional climate by affecting near-surface microclimatic conditions such as albedo, surface roughness, and separation of surface energy fluxes into sensible and latent heat (Bonan, 2008). These land-surface properties influence climate-vegetation feedback by integrating the biosphere, atmosphere, and hydrosphere (Bonan, 2008; Zeng et al., 2017). In addition, vegetation-climate interactions also affect large-scale vegetation distribution, biodiversity, and vegetation structure. The heterogeneous vegetation features such as woody cover, stem density, growth form, and vegetation height also influence animal habitat diversity (Tews et al., 2004; Schuldt et al., 2014). The seasonality and inter-annual variability in climate influence the phenology of plants such as leaf green-up, flowering, and leaf senescence. Phenology determines whether a plant is evergreen or deciduous. Climate change can influence the plant phenology (Buitenwerf, Rose and Higgins, 2015) and may have implications for biodiversity (Walther, 2010; Piao et al., 2019). The impact of climate change on vegetation structure and phenology can influence biosphere-atmosphere coupling (Bonan, 2008; Piao et al., 2019). Therefore, it is necessary to develop an understanding to assess the potential future vegetation dynamics so that suitable policies can be recommended for biodiversity conservation. This type of assessment would require the ability and tool to predict the response of vegetation distribution, biome boundaries, plant growth, and related vegetation dynamics to climate change, atmospheric $\mathrm{CO}_{2}$ concentration, soil conditions. I have investigated the impact of climate change on biome boundaries and productivity in Chapter 3 and the impact on vegetation structure and phenology in Chapter 4.

In the past, vegetation-related studies in the Asian tropics were mostly influenced by its socio-political history and had a forest-centric focus on understanding Asian 
vegetation. The vegetation classification of South and Southeast Asia originated in the colonial era (Brandis, 1906; Ratnam et al., 2016) and was carried out by foresters mainly trained in forestry traditions focusing on timber extraction (Sankaran and Ratnam, 2013). Such an approach had neglected diverse open biomes such as grassland and savanna. Consequently, most vegetation types with some degree of tree cover in them were described as forests (Champion and Seth, 1968). This practice has led many forest conservationists to classify areas with open tree canopies as degraded forests resulting from human management for thousands of years (Champion and Seth, 1968). This has misled the Asian savannas to be classified as 'degraded forests' (Ratnam et al., 2016), and all conservation policies are formed around restoring these so-called degraded forests. I have discussed this in detail in Chapter 5, where I have proposed a new method for classifying an area as forest and savanna for better conservation policy.

\subsubsection{Biodiversity conservation in protected areas under climate change}

Since the last ice age, nearly $70 \%$ of the natural vegetation across the world has been lost either due to natural cause such as fire, drought or cleared for human use, which has led to the loss of biodiversity and faster species extinction (Ellis, 2013; IPBES, 2019). It has been predicted that approximately 10 million $\mathrm{km}^{2}$ of natural habitat will be converted for agriculture by 2050 (Strassburg et al., 2012). The pressures of the human population on habitats intensify and would have severe implications for protected area effectiveness for biodiversity conservation (Curran et al., 2004). Between 1950 and 2009, the population in South Asia has been grown from 473 million to 1.6 billion and is projected to increase by $41 \%$ by 2050 (United Nations Statistics Division, 2007). This population explosion has led to increasing population densities, intensified land-use, invasive species and increasing habitat fragmentation threatening the protected areas that are often the only refuge for endangered species (Clark, Bell, Hersh and Nichols, 2011). The protected areas in South Asia have a significant contribution toward biodiversity conservation that enhances the diversity of terrestrial ecosystems. Protected areas account for approximately $7.2 \%$ of South Asia's total land area (Pachauri et al., 2014). Numerous studies have shown that protected areas are among the prime reserves for tropical biodiversity. However, the aboveground forest carbon stocks have been degraded due to increasing deforestation in the region (Sodhi et al., 2010; Wilcove et al., 
2013). The United Nations Convention on Biological Diversity has considered protected areas to be instrumental and indispensable in conservation.

South Asia is the most vulnerable region to climate change in the world, which is posing a significant threat to the protected areas (Eckstein, Hutfils and Winges, 2018; Hasnat, Kabir and Hossain, 2018). Therefore, it is vital to consider the potential impact of climate change for designing future management and conservation strategies for protected areas. This approach would help to boost the management plan and anticipatory risk assessments for conservation. Ecosystem models are capable of investigating the potential impact of climate change on vegetation and identify threatened areas. The recently enhanced computing capacity has made it possible for a complex vegetation model to simulated vegetation dynamics at higher spatial resolution. Studies exploring the conservation of protected areas have usually employed statistical, bioclimatic envelope models focusing on a limited number of species on a small scale (Sieck et al., 2011). Only a few studies have utilized a mechanistic and process-based model, such as a dynamic vegetation model, to assess the impact of climate change on protected areas. The application of modern modelling tools could benefit the assessment of global change impact on biodiversity in the protected areas. The existing tools have not been utilized to their full potential in exploring alternate management scenarios under climate change. In chapter 5, I have explored the impact of climate change on protected areas and threatened biomes such as savanna to evaluate the future trend.

\subsection{Motivation}

Understanding and assessing the response of vegetation to the future climate change is critical for developing adaptation strategies for mitigating the consequences (Jones et al., 2009; Negi et al., 2012). Vegetation interacts with the atmosphere through various ecophysiological processes like photosynthesis and evapotranspiration (Menon et al., 2007; Le Quéré et al., 2009). Vegetation responds to climate change at many levels. Change in environmental conditions such as temperature, precipitation regime, nutrient, light, and in atmospheric $\mathrm{CO}_{2}$ concentration influence plant physiology and biochemistry, thereby influencing the allocation of carbon to different parts of plant such as leaves, stems and roots (Hartmann et al., 2018). However, some studies have shown that, plants have evolved different functional strategies to cope with adverse climatic conditions such as drought, heat stress, cold or inundation, for example, the evergreen 
and the deciduous strategies of trees, modified leaf strategies i.e., broad-leaf and needle leaf tree (Strauss and Cacho, 2013; Kergunteuil et al., 2019). Therefore, changes in environmental conditions would eventually lead to changes in the species composition of an ecosystem, which can shift biome composition. In many cases, these changes can have a damaging effect on the biodiversity of biomes such as savanna and grassland (Jones et al., 2009; Gonzalez et al., 2010; Ratnam et al., 2016).

Vegetation responds slowly and cannot keep pace with the climate change (Scheiter, Moncrieff, et al., 2020). There exist time-lags between the change in climate and ecosystem. Vegetation could take several decades to recover if the ecosystem is resilient enough to bounce back to the pre-disturbed state given proper management (Van Nes and Scheffer, 2007; Veraart et al., 2012). However, in the recent past, the altered global climate state has accelerated the change in ecosystem functions and vegetation structure (Jones et al., 2009). Such changes coupled with the anthropogenic changes such as land use change including shifting cultivation is causing loss of biodiversity and natural ecosystem. The loss of biodiversity and protected areas leads to reduction in vegetation cover and species diversity that further increases the vulnerability of fragile ecosystems (Kehoe et al., 2017).

The global distribution of vegetation pattern has changed in the past and is likely to continue changing in future. In the recent recorded history, climate has changed at faster rate than it did in the past (Beerling and Royer, 2011), due to rapid increase in greenhouse gas (GHG) concentrations (Meinshausen et al., 2011). The climate projection by most general circulation models (GCM) hare associated with uncertainties due to the complex changes in climatic pattern, rising temperature, rising level of GHGs, and altered precipitation regime (Ahlstrom et al., 2013). Therefore, how vegetation would respond to these changes and where current vegetation pattern will change most dramatically also remains uncertain (Alo and Wang, 2008; Ahlstrom et al., 2013). Finding answer to these questions is critical for two reasons, first, ecosystems provide various services on which major part of human population depend for their well-being and livelihood, especially in South Asia (Kumar and Yashiro, 2014). Second, ecosystems are reservoir of carbon and serve as a natural potential carbon sink, which if released as a consequence of major changes, may accelerate (e.g., due to increasing methane emission from permafrost or carbon emissions from soils, wildfires or forest die-back), or slow down (e.g., through increased vegetation growth due to $\mathrm{CO}_{2}$ fertilization) climate 
change (Randerson et al., 2006; Turetsky et al., 2019). Therefore, an investigation of vegetation dynamics, including the identification of vegetation response to climatic changes, is essential for coping with future climate change.

A major challenge in the field of plant ecology and biogeography is to develop an understanding on how climate and vegetation interact to define the distribution of past, current and future vegetation distribution (Thuiller et al., 2008; Wullschleger et al., 2014; Harris et al., 2016). Understanding and predicting the outcome of the complex vegetation-climate interaction under different management and potential future climate scenarios has become possible due to the development of Dynamic Global Vegetation Models (DGVMs, Peng, 2000; Quillet et al., 2010). DGVMs are capable of simulating the terrestrial balances of carbon and water as well as vegetation dynamics in response to changing climate (Prentice et al., 2007; S. Sitch et al., 2008; Pappas et al., 2013). They have become an indispensable tool to project vegetation patterns at different spatial and temporal scale, and associated biogeochemical cycles (Bachelet et al., 2018). The geographical pattern of vegetation emerges as a result of different responses of plant types to climate, with respect to productivity, bioclimatic constraints, access to resources and space, and sensitivity to natural disturbances such as fire (D’Onofrio, von Hardenberg and Baudena, 2017).

Although tropical Asia (South Asia and South East Asia) has rich biodiversity and is vulnerable to climate change, the region is underrepresented in vegetation modelling studies and global biodiversity assessments (Hughes, 2017). Some global scale modelling studies using vegetation models have investigated climate change impact on vegetation (Hickler et al., 2006; Sato, Itoh and Kohyama, 2007; Smith et al., 2014), however, studies explicitly focusing on this region are rare (Ravindranath, Murali and Sudha, 2006; Chaturvedi et al., 2011; Kumar and Scheiter, 2019). Tropical Asia has very heterogeneous vegetation and climate pattern as compared to rest of the world, which might not be well represented in global-scale simulations. The global scale studies that focus on savannas of South America, Africa and Australia (Figure 1.2a), but have not represented the regional scale features like Asian savannas (Lloyd et al., 2008; Lehmann et al., 2011, 2014; Staver, Archibald and Levin, 2011). Asian savannas have been misinterpreted since the colonial era as degraded forest due to which management plans always focused on re-foresting them (Ratnam et al., 2016; Bastin et al., 2017; Griffith et al., 2017). Management practices such as suppressing fire, restricting grazing and 
afforestation with non-native plants have further deteriorated the savanna ecosystem(Nguyen, Murphy and Baker, 2019). In many cases these new plant introduced for re-forestation of open ecosystems, have become an excessive invasive species taking over the local ecosystem (Hiremath and Sundaram, 2013; Bhadouria, TRIPATHI and Rao, 2018). Such conversion is translated into a major impact on biodiversity and ecosystem services (Ratnam et al., 2011; Fernandes, Coelho, Machado, Ferreira, Aguiar, et al., 2016).

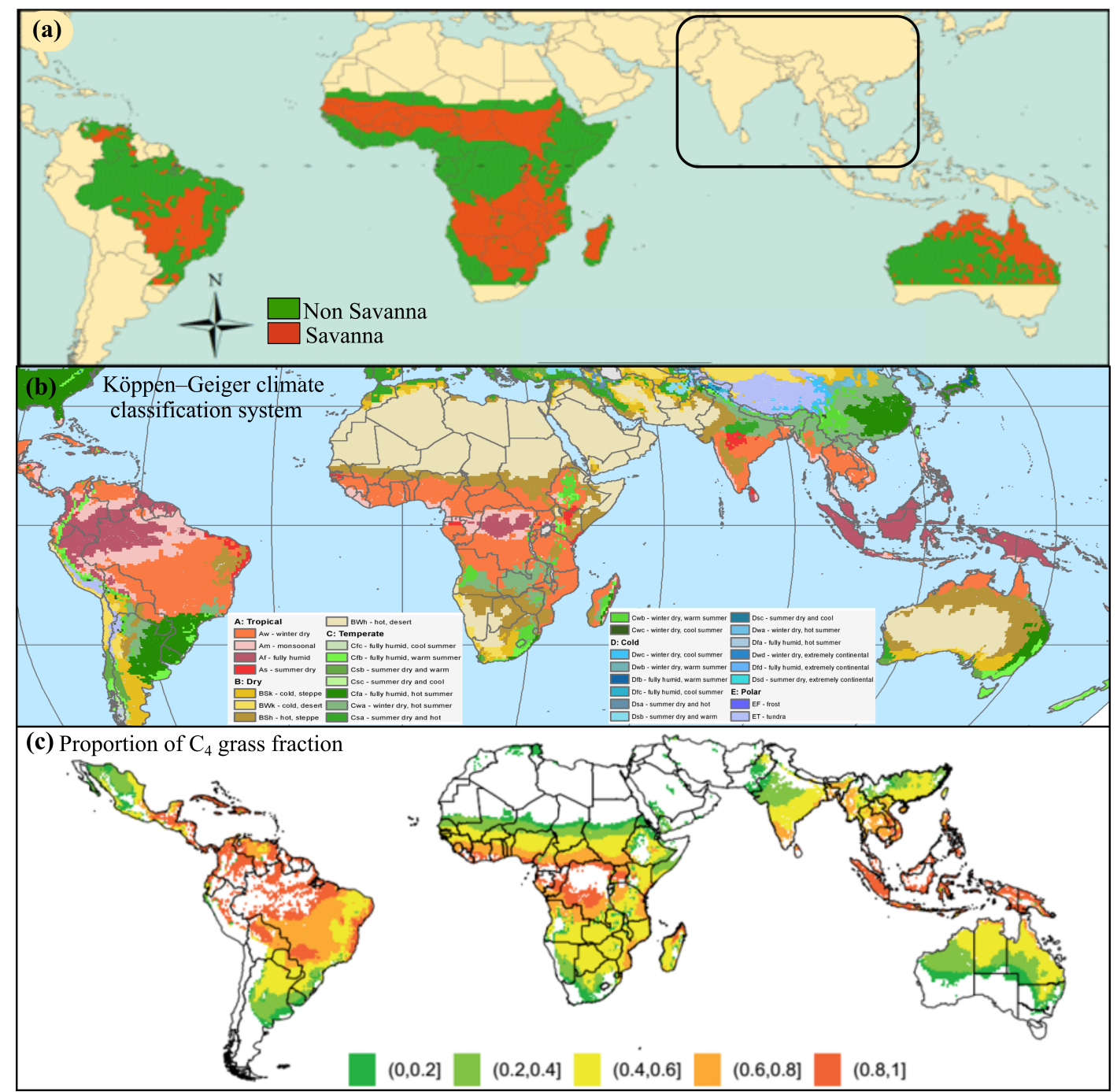

Figure 1.2 (a) The global extent of savanna and forest distribution, adapted from Lehmann et al. (2011). (b) The Köppen-Geiger climate classification system showing tropical region of Asia also has similar climatic setting to other savanna regions e.g., Africa, South America and Australia. 25 year of climate data were used to derive these map ( TYN SC 2.03, Mitchell et al.,2004, https://sedac.ciesin.columbia.edu/maps) (c) The fractional distribution of $C_{4}$ grass adapted from NACP MsTMIP: Global and North American Driver Data forMulti-Model Intercomparison(Wei et al., 2014). Souce:http://dx.doi.org/ 10.3334/ORNLDAAC/1220). 
In South Asia, the functional drivers and diversity of savannas along with adjacent forests and grasslands are poorly understood (Ratnam et al., 2016; Singh et al., 2017). Insufficient knowledge on this limits the formulation of appropriate management strategies due to lack of focus on Asian Savannas. Many global scale studies have not considered the Asian savannas despite the region's climatic condition are similar to that of Africa, South America or Australia (Figure 1.2b; Murphy and Bowman, 2012; Ratnam et al., 2016). However, there are mounting evidences that suggest this ecosystem to be of ancient origin with varying degree of human impact (Mondal and Sukumar, 2016; Ratnam et al., 2016). Large areas in the region have higher fraction of $\mathrm{C}_{4}$ grass cover (Figure 1.2c; Wei et al., 2014) which is the characteristic feature of savanna biome (Ratnam et al., 2016). Misinterpretation of savanna as degraded forest also has led the forest conservationists to consider the open ecosystem for afforestation as an appropriate conservation policy with focus of carbon sink or climate mitigation (Chapter 5; Kumar et al., 2020). Such inappropriate management activities especially when considering climate change makes it an urgent need to investigate this issues and consequences of misinterpreting vegetation.

The distribution of savannas is also not well reproduced in different vegetation models and these areas are simulated as forest (Chapter 5; Kumar et al., 2020). In addition, the distribution of deciduous and evergreen forests in Southeast Asia, which is maintained by rainfall seasonality, is not well represented in global simulations conducted with LPJ-GUESS (Smith et al., 2014) or SEIB-DGVM (Sato, Itoh and Kohyama, 2007), however, is simulated by a LPJ-GUESS version that includes a complex representation of hydrology (Hickler et al., 2006) by a JSBACH version with variable traits (Verheijen et al., 2013). For tropical Asia, GCMs project an increasing frequency of droughts and changes in rainfall seasonality (Hijioka, Lin, J. J. Pereira, et al., 2014; Y. Zhang et al., 2016), which potentially can have severe impacts on vegetation structure and phenology. It has been well established that the spatial vegetation patterns will change under climate change, but by how much and where? The answer given by current research remains tentative, but previous studies indicate that the changes will be wide-spread if atmospheric $\mathrm{CO}_{2}$ increase and warming are not limited to a small magnitude (Lucht et al., 2006; Heimann and Reichstein, 2008).

Climate change and rising atmospheric $\mathrm{CO}_{2}$ will cause widespread shifts in the distribution of major vegetation or biomes types at large scale by the year 2100 (Lucht 
et al., 2006). However, the response of terrestrial ecosystem to climate change and rising $\mathrm{CO}_{2}$ is uncertain and need further investigation for its implication on spatial distribution of vegetation types or biomes and other underlying ecosystems functions (Nolan et al., 2018; Wang et al., 2019). It is important to do simulations for various climate scenarios (Reprensentative Concentration Pathways, RCPs) and to be able to assess potential trajectories of future vegetation change and related uncertainties. Different climate scenarios (RCPs) can also serve to understand processes and how different forcing (particularly $\mathrm{CO}_{2}$ ) contributes to simulated vegetation changes. I have conducted model simulations using a DGVM to investigate the future distribution of different biomes and their productivity in South Asia in Chapter 3, and climate change impacts in tropical Asia with focus on deciduous and evergreen vegetation in Chapter 4 are explored under an ensemble of climate scenarios.

\subsubsection{Dynamic Global Vegetation Models (DGVMs)}

DGVMs are the physiologically based models used to simulate the impact of climate on vegetation distribution, forms, and function at different spatial and temporal scales (Prentice et al., 2007; S. Sitch et al., 2008). DGVMs simulate biogeochemical cycles, vegetation structure, and ecological processes such as establishment, competition, growth, and mortality, that regulate the balance between different vegetation types (Cramer et al., 2001; Scheiter and Higgins, 2009). There are many different DGVMs, each designed with different objectives, and all are based on the same ecological principles to simulate climate-vegetation interactions. DGVMs use biogeographical rules and ecophysiological principles to the model distribution of vegetation types based on climate (Prentice et al., 2007). DGVMs also provide a dynamic representation of the plant's biogeochemistry, land-surface energy budget, and an accounting system for components of global carbon, nitrogen, and water budgets (Bonan, 2008).

In most global scale studies, DGVMs represent vegetation as plant functional types (PFTs), to represent the wide range of plant species with a similar functional role in an ecosystem with respect to environmental conditions like water and nutrient availability (Lavorel et al., 2007). However, the PFT based DGVMs have been criticized due to the generalization of complex and heterogeneous plant types and ignoring the growing knowledge of community plant ecology (Harrison et al., 2010; Scheiter, Langan and Higgins, 2013). Most DGVMs typically use fixed plant traits to represent a limited 
number of static PFTs, and poorly represent competition (Fisher et al., 2010; Quillet, Peng and Garneau, 2010), as it is modelled at the PFT level and not at the individual plant level (Clark, Bell, Hersh, Kwit, et al., 2011). Such descriptions of plants within DGVMs limit their capability to model heterogeneous plant community structure and plant ability to adapt to changing environment. Recently the limitations of PFTs have been addressed by using functional trait (FT) approaches in DGVMs to simulate trait variation in plant communities (Pavlick et al., 2013; Scheiter, Langan and Higgins, 2013; Verheijen et al., 2013; Sakschewski et al., 2015). Scheiter et al. (2013) advocated that the next generation of DGVMs should implement ideas derived from coexistence theory (Chesson, 2000) and community assembly theory (Webb et al., 2010) into the processbased paradigm of dynamic global vegetation modelling. I proposed in Chapter 2 of this thesis that there is a need to revisit PFT schemes in DGVMs, and to identify key traits and processes required in FT approaches, to better account for different plant communities in South Asia.

The individual-based DGVMs are capable to simulate the rate at which individual plants grow, reproduce, and die and how these rates are influenced by the plant's traits and the abiotic and biotic components (Thuiller et al., 2008). Trait-based dynamic vegetation models are becoming popular nowadays among ecologists and ecosystem modelers, due to their flexibility to represent plant traits diversity. One such model is the Adaptive Dynamic Global Vegetation Model Version 2 (aDGVM2) which is a nextgeneration vegetation model (Scheiter et al., 2013; Langan et al., 2017; Gaillard et al., 2018).

\subsubsection{The aDGVM2}

The aDGVM2 is an individual-based dynamic vegetation model in which each plant can have a specific and potentially unique combination of trait values that define plant type, leaf characteristics, carbon allocation to plant compartments, plant architecture i.e., roots and crown shape, response to fire, reproduction and mortality (Scheiter et al., 2013; Langan, 2019). These traits influence how a plant performs under given environmental conditions and are regulated by trait trade-offs constraint which accounts for mass conservation for allocation, stability trade-offs for architecture, leaf economic spectrum and resource competition between (Scheiter et al., 2013; Langan, 2019). The implementation of flexible traits in aDGVM2 allows us to move away from 
the paradigm of fixed-trait plant function types and can model resource competition at individual plant level instead of PFT or plant cohort level (Figure 1.3).

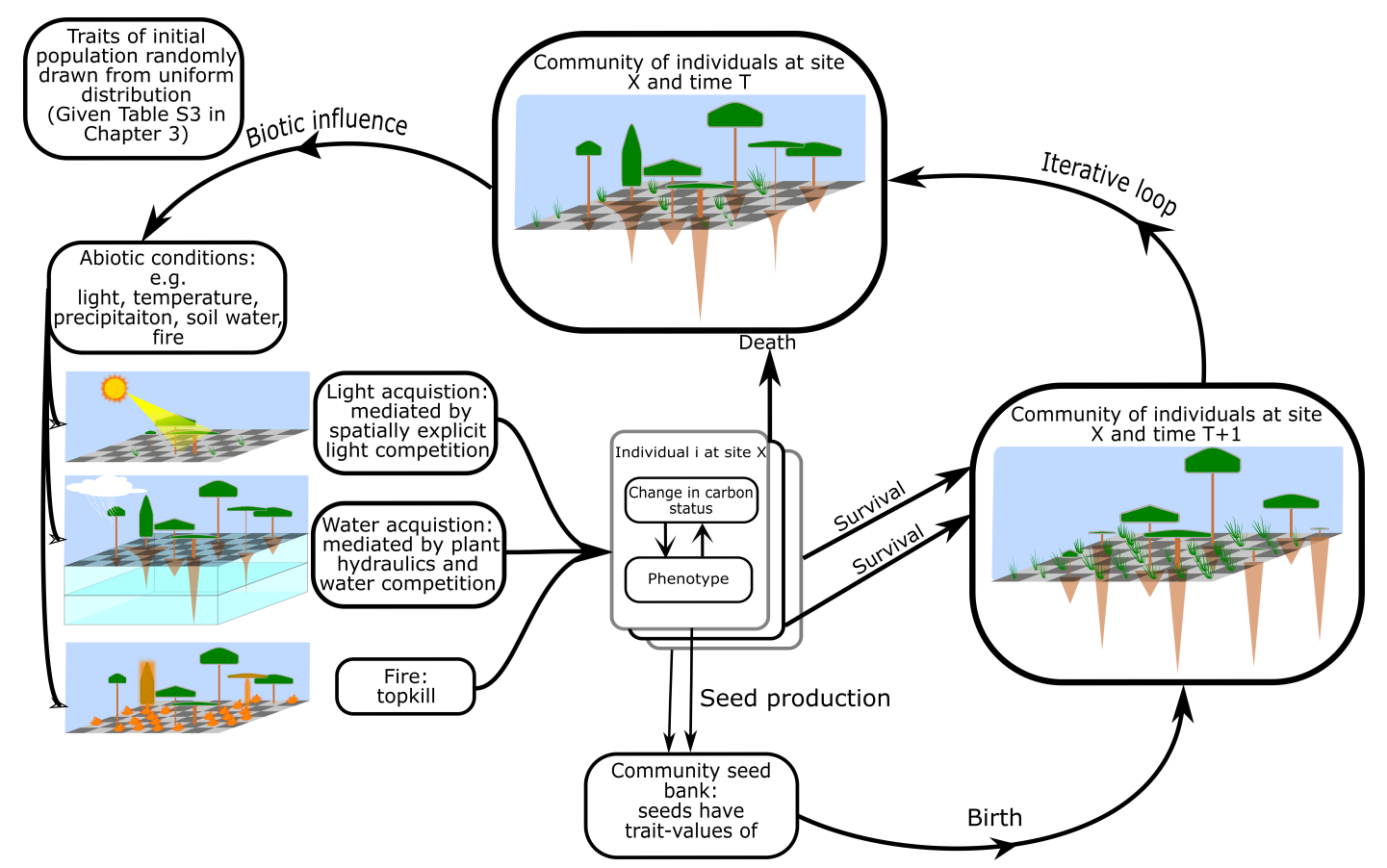

Figure 1.3 Conceptual model of aDGVM2 depicting the iterative process through which a community of plants assembles. Individuals are characterized by their traits that influence their carbon (C) status and phenotype. All individuals at a site form the community, which influences resources, environmental conditions and disturbances via engineering and modulating impacts. These conditions interact to influence growth of the individuals. Individuals, through reproduction, can add their traits to the community trait pool. Crossover and mutation of the community trait pool yield the community seed bank. Flow chart of aDGVM2 adapted from Langan et al.(2017).

At the beginning of simulations, the aDGVM2 is initialized with individuals defined by a set of traits regulated by trade-offs. The stochastic iterative sampling of these trait spaces allows plants to have potential traits combination and most adapted lifeforms to prevail in given environmental conditions. This selection occurs through trait selection between successive generations via cross-over and mutation (Langan, 2019). In aDGVM2 trait inheritance and trait-alteration during reproduction phase affect community assembly and allow dynamic adaptation of plant to environmental conditions. The ability of the aDGVM2 of environmental selection and filtering makes it suitable to study vegetation community assembly, functional diversity and evolution fully based on traits. Further the impact of changing environmental condition on vegetation community assembly and trait biodiversity can be simulated with aDGVM2 
(Langan, 2019). The development of aDGVM2 has been described in detail in Langan et al. (2017) and Scheiter et al. (2013). I have furthered this development, and modified the aDGVM2 to simulate photosynthesis at leaf level for individual plants and added $\mathrm{C}_{3}$ grasses, described in Chapter 3 of this thesis.

I have used aDGVM2 (Scheiter et al., 2013; Langan et al., 2017; Gaillard et al., 2018) for studies conducted for this thesis. In Chapter 3 I have described in detail the changes made in aDGVM2 for South Asia (Kumar et al., 2020b) to assess the impact of climate change on vegetation distribution (Chapter 3; Kumar et al., 2020b), structure, phenology (Chapter 4, Scheiter, Kumar et al., 2020) and threatened biomes (Chapter 5; Kumar et al., 2020a).

\subsubsection{Structure of the Thesis}

The overarching aim of this thesis is to investigate the impacts of future climate change on biome distributions, biome boundaries, vegetation structure and phenology in South Asia and South east Asia, and to identify the threatened biomes.

My thesis is based on four publications, Kumar and Scheiter (2019) (Chapter 2), Kumar et al. $\left(2020 \mathrm{~b}^{\dagger}\right)$ (Chapter 3), Scheiter, Kumar et al. (2020) (Chapter 4) and Kumar et al. (2020a) (Chapter 5) and I divided this thesis into 6 chapters. In Chapter 1, I started with a general introduction outlining the background of vegetation, biogeography and ecosystem modelling in South Asia and motivation for doing this work. In Chapter 2, I propose how to develop a region-specific DGVM for South Asia by considering all the heterogeneous vegetation types. I proceed with descripting new additions to the aDGVM2 in Chapter 3. I used the updated aDGVM2 to simulate the future vegetation distribution under different climate scenarios and looked into the role of $\mathrm{CO}_{2}$ fertilization on vegetation. In Chapter 4, the impact of climate change on the phenology and forest structure in South Asia as well as in Southeast Asia is investigated. I used the projected climate scenarios of five different general circulation models (GCMs) for two RCPs to focus on the robust response of the tropical ecosystem of tropical Asia. In Chapter 5, I focus more the conservation aspect of a threatened savanna biomes and utility of aDGVM2 in predicting their likely future distribution. In Chapter 6, I synthesize the findings of the previous chapters and provides suggestions for further ways in which

\footnotetext{
${ }^{\dagger}$ under review in Biogeoscience doi: $10.5194 /$ bg-2020-169
} 
aDGVM2 could be improved to include cold adapted vegetation for global scale simulation.

My thesis focuses on advancing our understanding of vegetation dynamics and the impact of projected climate change on biome distribution in South Asia. Specifically, I address the following questions.

In Chapter 2, I proposed new ideas for modelling the vegetation of South Asia and investigated the following questions:

1) What are the challenges to represent regional vegetation in modelling in South Asia?

2) What are the missing plant types and growth forms not represented in dynamic vegetation model?

3) How can available trait database improve the representation of diverse vegetation in dynamic vegetation model?

In Chapter 3, I investigated the following questions:

1) How do projected changes in climate and $\mathrm{CO}_{2}$ following two Representative Concentration Pathways (RCP8.5 and RCP4.5) change the distribution, boundaries and climatic niches of biomes in South Asia?

2) How does the relationship between projected biomass, ET, temperature and precipitation change in response to $\mathrm{CO}_{2}$ fertilization?

3) What is the sensitivity of predicted changes in relation to presence and absence of $\mathrm{CO}_{2}$ fertilization?

In Chapter 4 using ensemble climate projection, the following questions were investigated:

1) Does elevated $\mathrm{CO}_{2}$ lead to higher woody biomass due to $\mathrm{CO}_{2}$ fertilization, even in areas where precipitation decreases until 2099?

2) How the enhanced woody biomass affects the vegetation structure and phenology?

3) To what extent the stochasticity of aDGVM2 affect the future vegetation state within the ensemble climate projection?

4) How does the selection of variables used to track vegetation change influence the area affected by vegetation change?

In Chapter 5, I asked: 
1) What is the role of grass biomass in defining biome states?

2) How does misinterpretation of savanna as degraded forests mislead management efforts?

3) How are grassland-savanna-forest boundaries influenced by RCP4.5 and RCP8.5, and do Asian savannas exhibit similar shifts towards tree-dominated states as African savannas?

\subsection{Thesis overview}

In Chapter 1, I explored the different biomes type and their relevance in modelling regional vegetation dynamics. I explored the current challenges and opportunities of DGVMs integrating traits and ecological processes to simulate vegetation dynamics. I discussed the limitations and challenges of DGVMs such as most of them do not explicitly represent the regional vegetation types or biomes e.g., Asian savanna. I highlighted the need for a better consideration for the representation of biome diversity in the model framework. I also focused on the complexity of available ground data for model parameterizations. This chapter introduces the general background of the thesis, identifies research gaps and which lead to the questions and hypotheses that have been studied in following chapters.

Chapter 2 presents the details about biome diversity and recent progress in the vegetation modelling in South Asia. I discuss the requirement for a more detailed representation of vegetation in dynamic vegetation model for South Asia. I highlight the current challenges and opportunities of models integrating traits and processes to simulate vegetation states and dynamics. The Chapter further outlines the current challenges in DGVMs to represent regional vegetation and existing scenarios of vegetation modelling in the region with current limitation and future scope. Based on the type and environmental condition, I propose the necessities for developing vegetation model for the regions. I put forward the needs and priorities for modelling different type of vegetation type. Therefore, Chapter 2 outlines the detailed information of about vegetation type and way to include them in the vegetation model by using either plant functional type approach or functional trait approach.

Chapter 3 presents the improvement made in ecophysiological process in aDGVM2 and conducted simulations with focus on the vegetation of South Asia. I investigate the impact of climate change and elevated atmospheric $\mathrm{CO}_{2}$ on biome 
boundaries and biomass. This highlights that climate change would favor shift of open biomes toward woody vegetation and will threatened open biomes such as savannas and grasslands. The projection shows transitions of deciduous forest to evergreen forest in the mountain regions. The model simulated a strong $\mathrm{CO}_{2}$ fertilization effect with the rising $\mathrm{CO}_{2}$ implying the regions has potential to remain a carbon sink in the 21 st century.

Chapter 4 presents the simulation with climate forcing from five different climate models for representative concentration pathways RCP4.5 and RCP8.5. It explores potential trajectories of future vegetation in tropical Asia, and quantified related uncertainties. The prediction showed that transitions from small to tall woody vegetation and from deciduous to evergreen vegetation. It is found that phenology patterns were less responsive to climate change and elevated $\mathrm{CO}_{2}$ than biomes and biomass, indicating that the selection of variables and methods used to track vegetation changes is crucial and has implication of management policy.

Chapter 5 focuses on the old open grassy biomes such as Asian savannas, which have been misinterpreted as degraded deciduous forest since colonial era. This misinterpretation may lead reflects mismanagement of savanna biomes. I present a basic way to differentiate between savanna and forest by considering or neglecting the grass layer. Chapter 5 further investigates the impact of climate change on savanna and other protected areas, and proposed management strategies for such threatened biomes.

In Chapter 6, I bring together and contextualize all chapters. I synthesize what is learnt from simulations and throughout I attempt to place it in the broader context of South and Southeast Asian vegetation. The Chapter outlines the implication of the findings on management and conservation policies. It highlights the expansion of aDGVM2 to better represent cold adapted biomes of the Himalayas and beyond. I present how aDGVM2 can be used to study biome- trait diversity and lags effect on biodiversity. 


\section{CHAPTER 2}

\section{BIOME DIVERSITY IN SOUTH ASIA - HOW CAN WE IMPROVE VEGETATION MODELS TO UNDERSTAND GLOBAL CHANGE IMPACT AT REGIONAL LEVEL?}

Dushyant Kumar ${ }^{1}$, Simon Scheiter ${ }^{1 *}$

${ }^{1}$ Senckenberg Biodiversity and Climate Research Centre (SBiK-F), Senckenberganlage 25, 60325 Frankfurt am Main, Germany

\section{Abstract}

The distribution of biomes in South Asia is expected to be affected severely by climate change. Understanding plant-climate interactions and the impact of climate change, rising $\mathrm{CO}_{2}$, land use change, deforestation and fire on vegetation has become a major challenge for ecologists. Therefore, developing the capacity to project vegetation change is of critical importance if we are to mitigate and efficiently adapt to climate change impacts. The lack of an accurate representation of different vegetation types and ecosystem processes at regional scale is a main source of uncertainty in Dynamic Global Vegetation Models (DGVMs). This manifests in a lack of key growth forms such as bamboo, lianas and mangroves and biome types such as savanna, which are essential components of ecosystems in South Asia. Plant communities like mangroves and bamboos, despite covering just small areas, account for high carbon sequestration whereas lianas can decrease carbon sequestration capacity of host trees. Here, we review the current state of vegetation modelling for South Asia and we propose a research agenda for an improved representation of biome diversity in DGVMs. We account for both the traditional plant functional type (PFT) approach and for the functional trait (FT) approach that considers growing knowledge on plant-trait variability and ecoevolutionary principles of different plant communities. We argue that an adequate

$\$$ This chapter was published in the journal Science of the Total Environment as "Kumar, D. \& Scheiter, S. (2019). Biome diversity in South Asia-How can we improve vegetation models to understand global change impact at a regional level? Science of The Total Environment, 671, 1001-1016, doi: 10.1016/j.scitotenv.2019.03.251."

Author contributions: D.K. led the manuscript writing and the study; D.K and S.S conceived the idea for this review article. S.S. conducted simulations and D.K. analysed simulation results for figures. 
Chapter 2-Biome diversity in South Asia - How can we improve vegetation models to understand global change impact at regional level?

representation of different vegetation types and growth forms characteristic of the South Asian biomes is necessary in DGVMs for robust assessments of climate change impacts on their distribution, diversity and carbon budget.

Keywords: South Asia, Biomes, Dynamic global vegetation model, Diversity, aDGVM, Savanna, PFT, Climate change, Functional traits

\subsection{Introduction}

Interactions between climate and vegetation at the local scale influence the ecology, structure and distribution of biomes (Quillet, Peng and Garneau, 2010). For decades ecologists have recognized climate as a primary determinant of large-scale vegetation distributions (Walter, 1985; Greve et al., 2011). Yet, the relationship between climate and vegetation patterns is not necessarily deterministic (Murphy and Bowman, 2012; Zeng et al., 2013) and similar climate conditions can support different plant communities. Knowledge of climate-vegetation interactions is particularly important in highly heterogeneous environments such as the tropics of South Asia (Gautam, Timilsina and Acharya, 2013; Cho et al., 2015; Wang et al., 2017). South Asia comprises steep gradients in climate, topography and soil, all of which influencing heterogeneity of biome patterns (Tripathi, Behera and Roy, 2017). Evolutionary history and multi-stability of different biome types further contribute to this complexity (Cadotte, Cardinale and Oakley, 2008). Understanding the complexity of South Asian geography and plant species richness (Chitale, Behera and Roy, 2014; Panda, Behera and Roy, 2017) is a unique challenge to biogeographers and ecologists (Katayama et al., 2014; Squires, 2014). However, general explanations for the rich diversity and tools to project past, current and future biome patterns at high spatial resolutions are still not sufficient.

Biome diversity in South Asia is threatened by both climate change (Parmesan and Yohe, 2003; Hooper et al., 2012; Chitale, Behera and Roy, 2014) and land use impacts (Foley et al., 2005; Pandit et al., 2007; Newbold et al., 2015). Recent decades showed dramatic losses of species in many South Asian ecosystems and degradation of biodiversity. For instance, Pandit et al (2007) documented that deforestation has reduced the number of endemic species in the Himalayan ecosystems. It has been predicted that Asia could lose three quarters of its original forests, and half of its biodiversity by 2100 (Sodhi et al., 2004; Deb, 2017; Deb et al., 2017). This might cause a decrease in 

understand global change impact at regional level?

resilience, and eventually drive the extinction of rare and endangered tree species in the regions (Allen et al., 2014; Deb et al., 2018).

Ecosystems supply a range of ecosystem goods and services to people, such as food, wood for heating, cooking and construction, carbon sequestration, ecotourism or biodiversity (Parr, Gray and Bond, 2012). The increasing pressure of the human population in South Asia has serious consequences for the provision of ecosystem services. In some regions, deforestation has resulted in a rapid invasion of alien plants such as Lantana species (Sharma, Singh and Raghubanshi, 2005). These species can negatively affect nutrient cycling (Ramaswami and Sukumar, 2016) and prevent regeneration of native forest species by decreasing germination success and growth rates in a plant's seedling (Sharma et al., 2005ab). Invasive Lantana species may lead to a decline of native trees and a reduction of forest diversity and carbon sequestration. To counter deforestation, the Indian government has established a large afforestation program ((Ravindranath, Chaturvedi and Murthy, 2008). Yet, government policies for afforestation of non-forest lands pose a threat to biomes such as savanna (Ratnam et al., 2016) and grassland.

Predicting the potential effects of future climate change and human impacts on vegetation dynamics requires large-scale bio-geographical models (Root et al., 2005; MacDonald et al., 2008). There are two basic approaches to modelling vegetation response to climate change: static (time-independent) and dynamic (time-dependent) vegetation models. Static models predict the distribution of potential vegetation by relating the geographic distribution of climate parameters and vegetation, with the assumption of equilibrium conditions for both climate and vegetation. Such climate envelope models or species distribution models are typically based on statistical methods (Franklin, 2010). Dynamic processes are generally ignored (Peng, 2000). Static models do not consider the impact of changing atmospheric $\mathrm{CO}_{2}$ concentrations (Kearney and Porter, 2009; Linder et al., 2012) and also ignore succession and evolution (Mucina and Rutherford, 2006; Hughes, Pennington and Antonelli, 2013). On the other hand dynamic models such as Dynamic Global Vegetation Models (DGVMs) are based on mechanistic process and include time-dependent processes such as growth, establishment, competition, mortality and disturbance (Cramer et al., 2001; Prentice et al., 2007) ). Yet, most DGVMs do typically not represent the diverse vegetation of South Asia, for instance savanna, mangroves, bamboos and dry deciduous forest. Recently, Ratnam et 
Chapter 2-Biome diversity in South Asia - How can we improve vegetation models to understand global change impact at regional level?

al. (2016) demonstrated that most of the southern part of the Indian subcontinent is savanna. We claim that we need a better understanding of vegetation patterns in South Asia as well as of the underlying processes and environmental drivers, so that we can predict vegetation distributions under projected climate change and deduce adaptation mechanisms to mitigate the consequences of global change (Jones et al., 2009; Negi et al., 2012). Here, we review the state-of-the-art in process-based vegetation modelling for South Asia and we identify knowledge gaps, in particular with respect to vegetation types and growth forms not accounted for in DGVMs. We then provide suggestions how to implement these missing vegetation types and growth forms to reduce uncertainty of DGVMs in the study region.

\subsection{South Asia's biome diversity}

South Asia covers 5 million $\mathrm{km}^{2}$ and is bounded by the Indian Ocean in the south and the Himalayan mountain range in the north. The meteorological conditions are controlled primarily by the movement of the inter-tropical convergence zone (ITCZ, Patra et al., 2013). South Asia experiences dry seasons without rainfall during autumn, winter and spring when the ITCZ is located over the Indian Ocean (between the Equator and $5^{\circ} \mathrm{S}$ ), whereas the region receives about $70 \%$ of total annual precipitation during summer (June-September) when the ITCZ is located north of the equator (Patra et al., 2013). Climatic conditions vary from arid in the west to humid in the east and temperate in the north to tropical in the south. Elevation ranges from sea level in peninsular south India to $8,500 \mathrm{~m}$ in the Himalayas. Elevation gradients are associated with steep temperature gradients and a variety of soil types and topographies. South Asia's topography consists of different mountain ranges, plateaus, dry regions, river basins and humid regions.

The complexity of environmental conditions has resulted in a rich diversity in biome types (Ramankutty et al., 2010), Figure 2.1a), with deserts to grasslands in the northwest, savannas on the Indian peninsula, tropical deciduous and evergreen forest in the Western Ghats and eastern India as well as lowland and montane forests in the lower Himalayas. The region hosts five of the fourteen major ecological regions or biomes of the world. These biomes harbor different ecosystems, which are the result of unique combinations of abiotic factors such as climate, geology, soil and diverse topography. 

understand global change impact at regional level?

Some of the biomes in India and Myanmar host remarkable biodiversity and are amongst the major biodiversity hotspots of the world (Myers et al., 2000).

South Asia is one of the world's most densely populated regions, accordingly, a large fraction of the area is utilized for cultivation accounting for nearly one million $\mathrm{km}^{2}$. Non-forested areas like grassland, savanna, barren and shrubland account for 0.35 million $\mathrm{km}^{2}, 0.22$ million $\mathrm{km}^{2}, 1.5$ million $\mathrm{km}^{2}$ and 0.89 million $\mathrm{km}^{2}$, respectively (Defries and Townshend, 1994; Patra et al., 2013). Forested areas are classified as broadleaf evergreen, broadleaf deciduous and mixed coniferous and account for 0.11 million $\mathrm{km}^{2}$, 0.10 million $\mathrm{km}^{2}$ and 0.05 million $\mathrm{km}^{2}$, respectively (Defries and Townshend, 1994; Patra et al., 2013). About 18.6 percent of the total land area of the region is still covered by forest and it accounts for $1.98 \%$ of the total forest area in the world (http://www.fao.org/docrep/004/y1997e/y1997e0s.htm\#fn39). In India, 21\% of the area is classified as forest (FSI, 2017) with tropical forests accounting for approximately $86 \%$ of the forested area (Singh and Singh, 1988).

\subsection{South Asia's contribution to global carbon cycle}

South Asia has undergone rapid economic growth over the past two decades, which has been associated with significant changes in the rates of land-use change and large increases in fossil fuel emissions (Patra et al., 2013; Cervarich et al., 2016). Landuse changes reshape landscapes and may cause substantial environmental risks. For example, land-use change causes accelerated carbon and greenhouse gas emissions (Houghton, 1999; Kaye et al., 2004; Foley et al., 2005; Tian et al., 2010), change in surface fluxes (Zhang, Henderson-Sellers and McGuffie, 1996; Feddema et al., 2005; Pielke, 2005; Snyder, 2010) and land degradation (Thornes, 1996; Drake and Vafeidis, 2004). Some of these consequences ultimately lead the loss of biodiversity (Pimm et al., 1996; Sala et al., 2000).

The tropical terrestrial ecosystems of Asia, including South and Southeast Asia, play a crucial role in regional and global carbon cycling (Brown, Gillespie and Lugo, 1991; Flint and Richards, 1994; Houghton, 2002; Tian et al., 2003). In the majority of the region where deforestation occurred, forest land was primarily converted to cropland which will significantly reduce carbon storage in the terrestrial ecosystem (Achard et al., 2002, 2004; Canadell, 2002). 
Chapter 2-Biome diversity in South Asia - How can we improve vegetation models to understand global change impact at regional level?

A study using an inversion ensemble method, found that the land biosphere in South Asia was close to carbon neutral, with an annual flux of -0.05 ( -0.18 to 0.03$) \mathrm{PgC}$ per year for 1996-2012 (Thompson et al., 2016). The terrestrial net biome productivity calculated based on bottom-up models in combination with emissions from fire based on the Global Fire Emissions Database version 4.1 (GFED4, (Van der Werf et al., 2010) show net carbon sink of $217 \pm 147{\mathrm{TgC} \mathrm{yr}^{-1}}$ for South Asia (Cervarich et al., 2016).

To compensate for greenhouse gas emissions, afforestation initiatives have increased the forest extent in South Asia by ca. 3\% (2.1 Mha) between 1990 and 2010 (FA0, 2010; Thompson et al., 2016). India alone has increased the extent of forest through plantations by ca. $7 \%$ from 1990 to 2010 , leading to a $26 \%$ increase in the carbon sequestration in living forest biomass (FA0, 2010). Quantifying the region's terrestrial carbon budget and related carbon fluxes would help to determine carbon sequestration capacity of its forests and other ecosystems.

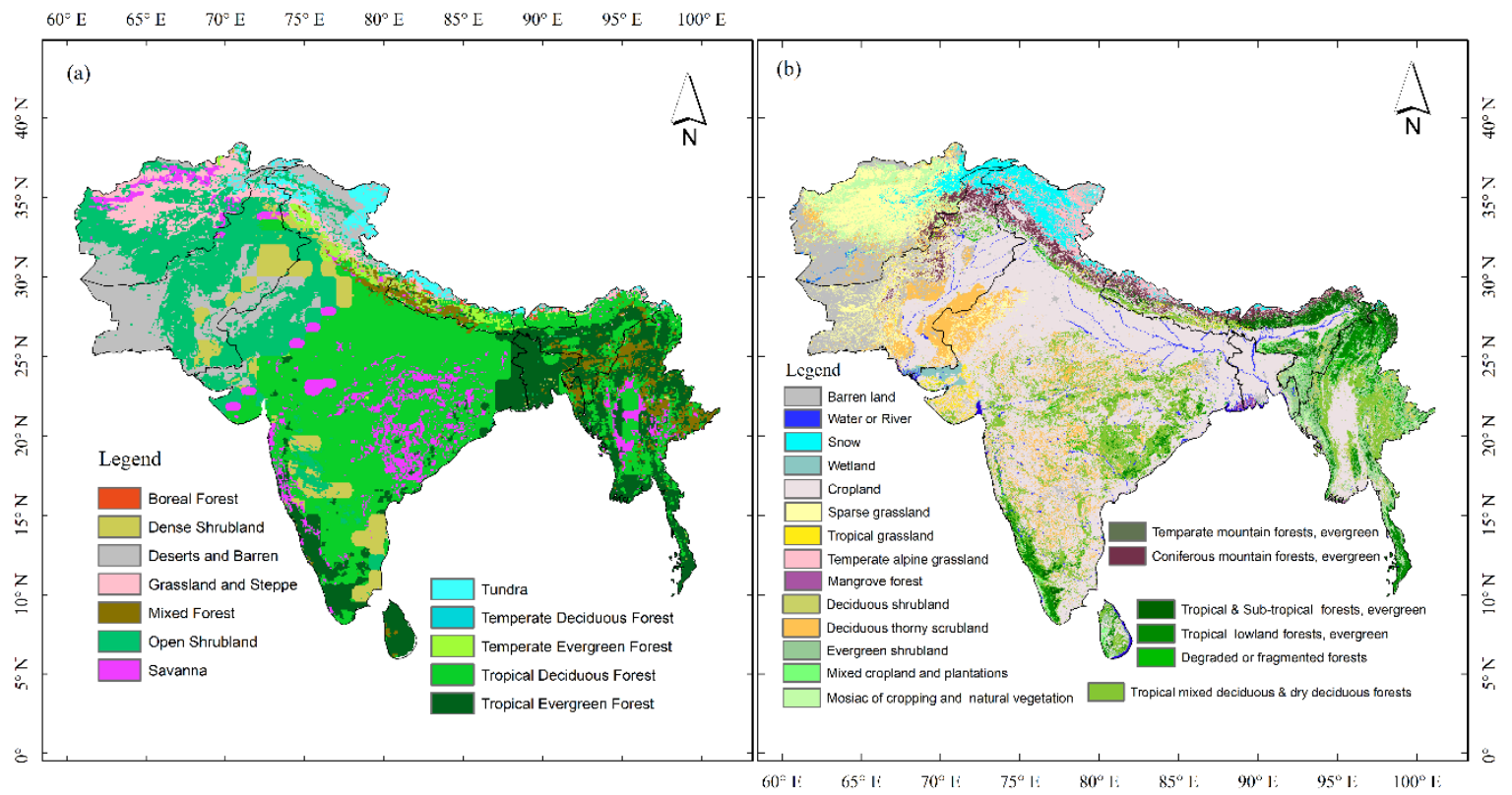

Figure 2.1 (a) Major potential natural vegetation types of South Asia (Ramankutty et al., 2010) and (b) Global land cover map (GLC2000, http://forobs.jrc.ec.europa.eu /products/glc2000/glc2000.php).The ISLSCP-II data product was derived from the land cover data set of Loveland et al. (2000) following the Olson Global Ecosystems (OGE) framework (Olson, 1994) classification scheme. 

understand global change impact at regional level?

\subsection{Anthropogenic impacts in South Asia}

South Asia is home to well over one fifth of the world's population, making it the most densely populated region in the world. Increasing demands for resources due to a population explosion are the driving force behind deforestation (Singh, Singh and Agrawal, 1991) and land transformation, mainly into cropland, resulting in biodiversity loss (Vitousek et al., 1997; Cincotta, Wisnewski and Engelman, 2000). In India, the largest country in South Asia, nearly 173,000 villages are classified as forest villages. Communities in these forest villages largely depend on the natural resources that ecosystems provide (Kishwan, Pandey and Dadhwal, 2009) and human activities alter forest biomass and plant community composition (Agarwala et al., 2016). In the eastern part of South Asia, population density has been increasing steadily over the past decade at a rate of $1.5 \%$ per annum (United Nations Statistics Division, 2007), implying that remaining forests will continue to face high risk of degradation both locally, and over the entire region.

Another common anthropogenic activity in the region is the practice of slash and burn, also known as shifting cultivation; it accounts for $49 \%$ of forest degradation in tropical Asia (Ruangpanit, 1995). Cutting and burning forests alters the natural fire regime and inhibits time to recover, which further degrades ecosystems and causes more carbon emission in the region. This practice leads to land transformation, allowing spread of invasive species which often grow faster than local species and out-compete the local flora (Rai and Singh, 2015). Nevertheless, the slash and burn practice is intricately linked to the culture and livelihood of communities in the Eastern part of South Asia (Ramakrishnan, 1992). The sustainability of this practice has been questioned by many ecologists (Karthik, Veeraswami and Samal, 2009) while others have appreciated the practice (Raman, Rawat and Johnsingh, 1998).

Changes in land use policy aim to mitigate land degradation. For instance, under programs such as Green India mission and Compensatory Afforestation Fund Management and Planning Authority (CAMPA) more area is likely to be afforested. Afforestation improves provision of certain ecosystem services (e. g. carbon sequestration), but these secondary forests are typically different from primary forest in terms of growth rates and biodiversity and they support fewer species than primary forest (Bremer and Farley, 2010; Wang and Cao, 2011). 
Chapter 2-Biome diversity in South Asia - How can we improve vegetation models to understand global change impact at regional level?

Another significant anthropogenic factor which has become a major issue is the ozone pollution or ozone depletion. Exposure of vegetation to ozone reduces photosynthetic rates (Reich and Amundson, 1985) and plant growth, and alters the plant's mechanism of ozone response (Mauzerall et al., 2001) such as stomata regulation (Karnosky et al., 2003, 2005; Felzer et al., 2007). Plant leaves suffer visible injury due to exposure to ozone (Krupa and Manning, 1988; Somers et al., 1998). Exposure to ozone affects the amounts of carbon sequestered in vegetation and soils, and the harvestable portions of crops (Reich and Amundson, 1985; Reich, 1987). The complex interactions between ozone and stomata regulation (Jensen and Roberts, 1986; Felzer et al., 2009) impair the stomatal function and reduce formation of roots in young and mature vegetation (McLaughlin et al., 2007). This competitive interaction in natural environments often leads to a dominance of ozone-tolerant species, reducing the diversity of the community. The development of flux-based models linked to effects on carbon assimilation and allocation offer a basis to improve the capacity for risk assessment (Felzer et al., 2007), but there is a range of potential impacts of ozone, especially at the ecosystem level, for which the necessary mechanistic understanding does not exist to allow the inclusion in local or global risk assessments (Ashmore, 2005). Ozone is a key challenge towards understanding the carbon sequestration effects on natural ecosystems.

\subsection{Dynamic global vegetation models (DGVMs)}

DGVMs simulate ecological processes to simulate climate-vegetation interactions and distributions of vegetation types in response to biotic and abiotic conditions. They are often linked with carbon and nitrogen cycles to simulate biogeochemistry and plant physiological processes, including growth and decay (Bachelet et al., 2001). DGVMs include environmental factors such as climate, soil properties, atmospheric $\mathrm{CO}_{2}$ concentration, or disturbance regimes (fire or herbivory, (Bond and Midgley, 2012; Hoffmann et al., 2012). Traditionally, DGVMs simulate functioning and distribution of predefined plant functional types (PFTs), i.e. groupings of species with similar physiological and ecological functions (Woodward, Lomas and Lee, 2001; Prentice et al., 2007). PFTs use a finite set of static parameters to aggregate traits of individual plants with similar functions in an ecosystem, and similar responses to environmental conditions such as water and nutrient availability (Díaz and Cabido, 

understand global change impact at regional level?

1997; Lavorel et al., 1997; Kattge et al., 2011). Some DGVMs simulate individual species instead of PFTs (e.g. Hickler et al., 2012).

The PFT schemes used in contemporary DGVMs have been successful in representing global biogeographic patterns. Yet, they usually do not represent vegetation heterogeneity in plant communities at regional scale and ignore much of our growing knowledge of comparative plant ecology (Harrison et al., 2010). The PFT approach often implies a simplistic representation of competition (Fisher et al., 2010; Quillet, Peng and Garneau, 2010), because competition is modelled between PFTs and not between individual plants (Clark, Bell, Hersh and Nichols, 2011). This issue has recently been addressed by using Functional Trait (FT) approaches in DGVMs to simulate trait variation in plant communities (Pavlick et al., 2013; Scheiter, Langan and Higgins, 2013; Sakschewski et al., 2015; Yang et al., 2015, 2016). Yet, this increased level of detail in models requires large amounts of data on plant-trait variability and eco-evolutionary principles of plant communities for parameterization. Increased model complexity further implies increases in model computation times (discussed in details in section 2.9). We argue that there is need to revisit PFT schemes in DGVMs and to identify key traits and processes required in FT approaches and ultimately to better account for different plant communities in South Asia. The generalization of plant representation and ecosystem processes by DGVMs results in uncertainty of vegetation dynamics at regional scale and in our projections of future vegetation. Harper et al. (2016) showed that using a trait-based representation of PFTs could increase confidence in the simulations of vegetation and carbon dynamics.

\subsection{Current status of vegetation modelling in South Asia}

Most global scale DGVMs are generic and have simple representation of various vegetation types for example tropical areas are typically represented by few PFTs (Snell, Cowling and Smith, 2013). They are optimized to reproduce overall patterns, temporal variability and carbon stocks of vegetation and soil at global scale, but do often not provide reliable estimates at regional scales (Tang et al., 2010). Many tropical vegetation types characteristic of South Asia, such as mangroves, xerophytes, montane vegetation, and growth forms such lianas, bamboos and shrubs are not or not adequately included in in most DGVMs (but see for example Gaillard et al., 2018 for shrubs or Verbeeck and 
Chapter 2-Biome diversity in South Asia - How can we improve vegetation models to understand global change impact at regional level?

Kearsley, 2016 for lianas). These vegetation types and growth forms may be critically altered by future global change (Berger et al., 2008).

South Asia exhibit substantial heterogeneity in vegetation cover and need explicit representation in DGVMs. Most previous DGVM studies for the South Asia focused on impacts of different climate change scenarios on Indian forests (Ravindranath, Murali and Sudha, 2006; Chaturvedi et al., 2011; Gopalakrishnan et al., 2011). These studies revealed shifts in forest boundaries (Ravindranath, Murali and Sudha, 2006; Chaturvedi et al., 2011; Gopalakrishnan et al., 2011) and changes in forest productivity (Ravindranath et al., 2011) by the end of century. The upper Himalayas, central and northern parts of the Western Ghats, and parts of central India are projected to be most vulnerable to climate change, whereas forests in the north-eastern region of the country are more resilient (Chaturvedi et al., 2011; Gopalakrishnan et al., 2011). Two regional studies focusing on potential impacts of climate change on forests in the north of Himachal Pradesh (Deshingkar et al., 1997) and in the Western Ghats (Ravindranath, Somashekhar and Gadgil, 1997) indicated moderate to large-scale shifts in forest types with implications for forest die-back and biodiversity.

Vegetation models serve as tool to simulate vegetation-climate interaction and their output could be used for better management of ecosystems in future. We ran simulations with aDGVM (Scheiter and Higgins, 2009; Scheiter et al., 2012), a dynamic vegetation model originally developed for African savannas, for South Asia. We found that the IPCC RCP 4.5 climate change scenario affect simulated future vegetation patterns, especially along the Himalayas and Western Ghats by the end the century (Figure 2.2). In these simulations, the presence or absence of fire shapes the extent of forest and savanna in South Asia (Figure 2.2a, d). While aDGVM broadly simulates patters of forest, savanna, grasslands and woodland it does not represent dry and moist deciduous forest type and mangroves as well as growth forms such as shrubs and bamboos.

\subsection{Current challenges in vegetation modelling}

Models applied at regional scale for South Asia range from statistical species distribution models (Pearson and Dawson, 2003) to DGVMs. Statistical species distribution model can be fitted for many species but do not directly represent the 

understand global change impact at regional level?

complex relationships between climate and plants such as competition, carbon dynamics, nutrient cycling (Pearson and Dawson, 2003) and they typically ignore $\mathrm{CO}_{2}$. On the other hand DGVMs, as discussed in section 2.5, represent the key ecophysiological processes of plant growth and competition as a function of environmental conditions. Yet, most of the regional models have several caveats and limitations. The first limitation is that many DGVMs typically use bioclimatic limits (Haxeltine and Prentice, 1996) to constrain the climatic niche where modelled PFTs can grow (e.g. BIOME3 (Haxeltine and Prentice, 1996) or LPJ (Sitch et al., 2003)). For example, Sitch et al. (2003) assume different temperature limits for survival and establishment of PFTs. However, it has been argued that this may imply that areas will be projected as climatically unsuitable for particular PFTs, although in reality they could be tolerable, or vice versa (Reu et al., 2014). Climate envelopes in DGVMs were derived from contemporary distribution patterns of PFTs and might not be valid when projecting vegetation into the future (Scheiter, Langan and Higgins, 2013). One reason is that temperature threshold are influence by elevated atmospheric $\mathrm{CO}_{2}$ concentration (Ehleringer, Cerling and Helliker, 1997). Elevated $\mathrm{CO}_{2}$ increases water use efficiency (WUE) or the photosynthetic efficiency and will likely modify bioclimatic limits as well as biome boundaries in climate space (Franks, Wheeler and Goodnight, 2012).

Second, DGVM simulation results are at the same resolution as input data. Therefore, DGVMs are often limited by the coarse spatial and temporal resolution of data available for model input and parameterization. Most DGVMs are deterministic in the sense that they simulate similar biome types for similar climate conditions and similar model initialization. When conducting model simulations with coarse resolution environmental data, vegetation is homogenous within areas with similar climate, e.g. within a grid cell of $1^{\circ}$. Vegetation heterogeneity within the grid cell cannot be resolved (but note that tiling schemes are often applied to account for areas used for land use or covered by water and human settlements). Therefore, higher resolution data for climate, soil as well as topography and consideration of associated processes such as water balance, radiation and seed dispersal are required (Moorcroft, Hurtt and Pacala, 2001). High resolution climate data can be derived from regional climate models (RCMs, (Rummukainen, 2010; Feser et al., 2011)). While these models can capture important climate phenomena of a region such as monsoons or extreme events, model runs are typically computationally expensive such that high resolution data is only available for 
Chapter 2-Biome diversity in South Asia - How can we improve vegetation models to understand global change impact at regional level?

small regions (Valdes et al., 2017). Alternatively, high resolution data can be obtained from statistical interpolation methods (Fick and Hijmans, 2017). The disadvantage of this approach is that interpolated climate data often ignore important local climate phenomena (Hijmans et al., 2005) and they often provide climatologies instead of continuous time series.

Third, there are only few DGVMs studies for South Asia, most of which were conducted with the BIOME model (versions 3 and 4, Ravindranath et al., 2006; Ravindranath and Sukumar, 1998, 1996)). The BIOME model has a very simple representation of plant physiology in the context of Indian ecosystems (Ravindranath and Sukumar, 1998; Ravindranath, Murali and Sudha, 2006).

Fourth, how vegetation was traditionally represented in many DGVMs has recently received much criticism (Van Bodegom et al., 2012; Pavlick et al., 2013). Models did not satisfactorily represent the variability in vegetation responses to the environment as observed in nature, hindering representations of vegetation-climate interactions and very likely biasing estimates of carbon budgets (Verheijen, 2015). In traditional DGVMs (e.g. LPJ (Sitch et al., 2003), SDGVM (Woodward and Lomas, 2004) or ORCHIDEE (Krinner et al., 2005), only a limited number of vegetation types are used to represent the vast number of plant species and their responses to the environment.

Fifth, soil is the largest terrestrial pool of organic carbon (Jobbágy and Jackson, 2000; Tarnocai et al., 2009) and soil respiration plays a significant role. Soil respiration varies among different vegetation types which could be well explained by the soil condition (Wang et al., 2013; Huntingford et al., 2017). Vegetation, depending on its characteristics (e.g., $\mathrm{C}_{3}$ or $\mathrm{C}_{4}$, evergreen or deciduous, trees or grasses) and climate control soil moisture (Arora, 2002) and soil temperature and thereby soil heterotopic respiration (Jenkins and Adams, 2010). For example, bamboos (Xu et al., 2013) and mangroves (Alongi, 2012; Donato et al., 2012) constitute a significant part of the South Asian biomes and are capable of higher rate of carbon sequestration in the tropics (Donato et al., 2011). Lianas or bamboo or succulents not only have different effects on carbon cycling but they also serve as habitat for different animal communities.

To understand cascading effects on biodiversity at different trophic levels and biotic interactions, we need to understand what's going on in different biomes in terms 

understand global change impact at regional level?

of diversity, vegetation structure, ecosystem services etc. Therefore, for the representation of vegetation and diversity, when we look at regional scale rather than at global scale; we need more diversity in models if we are to understand climate change impacts on diversity at various trophic levels. Given these caveats, we suggest that DGVMs should reflect real-world processes with more detailed vegetation types (more PFTs) or more flexible FT approaches to better represent diversity and the carbon cycle in ecosystems (Frasson et al., 2015; Harper et al., 2016, 2018).

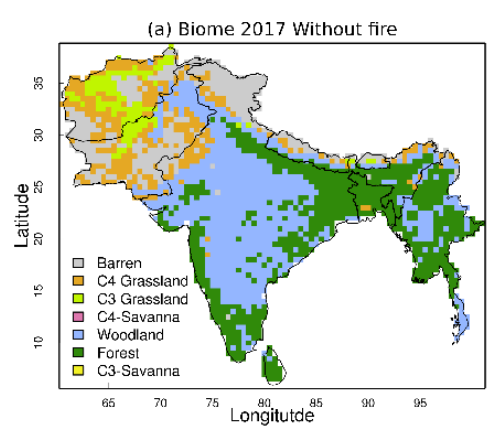

(d) Biome 2017 With fire
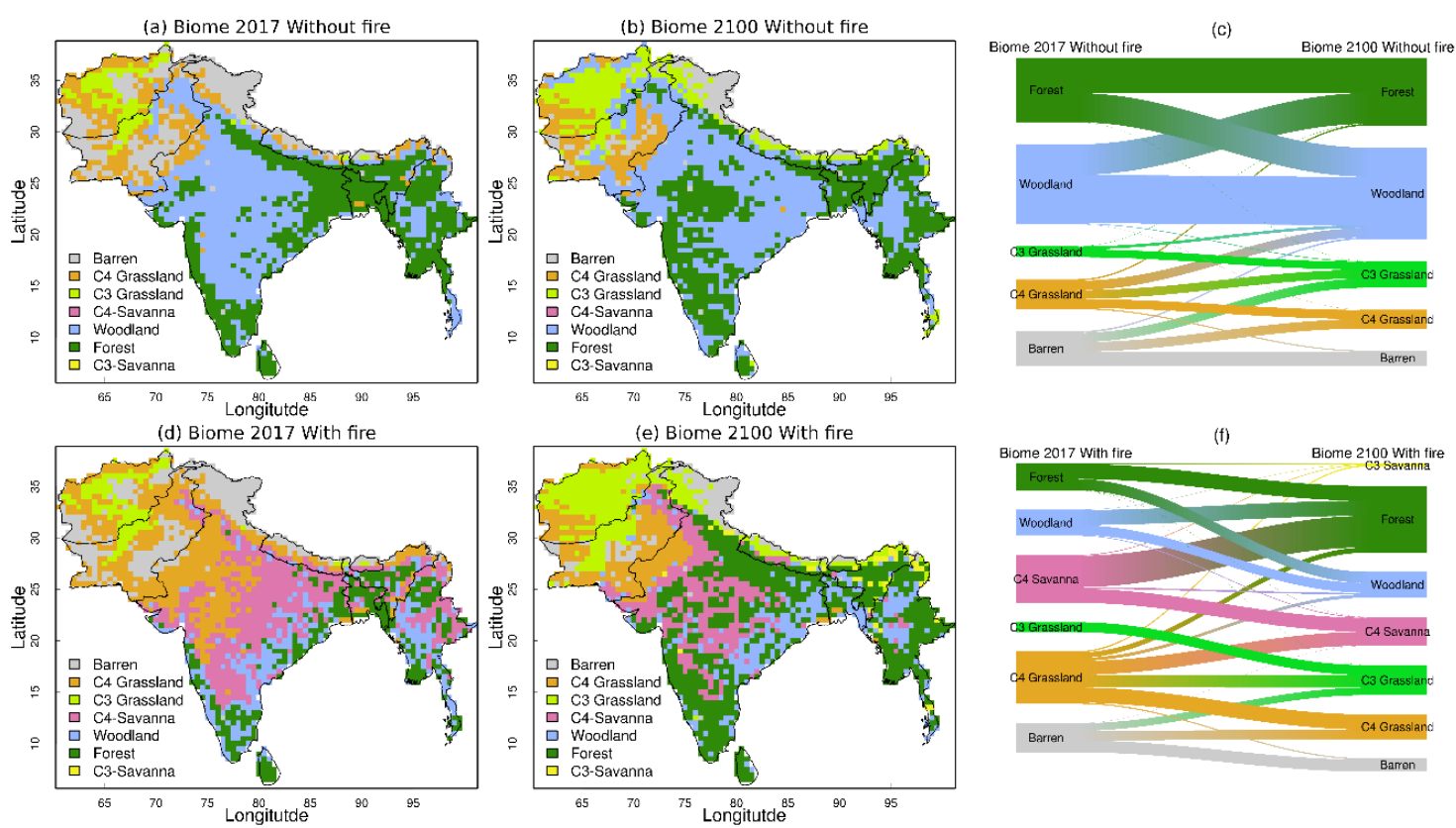

Figure 2.2 Biomes simulated by aDGVM (Scheiter et al., 2012; Scheiter \& Higgins, 2009) without fire ( $a$ and $b$ ) and with fire ( $d$ and e) for the years 2017 ( $a$ and $d$ ) and 2100 (b and e). Sankey graph shows the biome shifts from 2017 to 2100 (c) without fire and (f) with fire. Under both scenarios, biomes are sensitive to climate change and biome shifts occurred. For the biome classification scheme, see Scheiter et al. (2012).

\subsection{Potential of developing DGVMs in South Asia}

Numerous vegetation types and growth forms are characteristic of South Asia's flora, some of which are not represented in state of the art DGVMs. For example, tropical dry deciduous and wet deciduous forests are typically represented as tropical deciduous forest even though they represent distinct vegetation types differing in productivity and their response to environmental resources. Lavorel et al. (2007) found that DGVMs using fewer than 13 PFTs might be unable to simulate fine scale vegetation patterns, and simulate abrupt changes in vegetation along environmental gradients instead of smooth 
Chapter 2-Biome diversity in South Asia - How can we improve vegetation models to understand global change impact at regional level?

transitions that are more common in nature (Quillet, Peng and Garneau, 2010). Table 2.1 lists South Asian biomes, biome-specific growth forms (Ramankutty et al., 2010; Figure $2.1 \mathrm{a}, \mathrm{b})$ and processes that are relevant for modelling each of these biomes. In the following sections, we describe vegetation types and growth forms and suggest how they can be incorporated into DGVMs to allow more reliable projections of past, present and future vegetation dynamics in South Asia.

Table 2.1 Biomes, growth forms and processes relevant for modelling South Asia's vegetation. We argue that including these key growth forms (within a PFT or a FT approach) and processes into dynamic global vegetation models (DGVMs) will allow us to better represent the biome distributions and biome boundaries of South Asia, as well as climate change and land use change impacts on vegetation.

\begin{tabular}{|c|c|c|}
\hline Biome & Growth form & Processes \\
\hline \multirow{6}{*}{ Evergreen Forest } & Dry forest tree & Water Competition \\
\hline & Wet forest tree & Light availability \\
\hline & Dry montane temperate tree & Cold Tolerance \\
\hline & Moist montane temperate tree & Photoperiod \\
\hline & Lianas & Phenology \\
\hline & Bamboos & \\
\hline \multirow[t]{3}{*}{ Deciduous Forest } & Dry forest tree & Light availability \\
\hline & Wet forests tree & Water Competition \\
\hline & Lianas & Phenology \\
\hline \multirow[t]{2}{*}{ Savanna } & $\mathrm{C}_{4}$ grass $^{*}$ & Surface Fire \\
\hline & Fire tolerant tree $\$$ & \\
\hline \multirow[t]{2}{*}{ Shrubland } & $\mathrm{C}_{4}$ grass $^{*}$ & Water competition \\
\hline & Shrub* & Fire \\
\hline \multirow[t]{2}{*}{ Grassland } & Annual $\mathrm{C}_{4}$ and $\mathrm{C}_{3}$ grass & Frost \\
\hline & Annual $\mathrm{C}_{4}$ and $\mathrm{C}_{3}$ grass & Water availability \\
\hline \multirow[t]{3}{*}{ Thicket/Thorny Forest } & Shrub* $^{*}$ & Water availability \\
\hline & $\mathrm{C}_{4}$ grass $^{*}$ & \\
\hline & Succulent tree & CAM Photosynthesis \\
\hline Mangroves & Mangrove tree & $\begin{array}{l}\text { Saline water } \\
\text { Viviparous germination }\end{array}$ \\
\hline
\end{tabular}

* Included in existing DGVMs

\$Included in aDGVM (Scheiter et al., 2012) and ED2 (Trugman et al., 2018)

\subsubsection{Tropical deciduous forest}

Tropical deciduous forests cover the major portion of South Asia's forested area and comprise both dry and moist deciduous forest (Figure $2.1 \mathrm{a}, \mathrm{b}$ ). These forests are found in southern India (Deccan region), Western Himalayas, Myanmar and along the Western Ghats (Reddy et al., 2015). Tropical dry deciduous forests occupy $34.80 \%$ and 
tropical moist deciduous forests occupy 33.19\% of the total forest cover in India (Reddy et al., 2015). Both forest types are generally represented by a single PFT in DGVMs (typically by 'tropical broad-leafed raingreen trees'). Yet, dry and moist deciduous forests have different successional strategies in response to water and light availability (Lohbeck et al., 2015).

Dry forest species have greater drought survival rates due to higher stem hydraulic conductance, higher capacity for $\mathrm{CO}_{2}$ assimilation (Brenes-Arguedas, Roddy and Kursar, 2013), higher stem density and tough, thick tissues with high cell survival at low water content (Kursar et al., 2009). They have thicker and deeper tap roots which are associated with drought tolerance. Despite their higher photosynthetic capacity, these species are shade-intolerant with lower growth rates in the shady understory, probably because of higher maintenance costs of the root systems (Brenes-Arguedas, Roddy and Kursar, 2013). Moist forest species have lower photosynthetic capacity and higher leaf area ratio to capture light efficiently in shady forests (Brenes-Arguedas, Roddy and Kursar, 2013). Deeper and thinner roots allow for resource acquisition in poor soils (Poorter and Markesteijn, 2008). These traits characterize shade-tolerant species and explain high growth rates of moist forest species in the shady understory of forest.

In most DGVMs, plant water stress is driven by external factors, such as precipitation, humidity and soil type and texture (Xu et al., 2016). However, a more realistic approach would be to describe plant water stress through whole plant hydraulic strategies and functions of water pressures within the plant vascular system, defined via water potential in leaf, stem, branches and soil (Matheny, Mirfenderesgi and Bohrer, 2017). A decline in leaf water potential can reduce photosynthesis in tropical dry forest (Brodribb, Holbrook and Gutierrez, 2002) and other ecosystems (Xu and Baldocchi, 2003; Manzoni, 2014), and trigger leaf shedding if leaf turgor cannot be maintained (Sobrado, 1993). Leaf water potential is also influenced by leaf, stem and root hydraulic traits (Cochard et al., 2002). Interspecific hydraulic trait variation allows plants in similar environments to display different phenological and photosynthetic responses to water stress (Poorter and Markesteijn, 2008; Méndez-Alonzo et al., 2013). The coordination of various hydraulic traits in different plant tissues (Markesteijn et al., 2011; MéndezAlonzo et al., 2012; Zhu et al., 2013) possibly explains the phenology of deciduous trees because natural selection favors efficient water transport along hydraulic pathways (Hickler et al., 2006; Langan, Higgins and Scheiter, 2017). 
Chapter 2-Biome diversity in South Asia - How can we improve vegetation models to understand global change impact at regional level?

Dry and moist deciduous trees could be integrated into DGVMs by including traits associated with plant hydraulics, drought tolerance and phenology. Most existing DGVMs use a formulation based on Darcy's law to describe water transfer through the soil-plant-atmosphere continuum. This approach assumes that water transfer is controlled by a plant's hydraulic conductivity and the gradient between the hydraulic potential of soil and plant (Roman et al., 2015; Christoffersen et al., 2016; Gentine et al., 2016). This approach has been effective for simulating how drought affects tropical forests at large scales (Xu et al., 2016), yet, it mostly ignores factors affecting xylem capacitance and conductance (Sperry et al., 1998) and is incapable of simulating water storage capacity of plant biomass (Matheny, Mirfenderesgi and Bohrer, 2017; Santiago et al., 2017). This limitation can be addressed by modelling dynamic changes in xylem capacitance as a function of xylem water potential by assuming a relationship between the water stored in the plant and the water potential of the water stored in plant biomass (Huang et al., 2017; Mirfenderesgi, Matheny and Bohrer, 2017).

\subsubsection{Tropical evergreen forest}

Tropical evergreen forest is found in the Northeast of India, Western Ghats, Tamil Nadu coast, Lakshadweep, Andaman and Nicobar, Bangladesh, Myanmar and the lower foothills of Nepal (Figure 2.1a, b). Indian tropical evergreen forests are divided into wet and dry evergreen forest (Joshi et al., 2006; Reddy et al., 2015). Dry evergreen forests receive less rainfall $(<2000 \mathrm{~mm})$ than wet evergreen forests $(>2000 \mathrm{~mm}$, (Mani and Parthasarathy, 2006). Tropical dry evergreen forests occur as patches and they are shortstatured and largely three-layered with a sparse and patchy understory flora (Venkateswaran and Parthasarathy, 2005). Yet, structure and physiognomy of dry evergreen forests varies in different climatic regimes (Blasco, Whitmore and Gers, 2000). Tree inventories for tropical dry evergreen forests show large differences in density and basal area, probably due to different geographical location and varying annual rainfall patterns (Mani and Parthasarathy, 2006). The spatial heterogeneity of climatic conditions on the western coast of southern peninsular India supports tropical dry evergreen forest (Champion and Seth, 1968). They are further distributed on the eastern (Coromandel) coast of India and extending about $50 \mathrm{~km}$ inland, northern Sri Lanka (Blasco and Legris, 1973), northeastern Thailand (Bunyavejchewin, 1999) and southwest China (Hongmao et al., 2002). Wet evergreen forests are dominated by broad-leaved evergreen trees 

understand global change impact at regional level?

growing taller than $30 \mathrm{~m}$ in height whereas trees in dry evergreen forest are typically 9$12 \mathrm{~m}$ tall (Daniels et al., 2007).

Most DGVMs do not explicitly represent the differences between dry and wet evergreen forest and represent both forest types by a single PFT ('tropical broad-leaved evergreen tree'). We suggest to include two distinct PFTs to describe wet and dry evergreen forest types in DGVMs. This could be achieved by including traits associated with phenology, distinct tree architecture, resource allocation and competition for water and light, analogously to the tropical deciduous forest (see section 2.81). Trees in dry evergreen forest are water limited and have different allocation and phenology schemes than trees in wet evergreen forests (Borchert, 1994; Reich, 1995; Hasselquist, Allen and Santiago, 2010). These differences could serve to simulate forest with different height structure and type. A better representation of seasonality of water availability, plant structure and plant hydraulics (see section 2.81) along with phenology could enhance the performance of DGVMs in the unique tropical evergreen forest biome in the South Asia.

\subsubsection{Temperate montane forests}

Temperate montane forests are found in the Himalayas at altitudes ranging from 1800 to 4000 meters where humidity and temperature are low (Reddy et al., 2015). Himalayan ecosystems are projected to be extremely sensitive to future climate change (Chaturvedi et al., 2011). Temperate forest has been broadly classified into moist temperate and dry temperate forest (Joshi et al., 2006; Reddy et al., 2015). In Himalayan moist temperate forest, annual rainfall varies from $1500 \mathrm{~mm}$ to $2500 \mathrm{~mm}$. These forests are dominated by Quercus, Pinus and Juniperus species that can grow up to 45 meters tall. On the other hand, Himalayan dry temperate forests are dominated by Rhododendron species and are found in a narrow belt between 3000 to 4000 meters in the western Himalayas. Due to the high elevation, the Himalayan region experiences alpine and tundra like climate which is suitable for sub-alpine forests. Sub-alpine forests are found throughout the Himalayas from Ladakh in the west to Arunachal Pradesh in the east at the altitude from 2800 meters to 3800 . These forests receive less than $650 \mathrm{~mm}$ mean annual precipitation. Epiphytic mosses and lichens are abundant in these forests.

Generally, DGVMs represent these forests by either the 'temperate needle-leaved tree' PFT or the 'temperate broad-leaved tree' PFT, while neglecting the heterogeneity 
Chapter 2-Biome diversity in South Asia - How can we improve vegetation models to understand global change impact at regional level?

of Himalayan temperate forest which is related to heterogeneity in topography and climate. In cold-adapted plants, temperature is a key driver of the resumption of tree activity in spring, although temperature effects vary among organs (Delpierre et al., 2016). Temperate species are tolerant to extremely low temperatures (Strimbeck et al., 2015); they prevent cavitation by higher hydraulic resistance of the soil-plant continuum (Cochard et al., 2009). Low temperature inhibits investment of carbon into structural growth for a substantial fraction of the growing season (Körner, 2003). Temperate species usually have higher leaf nitrogen, leaf mass per unit area, photosynthetic assimilation and respiration rates as compared to tropical species (Xiang et al., 2013). In addition, environmental factors such as the length of the photoperiod and water stress play an important role in shaping phenology of all tree organs (leaves and reproductive structures, wood, roots, reserve compounds) in the temperate zones (Delpierre et al., 2016). Our knowledge on temperature dependence of carbon allocation, hydraulic conductivity, phenology along with the dependence of root growth and mortality on soil temperature and moisture should be incorporated into DGVMs (Delpierre et al., 2016).

Current DGVMs usually use bioclimatic limits to separate temperate vegetation from tropical and boreal vegetation. We suggest to represent these cold-adapted vegetation types using traits related to their ecophysiology and cold adapting strategies such as resistance to freeze induced embolism or different carbon allocation strategies which would evolve according to the environmental conditions.

\subsubsection{Thickets and thorny forest}

Thickets and thorny forests are open forests dominated by thorny, hardwood species. They are mostly found in arid regions in the North-West of South Asia extending into Pakistan and Deccan where mean annual rainfall is less than $700 \mathrm{~mm}$. Acacias, palms, euphorbias and invasive cacti (Novoa et al., 2015) are common in these areas. Trees are scattered, do not grow beyond $10 \mathrm{~m}$ and have deep roots in order to access moisture in deep soil layers (Shankarnarayan, Harsh and Kathju, 1987; Schenk and Jackson, 2002, 2005; Pierret et al., 2016). Many tree species in this biome are fine leaved which is primarily an adaptation to avoid overheating (Wright et al., 2017). Fine-leaved species evolved to maximize plant performance in harsh conditions (Wright et al., 2017).

Under water limited conditions, leaves evolved into thorns and spines which minimizes the transpiration (Givnish, 1979) and serves as protection against herbivory. Due to 

understand global change impact at regional level?

sufficient solar radiation in these dry and open habitats, fine leaves are sufficient for carbon assimilation and a positive carbon balance of these plants.

In arid regions, plants further adapted to the prevailing dry and hot climate and to frequent drought by evolving succulence. Succulent plants conserve water in stems, and most of these plants fix $\mathrm{CO}_{2}$ through the crassulacean acid metabolism (CAM) photosynthetic pathway (Holtum et al., 2017). Succulents are adapted to arid conditions of Western and Deccan regions of South Asia. Most DGVMs do not represent succulents, and thickets and thorny forests are represented as tropical deciduous forest functional type. In reality, these forest types differ strongly in structure, phenology and function. For a better representation of this biome in DGVMs, we suggest that resource allocation strategies of plants should be adapted to allow carbon allocation into thorns for protection against grazing and roots to access deeper soil water. The costs or trade-offs of this allocation strategy should be explicitly modeled. We also suggest to model the partitioning of above and below ground biomass with an adaptive allocation model in such a way that thorny trees could be differentiated structurally from forest tree.

Wright et al. (2017) showed that leaf size follows the temperature distribution. This relation could be used to distinguish between broad and fine leaved PFTs in DGVMs and to better represent leaf energy balance in different climate settings. Succulents could be implemented by adding a water storage pool that is filled when water is available and used in dry periods. CAM plants make up almost $50 \%$ of plant biomass in arid and semiarid regions of the world (Syvertsen et al., 1976). CAM plants are able to fix $\mathrm{CO}_{2}$ in organic acids in the mesophyll chlorenchyma during the dark and then utilize the $\mathrm{CO}_{2}$ for the formation of carbohydrates via the $\mathrm{C}$ pathway during the light period (Hartzell, Bartlett and Porporato, 2018). The environmental variability at the daily and weekly timescale is an important factor in CAM functioning (Hartzell et al., 2015) and should be considered in models. Physiological models of CAM have already been introduced (see e.g. Bartlett et al., 2014; Owen \& Griffiths, 2013) and implemented in some models (Hartzell, Bartlett and Porporato, 2018). Yet, due to their complexity, CAM models have not been widely adopted and most DGVMs are confined to the $\mathrm{C}_{3}$ and $\mathrm{C}_{4}$ pathways. We conclude that fine leaved PFTs, succulence and the CAM photosynthetic pathway should be implemented in DGVMs as these features are important components of dryland and tropical ecosystems. 
Chapter 2-Biome diversity in South Asia - How can we improve vegetation models to understand global change impact at regional level?

\subsubsection{Savanna}

Savannas are mixed tree-grass systems characterized by a discontinuous tree layer in a continuous grass layer (Scholes and Archer, 1997; House et al., 2003). Savannas are often maintained through herbivory and frequent burning which lead to the formation of savanna mosaics. In addition, the ecosystem state depends on age and origin of the ecosystem (Moncrieff et al., 2014), and the intensity of biotic disturbance. Small differences in soil, topography and climate can determine whether savanna or dry forest occurs in a particular area (Prance, 2006). It has been argued that savannas in South America (Langan, Higgins and Scheiter, 2017; Wuyts, Champneys and House, 2017) and Africa (Scheiter and Higgins, 2009; Favier et al., 2012; Higgins and Scheiter, 2012) are bi-stable, that is, vegetation is in a savanna state in the presence of fire while environmental conditions would allow a forest state. aDGVM model simulations indicate vast bi-stable area in South Asia (Figure 2.3).Simulations with fire show large extent of savannas (Figure 2.2e, f), whereas in the absence of fire, savanna regions are occupied by forest, woodland or grassland (Figure 2.2a, b).

South Asian savannas are often misinterpreted as degraded forests although most of these savanna systems are ancient (Ratnam et al., 2016). Large areas in South India and on the Deccan plateau classified as tropical dry forests comprise fire-resistant savanna tree species, an understory dominated by shade-intolerant $\mathrm{C}_{4}$ grasses and they require fire to maintain grass-tree co-existence. Hence, these ecosystems should be classified as mesic savannas (Ratnam et al., 2011).

Savanna tree species in a fire-prone environments are highly fire tolerant and generally recover rapidly after fire (Bond and Midgley, 2001; Hoffmann, Orthen and Franco, 2004; Schutz, Bond and Cramer, 2009). They invest more resources to root and underground storage, to seed establishment and to resprouting than forest tree species (Hoffmann, Orthen and Nascimento, 2003; Schutz, Bond and Cramer, 2009; Simon et al., 2009; Wigley, Bond and Hoffman, 2009; Ratnam et al., 2011). Saplings of savanna trees grow rapidly in height in order escape the flame zone (Higgins, Bond and Trollope, 2000; Wigley, Bond and Hoffman, 2009). Surface fires consume grass biomass and small saplings whereas tall trees are not damaged by fire (Williams et al., 1999; Bond, 2008; Hoffmann et al., 2012). Many savanna species have a high bark growth rate and thick bark. These traits protect the inner cambium and minimize fire damage (Champion and 

understand global change impact at regional level?

Seth, 1968; Charles-Dominique et al., 2017; Gignoux et al., 1997; Hoffmann et al., 2009, 2003). These features result in very low fire related mortality in adult savanna trees.

A distinction between forest and savanna trees is ignored in many DGVMs (for exceptions see Baudena et al., 2015; Scheiter et al., 2012 and Trugman et al., 2018). Fire tolerance traits and adaptations of savanna trees to fire, in particular resprouting from apical bud after fire (Burrows, 2002; Williams, 2009) and differential effects on small and tall trees (demographic bottlenecks, Higgins et al., 2000) should be included in DGVMs to enhance model performance in the savanna biome of South Asia. (Scheiter et al., 2012) showed that the presence of a savanna tree type extends the area covered by savannas in Africa, compared to a model without the savanna tree type. Trugman et al. (2018) showed that tropical vegetation dynamics depend not only on rainfall and changing fire frequencies but also on fire survival strategies of trees. Fire survival strategy is also important in regulating tree size demography in ecosystems exposed to fire, which facilitates coexistence of different plant functional groups in tropical ecosystem.

\subsubsection{Shrubland}

Shrubs form an important component of various vegetation formations in South Asia. Shrublands are found in the semi-arid regions, especially in Afghanistan, Pakistan, the western and southern part of India. The distribution of rainfall patterns seems to be the most important factor in maintaining shrub cover, although shrublands occupy different geological formations and soil types (Dakshini, 1989).

Shrubs are semi-woody (Götmark, Götmark and Jensen, 2016) multi-stemmed plants with branches rising from the base, growing up to 3 to $4 \mathrm{~m}$ in height (Zizka, Govender and Higgins, 2014; Götmark, Götmark and Jensen, 2016). They can be either evergreen or deciduous and woody vegetation cover is typically less than $10 \%$ in shrubdominated ecosystems.

For a given biomass, shrubs have higher sapwood area and higher hydraulic conductivity than trees due to relatively larger total stem cross-section area (Götmark, Götmark and Jensen, 2016). These features imply a competitive advantage of shrubs under more arid and water-limited conditions. Shrubs can cope with fire (Clemente, Rego and Correia, 1996) due to their ability to re-sprout efficiently after being damaged by fire 
Chapter 2-Biome diversity in South Asia - How can we improve vegetation models to understand global change impact at regional level?

(Hoffmann and Solbrig, 2003). Mature trees typically grow taller than shrubs due to their single-stemmed architecture (Zizka, Govender and Higgins, 2014), giving trees a competitive advantage in dense ecosystems where light is limiting. In addition, tall trees have an advantage in fire-driven ecosystems, once they grow tall enough to avoid fire damage of leaves (Hoffmann et al., 2012).

DGVMs often ignore the multi-stemmed architecture of shrubs and treat them as trees with adjusted architecture and hydraulic properties (Gaillard et al., 2018). The implementation of shrubs in DGVMs requires a better representation of the multistemmed architecture, fire response, hydraulic conductivity and water competition as well as the emerging trade-offs between shrub and tree growth form.

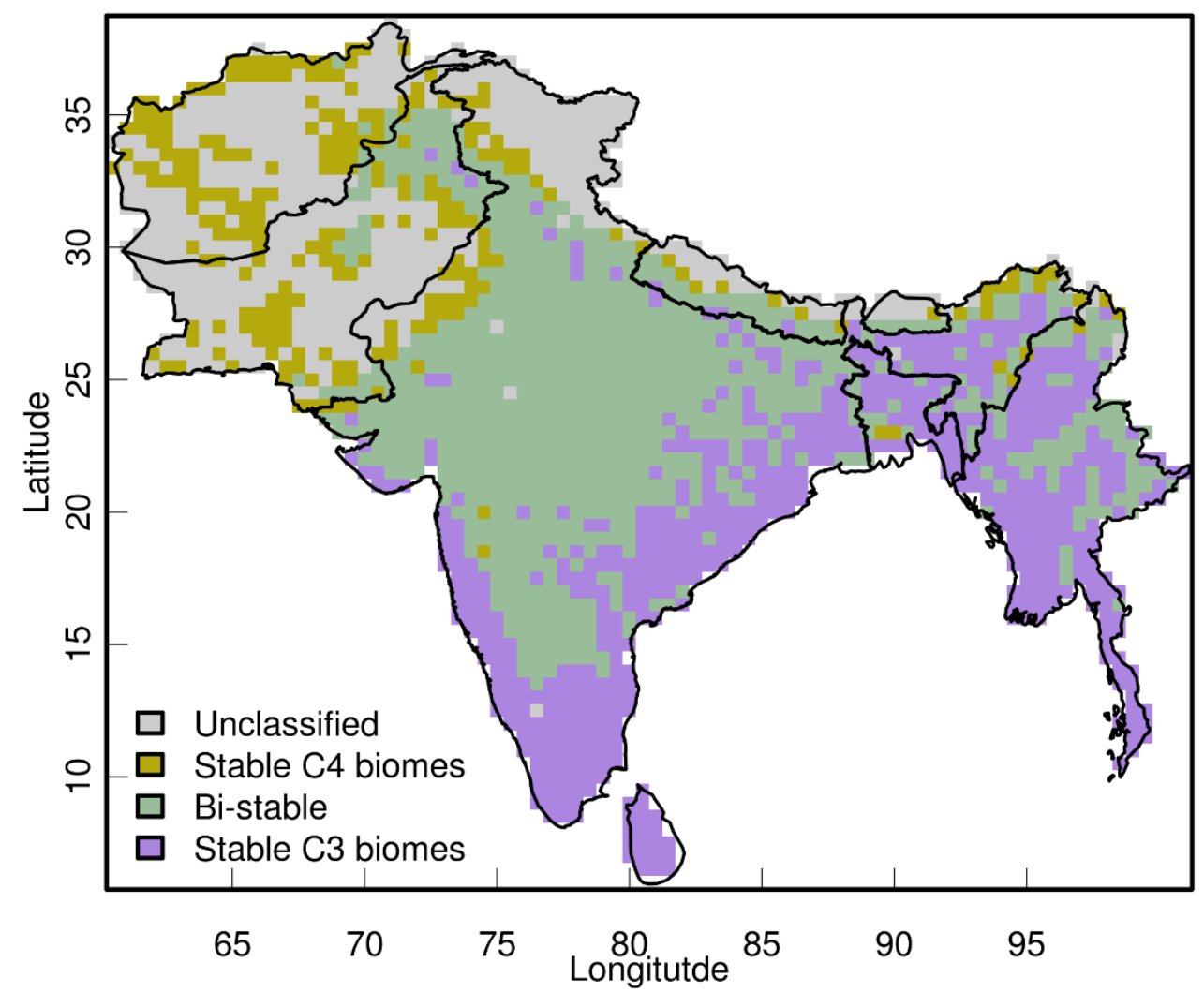

Figure 2.3 Bi-stability between $C_{4}$ dominated biomes (savanna and $C_{4}$ grassland) and $C_{3}$ dominated biomes (forest and woodland) simulated by aDGVM (see Figure $1 a, e)$. Vegetation in a grid cell is bi-stable if it is in a $C_{4}$ biome state in the presence of fire but in a $C_{3}$ biome state in the absence of fire.

In Gaillard et al. (2018), we integrated shrubs into the recent version of aDGVM2 by explicitly considering their multi-stemmed architecture. We showed that the ability to model shrubs and trees as distinct growth forms improves our understanding of the current distribution of ecosystems with a substantial component of shrubs (Gaillard et 

understand global change impact at regional level?

al., 2018). The shrub implementation in aDGVM2 was developed for Africa (Gaillard et al., 2018) but preliminary results show that aDGVM2 can simulate shrub dominated areas in the North-West of India (Kumar et al., 2020b). Shrub encroachment is a major concern in Indian savannas but also in savannas globally (Stevens et al., 2017)and the model will allow us to understand past and future shrub encroachment.

\subsubsection{Grassland}

Grasslands occupy nearly $24 \%$ of the area of South Asia in several biogeographical regions. They consist of a community in which grasses predominate, along with forbs as co-dominants and exhibit a wide range of ecological characteristics (Singh, Lauenroth and Milchunas, 1983). Woody plants are either absent or present in low densities. Grasslands dominate in the areas of low to moderate annual precipitation, drought, extreme temperature fluctuations, relatively shallow soil, fire and grazing (White et al., 2000). In South Asia, grasslands are mostly dominated by $\mathrm{C}_{4}$ grass species in the tropical regions (Indian peninsular and montane areas in the Western Ghats and Himalayas) and by $\mathrm{C}_{3}$ grass species in the temperate regions (Northwest of Pakistan). Except montane grasslands of the Himalaya and the Western Ghats, grasslands in India are anthropogenic in origin and evolved under the influence of fire, livestock grazing, clearing forest, flood, drought (Bor, 1960; Singh, Lauenroth and Milchunas, 1983) and inherent properties of soil (Kotwal and Pande, 1980; Pandey, Kandya and Kotwal, 1985). The extent of grassland is prone to human expansion, heavy infestation by unpalatable and thorny alien invasive plants, soil erosion and compaction. A need for an assessment of grass cover and long term ecological studies on various grasslands in India was already expressed in the 1970's (Dadadghao and Shankarnarayan, 1973; Yadava and Singh, 1977).

Most DGVMs simulate only two PFTs representing entire $\mathrm{C}_{3}$ and $\mathrm{C}_{4}$ grass herbaceous communities including grasses, forbs and other herbaceous species. An explicit representation of seasonal, annual and perennial grasslands found in South Asia is missing. The boundary between $\mathrm{C}_{3}$ and $\mathrm{C}_{4}$ grasslands is typically defined by bioclimatic limits while underlying processes defining the boundary are not explicitly considered. This approach is particularly critical under pre-industrial or elevated $\mathrm{CO}_{2}$ concentration because it has been shown that the relative dominance of $\mathrm{C}_{3}$ and $\mathrm{C}_{4}$ grasses is related to temperature and $\mathrm{CO}_{2}$ and not only defined by a bioclimatic limit based on 
Chapter 2-Biome diversity in South Asia - How can we improve vegetation models to understand global change impact at regional level?

temperature (Ehleringer, Cerling and Helliker, 1997). In addition, $\mathrm{C}_{3}$ and $\mathrm{C}_{4}$ grasses may coexist while the utilization of bioclimatic limits implies that an area is dominated by $\mathrm{C}_{3}$ or $\mathrm{C}_{4}$ grasses exclusively. Different types of grasslands with different height structure, water requirement and demography should be represented in more details in DGVMs. We suggest that a better representation of reproductive strategies (Pfeiffer et al., 2019), water competition, light competition, fire seasonality and soil properties should enhance the performance of DGVMs to simulate grasslands in South Asia.

\subsubsection{Mangroves}

Mangroves are characteristic intertidal plant communities of sheltered subtropical and tropical coastlines (Saenger, 2002). In South Asia, mangroves are mainly found in the river deltas along the east coast and west coast of peninsular India and coastal regions of Sri Lanka (Figure 2.1b). During the last century, 40\% of the mangrove areas were lost (Kumar, 2000) and they are considered vulnerable to climate change (Berger et al., 2008). Coastal processes in different geomorphological settings (e.g. inundated coastal area) along with natural disturbances (e.g., hurricanes) define the structural complexity of mangrove forests, including maximum stand height and tree morphology (Doyle, Smith III and Robblee, 1995; Doyle and Girod, 1997; Duke, 2001). Mangrove tree species are halophytic evergreen and have pneumatophores/stilt roots and viviparous germination, i.e. the seeds germinate while still on the mother trees.

Field studies have reported that various factors such as regulators ( $\mathrm{pH}$, salinity), resources (light, nutrient, space), and hydroperiod (frequency and period of inundation) control mangrove structure and function (Huston and Huston, 1994). Water salinity is a critical regulator influencing the structure of mangrove forests (Ball, 2002; CastañedaMoya, Rivera-Monroy and Twilley, 2006; Castañeda-Moya, Twilley and RiveraMonroy, 2013). Nutrients such as nitrogen and phosphorus are key resources that define growth and spatial distribution patterns (Kristensen et al., 2008). The processes governing mangrove response to hydro-period

Mangroves are usually not represented explicitly in DGVMs. Yet, several models have been developed independently to understand the dynamics of mangrove ecosystems and to provide capability to forecast their vegetation dynamics under different management scenarios and natural disturbance regimes. Some of these models are 

understand global change impact at regional level?

individual-based models (IBMs) such as FORMAN and KIWI and address forest stand dynamics whereas MANGRO focuses on landscape dynamics (Doyle, Smith III and Robblee, 1995; Chen and Twilley, 1998; Berger and Hildenbrandt, 2000; Doyle, Girod and Books, 2003).

DGVMs should integrate mangroves explicitly to describe the essential processes of trees linked to resource, regulator and hydroperiod gradients, and test their relative importance in controlling mangrove forest dynamics. DGVMs coupled with explicit mangrove models would support research related to coastal protection and sustainable use of South Asia's coastal ecosystems. The individual-based approach of existing mangrove models would facilitate the inclusion into individual-based DGVMs.

\subsubsection{Lianas}

Lianas are woody vines that start growing as independent life form but subsequently depend on other plants (trees) to reach the forest canopy (Letcher and Chazdon, 2009; Vivek and Parthasarathy, 2015). In South Asia, lianas are found in the tropical dry evergreen forests at the Coromandel Coast and in the Eastern Ghats (Parthasarathy, Selwyn and Udayakumar, 2008) and Sri Lanka. Lianas play a major role in tropical forest dynamics (Putz, 1984; Schnitzer, Dalling and Carson, 2000) by competing with trees for both aboveground and belowground resources (Schnitzer and Bongers, 2002), resulting in reduced recruitment, regeneration, growth and survival of trees (Ingwell et al., 2010; Schnitzer and Carson, 2010). Although lianas and trees are woody plants, both growth forms differ from trees in their functional traits including climbing mechanism (Holbrook and Putz, 1996) and light requirements (Gianoli et al., 2010). Abundance, species diversity and distribution of lianas are explained by abiotic and biotic factors, such as total rainfall, rainfall seasonality, soil fertility, forest canopy structure and disturbance regimes (Schnitzer, Kuzee and Bongers, 2005; Addo-Fordjour, Rahmad and Shahrul, 2012). The majority of lianas is brevi-deciduous or deciduous, whereas $50 \%$ of the host trees are evergreen (Vivek and Parthasarathy, 2015). This reflects the distinctive vegetative traits and leafing phenology of tree and liana life forms in the same ecosystem. Leaf size of lianas varies from microphyllous to mesophyll. Smaller leaves can maintain favorable leaf temperature and greater photosynthetic wateruse efficiency under low water availability and high solar radiation (Muthumperumal and Parthasarathy, 2010). It has been argued that the prevalence of microphyllous leaves is a 
Chapter 2-Biome diversity in South Asia - How can we improve vegetation models to understand global change impact at regional level?

functional strategy adopted by lianas in tropical dry evergreen forest, which experiences 6-8 months of dry period. In recent years, the tropical dry evergreen forests on the Coromandel Coast experienced anthropogenic pressure, resulting in modified tree height (Baithalu, Anbarashan and Parthasarathy, 2012). These changes in host plants are likely to affect lianas depending on trees for their physical support.

We argue that lianas should be included in DGVMs as structurally distinct life form for a better representation of tropical forest dynamics where both lianas and trees compete for same resources (Schnitzer, Kuzee and Bongers, 2005). Lianas have a competitive advantage over trees with respect to accessibility of water and light. The effects of increasing liana abundance and biomass would alter the carbon cycle and carbon balance of tropical forests by reducing forest-level carbon storage and sequestration (Heijden et al., 2013, Phillips et al., 2002, Verbeeck and Kearsley, 2016). Including lianas in DGVMs would help to better understand the dynamics of South Asia's dry evergreen forest and potential impact of future climate change. As woody plants are already implemented in DGVMs, inclusion of lianas would primarily require modelling of the interactions between trees and lianas (Verbeeck and Kearsley, 2016).

\subsubsection{Bamboos}

Bamboos belong to the subfamily Bambusoideae in the family Gramineae, and have about 1500 known species worldwide (Li and Kobayashi, 2004). In India, bamboo forests cover about 14 million hectares of land, with 125 indigenous and 11 exotic bamboo species (FSI, 2011). Bamboos are widely distributed in temperate and tropical regions of South Asia (Sharma, 1980). Dwarf herbaceous species (Sasa kurilensis) of bamboo are found in temperate regions and giant species (Dendrocalamus membranaceus, Melocanna baccifera) that can grow up to $20 \mathrm{~m}$ tall in tropical regions (Bystriakova, Kapos and Lysenko, 2004). It is one of the fastest growing plants with a daily growth rate of 30-120 cm. The maximum height of between $5-20 \mathrm{~m}$ is reached in a single growing season of between 2 to 4 month length (He et al., 2014). Bamboos are an important carbon sink and have high carbon sequestration potential. However, their response to climate change is still poorly understood (Xu et al., 2013).

Bamboos have a unique phenology which controls resource allocation between mature individuals and young recruits via underground rhizomes (Song et al., 2016). 

understand global change impact at regional level?

Individual plant phenology affects the functioning of bamboo forest ecosystems (Mao et al., 2016). Warmer temperatures with longer periods of direct sunlight during the cloudy growing season increase resource accumulation within culms leading to high recruitment (Qin, Taylor and Cai, 1993). Light availability affects the variation in culm size and bamboo stand density (Taylor and Zisheng, 1988; Reid and Jinchu, 1991). During the recruitment period, non-structural carbon (NSC) of the leaves, branches, trunks and rhizomes of attached mature bamboos is re-allocated to the fast growing shoots of young recruits via underground rhizomes. The allocation of NSC to young recruits stops when the leaves of the young bamboos can assimilate enough carbohydrates (photoassimilates) to meet its plant's carbon demand (Fu, 2001, Song et al., 2011). This periodicity is mainly due to the unique strategy of bamboo growth and reproduction, the integral structure of the culms-rhizome system and soil nutrients (Mao et al., 2016).

Bamboos are susceptible to fire damage but are capable of rapid clonal growth that gives an advantage in post fire environments. It can quickly occupy the open space created by fire and monopolize its resources (Gagnon and Platt, 2008), allowing intense competition with tree recruits. Once fully gown, the bamboo canopy can limit light penetration to the forest floor (Montti, Campanello and Goldstein, 2011), and suppress germination, regeneration and recruitment of tree seedlings (Budke, Jarenkow and de Oliveira-Filho, 2010; Montti, Campanello and Goldstein, 2011). Fire intensity and frequency can affect clump regeneration, production and development in forest communities (Smith and Nelson, 2011; Kachina et al., 2017).

Including bamboos into DGVMs can help to understand interactions between bamboo and tree regeneration in post fire environments as well as under future climate change in South Asia. We argue that the implementation of specific carbon allocation schemes and phenology of bamboos along with its unique recruitment cycle in DGVMs would enhance the model's capabilities in simulating bamboo-dominated ecosystem. Bamboos are important for carbon sequestration in tropical ecosystem and have high economic value.

\subsection{A way forward toward next-generation DGVMs}

The complexity of vegetation dynamics makes it difficult to simulate the influence of climate on vegetation and on processes such as carbon assimilation, 
Chapter 2-Biome diversity in South Asia - How can we improve vegetation models to understand global change impact at regional level?

allocation and release, soil carbon dynamics and competition. Many of these ecological processes still remain uncertain and need to be further analyzed, both by empirical and by modelling studies (Van Bodegom et al., 2012; Pavlick et al., 2013). Special attention should be given to the representation and parameterization of PFTs or traits in FT approaches in DGVMs along with accurate benchmarking of predicted patterns of vegetation distribution in tropical ecosystems. Another major issue in vegetation modelling is the incorporation of disturbances (i.e., fire and drought) and a better description of the land cover (in particular land use and non-vegetated surfaces). Some of these disturbances are included in global scale studies but land use needs to be explicitly represented at regional or even site scale. Including disturbances in DGVMs is expected to improve simulation results, thereby increasing the agreement between simulations and observations (Ashmore, 2005; Felzer et al., 2007).

In order to improve the representation of vegetation in DGVMs, trait variability can be incorporated into DGVMs in two different ways (Wullschleger et al., 2014). The first approach would be to vary parameters of PFTs as a function of environmental variables. Plant community mean trait values are directly related to environmental conditions resulting in trait convergence for the PFT. This approach of trait-environment relationships has shown consistent patterns relating leaf functional traits to climate (Wright et al., 2005), soil fertility (Ordoñez et al., 2009) or both (Ordonez et al., 2009; van Ommen Kloeke et al., 2012). Incorporation of trait-environment relationships into JSBACH indicated major consequences of trait variability on vegetation and carbon dynamics for the current climate (Verheijen et al., 2013). It resulted in a productivity difference of up to $50 \%$ in the tropics and $35 \%$ change in dominant vegetation cover compared to simulations with fixed traits. Simulated vegetation showed better agreement with natural vegetation maps when trait variability was included in JSBACH (Verheijen et al., 2013).

The second approach is to implement trait variability based on trade-offs between traits and evolutionary rules to determine the survival of the fittest trait combinations for a set of environmental conditions (Kleidon and Mooney, 2000; Scheiter and Higgins, 2009; Scheiter, Langan and Higgins, 2013; Langan, Higgins and Scheiter, 2017). Scheiter et al.(2013) advocated the implementation of ideas derived from coexistence theory (Chesson, 2000) and community assembly theory (Webb et al., 2010) into process-based DGVMs. Information on trait trade-offs, including co-varying above- and 

understand global change impact at regional level?

below-ground traits (Freschet et al., 2010; Sloan et al., 2013) and on trait impacts on carbon fluxes (Cornelissen et al., 2007; Freschet, Aerts and Cornelissen, 2012) are already available and can foster the development of DGVMs based on eco-evolutionary principles. This requires a detailed quantitative understanding of different allometric relationships to predict differences in above- and below-ground biomass in different plant communities. A comprehensive understanding of how different trade-offs relate to different plant architectures (for example between single stem and multi-stemmed woody plants, lianas, bamboo) would provide additional insights to structural details of growth forms. Such a modelling approach would sidestep the inclusion of many additional PFTs into DGVMs because community assembly would select plant growth strategies that are appropriate for given environmental conditions.

The availability of functional and structural plant trait data from global trait database such as TRY (Kattge et al., 2011), GIVD and sDIV (Purschke et al., 2015), can facilitate the addition of new vegetation types and the parameterization of their ecological functions. While such information is partially available, it has not yet been compiled in an eco-evolutionary-based optimality approach for South Asian ecosystem. Nonetheless, it seems feasible to incorporate variable-trait approaches to represent growth forms for the modelling of vegetation dynamics, and carbon and nutrient cycling. Improving our representation of land cover therefore improves our understanding of the Earth system.

\subsection{Conclusions}

South Asia is the most populated part of the world, which implies high pressure on vegetation and biodiversity. Climate change and present-day land use pose threats on the future of many South Asian ecosystems. Their future trajectories are highly uncertain and DGVMs can be used to explore these climate-vegetation interactions. DGVMs have become an indispensable tool to formulate strategies to mitigate global change impacts on ecosystems and they have a wide range of potential applications for understanding diversity, biosphere-atmosphere interactions under different future climate and management scenarios (for example, elevated atmospheric $\mathrm{CO}_{2}$, fire or herbivory (Harrison and Prentice, 2003; Midgley and Bond, 2015; Harris et al., 2016)). Improving the representation of land cover, fire and other anthropogenic factors like ozone pollution in DGVMs therefore contributes to improve our understanding of the Earth system. 
Chapter 2-Biome diversity in South Asia - How can we improve vegetation models to understand global change impact at regional level?

Heterogeneous environments and floral distributions necessitate special attention to account for the different vegetation types and growth forms such as shrubs, lianas and bamboos. All of these vegetation types and growth forms have different structure and ecosystem functions. Current PFT schemes in DGVMs should be expanded to incorporate different communities and the eco-physiological process governing competition for resources. Improving the current generation of DGVMs both globally and at regional scale needs the combined effort of physiologist, ecologists and modelers to develop an understanding of the process explaining observed vegetation patterns. Processes such as carbon allocation, phenology, competition and disturbance in DGVMs are, in our opinion, the great challenges for improving the models. We also suggest that the incorporation of whole-plant hydraulic strategies into the representation of tropical dry and wet deciduous trees in DGVM would improve simulation of water and carbon fluxes. To test the potential for model improvement, modelers should seek to include the discussed growth forms within a broad variety of trait-based dynamic vegetation models. Furthermore, the DGVM community needs to continue to incorporate knowledge from experimental studies on the ecophysiological responses to environmental changes, ecoevolutionary principles of tropical ecosystems and observations from the functional structure of plants into the models. This would further require field and validation studies to advance our ecological understanding of specific growth forms.

In summary, we claim that seven major challenges need to be addressed for improved modelling of South Asia's biome diversity.

- Distinction between wet and dry forest types, both in deciduous and evergreen forests.

- Representation of vegetation types and growth forms native to South Asia such as bamboo, mangroves, shrubs, thickets and lianas using FT and PFT approaches.

- Representation of topography to account for spatial heterogeneity in vegetation types along the mountains of South Asia.

- Incorporation of anthropogenic disturbance.

- Collection of eco-physiological data for improved ecosystem understanding; aggregation into databases and development of advanced data-model fusion techniques. 
Chapter 2-Biome diversity in South Asia - How can we improve vegetation models to understand global change impact at regional level?

- Generation of high resolution environmental data (climate and soil) for driving DGVMs.

- Integration of observed plant trait variability into DGVMs.

Making effective use of our knowledge on South Asian ecosystems to improve DGVMs should be of high priority for more reliable projections of the future of these diverse ecosystems.

\subsection{Acknowledgments}

DK and SS thank the DFG Emmy Noether programme for funding (grant SCHE $1719 / 2-1)$ 


\title{
CHAPTER 3
}

\section{CLIMATE CHANGE AND ELEVATED $\mathrm{CO}_{2}$ FAVOR FOREST OVER SAVANNA UNDER DIFFERENT FUTURE SCENARIOS IN SOUTH ASIA}

Dushyant Kumar ${ }^{1}$, Mirjam Pfeiffer ${ }^{1}$, Camille Gaillard ${ }^{1}$, Liam Langan ${ }^{1}$, and Simon Scheiter $^{1} \S$

${ }^{1}$ Senckenberg Biodiversity and Climate Research Centre (SBiK-F), Senckenberganlage 25, 60325 Frankfurt am Main, Germany

\begin{abstract}
South Asian vegetation provides essential ecosystem services to the 1.7 billion inhabitants living in the region. However, biodiversity and ecosystem services are threatened by climate and land-use change. Understanding and assessing how ecosystems respond to simultaneous increases in atmospheric $\mathrm{CO}_{2}$ and future climate change is of vital importance to avoid undesired ecosystem change. Failed reaction to increasing $\mathrm{CO}_{2}$ and climate change will likely have severe consequences for biodiversity and humankind. Here, we used the aDGVM2 to simulate vegetation dynamics in South Asia under RCP4.5 and RCP8.5, and we explored how the presence or absence of $\mathrm{CO}_{2}$ fertilization influences vegetation responses to climate change. Simulated vegetation under both RCPs without $\mathrm{CO}_{2}$ fertilization effects showed decrease in tree dominance and biomass, whereas simulations with $\mathrm{CO}_{2}$ fertilization showed an increase in biomass, canopy cover, and tree height and a decrease in biome-specific evapotranspiration by the end of the 21 st century. The predicted changes in above ground biomass and canopy cover triggered transition towards tree-dominated biomes. We found that savanna regions are at high risk of woody encroachment and transitioning into forest. We also found transitions of deciduous forest to evergreen forest in the mountain regions.
\end{abstract}

$\S$ This chapter and supplementary information were published in the journal Biogeoscience as "Kumar, D., Pfeiffer, M., Gaillard, C., Langan, L., and Scheiter, S.: Climate change and elevated $\mathrm{CO}_{2}$ favor forest over savanna under different future scenarios in South Asia, Biogeosciences, 18, 2957-2979, doi:"10.5194/bg-18-2957-2021".

Author contributions: DK and SS conceived the study. DK included the changes to aDGVM2 for the study region, conducted model simulations, analysed results, created figures and led the writing. All authors contributed to the development of aDGVM2 and comments to the text. 
Vegetation types using $\mathrm{C}_{3}$ photosynthetic pathway were not saturated at current $\mathrm{CO}_{2}$ concentrations and the model simulated a strong $\mathrm{CO}_{2}$ fertilization effect with the rising $\mathrm{CO}_{2}$. Hence, vegetation in the region has the potential to remain a carbon sink. Projections showed that the bioclimatic envelopes of biomes need adjustments to account for shifts caused by climate change and elevated $\mathrm{CO}_{2}$. The results of our study help to understand the regional climate-vegetation interactions and can support the development of regional strategies to preserve ecosystem services and biodiversity under elevated $\mathrm{CO}_{2}$ and climate change.

Abbreviations: aDGVM2: adaptive dynamic global vegetation model version 2; RCP Representative Concentration pathways; ISIMIP: Inter-Sectoral Impact Model Intercomparison Project; SRTM: Shuttle Radar Topography Mission; GFDL-ESM2M: Geophysical Fluid Dynamics Laboratory Earth System Model

Keywords: aDGVM2, climate change, $\mathrm{CO}_{2}$-fertilization, biome shift, woody encroachment, evapotranspiration, biodiversity conservation, South Asia

\subsection{Introduction}

Global climate has been identified as the primary determinant of large-scale natural vegetation patterns (Overpeck, Rind and Goldberg, 1990). Climate change has affected global vegetation pattern in the past and caused numerous shifts in plant species distribution over the last few decades (Thuiller et al., 2008; Chen et al., 2011). It is expected to have even more pronounced effects in the future that may lead to drastically increasing species extinction rates in various ecosystems (Brodie et al., 2014). Natural ecosystems have been and continue to be exposed to increased climate variability and abrupt changes caused by increased intensity and frequency of extreme events such as heat waves, drought and flooding (Herring et al., 2018). At the same time, they are under severe pressure due to anthropogenic disturbance and land conversion. Rising levels of atmospheric $\mathrm{CO}_{2}$ are a strong driver of climate-induced vegetation changes (Allen et al., 2014). Anthropogenic $\mathrm{CO}_{2}$ emissions account for approximately $66 \%$ of the total anthropogenic greenhouse forcing (Forster et al., 2007) and are thus largely responsible for contemporary and future global climate change (Parry et al., 2007). Rising $\mathrm{CO}_{2}$ is expected to alter distributions of plant species and ecosystems (Parry et al., 2007) both indirectly through its influence on global temperatures and precipitation patterns (Cao et 
al., 2010), two main drivers of vegetation dynamics, and directly via its physiological effects on plants (Nolan et al., 2018) It is therefore of vital importance to understand how ecosystems respond to simultaneous increases in atmospheric $\mathrm{CO}_{2}$ and temperature, changes in precipitation regime, and altered ecosystem water balance in order to avoid critical ecosystem disruptions and the resulting consequences for biodiversity and humankind.

Increases in temperatures, decreases in precipitation as well as changes in precipitation seasonality can cause loss of vegetation biomass. Plant using $\mathrm{C}_{3}$ photosynthetic pathways are often not saturated at the current atmospheric $\mathrm{CO}_{2}$, whereas plants using the $\mathrm{C}_{4}$ photosynthetic pathways are already at their physical optimum at current atmospheric $\mathrm{CO}_{2}$ levels (Ehleringer and Cerling, 2002). The physiology of $\mathrm{C}_{3}$ plants implies that elevated atmospheric $\mathrm{CO}_{2}$ improves their ability for carbon uptake due to the $\mathrm{CO}_{2}$ fertilization (Woodrow and Berry, 1988) and enhances carbon (Leakey et al., 2009; Norby and Zak, 2011) as well as plant water use efficiency (Soh et al., 2019). This has also been observed in Long-term Long-term Free-Air Carbon dioxide Enrichment (FACE) experiments (Norby and Zak, 2011). Thus, elevated $\mathrm{CO}_{2}$ influences photosynthesis and thereby affects other physiological processes such as respiration, decomposition (Doherty et al., 2010), evapotranspiration (ET) and biomass accumulation (Frank et al., 2015). Increasing $\mathrm{CO}_{2}$ concentration has been associated with woody cover increase in structurally open tropical biomes such as grasslands and savannas (Stevens et al., 2017). This widespread proliferation of woody plants into arid and semiarid ecosystems has been attributed to increased water use efficiency in $\mathrm{C}_{3}$ plants that facilitates woody sapling establishment and growth due to higher drought tolerance (Kgope, Bond and Midgley, 2010; Stevens et al., 2017). These $\mathrm{CO}_{2}$ effects on plant growth and competition can alter community structure (height distribution), ecosystem productivity, climatic niches of ecosystems and biome boundaries (Wingfield, 2013; Nolan et al., 2018). Change in vegetation distribution and altered vegetation structure feed back on climate by altering fluxes of energy, moisture and $\mathrm{CO}_{2}$ between land and atmosphere (Friedlingstein et al., 2006). Feedback mechanisms also involve vegetationmediated changes in albedo, surface roughness, land-atmosphere fluxes and evapotranspiration, (Field et al., 2007; Richardson et al., 2013).

Enhanced plant growth due rising $\mathrm{CO}_{2}$ implies rapid leaf area development and more total leaf area could translate into higher transpiration (Leakey et al., 2009). 
However, elevated $\mathrm{CO}_{2}$ concentrations may decrease leaf stomatal conductance to water vapor which could reduce transpiration. Evapotranspiration (ET) is a key ecophysiological process in the soil-vegetation- atmosphere continuum (Feng, Zou and Luo, 2017). Annually, 64\% of the total global land-based precipitation is returned to the atmosphere through ET (Yongqiang Zhang et al., 2016). Environmental change and concurrent vegetation changes alter ET and affect water availability (Mao et al., 2015), especially in arid and semiarid regions. In these regions, ET affects surface and subsurface processes such as cloud development, land surface temperature, and groundwater recharge (Fisher, Whittaker and Malhi, 2011).

South Asia is home to approx. 1.7 billion people and is one of the region's most vulnerable to climate change (Eckstein, Hutfils and Winges, 2018). It hosts four of the world's biodiversity hotspots (Myers et al., 2000) and harbours different biome types ranging from tropical in the south to temperate in the north at the fringe of the Himalayas. These hotspots are characterized by high levels of diversity and endemism, and they are threatened by climate change and anthropogenic land-use (Deb, 2017). For instance, woody encroachment due to rising $\mathrm{CO}_{2}$ threatens South Asian savannas (Kumar, Pfeiffer, Gaillard, Langan, Martens, et al., 2020) and sifting cultivationin the north eastern part of South Asia threatens biodiversity (Bera et al., 2006).

Due to the absence of long-term field experiments such as FACE experiments, in the dominant biomes of the region, modelling studies are valuable tools to close existing knowledge gaps. Dynamic global vegetation models (DGVMs, Prentice et al., 2007)are particularly well-suited to address questions that focus on vegetation response to changing environmental drivers, e.g., climate and $\mathrm{CO}_{2}$. While most DGVM studies in South Asia focused on vulnerability of forests to climate change (Ravindranath and Bhat, 1997; Ravindranath, Murali and Sudha, 2006; Chaturvedi et al., 2011) they often overlooked the severely threatened savanna biome. These studies were further limited by the utilization of models with fixed eco-physiological parameters and traits e.g., fixed carbon allocation values to assign carbon to plant biomass pools, fixed specific leaf area (SLA), as well as pre-defined bioclimatic limits that were derived from contemporary climatology in order to constrain the spatial distribution of plant functional types (PFTs). Moreover, many DGVMs used in these studies do not account for life history, ecoevolutionary processes and trait variability among individual plants (Kumar and Scheiter, 2019). While some global-scale studies have investigated the potential effect of 
increasing $\mathrm{CO}_{2}$ on natural vegetation, carbon sequestration and biome boundaries (e.g. Hickler et al., 2006; Sato et al., 2007; Smith et al., 2013), detailed modelling studies focusing explicitly on different biomes in South Asia have not been conducted. The physiological effects of increased $\mathrm{CO}_{2}$ and climate change on South Asian vegetation is uncertain and needs to be addressed in order to improve understanding of regional ecosystem functioning as well as implications for biodiversity conservation.

To address the knowledge gaps in existing studies, we used the aDGVM2 (adaptive dynamic global vegetation model version 2), an individual- and trait-based vegetation model that combines elements of traditional DGVMs (Prentice et al., 2007) with newly implemented approaches for selection and trait filtering. In aDGVM2, environmental conditions select for the plants with trait value combination that make them successful under these conditions. Therefore, plant communities that are adapted to site-specific environmental conditions dynamically assembles and emerge as a reaction the environmental forcing (Scheiter, Langan and Higgins, 2013; Langan, Higgins and Scheiter, 2017). Originally, aDGVM2 had been tested for Amazonia (Langan, Higgins and Scheiter, 2017) and Africa (Gaillard et al., 2018; Pfeiffer et al., 2019). In order to adapt it to South Asian ecosystems and their diversity, we included $\mathrm{C}_{3}$ grasses, improved ecophysiological processes such as the leaf energy budget in order to estimate leaf temperature, implemented separate temperature sensitivities for $\mathrm{C}_{3}$ and $\mathrm{C}_{4}$ photosynthetic capacity $\left(\mathrm{V}_{\text {cmax }}\right)$ and included snow in the water balance model.

In this study we used the updated version of aDGVM2 and addressed the following questions:

(a) How do projected changes in climate and $\mathrm{CO}_{2}$ following two Representative Concentration Pathways (RCP8.5 and RCP4.5, Meinshausen et al., 2011) change the distribution, boundaries and climatic niches of biomes in South Asia?

(b) How does the relationship between projected biomass, ET, temperature and precipitation change in response to $\mathrm{CO}_{2}$ fertilization?

(c) What is the sensitivity of predicted changes in relation to presence and absence of $\mathrm{CO}_{2}$ fertilization?

Based on our results we analyzed climate-vegetation interactions to improve our understanding of how to manage and mitigate impacts on biomes under climate change and increasing $\mathrm{CO}_{2}$. 


\subsection{Material and methods}

\subsubsection{Study area}

Approx. 1.7 billion people populate South Asia, i.e., the Indian subcontinent, Afghanistan and Myanmar. South Asia incorporates a wide range of bio-climatic zones with distinctive biomes, ecosystem types and species (Rodgers and Panwar, 1988). Climatic conditions are controlled by interactions between the South Asian summer monsoon system and the region's complex topography. The climatic envelope ranges from tropical arid and semi-arid regions in the west, to humid tropical regions supporting rainforests in the northeast and temperate vegetation at the fringe of the Himalaya. Excluding the Himalayan regions, South Asia has a mean annual temperature of approximately $24^{\circ} \mathrm{C}$ with very low spatial variability. Mean annual precipitation (MAP) is $1190 \mathrm{~mm}$, ranging from less than $500 \mathrm{~mm}$ in the warm desert zone in the west to more than $3500 \mathrm{~mm}$ in the north-east. The steep elevation gradients ranging from sea level to $8800 \mathrm{~m}$ result in a rich diversity of ecosystems that can alternate in areas of a few hundred square-kilometres. Topography is recognized as a strong driver of ecological patterns, for example those related to forest structure and composition, floristic diversity, and soil fertility (Gallardo-Cruz, Pérez-García and Meave, 2009; Jucker et al., 2018; Sinha et al., 2018). South Asia hosts four major global biodiversity hotspots, namely the Western Ghats, Himalayas, Indo-Myanmar and Sri Lanka (Myers et al., 2000; www.con servation.org, Conservation International, 2013). These hotspots include a wide diversity of ecosystems such as mixed wet evergreen, dry evergreen, deciduous, and montane forests. Further vegetation types are alluvial grasslands and subtropical broadleaf forests along the foothills of the Himalayas, temperate broadleaf forests in the mid hills, mixed conifer and conifer forests in the higher hills, savanna in the Deccan region and southern part of Malaysia, and alpine meadows above the tree line (McKinnon et al., 2015; Conservation International, 2013).

\subsubsection{Description of aDGVM2}

For this study we used aDGVM2 (Scheiter et al., 2013; Langan et al., 2017; Gaillard et al., 2018), a DGVM with a dynamic trait approach. In the supplementary information, we summarize main features of aDGVM2 and explain how the 
physiological effect of changing $\mathrm{CO}_{2}$ concentration and rising temperature are simulated in a process-based way in the aDGVM2 by implemented photosynthesis routine. To adapt the aDGVM2 to the requirements of the study region, we incorporated new subroutines into the model. We improved the representation of (a) the water balance by including snow, (b) the carboxylation rate, (c) leaf temperature, and (d) we included $\mathrm{C}_{3}$ grasses (previous model versions only simulated $\mathrm{C}_{4}$ grasses).

\section{(a) Water balance.}

Water balance. In aDGVM2, the soil water module is based on the tipping-bucket concept. As the model was originally developed with strong focus on tropical and subtropical forest and savanna regions, the original model version only considered water input in form of rain (see Langan et al., 2017). In the updated model version, precipitation is assigned as snow when daily mean air temperature drops below $0^{\circ} \mathrm{C}$. Snow accumulates on the soil surface or is added to the top of an existing snowpack. The snowpack persists as long as air temperature remains below $0^{\circ} \mathrm{C}$. Once temperature rises above $0^{\circ} \mathrm{C}$, water from snowmelt is added to the soil water pool and becomes available to plants. This process may improve the water availability for plants at the beginning of spring, for example in the Himalayan region. Snowmelt $\left(\mathrm{S}_{\text {melt }}, \mathrm{mm} / \mathrm{day}\right)$ is calculated following Choudhury et al. (1998) as

$$
S_{\text {melt }}=1.5+K_{m} P_{\text {precip }}\left(T_{a}-T_{\text {snow }}\right) S_{\text {pack }},
$$

where $\mathrm{K}_{m}$ is the coefficient of snowmelt $\left(0.007 \mathrm{~mm} /\right.$ day $\left./{ }^{\circ} \mathrm{C}\right), \mathrm{S}_{\text {pack }}$ is the depth of the snowpack (m) and is equivalent to the accumulated solid portion of precipitation, $\mathrm{T}_{a}$ is daily mean air temperature $\left({ }^{\circ} \mathrm{C}\right), \mathrm{P}_{\text {precip }}$ is precipitation $\left(\mathrm{mm} /\right.$ day) and $\mathrm{T}_{\text {snow }}$ is the maximum temperature where precipitation falls as snow $\left(0^{\circ} \mathrm{C}\right)$. We do not consider insulation effects of the snowpack in the model

\section{(b) Carboxylation rate.}

In earlier versions of aDGVM2, leaf-level photosynthesis was calculated at population level, i.e., it was assumed that all plants of a simulated vegetation stand have the same leaf-level photosynthetic rate. Only $\mathrm{C}_{3}$ - and $\mathrm{C}_{4}$-type photosynthesis were distinguished. We therefore incorporated new routines to calculate photosynthesis at a daily time step for each individual plant. We further incorporated an empirical relation 
specific leaf area $\left(A_{S L A}, \mathrm{~mm}^{2} / \mathrm{mg}\right)$ and leaf nitrogen content per unit area $\left(N_{a}, \mathrm{~g} / \mathrm{m}^{2}\right)$ following Sakschewski et al. (2015),

$N_{a}=6.89 A_{S L A}^{-0.571}$.

The standard maximum carboxylation rate of rubisco per leaf area $\left(V_{c m a x, 25}\right.$, $\mu \mathrm{mol} / \mathrm{m}^{2} / \mathrm{s}$ ) was derived from the TRY database (Kattge et al., 2011) by Sakschewski et al. (2015) and is calculated as

$V_{c \max , 25}=31.62 N_{a}^{0.501}$,

where $V_{c \max , 25}$ is $V_{c \max }$ at $25^{\circ} \mathrm{C}$.

In the model, ASLA is linked to the matric potential at $50 \%$ loss of xylem conductance ( $P_{50}$, see Langan et al., 2017). The trade-off between AsLA and $V_{c m a x}$ mediated by leaf traits $\left(N_{a}\right)$ introduces variability in the spectrum of tree growth strategies in aDGVM2. In addition to the ASLA is linked to leaf longevity (LL) in aDGVM2, such that it affects the leaf turnover rates (represented by Equation 72, in Appendix, Langan et al., 2017). Leaves with high AsLA have shorter LL and higher turnover rates than leaves with low Asla (and vice-versa). The correlation between AsLA, P50 and LL represent the trade-off between two opposing resource strategies, i.e., conservation vs. rapid acquisition of soil water and nutrients (Wright et al., 2005). Trees that invest more carbon into their (low AsLA) enhances their structural stability, but have lower leaf turnover to mitigate the higher initial carbon investment.

The effect of temperature on photosynthesis is well-described (Kirschbaum, 2004), and temperature may influence photosynthesis both directly, via temperaturedependency of enzyme-mediated metabolic rates of carboxylation and the Calvin cycle (Sharkey et al., 2007), and indirectly via its effect on transpiration and plant water uptake and transport (Urban et al., 2017). The maximum carboxylation rate ( $\left.V_{c m a x}\right)$ increases with temperature until it reaches an optimum, and decreases again at temperatures above the optimum (Kattge and Knorr, 2007) due to reductions in enzyme activity. Above $30^{\circ} \mathrm{C}$ the electron transport chain is gradually inhibited, and at temperatures above $40^{\circ} \mathrm{C}$ the denaturation of Rubisco and associated proteins becomes relevant (Lloyd and Farquhar, 2008). The temperature dependency of the carboxylation rate $\left(V_{c \max }\right)$ is expressed as 
$V_{\text {cmax }}=\frac{V_{\text {cmax }, 25} 2^{0.1\left(T_{\text {leaf }}-25\right)}}{\left(1+e^{0.3\left(T_{\text {low }}-T_{\text {leaf }}\right)}\right)\left(1+e^{0.3\left(T_{\text {leaf }}-T_{\text {upp }}\right)}\right)}$,

where $T_{\text {leaf }}$ is the leaf temperature in ${ }^{\circ} \mathrm{C}$ (see next paragraph for calculation). The photosynthetic model of Collatz et al. (1991) and Collatz et al. (1992) assumes specific values of $T_{u p p}$ and $T_{l o w}$ for $\mathrm{C}_{3}$ and $\mathrm{C}_{4}$ plants, respectively (Table S 3.1 and Table S 3.2). This temperature range from $-10^{\circ} \mathrm{C}$ to $36^{\circ} \mathrm{C}$ and $13^{\circ} \mathrm{C}$ to $45^{\circ} \mathrm{C}$ for $\mathrm{C}_{3}$ and $\mathrm{C}_{4}$ photosynthetic pathways respectively, allows plants to grow most efficiently in their plant-specific climatic niches.

\section{(c) Leaf temperature.}

We calculate leaf temperature following the leaf-level energy budget concept (Gates, 1968). Leaf-level photosynthesis, activity of leaf enzymes and transpiration depend on leaf temperature $\left(T_{\text {leaf }},{ }^{\circ} \mathrm{C}\right)$, calculated as

$$
T_{\text {leaf }}=T_{\text {air }}+\left(\frac{R_{n}-\lambda E r_{g b}}{\rho C_{P}}\right) \text {, }
$$

where $T_{\text {air }}$ is air temperature $\left({ }^{\circ} \mathrm{C}\right), R_{n}$ is net radiation absorbed by the leaf $\left(\mathrm{MJ} / \mathrm{m}^{2} /\right.$ day), $\lambda$ is latent heat of vaporization $(\mathrm{MJ} / \mathrm{kg}), E$ is evapotranspiration ( $\mathrm{m} /$ day), $r_{g b}$ is the boundary layer resistance $(\mathrm{m} / \mathrm{s}), \rho$ is the air density $\left(\mathrm{kg} / \mathrm{m}^{3}\right)$ and derived from atmospheric pressure $(101.325 \mathrm{kPa}$ at sea level) that is scaled according to the elevation and $\mathrm{T}_{\text {air, }}$ and $C_{P}$ is the specific heat of dry air $\left(\mathrm{MJ} / \mathrm{kg} /{ }^{\circ} \mathrm{C}\right)$. Leaf temperature is used to calculate the temperature dependence of $V_{c \max }$ used in the photosynthesis model routines in equation (4). Absorbed net radiation $\left(R_{n}\right), r_{g b}$ and $E$ are model state variables calculated from climate input used in aDGVM2 ( $T_{\text {air }}$, long-wave and short-wave radiation) and $\rho$ is derived from atmospheric pressure $(101.325 \mathrm{kPa}$ at sea level) that is scaled according to the elevation and $\mathrm{T}_{\text {air. }}$ The value of latent heat of vaporization $(\lambda)$, and $C_{P}$ are $2.45 \mathrm{MJ} / \mathrm{kg}$ and $2.71 \mathrm{MJ} / \mathrm{kg} /{ }^{\circ} \mathrm{C}$ respectively, and are assumed as constant parameters in this model version.

\section{(d) $C_{3}$ grasses.}

$\mathrm{C}_{3}$ grasses were not included in previous aDGVM2 versions (Scheiter, Langan and Higgins, 2013; Langan, Higgins and Scheiter, 2017; Gaillard et al., 2018; Pfeiffer et al., 2019). We therefore implemented $C_{3}$ grasses, following the approach used for $C_{4}$ 
grasses in previous model versions but adjusted the photosynthetic pathway (see Appendix S2 in Langan et al., 2017). $C_{3}$ and $C_{4}$ grasses use a different leaf-level photosynthesis model (Farquhar, von Caemmerer and Berry, 1980) following the implementations of Collatz et al. (1991; 1992). The optimum temperature ranges for carboxylation for $\mathrm{C}_{3}$ and $\mathrm{C}_{4}$ grasses are also different (Table $\mathrm{S} 3.1$ ). As $\mathrm{C}_{3}$ grasses have higher cold tolerance than $\mathrm{C}_{4}$ grasses (Liu and Osborne, 2008), we implemented frost intolerance for $\mathrm{C}_{4}$ grasses but not for $\mathrm{C}_{3}$ grasses. Frost is assumed to damage the tissue of $\mathrm{C}_{4}$ grasses, and in aDGVM2, we kill $10 \%$ of the living leaf biomass of $\mathrm{C}_{4}$ grasses per frost day independent of frost severity.

\subsubsection{Model forcing data}

\subsubsection{Climate data}

We used GFDL-ESM2M climate data for the period 1950 to 2099 from the InterSectoral Impact Model Inter-comparison Project (ISIMIP2), as historical climate simulated by GFDL-ESM2M showed satisfactory performance over for South Asia (McSweeney and Jones, 2016). The general circulation model (GCM) output was biascorrected in ISIMIP and downscaled to a spatial resolution of $0.5^{\circ} \times 0.5^{\circ}$ (Warszawski et al., 2014). We used average, maximum and minimum air temperatures, precipitation, surface downwelling shortwave radiation and long-wave radiation, near-surface wind speed, and relative humidity at a daily temporal resolution. We used two representative concentration pathways, namely RCP4.5 and RCP8.5 (Meinshausen et al., 2011). These scenarios assume increases in radiative forcing of 4.5 and $8.5 \mathrm{Wm}^{-2}$ by 2100 (Vuuren et al., 2011) and increases of atmospheric $\mathrm{CO}_{2}$ concentrations to $560 \mathrm{ppm}$ and $970 \mathrm{ppm}$ by 2100, respectively (Vuuren et al., 2011).

\subsubsection{Projected changes in temperature and precipitation}

Mean annual precipitation (MAP) from GFDL-ESM2M does not show a clear trend when averaged for South Asia under RCP4.5 and RCP8.5, due to high inter-annual variability of precipitation (Figure S3.1). Yet, there are region-specific differences in precipitation change. The Western Ghats which located between $73^{\circ}-77^{\prime} \mathrm{E}$ and $8^{\circ} \mathrm{N}-$ $21^{\circ} \mathrm{N}$ and eastern Himalayan region are projected to become wetter under both RCP4.5 and RCP8.5, whereas the western part of the region is projected to become drier by the 
end of the century under both RCPs (Figure S3.2). MAP is projected to increase by more than $600 \mathrm{~mm}$ in the Eastern Himalayas and Western Ghats, but predicted to decrease by $400-600 \mathrm{~mm}$ in the western and central area of the region (Figure S3.2). By the end of the 21 st century, mean annual temperature (MAT) of South Asia is expected to increase between ca. $1^{\circ} \mathrm{C}$ and $3.5^{\circ} \mathrm{C}$ under RCP4.5 and between $1^{\circ} \mathrm{C}$ and $6^{\circ} \mathrm{C}$ under RCP8.5, relative to the average temperature in the baseline period of 2000-2009 (Figure S3.1, S3.2). The western parts of the region and the Himalayan mountains are projected to experience higher increases in temperature than the rest of the region (Figure S3.2).

\subsubsection{Soil and elevation data}

Soil data was obtained from FAO (Nachtergaele et al., 2009; http://www.fao.org /soils-portal) and includes information on soil properties and types. The soil properties include parameters required by aDGVM2: volumetric water-holding capacity, soil hydraulic conductivity, soil bulk density, soil depth, soil texture, soil carbon content, soil wilting point and field capacity (for details see Figure S3.3b and Langan et al., 2017). A digital elevation model (DEM) at 90m spatial resolution was obtained from the Shuttle Radar Topography Mission (SRTM, Jarvis et al., 2008; http://srtm.csi.cgiar.org). It was resampled to a spatial resolution of $0.5^{\circ} \times 0.5^{\circ}$, to match the spatial resolution of climate data. Elevation values were used to estimate surface pressure. In the model, elevation is used to calculate the surface pressure at a given altitude, which is used to scale up air density and partial pressure of oxygen. The partial pressure of oxygen is used to estimate the $\mathrm{CO}_{2}$ compensation point of photosynthesis (Eq. 2 of Appendix S2 in Langan et al., 2017). We did not use slope and aspect in the model.

\subsubsection{Model simulation protocol}

To understand how climate and $\mathrm{CO}_{2}$ fertilization interact to influence the future vegetation state in South Asia, we simulated all combination of two climate scenarios (RCP4.5 and RCP8.5) and two $\mathrm{CO}_{2}$ scenarios $\left(\mathrm{CO}_{2}\right.$ fertilization enabled or disabled, four scenarios in total). We simulated potential natural vegetation between 1950 and 2099 using daily climate data for RCP4.5 and RCP8.5 (see section 3.2.3.1). For both scenarios, simulations were run with $\mathrm{CO}_{2}$ increase in line with RCP4.5 (hereafter RCP4.5+eCO 2 ) and $\mathrm{RCP} 8.5$ (hereafter $\mathrm{RCP} 8.5+\mathrm{eCO}_{2}$ ) and with the same climate data but fixed $\mathrm{CO}_{2}$ after 
2005 at $375 \mathrm{ppm}$ for RCP4.5 (hereafter $\mathrm{RCP} 4.5+\mathrm{fCO}_{2}$ ) and $\mathrm{RCP} 8.5$ (hereafter $\mathrm{RCP} 8.5+\mathrm{fCO}_{2}$ ). Fixing the $\mathrm{CO}_{2}$ concentration after 2005 mimics a situation where $\mathrm{CO}_{2}$ fertilization would not occur and vegetation only responds to the climate signal. All simulations were conducted with natural fire as implemented in aDGVM2 and at $0.5^{\circ} \times$ $0.5^{\circ}$ spatial resolution. The aDGVM2 simulates 1 -hectare stands that are assumed to be representative for the vegetation at larger scale, i.e., we assume that the stand-level vegetation homogeneously covers all hectares within a simulated grid cell. The representative hectare approach is a concession to computational limitation, as photosynthesis and physiological processes are simulated individually for all individual plants of a stand (upto 36000 individuals). It balances adequate representation of trait diversity among individual against computational constraint. Also due to computation time constraints, we did not conduct replicate simulations.

To ensure that simulated vegetation had sufficient time to adapt to prevailing environmental conditions, we conducted simulations for 650 years, split into a 500 year spin-up phase and a 150 year transient phase. For the spin-up phase, we randomly sampled years of the first 30 years of daily climate data (1950 to 1979). For the transient phase, we used the sequence of daily climate data between 1950 and 2099. Trial simulations showed that a 500 year spin-up period is sufficient to ensure that vegetation is in a dynamic equilibrium state with environmental drivers.

\subsubsection{Model benchmarking and evaluation}

For benchmarking of aDGVM2 simulation results, we used five different remote sensing products: aboveground biomass (Saatchi et al., 2011), tree height (Simard et al., 2011), tree cover (Friedl et al., 2010), MODIS evapotranspiration (Zhang et al., 2010) and natural vegetation type (Ramankutty et al., 2010). All remote sensing data sets were aggregated to a $0.5^{\circ} \times 0.5^{\circ}$ spatial resolution, to match the spatial resolution of model simulations by calculating the mean of all values within each $0.5^{\circ}$ grid cell, or using nearest neighbor aggregation in the case of vegetation type ("raster" package in $\mathrm{R}$, Hijmans, 2020). We first compared model results and observations assuming that the entire study region is covered by natural vegetation (Figure 3.1). Then we repeated the comparisons only for areas with predominantly natural cover, i.e., we masked out areas with more than 50\% managed land (Figure S3.4, land cover classes 7 'Cultivated and Managed Vegetation' and 9 'Urban and Built-up' in Tuanmu and Jetz (2014)). We 
calculated Normalized Mean Squared Error (NMSE) and coefficient of determination $\left(\mathrm{R}^{2}\right)$ to quantify agreement between data and simulated variables.

\subsubsection{Biome classification}

The aDGVM2 simulates state variables such as biomass and canopy cover of individual plants in simulated vegetation stands ( 1 hectare which is a representative of grid cell). We used woody canopy area, abundance of shrubs and trees, and grass biomass to classify the simulated vegetation into biome types (Figure S3.5). We used 10-year averages of state variables for the periods 2000-2009, 2050-2059 and 2090-2099 to represent the 2000s, 2050s and 2090s, respectively. We classified areas with woody canopy cover below $5 \%$ as barren if grass biomass was below $100 \mathrm{~kg} / \mathrm{ha}$, and as grassland if grass biomass exceeded $100 \mathrm{~kg} / \mathrm{ha}$. Grassland was classified as $\mathrm{C}_{3}$ grassland or $\mathrm{C}_{4}$ grassland based on predominance of $\mathrm{C}_{3}$ or $\mathrm{C}_{4}$ grass biomass. Simulated woody individuals were classified as trees if they had three or less stems and as shrubs if they had four or more stems (see supplementary information). The canopy cover of woody plants and grass biomass were used to separate woodland and savanna biomes. Grid cells with tree canopy cover greater than shrub canopy cover, tree canopy cover between 5\% and $45 \%$, and grass biomass below $100 \mathrm{~kg} / \mathrm{ha}$, were classified as woodland. Grid cells with the same woody cover characteristics but grass biomass higher than $100 \mathrm{~kg} /$ ha were classified as savanna. Savanna was further separated into $\mathrm{C}_{4}$ savanna or $\mathrm{C}_{3}$ savanna based on the predominance of $\mathrm{C}_{3}$ or $\mathrm{C}_{4}$ grass biomass. Areas with canopy cover greater than $45 \%$ were classified as forest if tree cover exceeded shrub cover, or shrubland if shrub cover exceeded tree cover, irrespective of grass biomass. Forests were subdivided into evergreen and deciduous forest based on the dominance of canopy area of both tree phenology types. Biomes considered in this study were hence $\mathrm{C}_{3}$ grassland, $\mathrm{C}_{4}$ grassland, shrubland, woodland, deciduous forest, evergreen forest, $\mathrm{C}_{3}$ savanna and $\mathrm{C}_{4}$ savanna.

Biomes differ in the amount of precipitation they receive and their temperatures. Whittaker plots describe the boundaries of observed biomes with respect to average temperature and precipitation. We used R-package ('plotbiomes' by Valentin Ștefan https://github.com/valentinitnelav/plotbiomes) to create Whittaker plot based on Ricklefs (2008) and Whittaker (1970). We overlaid the simulated biomes on Whittaker plots to assess at climatic niches of biomes under current climate to determine shifts in climatic 
niches by the end of this century as a result of climate change and elevated $\mathrm{CO}_{2}$ under both RCPs (see section 3.3.6).

\subsubsection{Calculation of biome-level evapotranspiration}

For analyzing evapotranspiration change, we calculated the amount of water transpired per unit leaf biomass. Simulated ET and leaf biomass for woody plants, $\mathrm{C}_{3}$ grass and $\mathrm{C}_{4}$ grass were summed and scaled to the grid level, taking latitudinal variation of grid cell area into account. Absolute change in evapotranspiration quantity can either result from the change in biome area or from a change in total amount of leaf-biomass over time or from changes in water use efficiency. In order to eliminate the effects caused by change in biome area and leaf biomass, we calculated biome level evapotranspiration by normalizing evapotranspiration with biome-level leaf biomass (Equation 6). Due to the normalization differences in evapotranspiration at biome level, are comparable between different biomes and independent from biome attributes such as its spatial extent and biome-level biomass. The biome-level evapotranspiration is calculated as the ratio of total annual ET over total leaf biomass for all respective biomes:

$\mathrm{E}_{\text {biome }}=\frac{\sum_{i=1}^{G}\left(\mathrm{E}_{\text {grid }, i} \mathrm{~A}_{\text {grid }, i}\right)}{\sum_{i=1}^{G}\left(\mathrm{~B}_{\text {grid }, i} \mathrm{~A}_{\text {grid }, i}\right)}$,

where Ebiome is biome-level ET ( $\mathrm{mm} / \mathrm{kg} / \mathrm{year}), 1,2, \ldots, \mathrm{G}$ represent the grid cells of the biome, Agrid, $i$ is the area of grid cell $i\left(\mathrm{~m}^{2}, \mathrm{E}_{\text {grid }}, \mathrm{i}\right.$ is total evapotranspiration of grid cell $\mathrm{i}$ (mm/year), Bgrid,i is leaf biomass of grid cell $i\left(\mathrm{~kg} / \mathrm{m}^{2}\right.$. Choosing to normalize evapotranspiration to leaf biomass integrates over both increased water use efficiency and soil water availability constraints. It is therefore suitable to characterize overall change in the water balance over time at biome level, as it not only indicates water used to produce new biomass (as GPP over transpiration would express), but also includes water required to sustain existing biomass. We calculated the percentage change in Ebiome for respective scenarios between the 2010s and 2050s, and between the 2010s and the 2090s. 


\subsection{Results}

\subsubsection{Model performance and contemporary vegetation patterns}

The aDGVM2 captured contemporary large-scale patterns of biomass, canopy cover, tree height and evapotranspiration. Model results agreed well with remote sensing products used for benchmarking (Figure 3.1).

(a)

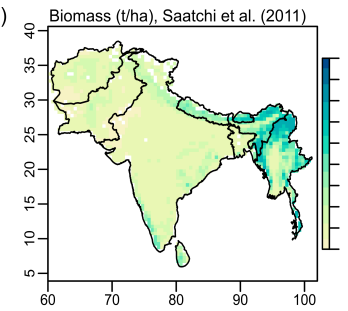

(b)

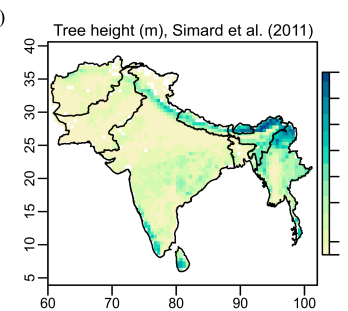

(c)

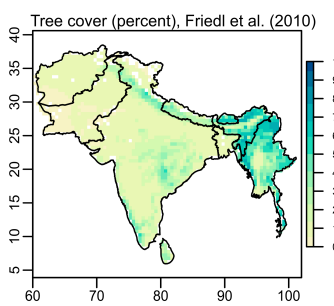

(d)

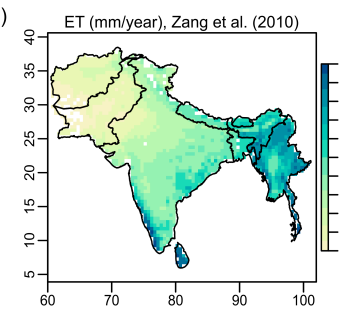

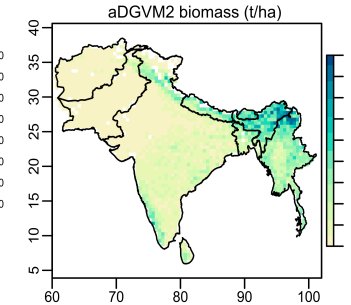
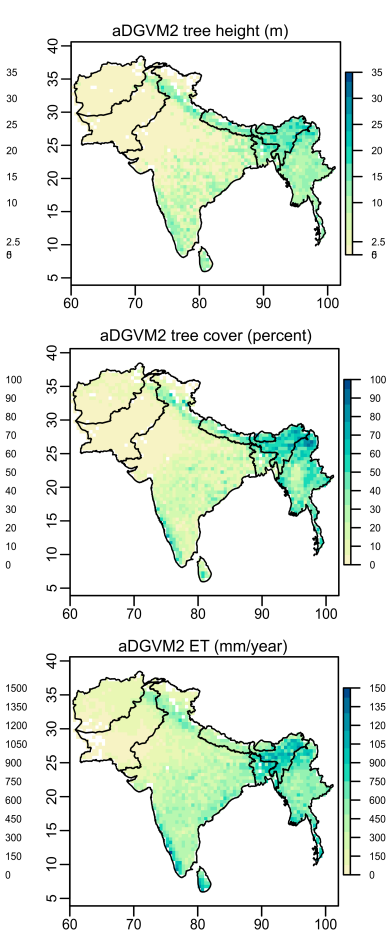
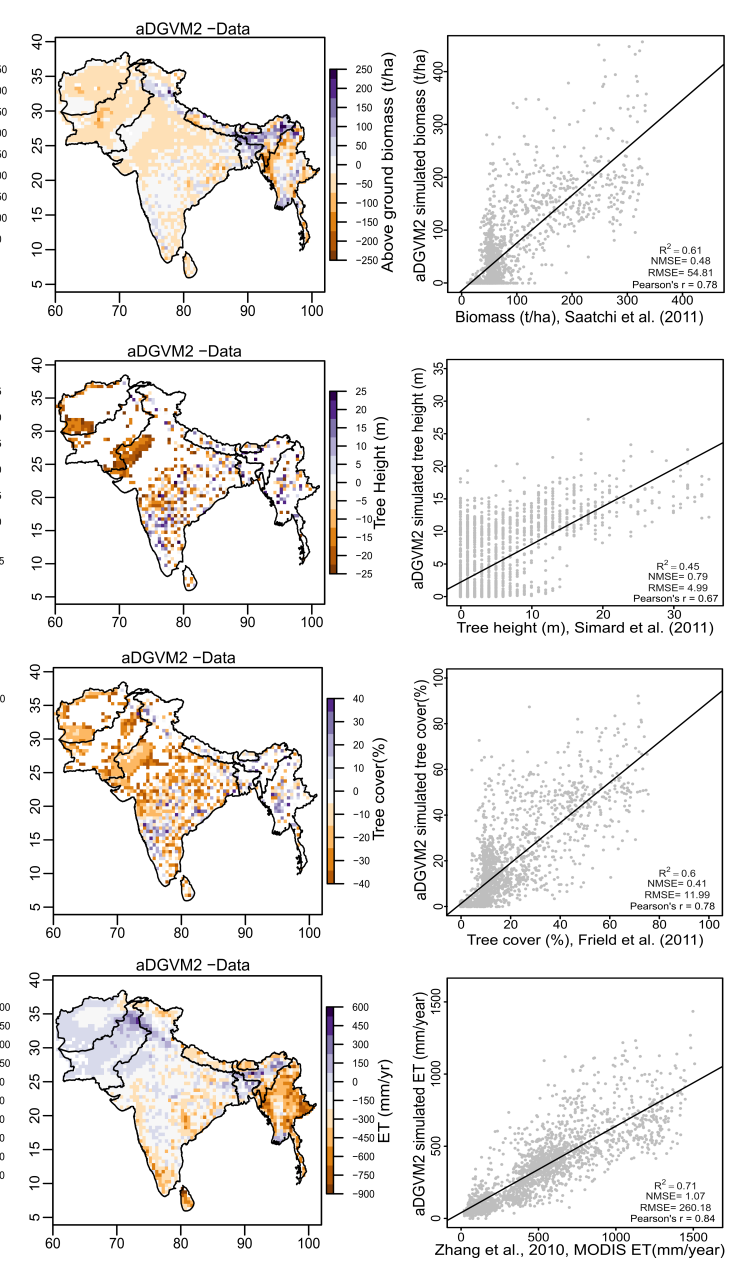

Figure 3.1 Comparison between aDGVM2 results and data for (a) simulated biomass and Saatchi et al. (2011) biomass, (b) simulated tree height and Simard et al. (2011), (c) simulated tree cover and Friedl et al. (2011) tree cover and (d) simulated evapotranspiration and Zang et al. (2010) evapotranspiration. In the figure the first column shows the remote sensing products, the second column shows aDGVM2 results, and the third column shows the difference between simulation and data and the fourth column shows the scatter plot between simulated state variables against benchmarking data. NMSE and RMSE are normalized mean square error and root mean square error, respectively. In the fourth column, each point represents one grid cell in the study region. For results with masked land use cover, see supplementary Figure S3.4 
Chapter 3-Climate change and elevated $\mathrm{CO}_{2}$ favor forest over savanna under different future scenarios in South Asia

$\mathrm{R}^{2}$ was $0.61,0.45,0.6$ and 0.71 , and NMSE was $0.48,0.78,0.4$ and 1.07 for biomass (Saatchi et al., 2011), tree height (Simard et al., 2011), tree cover (Friedl et al., 2010) and evapotranspiration (Zhang et al., 2010), respectively (Figures 3.1, 3.2). Data-model agreement improved when masking out managed land (Tuanmu and Jetz, 2014). $\mathrm{R}^{2}$ increased to $0.66,0.71,0.67$ and 0.80 , while NMSE decreased to $0.43,0.30,0.61$ and 1.03 for biomass, tree height, tree cover and evapotranspiration, respectively (Figure S3.4).

The model performed well in areas with higher fractional cover of natural vegetation, such as the Himalayas, Western Ghats and the northeast of the region, although the model overestimated biomass and canopy area in the Brahmaputra basin which lies between $28^{\circ} \mathrm{N}-34^{\circ} \mathrm{N}$ and $90^{\circ} \mathrm{E}-96.5^{\circ} \mathrm{E}$ in the northeast of the study region (Figure 3.1 a,c; Kumar et al., 2020a).

The model simulated evergreen forests along the Himalayan mountains, southern part of the Western Ghats and Sri Lanka, whereas deciduous forest was simulated in the northern Western Ghats, central India and southern parts of Myanmar (Figure 3.2a).
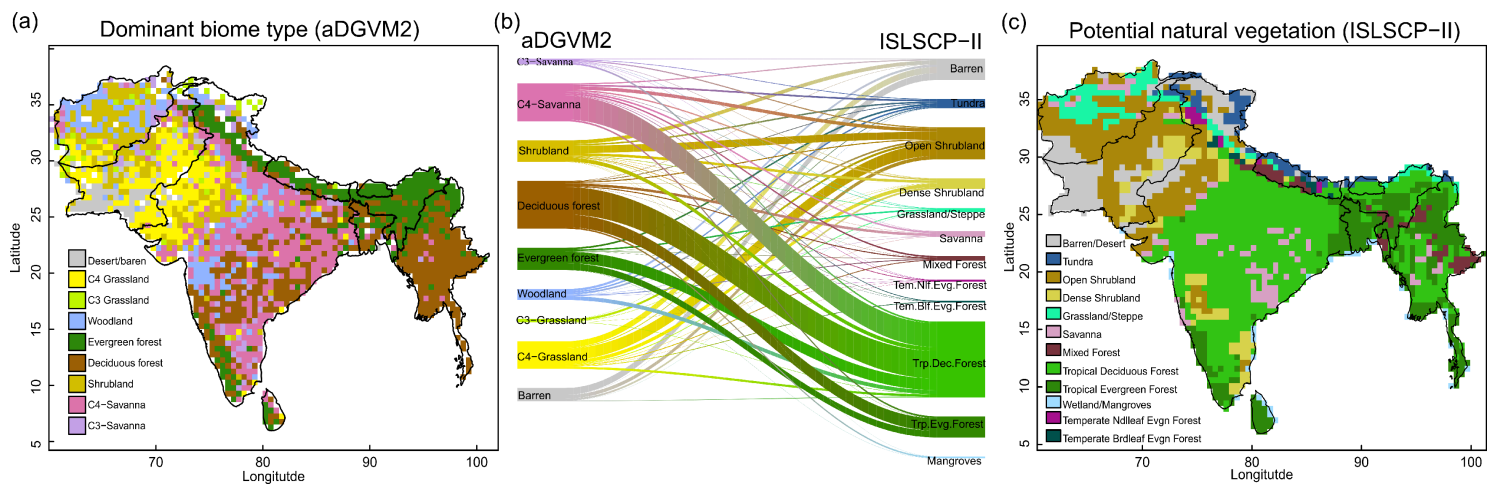

Figure 3.2 Comparison between simulated and observed biome patterns. (a) Simulated dominant biome type, (b) Sankey diagram showing overlap between simulated biomes and potential natural vegetation cover (ISLSCP-II, Ramankutty et al., 2010) and (c) potential natural vegetation. The Sankey graph shows how aDGVM2 biomes and PNV classes overlap

Savanna was simulated in southern, northern and western parts of India and some regions of central Myanmar. Shrublands were simulated in the arid regions of Pakistan, the western parts of India and Afghanistan. The aDGVM2 simulated woodland in the west of central India, and grassland in the drier regions (Figure 3.2a). A large proportion of 
simulated deciduous forest area is in good agreement with that in maps of potential natural vegetation (PNV, Figure 3.2b,c). However, a large proportion of simulated savanna area is represented as deciduous forest in the map of PNV (Figure 3.2b).

\subsubsection{Projected changes in biome distribution pattern}

The aDGVM2 projected increasing trends for canopy cover and above ground biomass in response to climate change and $\mathrm{CO}_{2}$, and hence, changes in biome type, predominantly from savanna and grassland to deciduous forest (Figure 3.3a,b). Simulations showed an increase in the area covered by evergreen and deciduous forests under both scenarios with $\mathrm{eCO}_{2}$, in contrast to simulations under both scenarios with $\mathrm{fCO}_{2}$ where $\mathrm{CO}_{2}$ was fixed after 2005 (Table 3.1). Under $\mathrm{RCP} 4.5+\mathrm{eCO}_{2}$, evergreen and deciduous forest cover increased by $3.1 \%$ and $21.2 \%$ until the $2050 \mathrm{~s}$, and $38.0 \%$ and $59.1 \%$ until the 2090s, respectively. Under $\mathrm{RCP} 8.5+\mathrm{eCO}_{2}$, evergreen and deciduous forest increased by $24.8 \%$ and $45.4 \%$ until the $2050 \mathrm{~s}$, and $46.5 \%$ and $60.2 \%$ until the 2090s, respectively.

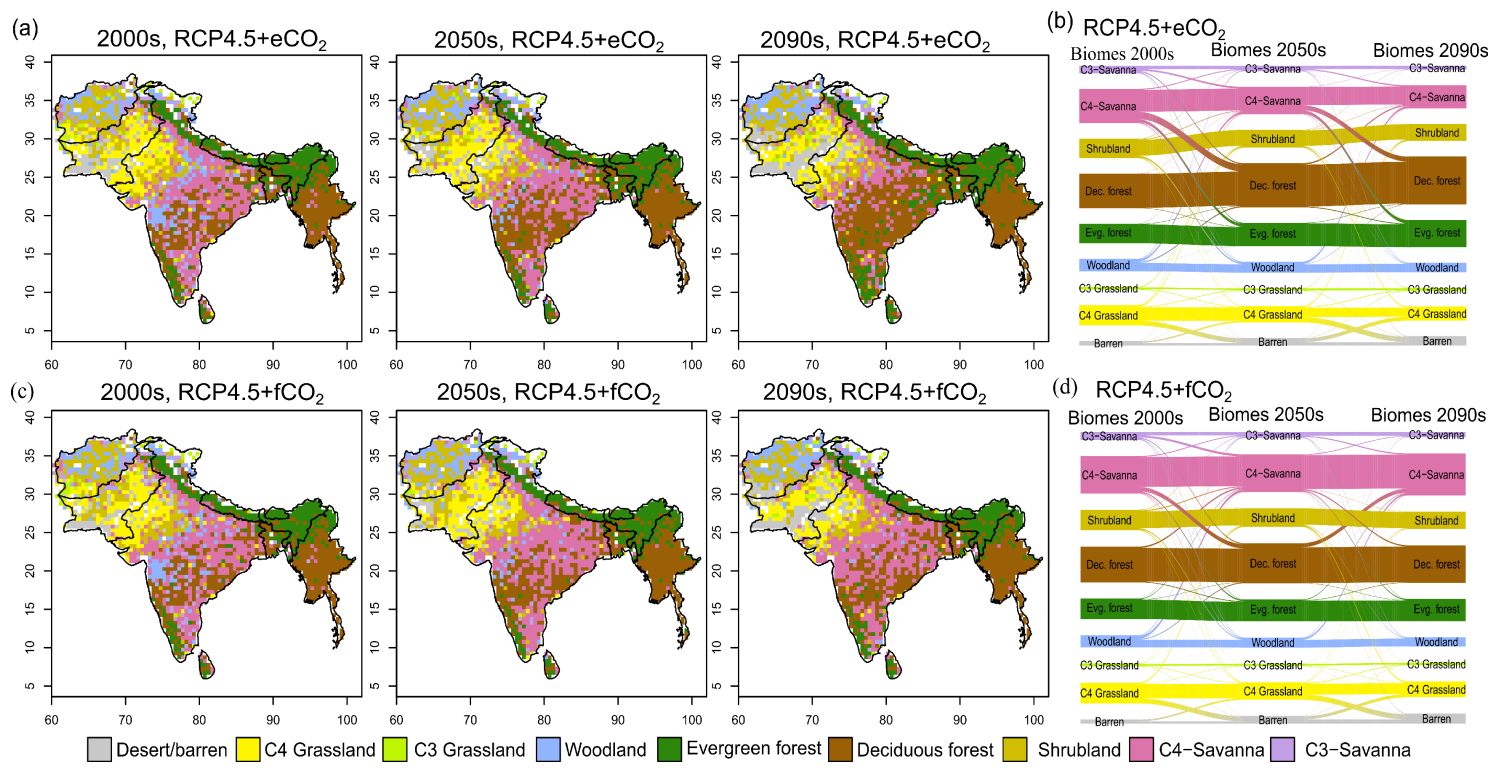

Figure 3.3 Simulated biome distribution for the 2000s, 2050s and 2090s under (a) $\mathrm{RCP} 4.5+e \mathrm{CO}_{2}$ and (c) $\mathrm{RCP} 4.5+\mathrm{fCO}_{2}$.The Sankey diagrams showing the fractional cover of biomes and transitions between biomes from the 2000s to the 2050 s and the 2050s to the 2090s under (b) $\mathrm{RCP} 4.5+\mathrm{eCO}_{2}$ and (d) $\mathrm{RCP} 4.5+\mathrm{fCO}_{2}$. See Figure S3.6 for simulated biome distribution under RCP8.5. 
Chapter 3-Climate change and elevated $\mathrm{CO}_{2}$ favor forest over savanna under different future scenarios in South Asia

The model simulated a small increase in forest area for $\mathrm{RCP} 4.5+\mathrm{fCO}_{2}$, where the area increased by $7.9 \%$ and $14.4 \%$ for evergreen and deciduous forest until the $2090 \mathrm{~s}$, respectively. Evergreen forests were mainly simulated along the Himalayas, Western Ghats and eastern parts of the study region under current conditions (2000s; Figure 3.3a), but expanded into the south of peninsular India in future periods (2050s and 2090s) under $\mathrm{RCP} 4.5+\mathrm{eCO}_{2}$. Deciduous forest cover also increased in future periods in central India and along the Himalayas (Figures 3.3, S3.6).

Table 3.1 Biome cover (in \%) for the 2000s, 2050s and 2090s, and percent (\%) change in biome cover from the 2000s to the 2050s and the 2000s to the 2090s under RCP4.5 and RCP8.5 with fixed and elevated $\mathrm{CO}_{2} . \Delta$ indicates percent change in biome cover between time periods.

\begin{tabular}{|c|c|c|c|c|c|c|c|c|c|}
\hline 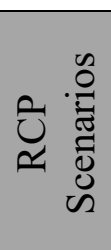 & $\underset{\bar{D}}{\vec{D}}$ & 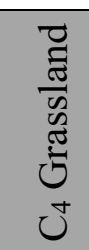 & 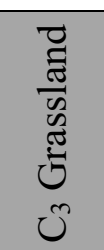 & $\begin{array}{l}\vec{\Xi} \\
\text { ज्ञ } \\
\overline{8} \\
8 \\
3\end{array}$ & $\begin{array}{l}\vec{y} \\
0 \\
\dot{0} \\
\dot{0} \\
\dot{0} \\
\dot{1} \\
\dot{1}\end{array}$ & 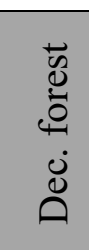 & $\begin{array}{l}\frac{\vec{E}}{\frac{\pi}{0}} \\
\frac{\vec{E}}{\tilde{E}}\end{array}$ & 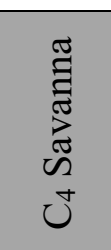 & 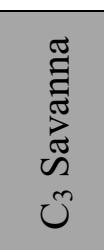 \\
\hline \multirow{5}{*}{ 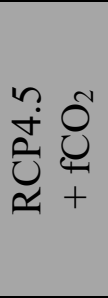 } & $2010 \mathrm{~s}$ & 5.6 & 15.4 & 4.6 & 18.2 & 11.7 & 17.6 & 6.9 & 17.7 \\
\hline & $2050 \mathrm{~s}$ & 6.3 & 14.8 & 3.2 & 15.7 & 11.2 & 18.6 & 6.7 & 22.1 \\
\hline & $2090 s$ & 10.4 & 12.3 & 2.3 & 10.0 & 12.7 & 20.1 & 6.0 & 24.7 \\
\hline & $\Delta 2050 \mathrm{~s}-2010 \mathrm{~s}$ & 13.0 & -3.7 & -32.2 & -13.6 & -4.0 & 5.6 & -3.0 & 25.4 \\
\hline & $\Delta 2090 \mathrm{~s}-2010 \mathrm{~s}$ & 87.0 & -20.1 & -50.0 & -45.2 & 7.9 & 14.4 & -12.7 & 40.1 \\
\hline \multirow{5}{*}{ 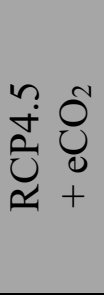 } & $2010 \mathrm{~s}$ & 5.7 & 15.2 & 4.8 & 18.6 & 11.5 & 17.5 & 6.8 & 17.5 \\
\hline & $2050 \mathrm{~s}$ & 6.5 & 13.9 & 3.5 & 15.0 & 11.9 & 21.2 & 7.0 & 19.6 \\
\hline & $2090 \mathrm{~s}$ & 10.4 & 10.4 & 2.5 & 10.7 & 15.9 & 27.9 & 6.2 & 15.1 \\
\hline & $\Delta 2050 \mathrm{~s}-2010 \mathrm{~s}$ & 13.5 & -8.2 & -26.9 & -19.7 & 3.1 & 21.2 & 3.8 & 12.1 \\
\hline & $\Delta$ 2090s-2010s & 82.0 & -31.6 & -48.4 & -42.4 & 38.0 & 59.1 & -8.4 & -14.1 \\
\hline \multirow{5}{*}{ 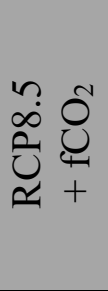 } & $2010 \mathrm{~s}$ & 6.3 & 14.7 & 4.5 & 18.8 & 11.7 & 17.3 & 6.3 & 18.0 \\
\hline & $2050 \mathrm{~s}$ & 8.8 & 12.3 & 2.5 & 14.7 & 12.9 & 21.7 & 6.6 & 19.0 \\
\hline & $2090 \mathrm{~s}$ & 9.4 & 15.0 & 2.5 & 11.0 & 10.8 & 14.2 & 6.7 & 29.0 \\
\hline & $\Delta 2050 \mathrm{~s}-2010 \mathrm{~s}$ & 39.0 & -16.5 & -43.7 & -21.9 & 10.1 & 25.0 & 4.1 & 5.4 \\
\hline & $\Delta 2090 \mathrm{~s}-2010 \mathrm{~s}$ & 48.8 & 1.8 & -43.7 & -41.6 & -7.9 & -17.9 & 5.7 & 61.0 \\
\hline \multirow{5}{*}{ 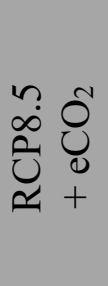 } & $2010 s$ & 5.9 & 14.8 & 4.7 & 18.0 & 11.6 & 17.5 & 7.1 & 17.9 \\
\hline & $2050 \mathrm{~s}$ & 9.7 & 10.5 & 3.2 & 13.9 & 14.5 & 25.4 & 7.1 & 14.1 \\
\hline & $2090 s$ & 6.3 & 11.5 & 4.2 & 12.6 & 17.0 & 28.0 & 7.0 & 12.2 \\
\hline & $\Delta 2050 \mathrm{~s}-2010 \mathrm{~s}$ & 64.9 & -29.5 & -32.6 & -22.9 & 24.8 & 45.4 & 0.7 & -21.6 \\
\hline & $\Delta 2090 \mathrm{~s}-2010 \mathrm{~s}$ & 7.0 & -22.2 & -10.9 & -30.3 & 46.5 & 60.2 & -1.5 & -32.2 \\
\hline
\end{tabular}


The extent of $\mathrm{C}_{4}$ savanna showed a significant decrease under scenarios with $\mathrm{eCO}_{2}$, although in $\mathrm{RCP} 4.5+\mathrm{eCO}_{2}$, it showed an increase by $12.1 \%$ between the $2010 \mathrm{~s}$ and the 2050s (Table. 3.1, Figure 3.3). Simulated $\mathrm{C}_{4}$ savanna area decreased by $14.1 \%$ relative to the $2000 \mathrm{~s}$ until the $2090 \mathrm{~s}$ under $\mathrm{RCP} 4.5+\mathrm{eCO}_{2}$. Under $\mathrm{RCP} 8.5+\mathrm{eCO}_{2}$, the model projected a decrease in $\mathrm{C}_{4}$ savanna area of $21.6 \%$ and $32.2 \%$ until the $2050 \mathrm{~s}$ and the 2090s, respectively. The area covered by $\mathrm{C}_{4}$ savanna increased under both RCPs with $\mathrm{fCO}_{2}$ (Table.3.1). $\mathrm{C}_{4}$ savannas were mainly located in the northern plain and peninsular India in the baseline period.

\subsubsection{Projected changes in biomass at biome level}

The aDGVM2 predicted an increase in mean biomass for evergreen and deciduous forest in the $\mathrm{eCO}_{2}$ scenarios for both RCPs (Table 3.2). Under RCP4.5+eCO 2 , mean above ground biomass in evergreen and deciduous forest increased by $8.1 \%$ and $14.4 \%$ by the $2050 \mathrm{~s}$ and $3.8 \%$ and $15.7 \%$ by the $2090 \mathrm{~s}$, relative to the baseline period. The increase is even higher under $\mathrm{RCP} 8.5+\mathrm{eCO}_{2}$ (Table 3.2). The mean biomass of woodland decreased under both RCPs except for the 2050s with $\mathrm{eCO}_{2}$ scenarios. The mean biomass of grassland increased under RCP4.5, but decreased for $\mathrm{C}_{4}$ grassland under RCP8.5 for both $\mathrm{fCO}_{2}$ and $\mathrm{eCO}_{2}$ scenarios. Shrublands in the western part of the study region showed an increase in mean biomass under $\mathrm{eCO}_{2}$ scenarios except for the $2050 \mathrm{~s}$ under both RCPs, and a decrease under $\mathrm{fCO}_{2}$ for both RCPs (Table 3.2). Our results showed that under RCP4.5 and RCP8.5 biomass decreased in the areas along the Himalayas, as well as in the central, north-eastern and western parts of the study region by the end of the century. Modelled biomass decrease is higher under RCP8.5 in these regions (Figures. 3.4, S3.7).

Biomass in the central and south-eastern part of the region is projected to increase under both RCPs with eCO 2 until the 2050s and 2090s, and to decrease in southern India and in parts of western South Asia (Figures 3.4, S3.7). We found increased biomass in Afghanistan, western Pakistan, Nepal and the southern part of Myanmar, and decreased biomass in the western arid part of the study region under both RCPs for both $\mathrm{eCO}_{2}$ and $\mathrm{fCO}_{2}$ (Figure 3.5), though the magnitude of change is different (Figures 3.4, S3.7). There were few areas in the western part of the study region, where the model predicted increased biomass only under $\mathrm{fCO}_{2}$ for both RCPs (Figure 3.5). In large parts of the study region, biomass increased under $\mathrm{eCO}_{2}$ for both $\mathrm{RCPs}$ but decreased under $\mathrm{fCO}_{2}$, that is, 
Chapter 3-Climate change and elevated $\mathrm{CO}_{2}$ favor forest over savanna under different future scenarios in South Asia

$\mathrm{CO}_{2}$ fertilization compensates climate change induced biomass die-backs in these regions

(Figure 3.5).

Table 3.2 Mean biomass (in t/ha) within biomes for the 2000s, 2050s and 2090s, and percent (\%) change in biomass from the 2000s to the 2050s and the 2000s to the 2090 s under RCP4.5 and RCP8.5 with fixed and elevated $\mathrm{CO}_{2} . \Delta$ indicates percentual biomass changes between time periods.

\begin{tabular}{|c|c|c|c|c|c|c|c|c|c|}
\hline 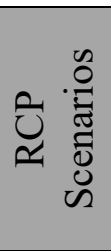 & $\underset{\nu}{\ddot{\varpi}}$ & 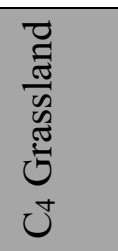 & 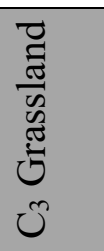 & $\begin{array}{l}\bar{Z} \\
\frac{\Xi}{0} \\
\overline{8} \\
0 \\
3\end{array}$ & $\begin{array}{l}\vec{y} \\
\dot{0} \\
\dot{0} \\
\dot{00} \\
\dot{0} \\
\dot{1}\end{array}$ & $\begin{array}{l}\overrightarrow{\tilde{w}} \\
\dot{0} \\
\dot{0} \\
\dot{0} \\
\tilde{0}\end{array}$ & 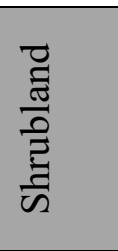 & 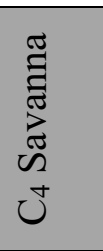 & 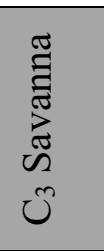 \\
\hline \multirow{5}{*}{ 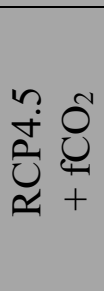 } & $2010 \mathrm{~s}$ & 0.9 & 1.5 & 30.4 & 189.7 & 142.1 & 4.0 & 35.5 & 36.8 \\
\hline & $2050 \mathrm{~s}$ & 0.9 & 1.8 & 29.2 & 191.0 & 144.0 & 3.6 & 38.0 & 44.7 \\
\hline & $2090 \mathrm{~s}$ & 0.9 & 2.1 & 24.5 & 188.1 & 148.4 & 3.3 & 32.6 & 31.8 \\
\hline & $\Delta 2050 \mathrm{~s}-2010 \mathrm{~s}$ & -1.1 & 19.5 & -4.0 & 0.7 & 1.3 & -10.9 & 6.8 & 21.4 \\
\hline & $\Delta 2090 \mathrm{~s}-2010 \mathrm{~s}$ & 4.4 & 35.1 & -19.4 & -0.9 & 4.4 & -17.8 & -8.2 & -13.7 \\
\hline \multirow{5}{*}{ 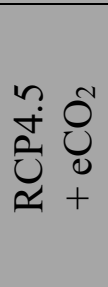 } & $2010 \mathrm{~s}$ & 0.9 & 1.4 & 30.7 & 189.2 & 142.5 & 4.0 & 35.9 & 37.3 \\
\hline & $2050 \mathrm{~s}$ & 1.0 & 1.5 & 34.7 & 204.6 & 162.9 & 4.3 & 48.1 & 53.2 \\
\hline & $2090 \mathrm{~s}$ & 1.0 & 1.6 & 29.3 & 196.4 & 164.9 & 4.1 & 43.2 & 51.8 \\
\hline & $\Delta 2050 \mathrm{~s}-2010 \mathrm{~s}$ & 17.2 & 5.6 & 13.0 & 8.1 & 14.4 & 6.0 & 34.0 & 42.7 \\
\hline & $\Delta 2090 \mathrm{~s}-2010 \mathrm{~s}$ & 12.6 & 8.3 & -4.6 & 3.8 & 15.7 & 2.5 & 20.4 & 39.1 \\
\hline \multirow{5}{*}{$\begin{array}{l}n \\
\infty \\
\infty \\
0 \\
0 \\
\simeq \\
\simeq\end{array}$} & $2010 \mathrm{~s}$ & 0.9 & 1.5 & 30.7 & 191.1 & 146.3 & 3.9 & 35.8 & 34.9 \\
\hline & $2050 \mathrm{~s}$ & 0.7 & 1.6 & 23.5 & 182.1 & 134.7 & 3.3 & 31.2 & 28.0 \\
\hline & $2090 \mathrm{~s}$ & 0.8 & 1.6 & 18.7 & 175.7 & 136.4 & 3.1 & 28.5 & 33.2 \\
\hline & $\Delta 2050 \mathrm{~s}-2010 \mathrm{~s}$ & -19.1 & 4.7 & -23.4 & -4.7 & -7.9 & -15.3 & -12.8 & -19.7 \\
\hline & $\Delta 2090 \mathrm{~s}-2010 \mathrm{~s}$ & -14.6 & 4.7 & -39.0 & -8.0 & -6.8 & -20.0 & -20.5 & -4.9 \\
\hline \multirow{5}{*}{ 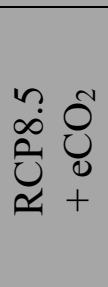 } & $2010 \mathrm{~s}$ & 0.9 & 1.3 & 31.2 & 188.3 & 146.1 & 4.1 & 36.5 & 32.0 \\
\hline & $2050 \mathrm{~s}$ & 1.0 & 1.4 & 32.1 & 206.3 & 162.7 & 4.0 & 45.1 & 47.2 \\
\hline & $2090 \mathrm{~s}$ & 0.7 & 1.1 & 30.8 & 206.0 & 183.4 & 4.7 & 49.8 & 50.7 \\
\hline & $\Delta 2050 \mathrm{~s}-2010 \mathrm{~s}$ & 9.9 & 8.7 & 2.8 & 9.6 & 11.3 & -1.5 & 23.6 & 47.4 \\
\hline & $\Delta 2090 \mathrm{~s}-2010 \mathrm{~s}$ & -22.0 & -12.7 & -1.6 & 9.4 & 25.6 & 15.5 & 36.6 & 58.2 \\
\hline
\end{tabular}



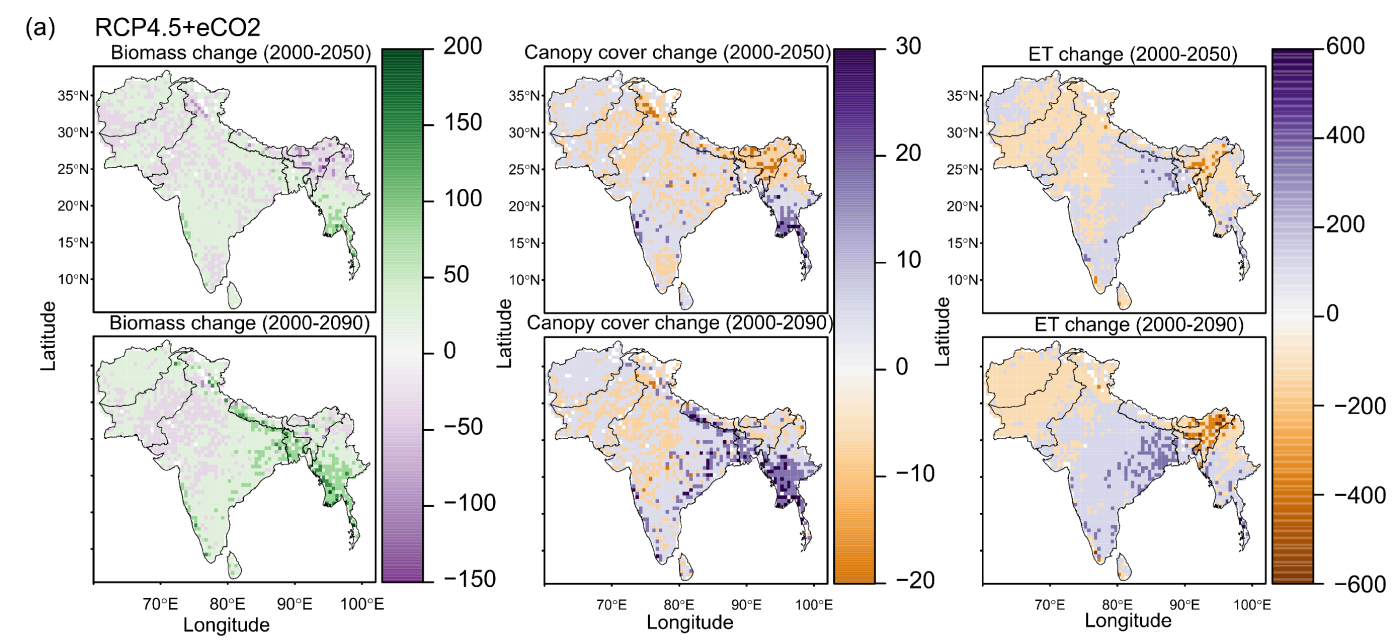

(b) $\mathrm{RCP} 4.5+\mathrm{fCO} 2$
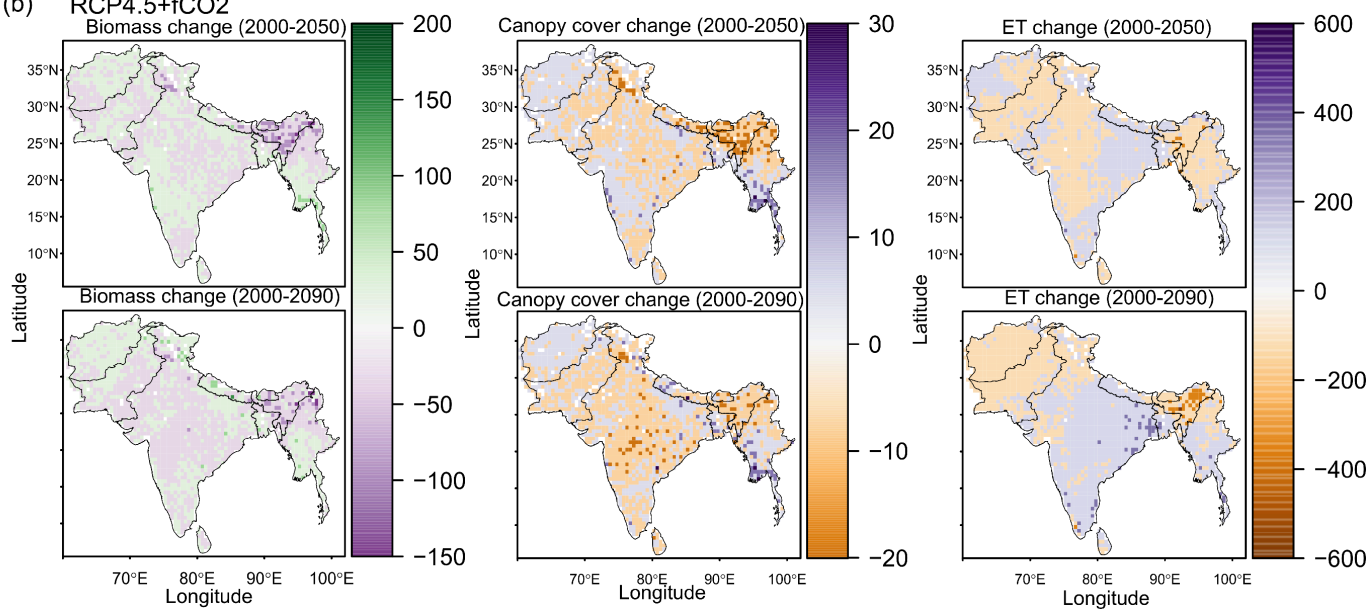

Figure 3.4 Projected change in biomass (t/ha), canopy area (\%) and evapotranspiration (ET, mm/year) between the 2000s and 2050s, and between the 2000s and the 2090 s under (a) $\mathrm{RCP} 4.5+e \mathrm{CO}_{2}$ and (b) $\mathrm{RCP} 4.5+\mathrm{fCO}_{2}$. See Figure $\mathrm{S} 3.7$ for projected change of these variables under RCP8.5
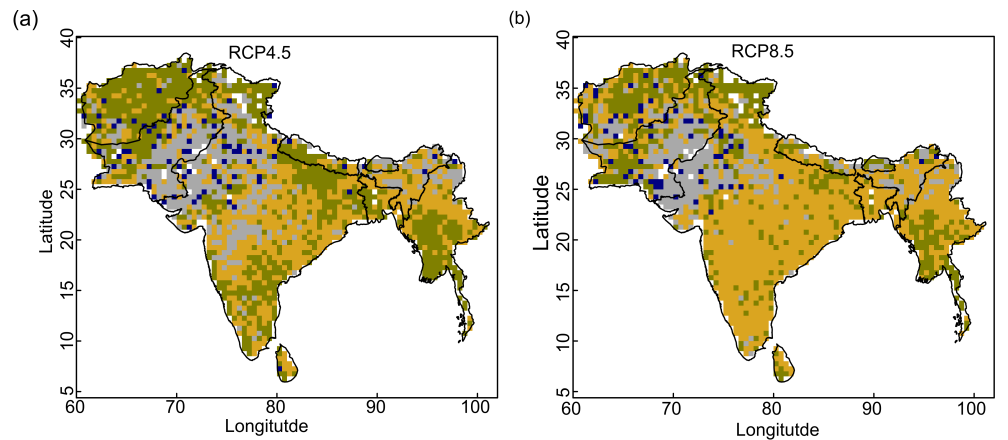

$\square$ Biomass increase under both $\mathrm{eCO}_{2}$ and $\mathrm{fCO}_{2}$ scenarios $\square$ Biomass increases under $\mathrm{eCO}_{2}$ and decreases under $\mathrm{fCO}_{2}$ scenarios
$\square$ Biomass decrease under both $\mathrm{eCO}_{2}$ and $\mathrm{fCO}_{2}$ scenarios
Biomass decreases under $\mathrm{eCO}_{2}$ and increases under $\mathrm{fCO}_{2}$ scenario

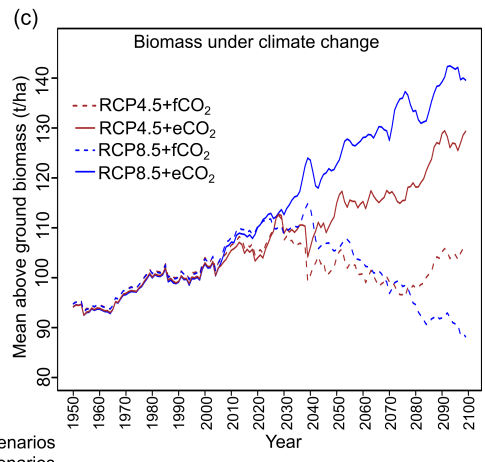

Figure 3.5 Maps showing areas where $\mathrm{CO}_{2}$-fertilization compensates biomass dieback caused by climate change between the 2000s and the 2090s under (a) RCP4.5 and (b) RCP8.5. and (c) aboveground biomass between 1950 and 2099 for South Asia in different scenarios. 


\subsubsection{Projected changes in evapotranspiration at biome level}

The response of simulated Ebiome varies in different biomes under both RCP4.5 and RCP8.5 (Table 3.3). Under the $\mathrm{RCP} 4.5+\mathrm{fCO}_{2}$ scenario the model predicted a decrease in ET in all biomes except for deciduous forest and shrubland where it increased by $1 \%$ and $2.1 \%$ until the $2050 \mathrm{~s}$, and by $0.3 \%$ and $11.9 \%$ by the $2090 \mathrm{~s}$, respectively. Simulated $\mathrm{E}_{\text {biome }}$ under $\mathrm{RCP} 8.5+\mathrm{fCO}_{2}$ for deciduous forest and shrubland increased by $4.2 \%$ and $5.2 \%$ until the $2050 \mathrm{~s}$, and by $5.2 \%$ and $16.4 \%$ until the $2090 \mathrm{~s}$, respectively. The model also predicted increased $\mathrm{E}_{\text {biome }}$ for $\mathrm{C}_{4}$ grassland, evergreen forest and $\mathrm{C}_{4}$ savanna until the 2090s under $\mathrm{RCP} 8.5+\mathrm{fCO}_{2}$ (Table 3.3). Comparisons of the $\mathrm{RCP} 4.5+\mathrm{fCO}_{2}$ and $\mathrm{RCP} 8.5+\mathrm{fCO}_{2}$ scenarios indicated that the former had a higher $\mathrm{E}_{\text {biome }}$ than the latter scenario across all biomes because precipitation decrease is higher in the RCP8.5 scenario than in the RCP4.5 scenario. Under both $\mathrm{RCPs}$ with $\mathrm{eCO}_{2}$, the model predicted a decrease in Ebiome across all biomes, except for a marginal increase in shrubland under RCP4.5 and deciduous forest under RCP8.5 until the 2050s and the 2090s (Table 3.3). In general, scenarios with $\mathrm{eCO}_{2}$ showed lower biome-specific evapotranspiration across $\left(\mathrm{E}_{\text {biome }}\right)$ most of the biomes compared to simulations with $\mathrm{fCO}_{2}$.

\subsubsection{Response of mean ET and mean above ground biomass to climate change}

The model predicted a larger increase in absolute annual mean ET (mm/year) under $\mathrm{eCO}_{2}$ than $\mathrm{fCO}_{2}$ for both $\mathrm{RCP}$ scenarios due to the corresponding increase in biomass (Figures 3.4, S4.7). We compared the spatially averaged annual values over entire South Asia of simulated absolute ET with MAP over the period from 1951 to 2099 and found a statically significant relation ( $p$-value $<0.005$ ). We found that absolute ET was positively correlated with MAP under all four scenarios (Figures 3.6a, S3.8a), but weakly correlated with MAT (Figures 3.6b, S3.8b).

For a given MAP, the spatially averaged annual value of above ground biomass (AGBM) was lower in scenarios with $\mathrm{fCO}_{2}$ than scenarios with $\mathrm{eCO}_{2}$ under both RCPs (Figure 3.6c, S3.8c). The spatially averaged annual value of AGBM decreased beyond a MAT of $23.5^{\circ} \mathrm{C}$ for both RCPs with $\mathrm{fCO}_{2}$, whereas it increased beyond $23.5^{\circ} \mathrm{C}$ under both RCP scenarios with $\mathrm{eCO}_{2}$ (Figures 3.6d, S3.8d). 

future scenarios in South Asia

Table 3.3 Biome-level ET normalized to biomass (Ebiomes, $\mathrm{mm} / \mathrm{kg} /$ year) for the $2000 \mathrm{~s}$, $2050 \mathrm{~s}$ and 2090s, and percent (\%) change in Ebiomes from the 2000s to the 2050s and the 2000s to the 2090s under RCP4.5 and RCP8.5 with fixed and elevated $\mathrm{CO}_{2} . \Delta$ indicates percentual ET changes between time periods

\begin{tabular}{|c|c|c|c|c|c|c|c|c|c|}
\hline 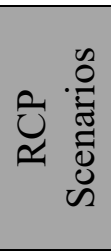 & 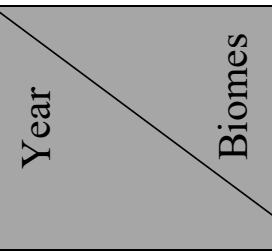 & 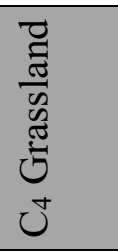 & 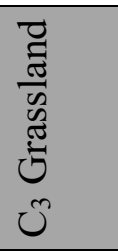 & $\begin{array}{l}\bar{\Xi} \\
\text { त्ञ } \\
\bar{\nabla} \\
8 \\
3\end{array}$ & $\begin{array}{l}\overrightarrow{0} \\
\dot{0} \\
\dot{0} \\
\dot{0} \\
\dot{01} \\
\overrightarrow{10}\end{array}$ & $\begin{array}{l}\overrightarrow{0} \\
\dot{0} \\
\stackrel{0}{0} \\
\dot{0} \\
\stackrel{0}{0}\end{array}$ & 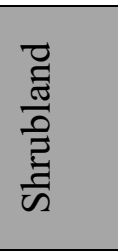 & 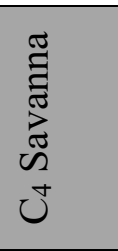 & 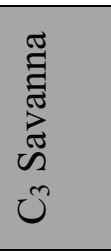 \\
\hline \multirow{5}{*}{ 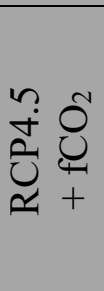 } & $2010 \mathrm{~s}$ & 186.7 & 95.5 & 257 & 159.7 & 288.5 & 183.3 & 252.5 & 194.2 \\
\hline & $2050 \mathrm{~s}$ & 170.9 & 80.5 & 217 & 157.4 & 291.3 & 187.2 & 244.6 & 151.9 \\
\hline & $2090 s$ & 185 & 72.3 & 209.6 & 140.7 & 289.3 & 205.2 & 247.1 & 179.1 \\
\hline & $\Delta 2050 \mathrm{~s}-2010 \mathrm{~s}$ & -8.5 & -15.7 & -15.6 & -1.4 & 1 & 2.1 & -3.1 & -21.8 \\
\hline & $\Delta 2090 \mathrm{~s}-2010 \mathrm{~s}$ & -0.9 & -24.3 & -18.5 & -11.9 & 0.3 & 11.9 & -2.1 & -7.8 \\
\hline \multirow{5}{*}{ 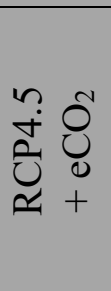 } & $2010 \mathrm{~s}$ & 185.4 & 93.4 & 259.7 & 159.7 & 288.1 & 190.9 & 251.6 & 188.4 \\
\hline & $2050 \mathrm{~s}$ & 161.2 & 79.7 & 217 & 147.8 & 283 & 183.2 & 238.2 & 153.4 \\
\hline & $2090 \mathrm{~s}$ & 164.1 & 73.4 & 210.2 & 138.7 & 280.4 & 197.2 & 236.6 & 157.1 \\
\hline & $\Delta 2050 \mathrm{~s}-2010 \mathrm{~s}$ & -13.1 & -14.6 & -16.5 & -7.4 & -1.8 & -4.1 & -5.3 & -18.6 \\
\hline & $\Delta 2090 \mathrm{~s}-2010 \mathrm{~s}$ & -11.5 & -21.4 & -19.1 & -13.2 & -2.7 & 3.3 & -6 & -16.6 \\
\hline \multirow{5}{*}{ 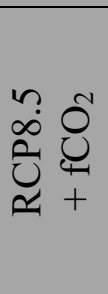 } & $2010 \mathrm{~s}$ & 172.8 & 87.4 & 257.5 & 160.9 & 286.5 & 185.5 & 244.7 & 188.1 \\
\hline & $2050 \mathrm{~s}$ & 153.7 & 72.7 & 243.2 & 158.3 & 298.5 & 195.1 & 241 & 162.7 \\
\hline & 2090 s & 195.6 & 67.6 & 231.1 & 162.7 & 301.3 & 216 & 267.5 & 150.2 \\
\hline & $\Delta 2050 \mathrm{~s}-2010 \mathrm{~s}$ & -11.1 & -16.8 & -5.5 & -1.6 & 4.2 & 5.2 & -1.5 & -13.5 \\
\hline & $\Delta 2090 \mathrm{~s}-2010 \mathrm{~s}$ & 13.2 & -22.6 & -10.2 & 1.1 & 5.2 & 16.4 & 9.3 & -20.1 \\
\hline \multirow{5}{*}{$\begin{array}{l}n \\
\infty \\
\infty \\
0 \\
0 \\
\simeq \\
\simeq \\
\end{array}$} & $2010 \mathrm{~s}$ & 177.5 & 91.1 & 256.4 & 162.7 & 284.5 & 192.5 & 243.7 & 191.7 \\
\hline & $2050 \mathrm{~s}$ & 143.9 & 76.9 & 235.6 & 149.4 & 285.4 & 184.6 & 228.8 & 153.1 \\
\hline & $2090 \mathrm{~s}$ & 141.4 & 59.2 & 218.3 & 143.9 & 284.9 & 186 & 242.3 & 143.2 \\
\hline & $\Delta 2050 \mathrm{~s}-2010 \mathrm{~s}$ & -18.9 & -15.6 & -8.1 & -8.1 & 0.3 & -4.1 & -6.1 & -20.1 \\
\hline & $\Delta 2090 \mathrm{~s}-2010 \mathrm{~s}$ & -20.3 & -35.1 & -14.9 & -11.6 & 0.1 & -3.4 & -0.6 & -25.3 \\
\hline
\end{tabular}


Chapter 3-Climate change and elevated $\mathrm{CO}_{2}$ favor forest over savanna under different future scenarios in South Asia
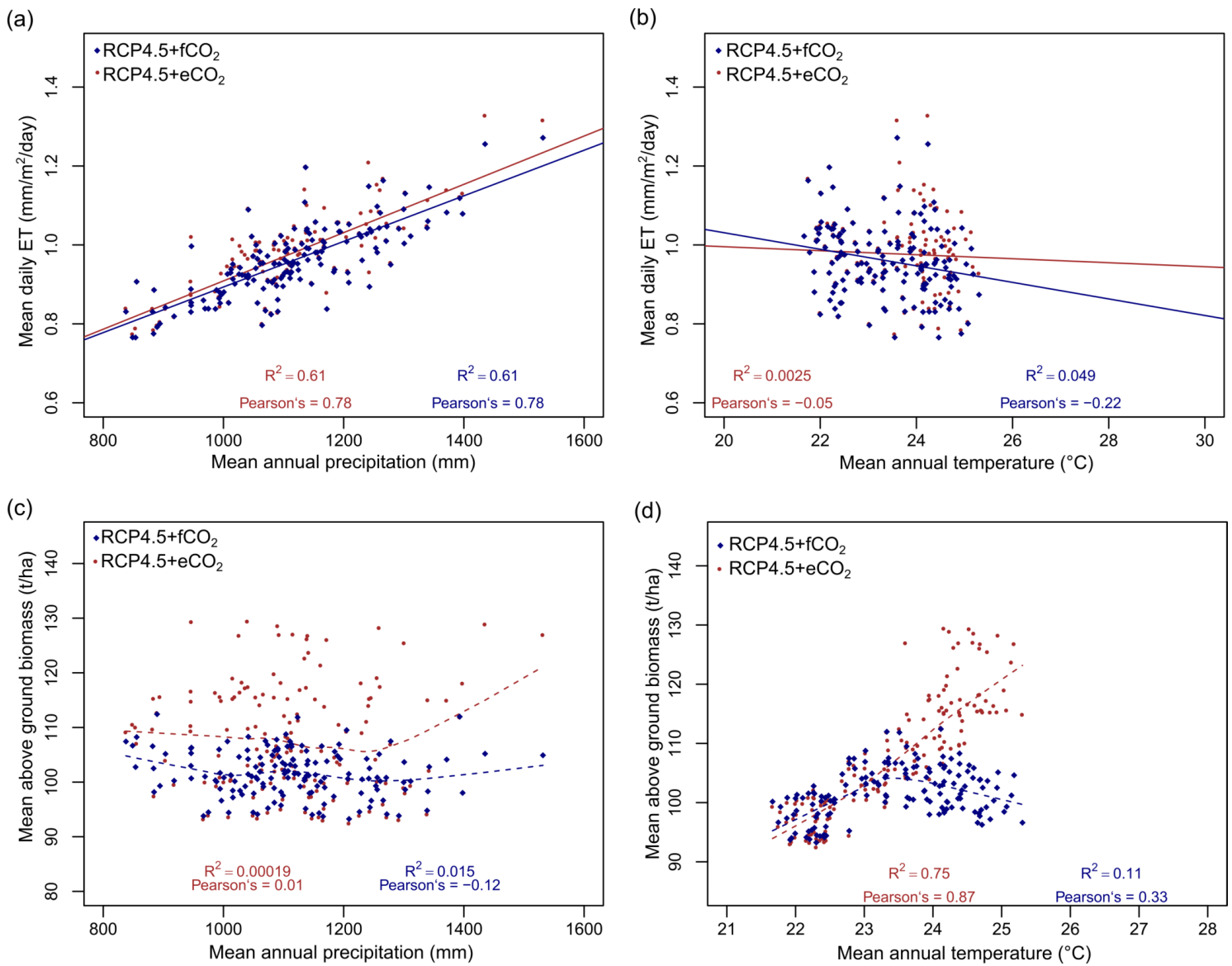

Figure 3.6 Relationship between (a) evapotranspiration (ET) and mean annual precipitation (MAP), (b) ET and mean annual temperature (MAT), (c) mean above ground biomass and MAP and (d) mean above ground biomass and MAT under RCP4.5. The lines (both solid and dotted) in all figures represent the bestfit regression line. Data points represent spatially averaged ET $(a, b)$ and biomass (c, d) over entire South Asia for each year from 1950 to 2099. See Figure $S 3.8$ for results under RCP8.5.

\subsubsection{Impact of climate change on climatic niches of biomes}

The climate niches of simulated biomes broadly overlapped with the biome niches in the Whittaker scheme (Figure 3.7, S3.9, Ricklefs, 2008; based on Whittaker, 1975). Under $\mathrm{RCP} 4.5+\mathrm{eCO}_{2}$ and $\mathrm{RCP} 8.5+\mathrm{eCO}_{2}$, the aDGVM2 simulated shifts of climatic niches of biomes. Evergreen and deciduous forest biomes were predicted to invade the niche space of savannas under $\mathrm{eCO}_{2}$ scenarios (Figure 3.7, S3.9). Savannas in turn were predicted to expand their climatic niche to MAT $>30^{\circ} \mathrm{C}$ by 2099 , a climatic space that was essentially not occupied by current biomes. Under RCP8.5 $+\mathrm{eCO}_{2}$ in the 2090s, forests completely occupied the climate space by 2090s which currently occupied by savanna (Figure S3.9). 

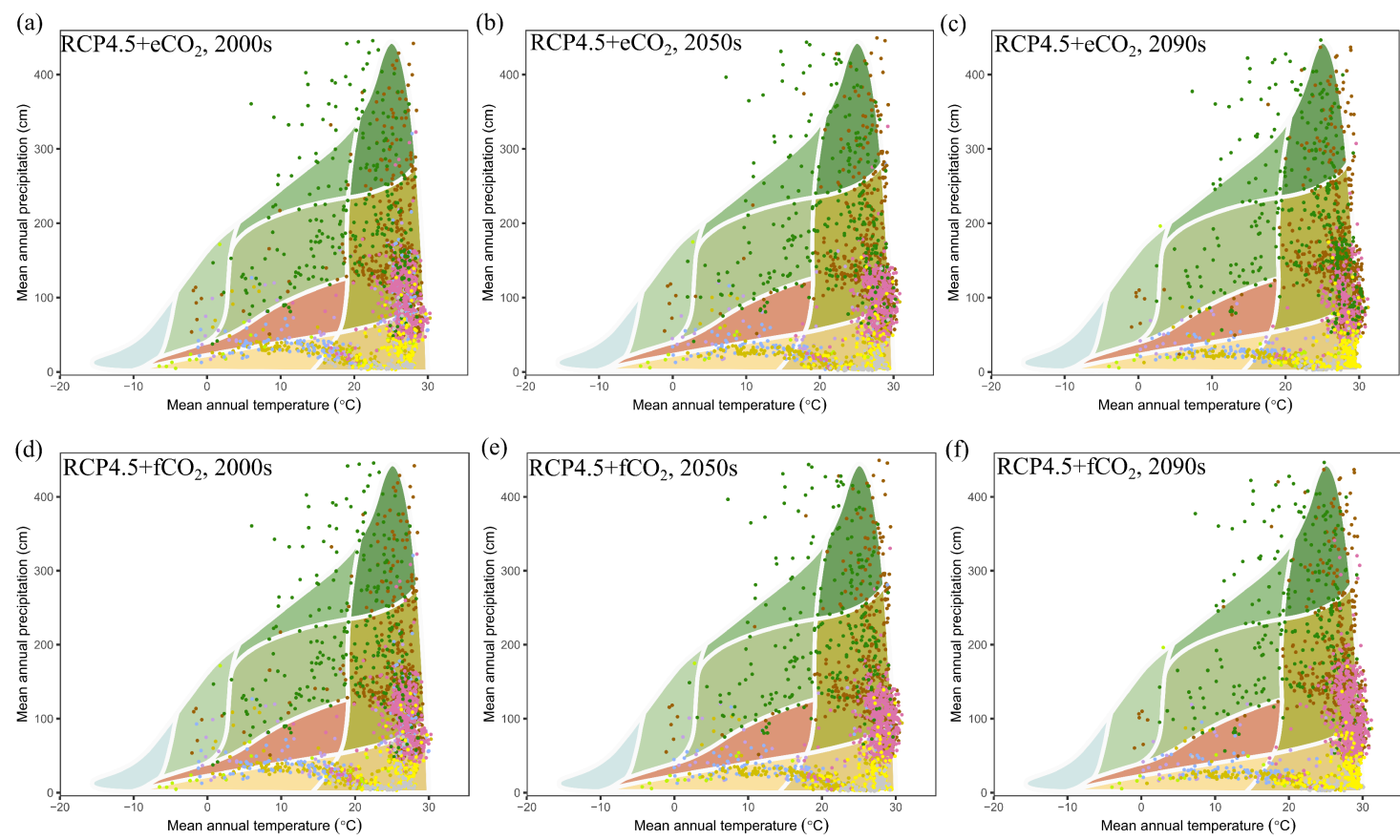

a DGVM2 biomes
Barren C4 Grassland • Evergreen
- C3 Grassland - C4-Savanna * Shrubland
- C3 Savanna - Deciduous forest • Woodland Whittaker biomes

Tundra

Temperate rain forest

Boreal forest Tropical rain forest

Tropical seasonal forest/savanna

Subtropical desert

Temperate grassland/desert

Woodland/shrubland

Figure 3.7 Simulated climate niches of biomes for the (a) 2000s, (b) 2050s and (c) 2090s under RCP4.5+eCO2 and (d) 2000s, (e) 2050s and (f) 2090s under $R C P 4.5+f C O 2$. The simulated biomes are overlaid on the climate envelopes of Whittaker's biomes and are plotted following Ricklefs (2008) and Whittaker (1975). See Figure S3.9 for projected change in climatic niches of biomes under $R C P 8.5$

In both scenarios with $\mathrm{fCO}_{2}$, savanna occupied the climate space delineated by MAT $>25^{\circ} \mathrm{C}$ and MAP between $500 \mathrm{~mm}$ and $1500 \mathrm{~mm}$ and did not experience major replacement by forest. The model predicted that savanna expansion in climate space was higher under RCP8.5 $+\mathrm{fCO}_{2}$ than under $\mathrm{RCP} 4.5+\mathrm{fCO}_{2}$ (Figure 3.7, S3.9). Other biomes also experienced shifts in their climate space (Figure 3.7). However, the results showed that for both current and future period grasslands and shrublands occupied the region with low MAP $(<500 \mathrm{~mm})$, and woodland occupied low MAP $(<800 \mathrm{~mm})$ regions, which corresponds to the western arid and semi-arid region of the study region under scenario with $\mathrm{eCO}_{2}$ (Figure 3.7). 


\subsection{Discussion}

\subsubsection{Impact of climate change and elevated $\mathrm{CO}_{2}$ on biomes and biomass}

Our simulations for $\mathrm{RCP} 4.5+\mathrm{eCO}_{2}$ and $\mathrm{RCP} 8.5+\mathrm{eCO}_{2}$ showed a strong positive response of vegetation growth, i.e., increases of biomass, canopy cover and canopy height. Mean biomass in most biomes was projected to increase, but the magnitude of increase differed considerably between different scenarios (Table 3.2). Projected change in canopy cover resulted in biome transitions. Under future conditions, the spatial distribution, extent and biomass of evergreen forests mostly remained at the current state, and evergreen forests were more resistant to climate change than deciduous forests. Expansion of deciduous forest into open biomes due to increasing woody cover resulted in significant loss of savanna area in the Deccan region under both RCPs with $\mathrm{eCO}_{2}$ by the end of the century. Transition from deciduous forests to evergreen forest was simulated for the mountain regions of South Asia (Scheiter, Kumar, et al., 2020) i.e., the Himalayas and the Western Ghats, where precipitation was predicted to increase. The trade-offs between specific leaf area (AsLA)-leaf longevity (LL) results in emergence of evergreen behaviour in wet regions South Asia. In the wet tropics, higher LL allows achieving a constant positive carbon balance from photosynthesis throughout the year, and increases the residence time of nutrients and carbon in the plant, and therefore enhances the photosynthetic gain per unit carbon and nutrient investment in leaves (Kikuzawa and Lechowicz, 2011). The deciduous behaviour is advantageous in dry regions, as in Deccan region, because trees that do not invest much carbon into their leaves per unit dry mass (higher A $S L A$ and lower LL), lose less investment when shedding them during the dry season. Phenology change as a result of climate change have already been observed (Cleland et al., 2007; Buitenwerf, Rose and Higgins, 2015). In Scheiter, Kumar, et al. (2020), we showed that climate change supports transitions to tall evergreen vegetation in tropical Asia and found increases in the abundance evergreen plants and decreases in the abundance deciduous plants in mainland Southeast Asia, central India and Pakistan. This relative advantage of evergreen plants over deciduous plants under elevated $\mathrm{CO}_{2}$ in aDGVM2 can be explained fact that increased intrinsic water use efficiency under eCO2 in evergreen plants are higher than in deciduous plants as demonstrated by Soh et al. (2019). Previous modelling studies also support aDGVM2 result showing transitions from deciduous to evergreen vegetation. With the BIOME4 
model, Ravindranath et al. (2006) simulated the response of forest to SRES A2 and B2 scenarios and reported similar changes toward evergreen phenology. A study by Chaturvedi et al. (2011) using the IBIS model also predicted transitions toward evergreen forest.

Woody encroachment in many ecosystems is attributed to rising $\mathrm{CO}_{2}$ and this is supported by studies based on both field observations (e.g., FACE experiments) and satellite data (Piao et al., 2006, 2009; Fischlin et al., 2007; Brienen et al., 2015; Schimel, Stephens and Fisher, 2015). The aDGVM2 also supports these findings i.e., increasing canopy cover and woody biomass under the $\mathrm{eCO}_{2}$ condition and agrees with the reported greening trend in South Asia during the last three decades (Wang et al., 2017). Elevated $\mathrm{CO}_{2}$ affects plants by increasing their photosynthetic rate, growth rate and water use efficiency, leading to an increase in biomass (Long et al., 2004; Norby and Zak, 2011). Increased photosynthetic rates under elevated $\mathrm{CO}_{2}$ are due to an increase in the rate of rubisco carboxylation for $\mathrm{C}_{3}$ plants, with a concurrent decrease of photorespiratory losses of carbon (Long et al., 2004). Due to the improved carboxylation efficiency, $\mathrm{C}_{3}$ plants can respond by reducing stomatal conductance, thereby reducing transpirational losses, improving leaf water status, water use efficiency, and favouring leaf area growth (Long et al., 2004; Norby and Zak, 2011). Evidence from both observation and modelling of forest dynamic suggests that combined effects of $\mathrm{eCO}_{2}$ and increased water use efficiency include increases in forest growth, canopy greening, wide spread increases in woody plant biomass and potential forest carbon sink. However, it is still unclear how the $\mathrm{CO}_{2}$ responses scale to the ecosystem level (Hickler, Rammig and Werner, 2015), and how nutrient limitation from the soil may influence ecosystem responses to $\mathrm{eCO}_{2}$. Körner (2015) argued that carbon from atmosphere can only be converted into biomass if other factors such as nutrients, temperature and water are not limiting. In addition, benefit of $\mathrm{eCO}_{2}$ can be down-regulated by broad scale forest die-off due to frequent drought and warmer temperature (Mcdowell et al., 2016; Choat et al., 2018), tree mortality due negative tree physiological responses and negative carbon balance and accelerated pest attacks. Rising background mortality rates combined with projected increases in intensity, frequency and duration of drought (Huang et al., 2016) increases the uncertainty regarding positive effect of $\mathrm{eCO}_{2}$.

In the long run, whether ecosystems act as carbon source or sink can be estimated using models that consider all factors that are relevant in the carbon cycle and its 
associated factors (Fatichi, Leuzinger and Körner, 2014; Körner, 2015). However, Terrer et al. (2019) showed that the global-scale response to $\mathrm{eCO}_{2}$ from experiments is similar to past changes in greenness (Piao et al., 2020) and biomass (Sitch et al., 2015) in response to $\mathrm{eCO}_{2}$. This suggests that $\mathrm{CO}_{2}$ will likely continue to stimulate plant biomass in the future despite the constraining effect of soil nutrients, however also argued that the empirical relationships with soil nutrients can be powerful for explaining large-scale patterns of $\mathrm{eCO}_{2}$ responses, despite ecosystem-level uncertainties. According to our simulations we can conclude that natural vegetation of South Asia likely will remain a carbon sink in the future (Figure 3.5).

\subsubsection{Impact of climate change and fixed $\mathrm{CO}_{2}$ on biomes and biomass}

Under both $\mathrm{fCO}_{2}$ scenarios, the spatial distribution of savanna areas remained in its contemporary state. Central India and the Deccan Plateau showed a transition of deciduous forest to savanna, because forest canopy opened up due to tree mortality caused by increasing temperature and reduced MAP. This indicates that plants experience temperature and drought stress under fixed $\mathrm{CO}_{2}$. These stresses were compensated by $\mathrm{CO}_{2}$ fertilization in $\mathrm{eCO}_{2}$ scenarios where the aDGVM2 simulated increased biomass and woody encroachment in areas affected by climate-induced dieback in $\mathrm{fCO}_{2}$ simulations. This aDGVM2 behaviour agrees with results presented by Lapola, Priess and Bondeau, (2009) who modelled biome shifts from forest to savanna in absence of $\mathrm{CO}_{2}$ fertilization for the Amazon region. Changes in precipitation regimes are likely to have a strong influence particularly in arid and semi-arid regions, such as grasslands (Verstraete, Scholes and Smith, 2009). The complex interactions of interannual precipitation variability and precipitation seasonality can result in rapid ecosystem transitions (e.g., between alternative stable states with high and low vegetation biomass; Holmgren and Scheffer, 2001). The decrease in simulated AGBM after MAT increases beyond $23.5^{\circ} \mathrm{C}$ under $\mathrm{fCO}_{2}$ scenarios can be explained by the longer exposure of vegetation to temperatures beyond the optimum temperature range of $\mathrm{C}_{3}$ photosynthesis during the main growing season. This effect was further enhanced by decreasing MAP and the absence of $\mathrm{CO}_{2}$ fertilization. This implies that the increase in MAT above $23.5^{\circ} \mathrm{C}$ together with weak $\mathrm{CO}_{2}$ fertilization would have negative consequences for carbon sequestration. The sensitivity of biomass to temperature and $\mathrm{CO}_{2}$ change has been investigated in many studies (Norby and Luo, 2004; Song et al., 
2019; Sperry et al., 2019). A meta-analysis by Lin et al. (2010) showed that warming significantly increased biomass by $12.3 \%$ (with a $95 \%$ confidence interval 450 of 8.4 $16.3 \%$ ) across all the terrestrial plants included. This observation is consistent with our model results. Biomass showed a positive relation with MAT which did not change with mean annual precipitation or experimental duration or $\mathrm{CO}_{2}$ enrichment (Lin, Xia and Wan, 2010). These findings are also supported by previous studies by Rustad et al. (2001), Walker et al. (2006), and Dormann and Woodin (2002) which have revealed that warming generally increases terrestrial plant biomass, indicating enhanced terrestrial carbon uptake via plant growth. Previous modelling studies using Biome-BGC 455 (Running and Hunt, 1993), Century (Parton et al., 1993), and TEM (Tian et al., 1999) have shown an increase in productivity when both climate change and $\mathrm{CO}_{2}$ effects were considered. However, the increase was smaller when only climate change effects were considered and both Biome-BGC and TEM suggest that without $\mathrm{CO}_{2}$ fertilization, average productivity would decline relative to current annual average as shown by our result (Figure 3.6d). This suggests complexity and challenges in seeking general patterns of terrestrial plant growth in a future warmer climate condition. It also implies that we need a better understanding of impacts of heat stress on vegetation and how it interacts with drought and $\mathrm{CO}_{2}$ fertilization. It is also unclear to what degree thermal acclimation may counteract some of the negative effects on plant growth caused by higher temperatures (Lombardozzi et al., 2015).

\subsubsection{Impact of climate change and $\mathrm{CO}_{2}$ change on climatic niches of biomes}

Elevated $\mathrm{CO}_{2}$ has a major impact on the climatic niche space of biomes. Our simulations showed forest invasion into the niche space currently occupied by savanna by the end of the century. The expansion of forests to drier areas corresponds to a widening of their climate niche space under $\mathrm{eCO}_{2}$. This expansion is mainly driven by $\mathrm{eCO}_{2}$ is corroborated by the fact that in absence of $\mathrm{CO}_{2}$ fertilization the climatic niche of biomes is stable, i.e., biomes occupy the same niche space under current and future conditions. These findings imply that the bioclimatic boundaries used to define biome niche space are not static, but are specific for given $\mathrm{CO}_{2}$ levels. Therefore, the thresholds of the Whittaker's biomes need to be redefined for a high- $\mathrm{CO}_{2}$ world such that they encompass the altered climatic envelopes of biomes under elevated $\mathrm{CO}_{2}$ in future (Figure 3.7). The shift in niche space can be attributed to the shift in plant communities caused 
by the combined effect of climate change and elevated $\mathrm{CO}_{2}$, which increases plant water use efficiency allowing them to grow under drier conditions. These community shifts can also lead to change the characteristics of biomes by altering community structure and ecosystem functions (Chapin et al., 1997).

\subsubsection{Effect of $\mathrm{CO}_{2}$ on $\mathrm{ET}$ and its interaction with climate change}

Climate change has direct effects on hydrological processes (Liu et al., 2008). ET and water deficit influence plant productivity and distribution (Stephenson, 1998). Higher biomass coincided with increased absolute amounts of $\mathrm{ET}$ for $\mathrm{eCO}_{2}$ scenarios in some parts of the study region under both RCPs by the end 21st century (Figures 3.5, S3.7). This change can be attributed to higher leaf biomass accumulated in plants enabled by increased photosynthetic efficiency under $\mathrm{eCO}_{2}$. The higher amount of leaf biomass offsets the water-saving effect caused by reduced stomatal conductance due to improved water use efficiency under $\mathrm{eCO}_{2}$ scenarios and resulted in reduced ET per unit leaf biomass (Warren et al., 2011). Our results showed that the strength of the $\mathrm{CO}_{2}$ fertilization effect is relevant when attempting to determine $\mathrm{E}_{\text {biome }}$ at biome level during the 21 st century.

Biome-specific ET decrease was less pronounced under RCP4.5 due to a lower concentration of atmospheric $\mathrm{CO}_{2}$ compared to $\mathrm{RCP} 8.5$. Our simulated decrease in ET in response to climate change and increasing $\mathrm{CO}_{2}$ concentration agrees with Kergoat et al. (2002) who have reported decreased ET under elevated $\mathrm{CO}_{2}$ concentration in a chamber experiment. However, reduced ET under $\mathrm{eCO}_{2}$ can reduce regional-scale atmospheric humidity and thereby enhance the vapor pressure deficit (VPD), between leaves and atmosphere, a driving force for water loss, which may partially counteract $\mathrm{CO}_{2}$-induced reduction of ET due to decreased stomatal conductance. Due to stomatal closure, photosynthetic rates under soil water stress conditions decline in aDGVM2 when atmospheric VPD increases. Projected increase in air temperature also increases the saturated water vapour pressure. As a result, VPD will increase, given that increase in actual vapor pressure is limited by soil water availability whereas the increase in saturated vapor pressure is not (Yuan et al., 2019) and potential evapotranspiration will increase with temperature (Warren et al., 2011). As future climate projections vary spatially and temporally, there was high model uncertainty on how ET will respond to changes in precipitation and temperature. 


\subsubsection{Implication of the projected change for conservation}

Changes in biome types imply changes in biodiversity, ecosystem function and productivity. Each biome is characterized by a range of distinctive ecological processes and functions. For instance, distribution of forest ecosystem in the mountains is largely regulated by the altitude and climatic factor (Saikia et al., 2017). They have high species richness and needed to be protected from the ever-increasing anthropogenic pressure and climate change. Open biomes such as grassland and savanna support high biodiversity (Parr et al., 2014). Pronounced increases in tree density in grasslands and savannas will alter vegetation structure and reduce grassland biodiversity. Such changes will negatively affect savanna-specific ecosystem services such as grazing potential, tourism and wildlife habitat availability (Parr, Gray and Bond, 2012). The threat posed to the biodiversity of Asian savannas by climate change is aggravated by inadequate management policies that misinterpret them as degraded forest (Ratnam et al., 2016). In this context, management policies aim to afforest open biomes, although paleoecological evidence indicates that these open biomes are not degraded forest but ancient ecosystems (Ratnam et al., 2016; Kumar, Pfeiffer, Gaillard, Langan, Martens, et al., 2020). Moreover, increased woody cover can negatively affect water resources in the semi-arid regions of the study area. Acharya et al. (2018) have shown that increased woody cover hinders the downward movement of water causing increased water inception which have negative effects on ground water recharge. It is therefore necessary to control the abundance of woody plants in semi-arid regions to control stream flow and enhance groundwater recharge (Bednarz et al., 2001).

In South Asia, biodiversity hotspots have a very unique topography, where climate varies strongly over short distances. As global biodiversity hotspots, mountain forest ecosystems in the Western Ghats, the Himalayas and north-eastern part of the study area (Indo-Myanmar) are particularly vulnerable to climate change (Myers et al., 2000) and need targeted management action to mitigate adverse effects. Conservation of these hotspots requires consideration of many different attributes of plant communities, ecosystems, landscapes, and plant diversity, how they will change, and how their ecosystem services are valued.

Conservation methods and policies that can accommodate minimal losses of ecosystem services and provide robust strategies to mitigate climate change impacts 
should be developed and implemented. In this context, DGVMs facilitate the exploration of vegetation-climate interactions by providing detailed results for different management and climate scenarios. Such an exploration of different possible scenarios is necessary to develop optimized mitigation and conservation strategies for protected areas in biodiversity hotspots. The value of DGVM modelling results lies in their potential to provide insights into multiple future trajectories. Based on the most likely trajectories, the results can be used to tailor best-practice strategies for decision makers that need to manage conservation areas or protected areas (Boulangeat et al., 2012).

\subsubsection{Limitations of this modelling study}

Our simulation results are constrained by the model formulation and the assumptions underlying aDGVM2. Disagreement between model results and data used for benchmarking can be attributed to the fact that the aDGVM2 simulates potential natural vegetation whereas remote sensing products integrate land use. This implies that enhancing the model to simulate observed land cover patterns would require additional information on anthropogenic impacts. Anthropogenic activities such as deforestation, habitat conversion and urbanization can modify the interactions between climate, plant communities and biomes (Hansen et al., 2001).

In addition, data-model disagreement can be explained by model uncertainties and processes currently not considered in aDGVM2. For instance, aDGVM2 uses carbon allocation parameters that are not easily measurable in the field, which limits the evaluation of simulated mechanisms. The model currently does not account for carbon that plants invest into nutrient acquisition (e.g. mycorrhiza) or into defences against predation and pathogens (Zemunik et al., 2015). There is insufficient ecophysiological data from the study region, required for parameterization of trait ranges used to simulate rgional plant communities (Kumar and Scheiter, 2019). The complexity of the interactions between global change and biomes as well as bio- diversity is difficult to model in absence of such data. While the model currently capture the more optimistic effects related to $\mathrm{CO}_{2}$ fertilization and temperature, associated mortality reasons such as pests attack, heat damage to plant tissues, etc are insufficiently represented in the models. The low resolution of input data both soil and climate data also limits the model's capability to capture high resolution regional heterogeneity in vegetation distribution. Further, the strength of $\mathrm{CO}_{2}$ fertilization modelled in aDGVM2 may be overestimated 
because the effect of nutrient limitation on productivity is not included in this version of aDGVM2 limitation (Körner et al., 2005; Terrer et al., 2018). Despite these caveats, we are nonetheless confident to capture general patterns of future global change and its consequences for biomes and their boundaries in South Asia.

\subsection{Conclusion}

The model reproduced the contemporary distribution of biomes, biomass, evapotranspiration and tree height. We investigated the impact of $\mathrm{eCO}_{2}$ and climate change on South Asian biomes and found that climate change and $\mathrm{CO}_{2}$ fertilization in combination are substantial drivers of biome change, and that elevated $\mathrm{CO}_{2}$ concentrations altered the climatic envelope of biomes in addition to causing increases in biomass, tree height and canopy cover. Continued biomass increase indicates that South Asia's natural vegetation will likely remain a carbon sink in the 21 st century. Our results also imply that woody encroachment poses threat to open biomes and causes transition of savanna biomes to deciduous forest in the future. The savanna biome is important in the context of biodiversity conservation. We showed that bioclimatic niches of biomes are not static, but are specific for given $\mathrm{CO}_{2}$ concentrations. We therefore argue that Whittaker plots used to illustrate niches of biomes need to be adjusted for future climate condition. We also found that simulated decrease in biomass-specific ET is more pronounced in scenarios with $\mathrm{eCO}_{2}$ than in scenarios with $\mathrm{fCO}_{2}$, which indicates that water use efficiency will likely increase due to $\mathrm{CO}_{2}$ fertilization.

The biome transitions simulated under $\mathrm{eCO}_{2}$ and changing climate indicate the need to adjust ecosystem management, mitigation strategies, and conservation policies for protected areas to allow targeted long-term management. To understand the significance of ecological responses to climate change, it is essential to improve and expand biological monitoring activities (Loreau et al., 2001). To achieve this, the most vulnerable biomes that we identified in this study could be proposed as high priority targets for programs that monitor vegetation-climate interactions, productivity and biodiversity (Proença et al., 2017). 
Chapter 3-Climate change and elevated $\mathrm{CO}_{2}$ favor forest over savanna under different future scenarios in South Asia

Code availability: The aDGVM2 code as well as scripts to conduct the model experiments and analyse the results is available upon request. Please contact any of the authors.

Competing interests: The authors declare that they have no conflict of interest.

Financial support: SS and DK thank the Deutsche Forschungsgemeinschaft (DFG) for funding (Emmy Noether grant SCHE 1719/2-1). MP acknowledges funding by the German Federal Ministry of Education and Research (BMBF, SPACES2 initiative, 'SALLnet' project, grant 01LL1802B). 


\section{SUPPLEMENTARY INFORMATION \\ aDGVM2 model description}

The aDGVM2 is an individual-based dynamic vegetation model that simulates growth, reproduction and mortality of individual plants at representative 1 ha stands. The model is process-based and represents physiological, phenological and demographic processes. It integrates from the leaf level to the plant level and from there to the community or stand level. Simulation results can be used to aggregate communities on yet larger spatial scales, for example to derive biomes. To simulate leaf-level ecophysiological processes the Collatz et al. (1991, 1992) implementation of the Farquhar photosynthesis scheme Farquhar et al. (1980), combined with the Ball et al. (1987) implementation of stomatal conductance. While in previous model versions, leaflevel ecophysiological rates were calculated at stand-level ignoring individual-specific physiological differences, the updated model version used in this study, calculates leaflevel ecophysiological rates at a daily time resolution for each individual plants (also see Section 3.2.2). The calculation of the $\mathrm{CO}_{2}$ compensation point (gammastar) depicts the dependency of carboxylation vs. oxygenation as a function of oxygen partial pressure and temperature (the latter via a $\mathrm{Q}_{10}$-function), and the $\mathrm{CO}_{2}$ compensation point is then used further to determine Je (electron transport-limited photosynthesis, this also takes into account photosynthetically active radiation, i.e., PAR) and $\mathrm{J}_{\mathrm{c}}\left(\mathrm{CO}_{2}\right.$ concentration limited photosynthesis, this also accounts for temperature-dependent $\mathrm{V}_{\mathrm{cmax}}$ ). In the aDGVM2 version developed for this study, Vcmax, the maximum carboxylation velocity is temperature-dependent (Equation 4) and reaches a peak around $37^{\circ} \mathrm{C}$ for $\mathrm{C}_{3}$ plants and $42^{\circ} \mathrm{C}$ for $\mathrm{C}_{4}$ plants. Beyond the temperature optimum, $\mathrm{Vcmax}$ declines at higher temperatures. This mimics the combined effect of decreasing enzyme activity due to the increased competitory binding of $\mathrm{O}_{2}$ at higher temperatures and eventually enzyme degradation at very high temperatures. Effects caused by changing atmospheric $\mathrm{CO}_{2}$ concentrations and rising temperatures, including changes in carboxylation vs. oxygenation, are therefore explicitly captured by the implemented photosynthesis scheme. In addition, effects of water limitation on stomatal conductance are represented by the Ball et al. (1987) implementation of stomatal conductance that ties photosynthesis to stomatal conductance via a diffusion-gradient definition.

The design of aDGVM2 allows tracking of state variables such as biomass, height, leaf area and photosynthetic rates of individual plants. In aDGVM2, each plant is 
characterized by a specific and potentially unique combination of trait values that influence how a plant performs under given biotic and abiotic conditions. It allows plant communities to adapt to their environment by dynamically changing their trait composition constrained by trade-offs between traits. These traits describe plant type (grassy or woody), leaf characteristics (specific leaf area, leaf longevity), leaf phenology (evergreen or deciduous), hydraulic characteristics (risk of xylem cavitation), plant architecture (carbon allocation strategy, root and crown shape, wood density), response to fire, reproduction and mortality (Scheiter et al., 2013; Langan et al., 2017). The aDGVM2 implements plant physiology models typically used in DGVMs (Prentice et $a l ., 2007)$. Fire systematically removes aboveground grass biomass while aboveground tree biomass removal is related to tree height (Higgins et al., 2008; Scheiter and Higgins, 2009). Plants with trait combinations that allow sufficient growth and reproduction rates can produce seeds and contribute their trait values to the community trait pool. Seeds can randomly mutate or exchange trait values, thereby allowing recombination within the community trait pool. Seeds are randomly drawn from the community trait pool and added to the plant population as seedlings. Plants with insufficient performance fail to contribute seeds to the seed bank and disappear from the population. Plant growth is constrained by light and water competition. Light competition is simulated by considering the impacts of neighbouring plants on the light available to a target plant Water competition is simulated via water uptake of plants from a common layered soil water pool. The probability of an individual's mortality increases if its annual carbon balance is negative. The aDGVM2 also includes a representation of shrubs as multistemmed woody plants, based on the stem number of individual woody plants as dynamic trait, which emerge as adaption to dry conditions (Gaillard et al., 2018). This trait allows simulation of shrubs vs. trees based on a functional trade-off between augmented accesses to soil water resources vs. height growth. It simulates shrubs as multi-stemmed woody plants. We define all woody individuals with a stem number between one and three as trees, whereas individuals with more than three stems are categorized as shrubs. The classification of individuals into these two categories is done a post periori, based on the model results. Stem numbers in a woody plant are emerging based on water availability, light availability and fire activity. Rapid height growth is characteristics of single-stemmed trees whereas augmented efficiency of water uptake due to higher sapwood area per unit of woody biomass is characteristic for multi-stemmed shrubs. 
Table S 3.1 List and description of traits that are optimized by the genetic optimization algorithm during model simulation. Values for trees and $C_{4}$ grasses were taken from Langan et al. (2017). C $C_{3}$ grasses were included for this study and values of $\mathrm{C}_{4}$ grasses were taken for model parametrization. ' $n a$ ' indicates that this trait is not used for grasses.

\begin{tabular}{|c|c|c|c|c|c|c|}
\hline \multirow[t]{2}{*}{ Description of traits } & \multicolumn{2}{|c|}{ Woody } & \multicolumn{2}{|c|}{$\mathrm{C}_{4}$-grass } & \multicolumn{2}{|c|}{$\mathrm{C}_{3}$-grass } \\
\hline & $\min$ & $\max$ & $\min$ & $\max$ & $\min$ & $\max$ \\
\hline $\begin{array}{l}\text { Matric potential at } 50 \% \text { loss of } \\
\text { conductance }\end{array}$ & -3 & -0.2 & -3 & -0.2 & -3 & -0.2 \\
\hline Allocation to roots & 0.2 & 0.4 & 0.2 & 0.8 & 0.2 & 0.8 \\
\hline Allocation to leaves & 0.35 & 0.5 & 0.2 & 0.8 & 0.2 & 0.8 \\
\hline Allocation to stem & 0.25 & 0.35 & 0 & 0 & 0 & 0 \\
\hline Allocation to bark & 0.001 & 0.05 & 0 & 0 & 0 & 0 \\
\hline Allocation to storage & 0.1 & 0.4 & 0.1 & 0.4 & 0.1 & 0.4 \\
\hline Allocation to reproduction & 0.05 & 0.2 & 0.05 & 0.2 & 0.05 & 0.2 \\
\hline $\begin{array}{l}\text { Phenology (rain/summer } \\
\text { green, evergreen) }\end{array}$ & 0 & 1 & 0 & 1 & 0 & 1 \\
\hline $\begin{array}{l}\text { Phenology (deciduous or } \\
\text { evergreen ) }\end{array}$ & 0 & 1 & 1 & 1 & 1 & 1 \\
\hline $\begin{array}{l}\text { Rain threshold for plant } \\
\text { activity }\end{array}$ & -3 & -0.2 & -3 & -0.2 & -3 & -0.2 \\
\hline $\begin{array}{l}\text { Rain threshold for plant } \\
\text { dormancy }\end{array}$ & -3 & -0.2 & -3 & -0.2 & -3 & -0.2 \\
\hline $\begin{array}{l}\text { Light threshold for plant } \\
\text { activity }\end{array}$ & 0.1 & 2 & 0.1 & 2 & 0.1 & 2 \\
\hline $\begin{array}{l}\text { Light threshold for plant } \\
\text { dormancy }\end{array}$ & 6 & 14 & 6 & 14 & 6 & 14 \\
\hline $\begin{array}{l}\text { Parameter for height } \\
\text { calculation }\end{array}$ & 0.4 & 0.4 & na & na & na & na \\
\hline $\begin{array}{l}\text { Parameter for height } \\
\text { calculation }\end{array}$ & 0.4 & 0.5 & na & na & na & na \\
\hline Parameter for root form & 0.01 & 10 & 0.01 & 10 & 0.01 & 10 \\
\hline Parameter for root form & -1 & 20 & 1 & 20 & 1 & 20 \\
\hline Maximum rooting depth & 0.3 & 3.6 & 0.3 & 2.4 & 0.3 & 2.4 \\
\hline Seed weight & 0.001 & 0.05 & 0.001 & 0.05 & 0.001 & 0.05 \\
\hline Parameter for canopy form & 21 & 25 & 20 & 60 & 20 & 60 \\
\hline $\begin{array}{l}\text { Storage to stem allocation } \\
\text { after fire }\end{array}$ & 0.2 & 0.4 & 0 & 0 & 0 & 0 \\
\hline $\begin{array}{l}\text { Storage to leaf allocation after } \\
\text { fire }\end{array}$ & 0.6 & 0.9 & 0.6 & 0.9 & 0.6 & 0.9 \\
\hline Stem Count & 1 & 10 & 1 & 1 & 1 & 1 \\
\hline
\end{tabular}

${ }^{*}$ New parameters; ${ }^{\$}$ Changed parameters 
Chapter 3-Climate change and elevated $\mathrm{CO}_{2}$ favor forest over savanna under different future scenarios in South Asia

Table S 3.2 List and description of traits that are constant during model simulation and are not optimized by the genetic optimization algorithm. Values for trees and $C_{4}$ grasses were taken from Langan et al. (2017). C $C_{3}$ grasses were included for this study and values of $C_{4}$ grasses were taken for model parametrization. 'na' indicates that this trait is not used for grasses.

\begin{tabular}{|c|c|c|c|}
\hline Description of traits & Woody & $\begin{array}{l}\mathrm{C}_{4} \\
\text { Grass }\end{array}$ & $\begin{array}{l}\mathrm{C}_{3} \\
\text { Grass }\end{array}$ \\
\hline Mortality due to negative carbon balance & 0.3 & 0.2 & 0.2 \\
\hline Mortality due to low height & 0.1 & 0.05 & 0.05 \\
\hline Mortality due to mechanic instability & 10 & 5 & 5 \\
\hline Mortality due to mechanic instability & 6 & 6 & 6 \\
\hline $\begin{array}{l}\text { Topkill constants parameter } 1 \\
\text { (Higgins et al. 2012) }\end{array}$ & 1.48 & 0 & 0 \\
\hline $\begin{array}{l}\text { Topkill constants parameter } 2 \\
\text { (Higgins et al. 2012) }\end{array}$ & 3.30698 & 0 & 0 \\
\hline $\begin{array}{l}\text { Topkill constants parameter } 3 \\
\text { (Higgins et al. 2012) }\end{array}$ & 0.02618 & 0 & 0 \\
\hline Ball berry equation parameter 1 & 9 & 5.48 & 9 \\
\hline Ball berry equation parameter 2 & 0.01 & 0.02 & 0.01 \\
\hline Maintenance respiration parameter & 0.015 & 0.025 & 0.015 \\
\hline Growth respiration parameter & 0.35 & 0.35 & 0.35 \\
\hline Fraction of leaf biomass that respires & $1^{\$}$ & 0.01 & 0.01 \\
\hline Fraction of wood biomass that respires & $0.1^{\$}$ & 0.01 & 0.01 \\
\hline Fraction of root biomass that respires & 0.01 & 0.01 & 0.01 \\
\hline Parameter for respiration model & 0.218 & 0.218 & 0.218 \\
\hline $\mathrm{C}: \mathrm{N}$ ratio of woody biomass & 150 & 120 & 120 \\
\hline $\mathrm{C}: \mathrm{N}$ ratio of woody biomass & 60 & 120 & 120 \\
\hline $\begin{array}{l}\text { Lower temperature limits for efficient } \\
\text { carboxylation }\end{array}$ & $-10^{*}$ & $15^{*}$ & $-10^{*}$ \\
\hline $\begin{array}{l}\text { Upper temperature limits for efficient } \\
\text { carboxylation }\end{array}$ & $36^{*}$ & $45^{*}$ & $36^{*}$ \\
\hline
\end{tabular}

*New parameters; ${ }^{\$}$ Changed parameters 
(a)

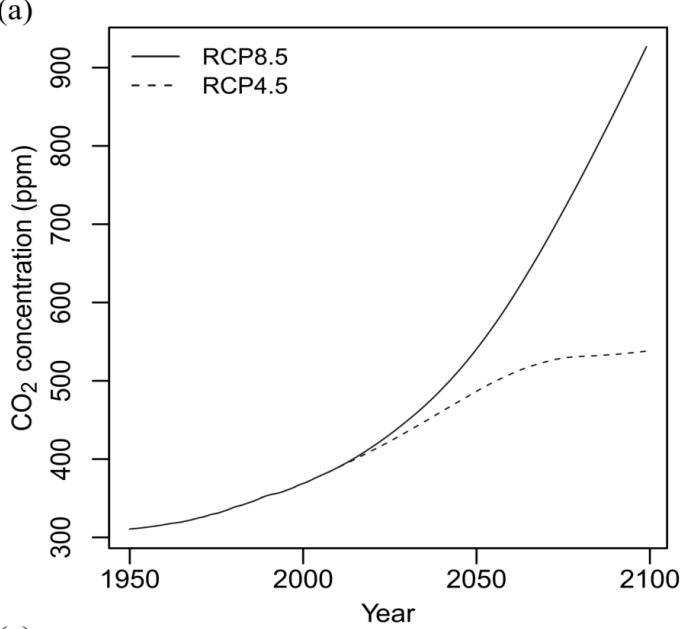

(c)

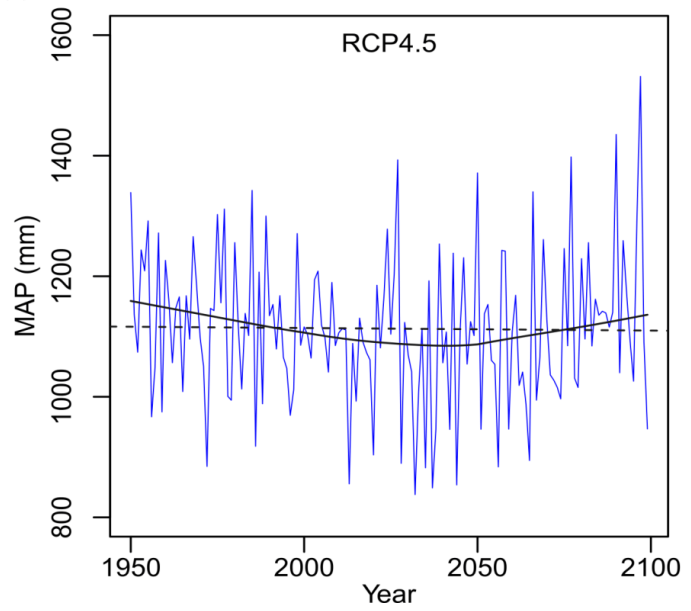

(b)

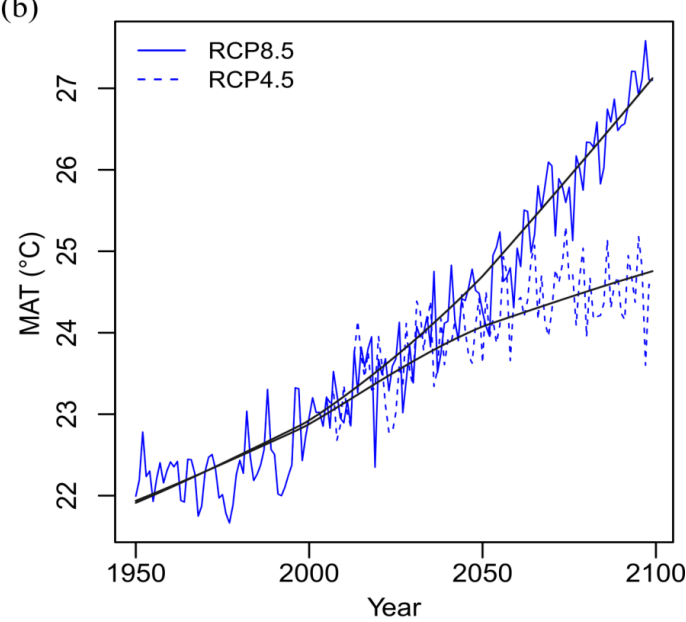

(d)

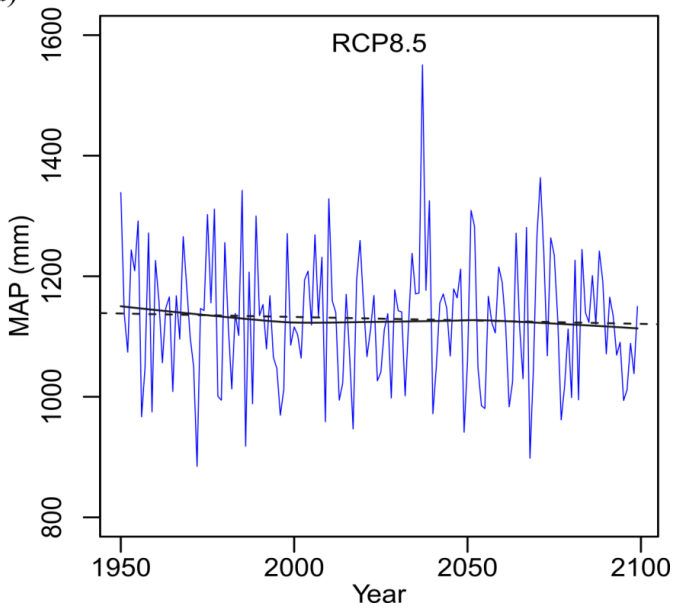

Figure S 3.1 Time series represent (a) $\mathrm{CO}_{2}$ concentration under $\mathrm{RCP} 4.5$ and RCP8.5; (b) mean annual temperature under RCP4.5 and RCP8.5; (c) mean annual precipitation for $R C P 4.5$ and (d) mean annual precipitation for RCP8.5 for South Asia between 1951 and 2099. In (b), (c) and (d) the black solid line represents a smoothed non-linear fit (LOWESS), and in (c) and (d) the black dashed line represents a linear smoothed fit (LOWESS) to the data. Mean annual precipitation and mean annual temperature were derived from GFLDM2M simulations 
Chapter 3-Climate change and elevated $\mathrm{CO}_{2}$ favor forest over savanna under different future scenarios in South Asia

(a)
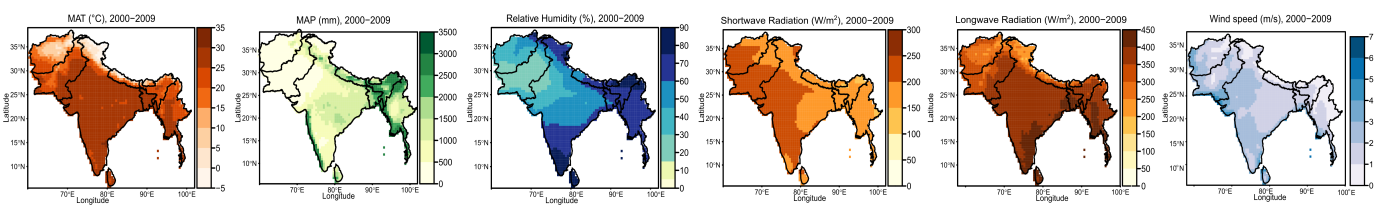

(b)
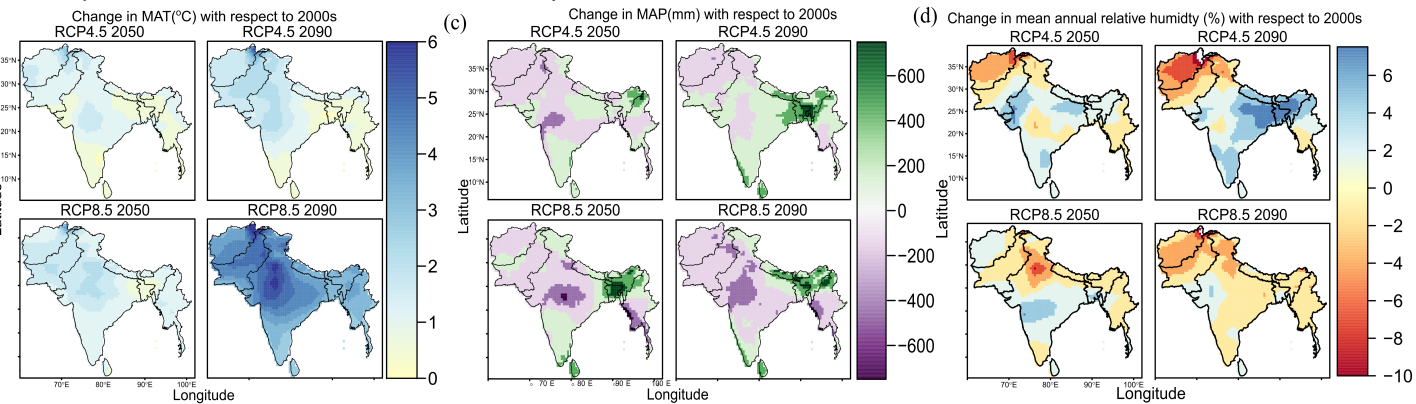

(e) Change in mean annual shortgwave radiation $\left(\mathrm{W} / \mathrm{m}^{2}\right.$

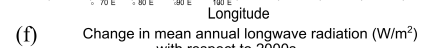

(g)
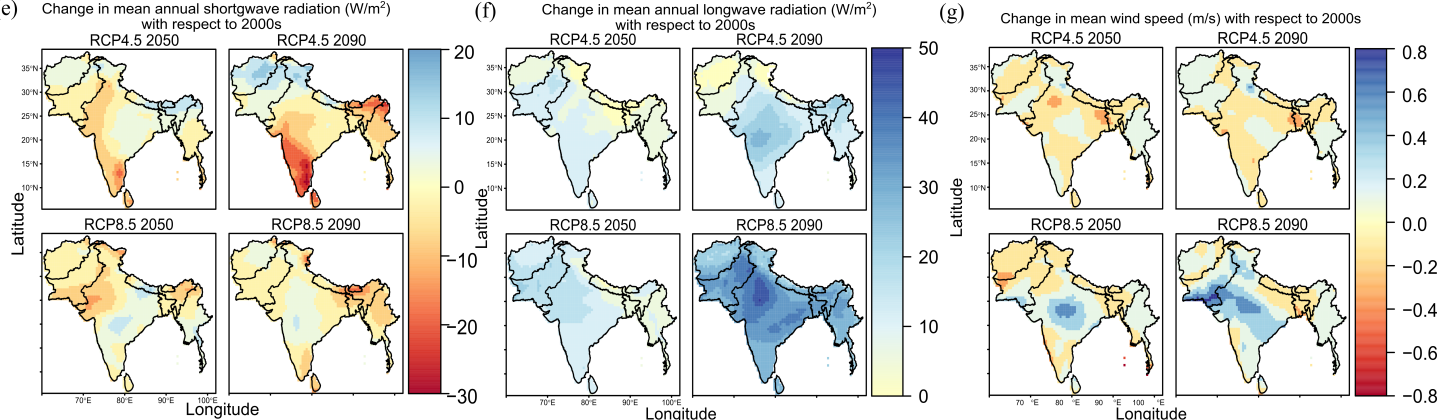

Figure S 3.2 (a) Baseline mean of the climate variables (2000-2009), projected change in (b) mean annual temperature (MAT), and (c) mean annual precipitation (MAP), (d) mean annual relative humidity, (e) mean annual short-wave radiation, (f) mean annual long-wave radiation and (g) mean annual wind speed until the 2050s and the 2090s, relative to the baseline (2000s-2009).

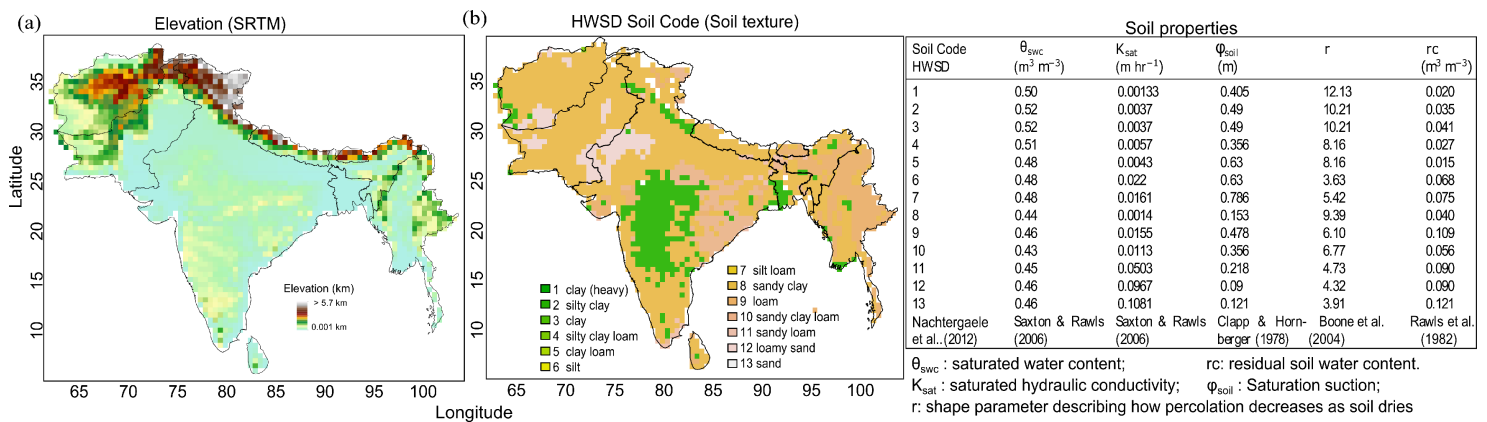

Figure S 3.3 (a) Shuttle Radar Topography Mission (SRTM) elevation data (Jarvis et al., 2008) and (b) spatial distribution of soil texture according to the Harmonized World Soil Database (HWSD soil code; Nachtergaele et al., 2009) and corresponding soil properties in the table, used in current study. 


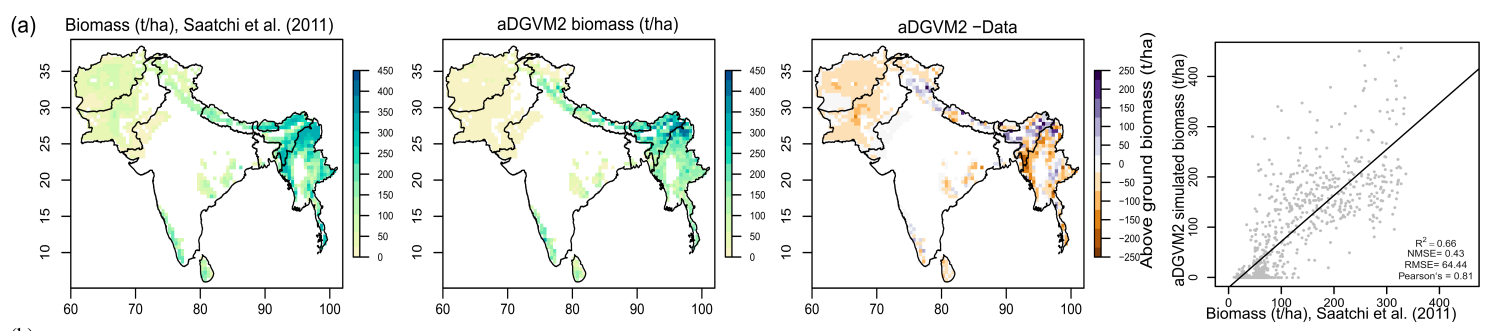

(b)
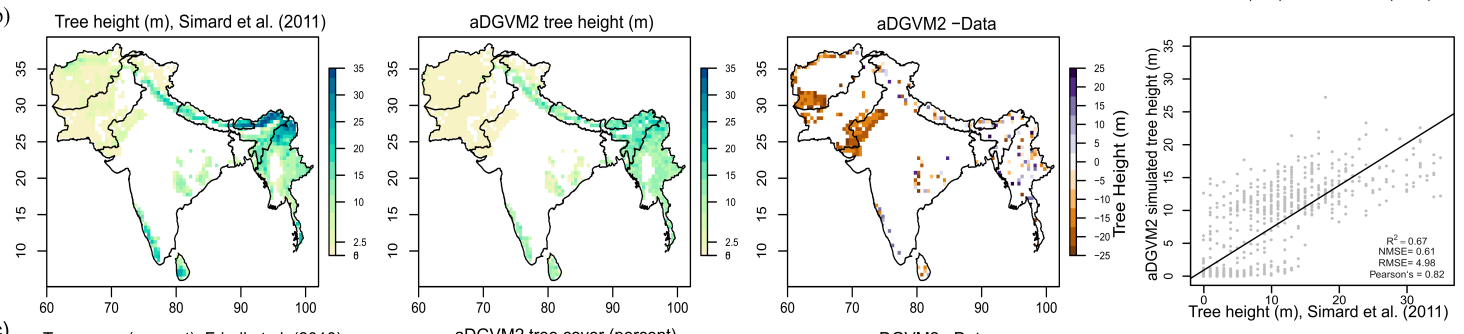

(c)
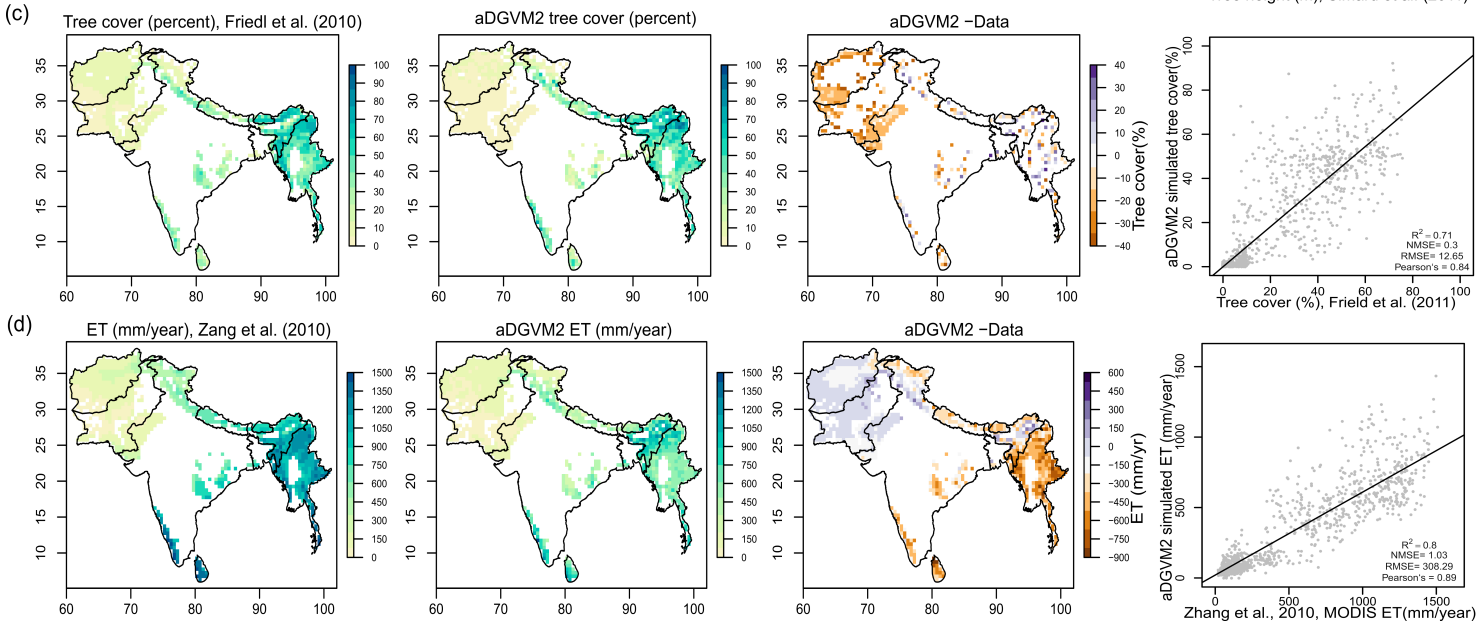

Figure S 3.4 Comparison between aDGVM2 results and remote sensing products when removing areas with more than 50\% land use cover for (a) simulated biomass and Saatchi et al. (2011) biomass, (b) simulated tree height and Simard et al. (2011), (c) simulated tree cover and Friedl et al. (2011) tree cover and (d) simulated evapotranspiration and Zang et al. (2010) evapotranspiration. In the figure the first column shows the remote sensing products, the second column shows aDGVM2 results and the third column shows the difference between simulation and data and the fourth column shows the scatter plot between simulated state variable and benchmarking data. NMSE and RMSE are normalized mean square error and root mean square error, respectively. In fourth column, each points represents one grid cell in the study region. 
Chapter 3-Climate change and elevated $\mathrm{CO}_{2}$ favor forest over savanna under different future scenarios in South Asia

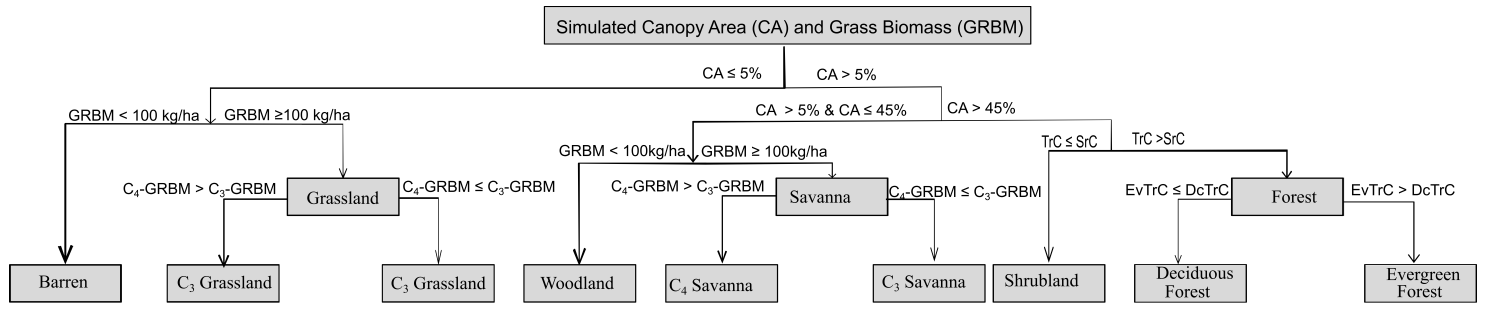

$\operatorname{TrC}=$ Canopy area of simulated trees (stem number $\leq 3) \quad$ EvTrC $=$ Canopy area of evergreen trees $\mathrm{SrC}=$ Canopy area of simulated shrubs (stem number $>3$ ) DCTrC = Canopy area of deciduous trees

Figure S 3.5 Flow chart illustrating classification of simulated vegetation into biomes using canopy area (CA) of different woody vegetation types and grass biomass (GRBM). Simulated stem numbers were used to distinguish between shrubs and trees
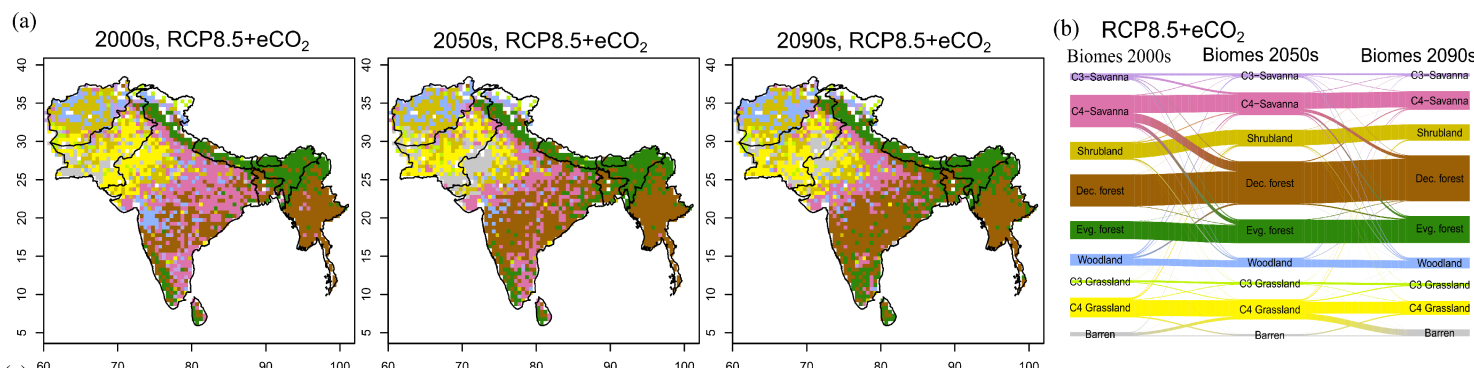

(c) ${ }^{60} \quad 2000 \mathrm{~s}, \mathrm{RCP} 8.5+\mathrm{fCO}^{90}$

2050s, $\stackrel{80}{\mathrm{RCP}} 8.5^{90}+\mathrm{fCO}_{2}$
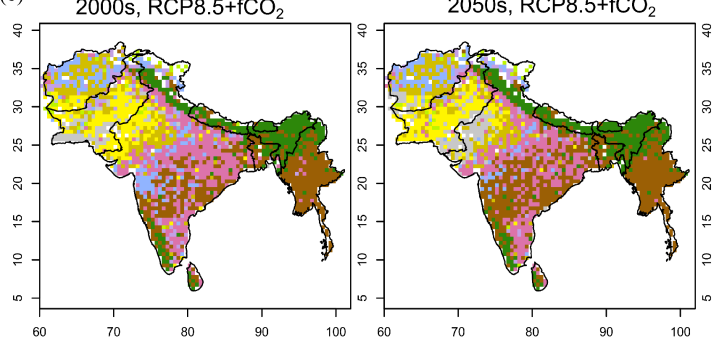

2090 s, $\mathrm{RCP} 8.5+\mathrm{fCC}_{2}^{90}$

(d) $\mathrm{RCP} 8.5+\mathrm{fCO}_{2}$

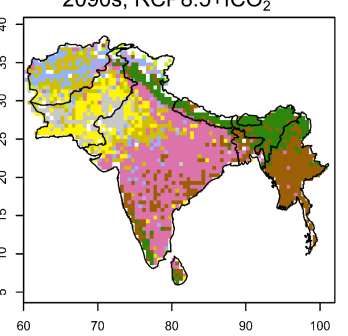

Biomes 2000s Biomes 2050s Biomes 2090

$\underset{\text { C3-savanna }}{\text { Biomes 2000s Biomes 2050s Biomes 2090s }}$

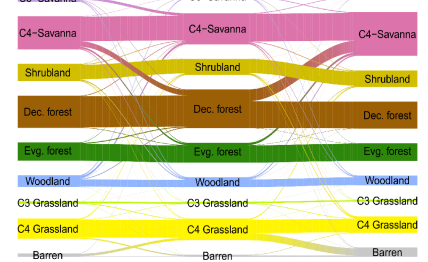

$\square$ Desertbarren $\square$ c4 Grassland $\square$ c3 Grassland $\square$ Woodland $\square_{\text {Evergreen forest }} \square$ Deciduous forest $\square$ shrubland $\square$ c4-Savanna $\square$ c3-Savanna

Figure S 3.6 Simulated biome distribution for the 2000s, 2050s and 2090s under (a) $\mathrm{RCP} 8.5+e \mathrm{CO}_{2}$ and (c) $\mathrm{RCP} 8.5+\mathrm{fCO}_{2}$, and Sankey diagrams showing the transition between biomes from the 2000s to the 2050s and the 2050s to the 2090s under (b) $\mathrm{RCP} 8.5+e \mathrm{CO}_{2}$ and (d) $\mathrm{RCP} 8.5+\mathrm{fCO}_{2}$. See Figure 3.4 for simulated biome distribution under RCP4.5 
Chapter 3-Climate change and elevated $\mathrm{CO}_{2}$ favor forest over savanna under different future scenarios in South Asia
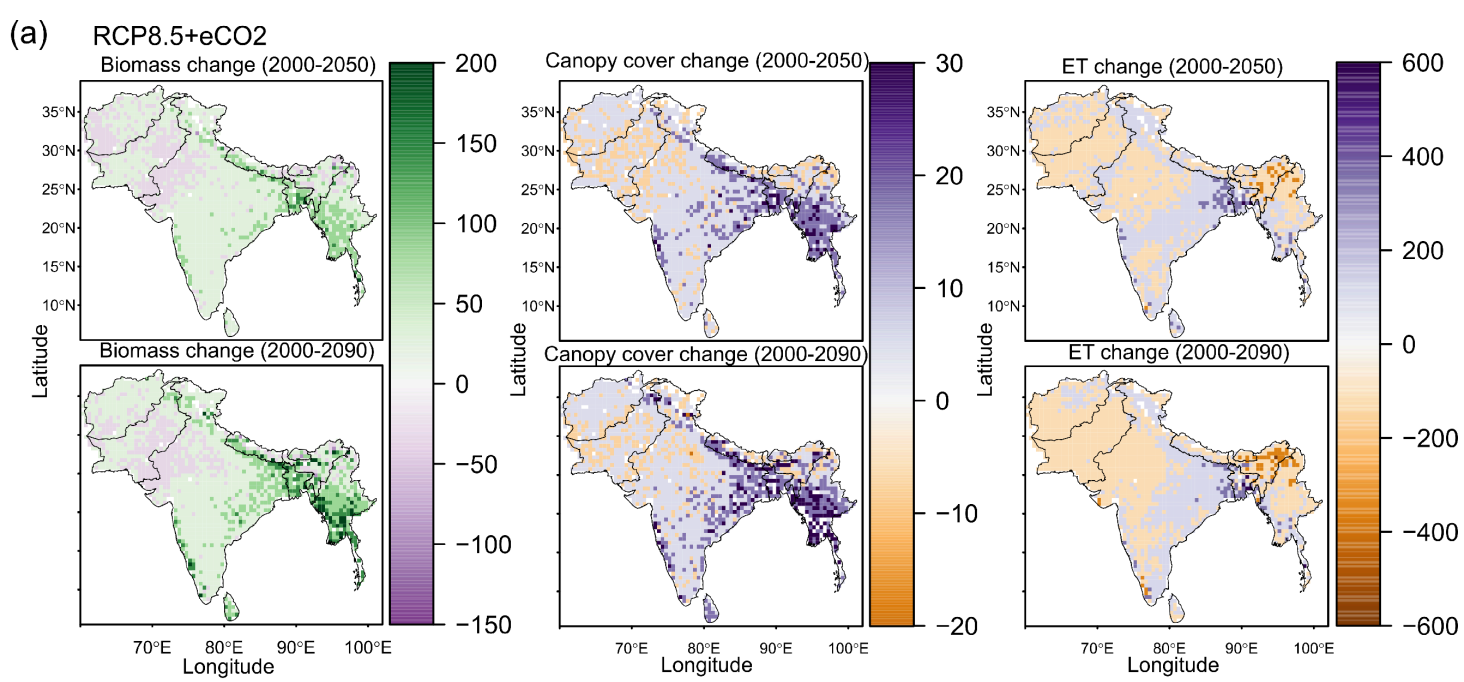

(b) $\mathrm{RCP} 8.5+\mathrm{fCO} 2$
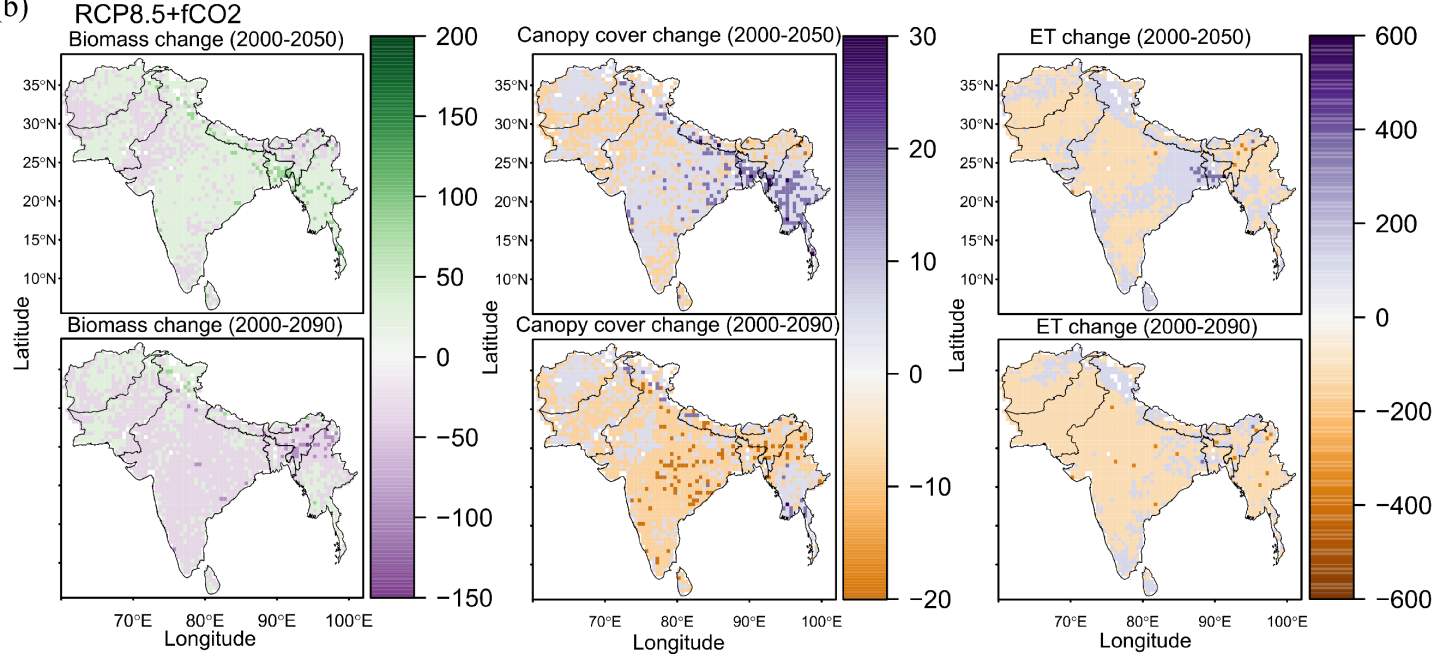

Figure S 3.7 Projected change in biomass, canopy area and evapotranspiration (ET) between the 2000s and 2050s, and between the 2000s and 2090s under (a) $\mathrm{RCP} 84.5+e \mathrm{CO}_{2}$ and (b) $\mathrm{RCP} 8.5+f C \mathrm{O}_{2}$. 
Chapter 3-Climate change and elevated $\mathrm{CO}_{2}$ favor forest over savanna under different future scenarios in South Asia
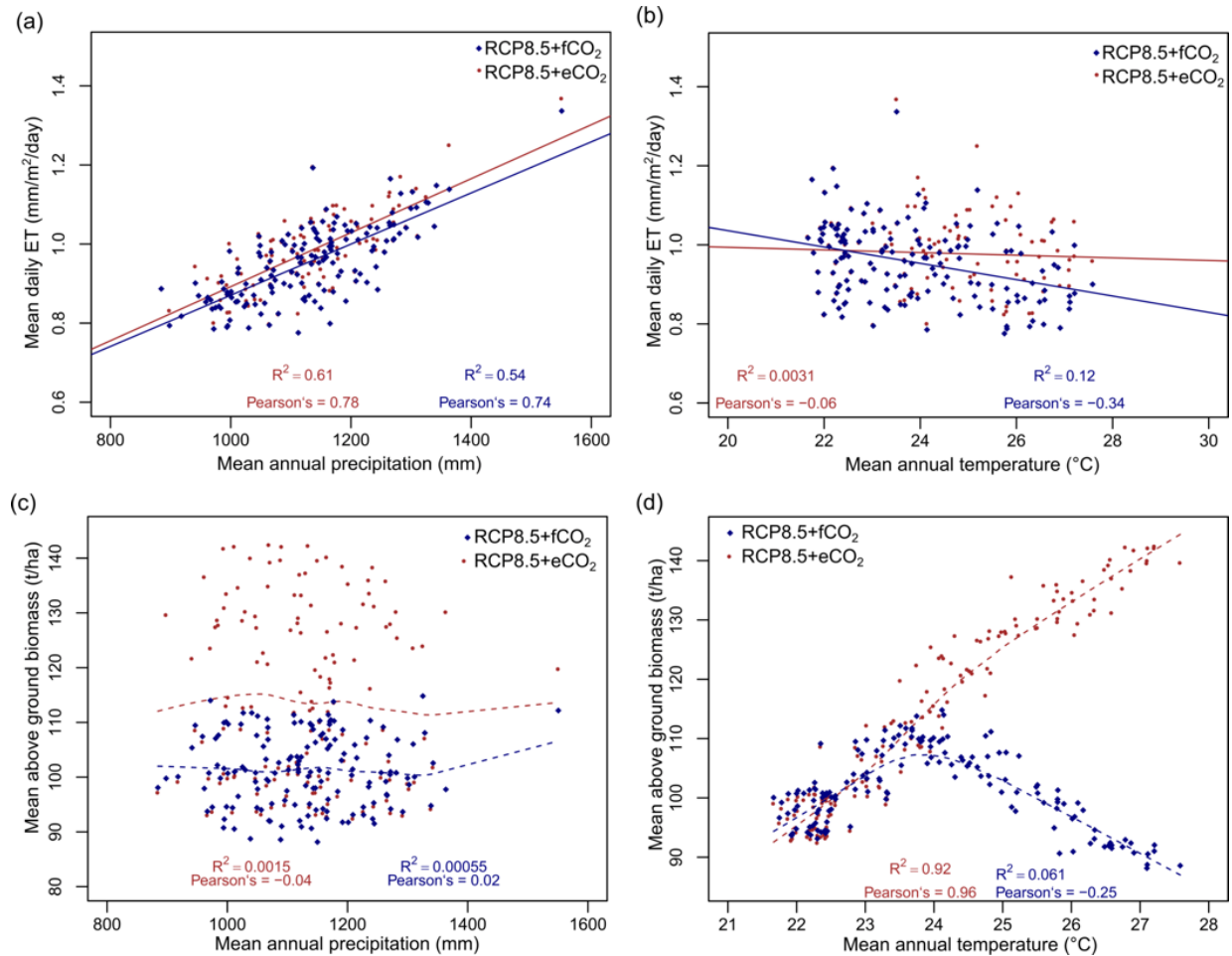

Figure S 3.8 Relationship between (a) evapotranspiration (ET) and mean annual precipitation (MAP), (b) ET and mean annual temperature (MAT), (c) mean above ground biomass and MAP and (d) mean above ground biomass and MAT under RCP8.5. The lines (both solid and dotted) in all figures represent the bestfit regression line. The dots represent spatially averaged ET $(a, b)$ and biomass (c, d) for each year from 1950 to 2099. See Figure 3.6 for results under RCP4.5.
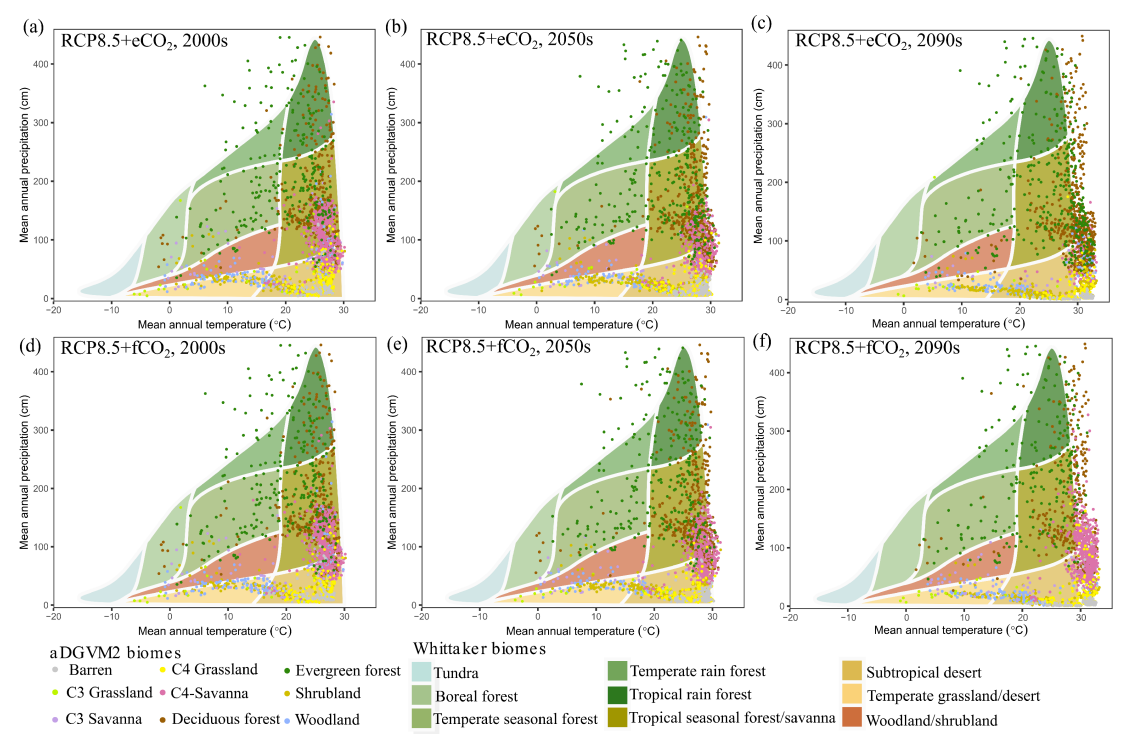

Figure S 3.9 Simulated climatic niches of biomes for the period of (a) 2000s, (b) 2050s and (c) 2090s under RCP8.5+eCO 2 and (d) 2000s, (e) 2050s and (f) 2090s under $\mathrm{RCP8.5}+\mathrm{fCO}_{2}$. The simulated biomes are overlaid on the climate envelopes of Whittaker's biomes and are plotted following Ricklefs (2008) and Whittaker (1975) 


\title{
CHAPTER 4
}

\section{CLIMATE CHANGE PROMOTES TRANSITIONS TO TALL EVERGREEN VEGETATION IN TROPICAL ASIA}

Simon Scheiter ${ }^{1}$, Dushyant Kumar ${ }^{1}$, Richard T. Corlett ${ }^{2}$, Camille Gaillard ${ }^{1}$, Liam Langan $^{1}$, Ralph Sedricke Lapuz ${ }^{2,3}$, Carola Martens ${ }^{1,4}$, Mirjam Pfeiffer ${ }^{1}$ and Kyle W. Tomlinson $^{2} \S$

${ }^{1}$ Senckenberg Biodiversity and Climate Research Centre (SBiK-F), Senckenberganlage 25, 60325 Frankfurt am Main, Germany

${ }^{2}$ Center for Integrative Conservation, Xishuangbanna Tropical Botanical Garden, Chinese Academy of Sciences, Menglun, Mengla, Yunnan, 666303, China

${ }^{3}$ University of the Chinese Academy of Sciences, Beijing, China

${ }^{4}$ Institute of Physical Geography, Goethe-University Frankfurt am Main,

Altenhoeferallee 1,

60438, Frankfurt am Main, Germany

\begin{abstract}
Vegetation in tropical Asia is highly diverse due to large environmental gradients and heterogeneity of landscapes. This biodiversity is threatened by intense land use and climate change. However, despite the rich biodiversity and the dense human population, tropical Asia is often underrepresented in global biodiversity assessments. Understanding how climate change influences the remaining areas of natural vegetation is therefore highly important for conservation planning. Here, we used the adaptive Dynamic Global Vegetation Model version 2 (aDGVM2) to simulate impacts of climate change and elevated $\mathrm{CO}_{2}$ on vegetation formations in tropical Asia for an ensemble of climate change scenarios. We used climate forcing from five different climate models for representative concentration pathways RCP4.5 and RCP8.5. We found that vegetation in tropical Asia will remain a carbon sink until 2099, and that vegetation biomass increases of up to $28 \%$
\end{abstract}

$\S$ This chapter and supplementary information were published in the journal Global Change Biology as "Scheiter, S, Kumar, D, Corlett, RT, et al. Climate change promotes transitions to tall evergreen vegetation in tropical Asia. Global Change Biology. 2020; 26: 5106- 5124, doi: 10.1111/gcb.15217."

Author contributions: D.K., S.S., K.W.T., R.T.C. and R.S.L conceived the study; DK included the changes to aDGVM2 for the study region, conducted model simulations runs; S.S. and D.K. analysed the data; D.K., L.L., M.P., C.M. and S.S. contributed to model development; S.S. led the writing with contributions from all co-authors. 
by 2099 are associated with transitions from small to tall woody vegetation and from deciduous to evergreen vegetation. Patterns of phenology were less responsive to climate change and elevated $\mathrm{CO}_{2}$ than biomes and biomass, indicating that the selection of variables and methods used to detect vegetation changes is crucial. Model simulations revealed substantial variation within the ensemble, both in biomass increases and in distributions of different biome types. Our results have important implications for management policy, because they suggest that large ensembles of climate models and scenarios are required to assess a wide range of potential future trajectories of vegetation change and to develop robust management plans. Furthermore, our results highlight open ecosystems with low tree cover as most threatened by climate change, indicating potential conflicts of interest between biodiversity conservation in open ecosystems and active afforestation to enhance carbon sequestration.

\section{Abbreviations:}

aDGVM2: adaptive dynamic global vegetation model version 2; RCP Representative Concentration pathways; ISIMIP: Inter-Sectoral Impact Model Intercomparison Project; SRTM: Shuttle Radar Topography Mission;

Keywords: aDGVM2, Biome shifts; climate change; $\mathrm{CO}_{2}$-fertilization; model ensemble; phenology; tropical Asia

\subsection{Introduction}

Tropical Asia includes seven of the 36 global biodiversity hotspots identified by Zachos and Habel (2011). These hotspots are characterized by high diversity and endemism, and they are threatened due to habitat loss (Hughes, 2017). Habitat and biodiversity loss in tropical Asia can be attributed to a variety of direct and indirect anthropogenic impacts. Direct impacts include land-cover change, for example by deforestation, conversion to cropland, plantations or other agricultural land use, and associated fragmentation (Hughes, 2017). Indirect impacts include regional and global climate change caused by anthropogenic emissions of greenhouse gases such as carbon dioxide $\left(\mathrm{CO}_{2}\right)$, methane $\left(\mathrm{CH}_{4}\right)$ and nitrous oxide $\left(\mathrm{N}_{2} \mathrm{O}\right)$. These changes in the composition of the atmosphere and changes in radiative forcing are the drivers of climate change (IPCC, 2018). Atmospheric $\mathrm{CO}_{2}$ concentrations also directly influence plant 
growth and productivity (Chen et al., 2019; Piao et al., 2020) and, along with climate change, broad-scale distribution patterns of species, biomes and biodiversity.

Indirect impacts will likely have the largest effects in remaining areas with intact vegetation that are protected from direct human impacts, such as legally protected areas. Yet, direct human impacts have already caused substantial losses of biodiversity in tropical Asia (Hughes, 2017). Many protected areas are under pressure by increasing human population and land use intensities in neighbouring buffer zones, or by changes in their protection status (Symes et al., 2016). Hannah et al. (2020) showed that species extinction risk in the tropics could be halved if $30 \%$ of the land surface were protected and climate change limited to $2^{\circ} \mathrm{C}$. Understanding indirect anthropogenic effects on undisturbed vegetation is therefore crucial to implement effective measures in conservation, land management and climate change mitigation.

Two important features of vegetation that can respond to climate change at local scale, and thereby influence large-scale patterns of vegetation distribution, carbon storage and biodiversity, are vegetation structure and plant phenology. Features of vegetation structure, such as woody cover, stem density, growth form and vegetation height, determine habitat suitability for animals (Tews et al., 2004; Smit and Prins, 2015) and link different trophic levels via biotic interaction networks (Walther, 2010; Schleuning et al., 2016). Vegetation structure and canopy characteristics also influence the near-surface microclimatic conditions, as well as albedo, surface roughness and partitioning of energy into sensible and latent heat fluxes (Ozanne et al., 2003; Bonan, 2008). These properties of the land surface couple biosphere, atmosphere and hydrosphere, and influence climate-vegetation feedbacks (Bonan, 2008; Zeng et al., 2017).

Plant phenology describes periodic life cycle events that are ultimately caused by seasonal and interannual variations in climate. It determines events such as leaf greenup, flowering and leaf senescence, and whether a plant is evergreen or a deciduous. Changes in phenology as a result of climate change have already been observed (Cleland et al., 2007; Buitenwerf, Rose and Higgins, 2015) and may have implications for biodiversity (Walther, 2010; Piao et al., 2019). Phenology influences biosphereatmosphere coupling through seasonal and intra-annual variations in albedo and biogeochemical fluxes (Bonan, 2008; Piao et al., 2019). 
Understanding the impacts of climate change on vegetation structure and phenology is essential to assess potential future vegetation dynamics, ecosystem functioning and to develop policy recommendations. Such an assessment requires (a) the capacity to predict plant growth and vegetation dynamics in response to climate conditions, atmospheric $\mathrm{CO}_{2}$ concentration, soil conditions and disturbance regimes; (b) estimates of the uncertainties associated with different climate change scenarios; and (c) a set of variables or vegetation classification schemes relevant for policy to track and quantify vegetation change.

Dynamic global vegetation models (DGVMs, Prentice et al., 2007) are widely used tools for simulation of vegetation dynamics and biogeochemical cycles. These models use ecophysiological principles to simulate vegetation dynamics at large spatiotemporal scales. DGVMs can include mechanistic representations of disturbances such as fire (Scheiter and Higgins, 2009; Hantson et al., 2016) or herbivory (Pachzelt et al., 2013; Pfeiffer et al., 2019), and biotic interactions such as competition for space, water, nutrients and light (Prentice et al., 2007). DGVMs simulate transient vegetation dynamics in response to fluctuating climate conditions and are often used as land surface schemes in general circulation models (GCMs, e.g. JSBACH, Reick et al., 2013). Conducting DGVM simulations for ensembles of climate change scenarios derived from different GCMs allows estimating potential future trajectories and to assess uncertainties. Variables and classification schemes for quantifying vegetation states and change can be tailored to specific research questions or specific study areas, or to procedures used for model testing. For example, basal area and vegetation height derived from field measurements can be used to quantify vegetation structure, eddy covariance measurements to quantify biogeochemical cycles, or biome distributions from remote sensing or modelling to quantify vegetation shifts. The selection of an appropriate set of variables is crucial, because it can influence whether a change is detected or not.

Despite the size and rich biodiversity of tropical Asia, this region remains underrepresented in global biodiversity assessments (Hughes, 2017) and in DGVM studies. While the region is included in global-scale DGVM simulations (e.g., Hickler et al., 2006; Sato, Itoh and Kohyama, 2007; Smith et al., 2014), studies explicitly focusing on this region are rare (Ravindranath et al., 2006; Chaturvedi et al., 2011; Kumar and Scheiter, 2019). Accordingly, important features of vegetation at regional scale might not be well represented in global-scale simulations. One feature in this regard is the Asian 
savanna. These ecosystems are often misinterpreted as degraded forest, with afforestation being considered as appropriate conservation policy (Ratnam et al., 2016; Kumar, Pfeiffer, Gaillard, Langan, Martens, et al., 2020). Models often simulate savanna areas as forest (Kumar and Scheiter, 2019).

A second feature not well represented in models is the distribution of deciduous and evergreen vegetation in mainland Southeast Asia. Due to rainfall seasonality, deciduous vegetation stretches from Myanmar to Vietnam, bordered by semi-evergreen and evergreen forests. This pattern is, for example, not represented in global simulations conducted with lund-potsdam-jena general ecosystem simulator (LPJ-GUESS) (Smith et al., 2014) or SEIB-DGVM (Sato, Itoh and Kohyama, 2007), but is simulated by an LPJGUESS version that includes a complex representation of hydrology (Hickler et al., 2006) and by a JSBACH version with variable traits (Verheijen et al., 2013). Representing this vegetation feature correctly is particularly important as changes in rainfall seasonality and an increasing frequency of droughts are predicted for tropical Asia (Hijioka et al., 2014; Zhang et al., 2016).

Here, we used a dynamic vegetation model, the adaptive Dynamic Global Vegetation Model version 2 (aDGVM2, Scheiter, Langan and Higgins, 2013; Langan, Higgins and Scheiter, 2017), to simulate current and future vegetation states in tropical Asia for an ensemble of the Coupled Model Intercomparison Project 5 (CMIP5) climate change projections provided by the Inter-Sectoral Impact Model Intercomparison Project (ISIMIP; Warszawski et al., 2014). To assess possible trajectories of future vegetation and quantify related uncertainties, we conducted simulations for an ensemble of two different representative concentration pathways (RCP4.5 and RCP8.5) and five different GCMs. We used different variables and classification schemes to track vegetation states and vegetation change under future climate conditions. We expected (a) that elevated $\mathrm{CO}_{2}$ will lead to higher woody biomass until 2099 due to $\mathrm{CO}_{2}$ fertilization, even in areas where precipitation decreases; (b) that these biomass changes will be associated with vegetation changes from shorter and deciduous vegetation towards taller and evergreen vegetation; (c) that variation within the simulated future vegetation states will be substantial due to variation within the ensemble of climate model projections, as well as stochastic effects in aDGVM2; and (d) that the area affected by vegetation change will be influenced by the variables used to track vegetation changes. In addition, we assessed 
how consideration of managed and cultivated land (Tuanmu and Jetz, 2014) modifies the area affected by climate change.

\subsection{Material and methods}

\subsubsection{Description of aDGVM2}

We used aDGVM2, an individual-based dynamic vegetation model that is based on concepts from community assembly theory and uses a functional trait approach. The aDGVM2 concept and a detailed model description are provided by Scheiter et al. (2013), Langan et al. (2017), and Kumar et al. (2020b). A short summary of the model description is provided in the Supporting Information. Model variables used in the analyses are described in the following paragraphs.

\subsubsection{Environmental forcing data}

We simulated vegetation for tropical Asia (South Asia, Southeast Asia, tropical China) for an ensemble of historic and future climate change trajectories. We used climate forcing compiled for the ISIMIP (Warszawski et al., 2014). These data comprise daily time series of bias-corrected and statistically downscaled climate variables at $0.5^{\circ}$ spatial resolution between 1950 and 2099. We used minimum, maximum and average near-surface air temperature, precipitation, near-surface relative humidity, near-surface wind speed and downwelling long- and short-wave radiation. We used climate data for RCP4.5 and RCP8.5 for five different GCMs: GFDL-ESM2M, HadGEM2-ES, IPSLCM5A-LR, MIROC-ESM-CHEM and NorESM1-M (Warszawski et al., 2014). Time series of mean annual precipitation and temperature for each ensemble member averaged for the entire study region are provided in Figure S 4.1.

We used RCP8.5 because it represents the worst-case scenario within all RCPs, with high carbon emissions, high energy consumption and low climate mitigation until 2099 (van Vuuren et al., 2011). In RCP4.5, it was assumed that carbon emissions peak towards the middle of the century and decrease afterwards. Cropland and utilized grassland areas decreased in RCP4.5 to the benefit of other vegetation types (van Vuuren et al., 2011), and feedbacks between such vegetation changes and the climate were considered. These two scenarios cover a range of possible scenarios and envelope the 
intermediate scenario RCP6.0. We decided to omit RCP2.6, a low-emission scenario with ambiguous climate mitigation and negative emissions, for example, by carbon capture and storage techniques.

Soil data were derived from the Harmonized World Soil Database (Nachtergaele et al., 2009) and we used elevation from the Shuttle Radar Topography Mission (Jarvis et al., 2008). Atmospheric $\mathrm{CO}_{2}$ concentrations were derived from van Vuuren et al. (2011) for RCP4.5 and RCP8.5. Model simulations were conducted at $1^{\circ}$ spatial resolution (see Section 4.2.3). Therefore, climate, soil and elevation data were resampled to the required $1^{\circ}$ spatial resolution using the nearest neighbour method.

\subsubsection{Model simulations}

We conducted aDGVM2 ensemble simulations for tropical Asia at $1^{\circ}$ spatial resolution and daily temporal resolution using climate data of five GCMs for RCP4.5 and RCP8.5 (Section 4.2.2), amounting to 10 scenarios in total. Replicate runs for these scenarios were not conducted due to the high computational demands. For each simulation, we conducted a 450-year model spin-up to allow modelled state variables, traits and plant communities to reach a dynamic equilibrium with environmental conditions. For model spin-up, we used a random sequence of years from the period between 1950 and 1980 for each ensemble member. After the spin-up, transient simulations were conducted using the time series between 1950 and 2099 of the respective scenario. Simulations were conducted in the presence of a natural surface fire regime, as represented by the aDGVM2 fire routines (Langan, Higgins and Scheiter, 2017; Supplementary Information). Anthropogenic fire was not simulated. We simulated potential natural vegetation in the absence of anthropogenic impacts (but see Section 4.2.8). All data processing procedures and model analyses were conducted with $R(R$ Core Team, 2018) and the 'raster' package (Hijmans, 2020).

\subsubsection{Biome types}

The aDGVM2 simulates biomass, phenology and height of individual woody plants (trees or shrubs) and grass patches, as well as plant population characteristics at plot level, such as number of plants or height structure. We used model state variables to classify vegetation in a grid cell into different biome types. To account for vegetation 
structure and phenology, we tailored a classification scheme that reflects these features. The classification scheme distinguishes seven different biomes characterized by evergreen and deciduous, tall and short woody vegetation, and woody and grassy vegetation.

When simulated woody cover in a grid cell is below $10 \%$ and aboveground grass biomass (including both $\mathrm{C}_{3}$ and $\mathrm{C}_{4}$ grasses) is below $300 \mathrm{~kg} / \mathrm{ha}$, vegetation is classified as desert. When woody cover is below 10\% and aboveground grass biomass (including both $\mathrm{C}_{3}$ and $\mathrm{C}_{4}$ grasses) is above $300 \mathrm{~kg} / \mathrm{ha}$, vegetation is classified as $\mathrm{C}_{3}$ or $\mathrm{C}_{4}$ grassland, depending on the fractional cover of the grass types. If woody cover exceeds $10 \%$, vegetation is classified as woody vegetation, irrespective of grass biomass. Woody vegetation is subdivided into the four combinations of evergreen and deciduous as well as short and tall. Vegetation is classified as evergreen if the number of evergreen woody plants exceeds the number of deciduous woody plants; otherwise, it is classified as deciduous. Woody vegetation is classified as short if the 90th percentile of the plant height distribution is less than $4 \mathrm{~m}$, otherwise it is classified as tall. The 4-m threshold was picked because application of different thresholds showed that the simulated distribution of tall vegetation derived from the 4-m threshold agreed well with observed forest distribution (Haxeltine and Prentice, 1996). In studies using both observations and models, vegetation height is typically not used in biome classification (for an exception using remote sensing data see Higgins, Buitenwerf and Moncrieff (2016).

In our biome scheme we assume that the four woody vegetation types include shrubland, savanna, woodland and different forest types. These types of woody vegetation are functionally different and often used in vegetation mapping, both using models and using observations from field studies or remote sensing. However, here we used four woody vegetation types to be able to focus on features related to phenology and vegetation height, and to constrain the number of biome types. In Kumar, Pfeiffer, Gaillard, Langan and Scheiter (2020) and Kumar, Pfeiffer, Gaillard, Langan, Martens, et al. (2020), we included different types of woody vegetation, and highlighted the importance of distinguishing between savanna and dry deciduous forest.

Biome classification was conducted for each grid cell and each ensemble member to obtain biome maps for each ensemble member. Consensus biome maps for each RCP were then generated by identifying the most frequent biome type in the ensemble in each 
grid cell. We tracked the number of ensemble members that represent the consensus biome type in each RCP as a proxy for model uncertainty.

\subsubsection{Dominant phenological type}

The aDGVM2 simulates four different phenological strategies: light-triggered evergreen, rain-triggered evergreen, light-triggered deciduous and rain-triggered deciduous (for details see Supplementary Information, and Langan, Higgins and Scheiter, 2017). To investigate the patterns of phenological strategies and their responses to climate change, we calculated the relative abundance of woody plants of each phenological strategy in each simulated grid cell. We assigned a dominant phenological type to each grid cell based on the most abundant phenological strategy of woody plants. We tracked both changes in the relative abundances of different phenological strategies and of the dominant phenological strategy in response to climate change.

Phenology classification was conducted for each grid cell and each ensemble member to obtain maps of the dominant phenology type for each ensemble member. Consensus maps of the dominant phenological type for each RCP were generated by identifying the most frequent dominant phenological type in the ensemble in each simulated grid cell. We tracked the number of ensemble members that represent the consensus-dominant phenological type in each RCP as a proxy for model uncertainty.

\subsubsection{Benchmarking}

Kumar, Pfeiffer, Gaillard, Langan and Scheiter (2020) parameterized aDGVM2 for South Asia (i.e. the western areas of the study region) and conducted data-model comparisons using multiple remote sensing products. Here, we compared simulated vegetation of all ensemble members and the ensemble means for both RCPs for current climate conditions (year 2019) to biomass and height derived from remote sensing. For biomass, we used the product of Saatchi et al. (2011), and for vegetation height we used the product of Simard et al. (2011). For simulated vegetation height, we used the 90th percentile of all woody plants in a grid cell. We calculated the coefficient of variation of biomass and height in each grid cell and for each RCP as a proxy for uncertainty. 
All remote sensing products were re-sampled to match the $1^{\circ}$ spatial resolution used in simulations. For re-sampling, we used averaging, to account for variation of highresolution benchmarking data within $1^{\circ}$ grid cells.

\subsubsection{Biomass and height changes}

To identify areas with substantial changes in woody biomass, $\mathrm{C}_{3}$ and $\mathrm{C}_{4}$ grass biomass and vegetation height, we calculated percentage changes in these variables between current (2019) and future (2099) conditions in each grid cell. For vegetation height, we used the 90th percentile of all woody plants simulated in a grid cell. We tracked if these four state variables changed by more than $\pm 5 \%, \pm 10 \%, \pm 50 \%$, and we distinguished between increasing or decreasing trends. Otherwise, biomass or height was classified as stable. We conducted this analysis for the ensemble means of biomass and height of both RCPs. We only provided results for the $\pm 10 \%$ and the $\pm 50 \%$ threshold to represent high and low sensitivity to vegetation change.

\subsubsection{Cultivated and managed vegetation}

Large areas in tropical Asia have been converted to cropland and plantations for food and timber production, and have been affected by urbanization, pollution and anthropogenic fire. To account for land use, we overlaid aDGVM2 results with a map of current anthropogenic impact derived from Tuanmu and Jetz (2014), a consensus landcover product aggregated from four different land-cover products. Specifically, we used 'cultivated and managed vegetation' (class 7) and 'Urban/Built-up' (class 9) of Tuanmu and Jetz (2014; Figure S 4.2).

To account for anthropogenic impacts in benchmarking (Section 4.2.6), we masked out areas with more than 50\% anthropogenic cover fraction. Kumar, Pfeiffer, Gaillard, Langan and Scheiter (2020) used a similar approach and found that data-model agreement improved for South Asia. To account for anthropogenic impacts in the assessment of biome and phenology transitions, we overlaid areas where aDGVM2 simulates transitions in natural vegetation with the grid cell's anthropogenic cover fraction. Specifically, we multiplied consensus maps indicating areas with (value $=1$ ) or without (value $=0$ ) vegetation change by the fraction of natural land (i.e. fraction of land not utilized). Values close to 1 indicate areas with a high fractional cover of natural 
vegetation that is highly susceptible to climate change. Values close to 0 indicate areas without simulated vegetation change or with high fractional cover of utilized land.

As we focused on natural vegetation, our approach does not account for past or future changes in land use, but only for recent land use as represented in the Tuanmu and Jetz (2014) data set. We also ignored impacts of past land use on growth, biomass or vegetation structure in simulations. Local-scale anthropogenic impacts, such as cattle farming, anthropogenic fire, fuelwood harvesting, deforestation or agriculture, were ignored in vegetation simulations. Yet, these impacts are widespread in the study region, and some of them have already been implemented in aDGVM and aDGVM2 (Scheiter et al., 2015, 2019; Scheiter and Savadogo, 2016; Pfeiffer et al., 2019).

The Tuanmu and Jetz (2014) data set is provided at a 30-arc second spatial resolution, and we aggregated the data to the $1^{\circ}$ resolution used in simulations. We summed the respective areas occupied by different classes, and then re-converted the areas to fractions based on the grid cell area size of the $1^{\circ}$ resolution used in simulations.

\subsection{Results}

\subsubsection{Vegetation state under current climate conditions}

Large-scale patterns of simulated aboveground biomass and vegetation height in 2019 showed agreement with remotely sensed biomass and height (Figure 4.1; Figure S4.3), indicating that aDGVM2 captured the main features of vegetation in tropical Asia. However, simulated aboveground biomass and height were lower than observations, primarily on the Indian peninsula. Land use is intense in this region (Figures S4.2, S4.4, S4.5), and explains data-model disagreement. Kumar, Pfeiffer, Gaillard, Langan and Scheiter (2020) showed that excluding utilized areas for benchmarking improves data-model agreement.

In model simulations, Myanmar, Thailand, Cambodia and most of the Indian peninsula showed both deciduous and evergreen vegetation (Figure 4.2a; Figure S4.6a). Phenology in these areas was mostly triggered by water (Figure 4.2c; Figure S4.6c). Pakistan was covered by short woody vegetation, and Afghanistan by grasslands and short deciduous vegetation. Phenology was mostly water-triggered with small areas of light-triggered phenology. The mountainous areas of India, the eastern parts of mainland 
Southeast Asia, tropical China and the islands of Indonesia, the Philippines and New Guinea were covered by tall evergreen vegetation (Figure 4.2a; Figure S4.6a), and phenology was triggered by both water and light (Figure 4.2c; Figure S4.6c).
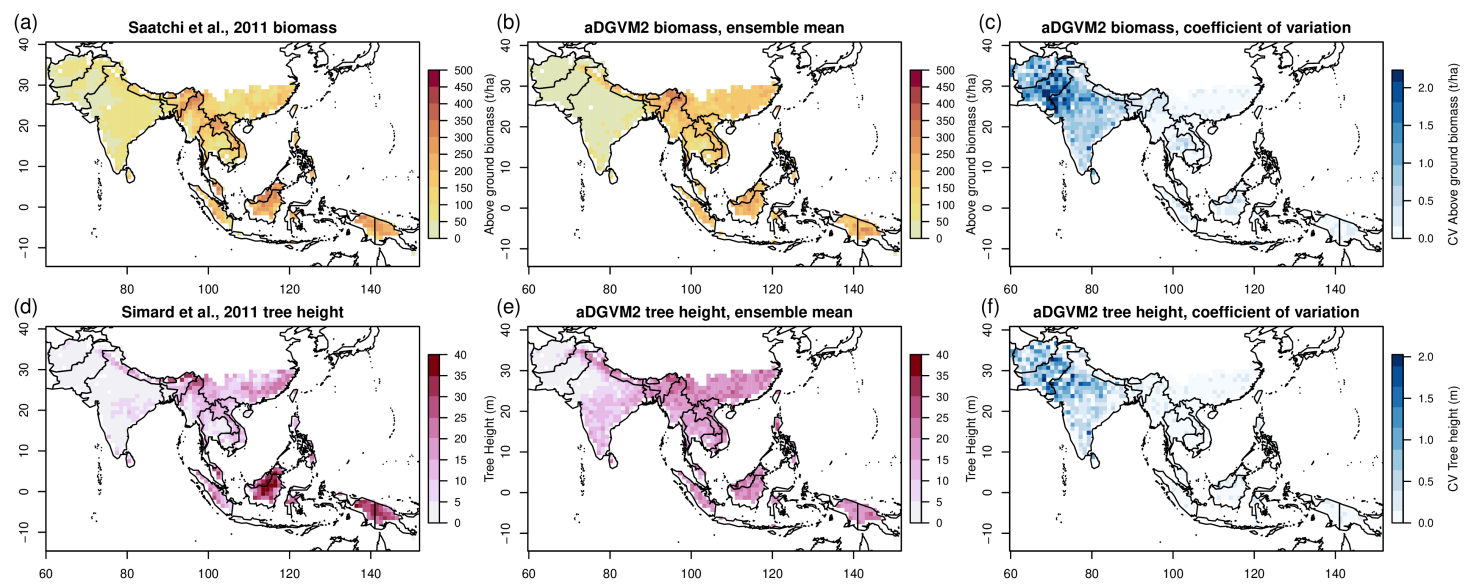

Figure 4.1 Biomass $(a-c)$ and tree height $(d-f)$ derived from remote sensing ( $a, d$; Saatchi et al., 2011; Simard et al., 2011) and simulated by adaptive dynamic global vegetation model version 2 (aDGVM2) under current conditions (b, e, year 2019). Panels (c, f) show model uncertainty, represented by the coefficient of variation. For aboveground biomass and height, we calculated mean and coefficient of variation for the ensemble of five different general circulation models for RCP8.5. Vegetation height of an ensemble member is represented by the 90th percentile of all woody plants. Results for RCP4.5 are provided in Figure S4.3. $R C P$, representative concentration pathway

Model results for different RCPs and GCMs varied considerably. We found variation between ensemble members with respect to the area covered by different biomes, and between ensemble members and the consensus maps of all ensemble members (Table 4.1; Table S4.1). For instance, in the ensemble mean for RCP4.5, 55.3\% of the area was covered by the tall evergreen biome type under current conditions with a range between $44.3 \%$ for GFDL-ESM2M and 58.2\% for MIROC-ESM. Mean aboveground biomass varied between ensemble members (Table 4.2) and ranged between $122.0 \mathrm{t} /$ ha for IPSL-CM5A-LR and 143.7t/ha for MIROC-ESM in RCP4.5, with an ensemble mean of $131.9 \mathrm{t} / \mathrm{ha}$ for 2000-2019.

For both aboveground biomass and vegetation height, the coefficient of variation of ensemble members was highest in more arid and seasonal areas with short vegetation (Figure 4.1c,f; Figure S4.3c,f). With respect to biome types, we found high agreement between ensemble members in areas covered by tall evergreen vegetation, while in areas 
covered by deciduous vegetation, agreement was typically lower (Figure 4.2b; Figure S4.6b). The dominant phenological type showed less large-scale areas of agreement than biome type (Figure 4.2d; Figure S4.6d).

\subsubsection{Climate change impacts on biomass and height}

Under future climate change, aboveground biomass in the study area showed substantial increases for both RCPs (Figure 4.3a; Table 4.2). In RCP4.5, ensemble mean aboveground biomass in the entire study region increased from $121.1 \mathrm{t} / \mathrm{ha}$ in the historic period (1950-1969) to $131.9 \mathrm{t} / \mathrm{ha}$ under current conditions (2000-2019), and to $148.7 \mathrm{t} /$ ha under future conditions (2080-2099), representing a 22.8\% increase between historic and future conditions and $12.7 \%$ between current and future conditions (Table 4..2). In RCP8.5, aboveground biomass increased to $163.0 \mathrm{t} / \mathrm{ha}$ in the future period (2080-2099), representing an increase of 34.8\% between historic and future conditions and an increase of $22.8 \%$ between current and future conditions (Table 4.2). Trend lines of inter-annual biomass change between consecutive years showed an increase until the 2040s in both RCP4.5 and RCP8.5. However, while inter-annual biomass change then decreased until 2099 in RCP4.5, it remained stable in RCP8.5 (Figure 4.3b). When averaged for the entire study period and all ensemble members, biomass changed by $0.29 \pm 1.66 \mathrm{t} / \mathrm{ha}$ in RCP8.5 and $0.19 \pm 1.74 \mathrm{t} / \mathrm{ha}$ in RCP4.5 between consecutive years (Figure 4.4). 

Asia

Table 4.1 Cover of different biome types for current (2019) and future (2099) climate conditions for RCP4.5 and RCP8.5. Cover is provided as percentage of grid cells covered by different biomes. Cover fractions for all ensemble members and the ensemble mean are provided. Values for current conditions are provided two times, because simulations for RCP4.5 and RCP8.5 slightly diverge due to model stochasticity and differences in the climate data sets. Models: 'M1' GFDLESM2M; 'M2' HadGEM2-ES; 'M3' IPSL-CM5A-LR; 'M4' MIROC-ESM; 'M5' NorESM1-M; 'Ens' ensemble mean. Table S1 provides cover fractions for biomes aggregated by height or phenology

\begin{tabular}{|c|c|c|c|c|c|c|c|c|}
\hline Biome & Time & RCP & M1 & M2 & M3 & M4 & M5 & Ens \\
\hline \multirow[t]{4}{*}{ Desert } & Current & 4.5 & 5.5 & 2.7 & 3.0 & 2.7 & 2.8 & 2.7 \\
\hline & Future & 4.5 & 3.9 & 3.0 & 4.1 & 2.7 & 3.0 & 2.8 \\
\hline & Current & 8.5 & 4.6 & 2.7 & 3.1 & 3.0 & 3.2 & 3.1 \\
\hline & Future & 8.5 & 4.8 & 3.0 & 3.6 & 3.0 & 2.8 & 2.8 \\
\hline \multirow[t]{4}{*}{$\mathrm{C}_{4}$ grassland } & Current & 4.5 & 4.6 & 8.9 & 6.4 & 9.2 & 6.4 & 7.2 \\
\hline & Future & 4.5 & 6.2 & 8.2 & 6.1 & 8.6 & 6.4 & 7.3 \\
\hline & Current & 8.5 & 5.7 & 8.8 & 6.0 & 8.6 & 6.6 & 7.2 \\
\hline & Future & 8.5 & 4.7 & 7.8 & 5.7 & 7.1 & 6.3 & 6.4 \\
\hline \multirow[t]{4}{*}{$\mathrm{C}_{3}$ grassland } & Current & 4.5 & 1.0 & 0.9 & 0.2 & 1.0 & 1.1 & 0.6 \\
\hline & Future & 4.5 & 0.7 & 0.7 & 1.1 & 0.7 & 0.9 & 0.6 \\
\hline & Current & 8.5 & 0.6 & 0.9 & 1.1 & 0.9 & 1.0 & 0.5 \\
\hline & Future & 8.5 & 0.7 & 0.6 & 0.9 & 1.0 & 0.6 & 0.7 \\
\hline \multirow[t]{4}{*}{ Short deciduous } & Current & 4.5 & 14.8 & 15.3 & 18.9 & 9.3 & 15.3 & 15.7 \\
\hline & Future & 4.5 & 12.5 & 13.2 & 16.4 & 8.7 & 12.3 & 12.4 \\
\hline & Current & 8.5 & 14.6 & 15.7 & 18.3 & 9.7 & 14.6 & 14.7 \\
\hline & Future & 8.5 & 13.6 & 12.5 & 16.5 & 8.4 & 11.9 & 12.6 \\
\hline \multirow[t]{4}{*}{ Tall deciduous } & Current & 4.5 & 28.0 & 12.6 & 14.2 & 14.6 & 13.0 & 15.8 \\
\hline & Future & 4.5 & 29.3 & 12.1 & 15.7 & 15.2 & 15.8 & 18.2 \\
\hline & Current & 8.5 & 28.8 & 11.5 & 13.7 & 14.3 & 13.2 & 15.9 \\
\hline & Future & 8.5 & 28.0 & 12.5 & 14.9 & 16.3 & 16.4 & 17.7 \\
\hline \multirow[t]{4}{*}{ Short evergreen } & Current & 4.5 & 1.9 & 4.4 & 4.6 & 5.1 & 3.3 & 2.7 \\
\hline & Future & 4.5 & 1.4 & 4.7 & 2.9 & 3.0 & 2.1 & 1.4 \\
\hline & Current & 8.5 & 1.7 & 4.1 & 4.7 & 4.3 & 3.5 & 2.8 \\
\hline & Future & 8.5 & 1.1 & 4.2 & 2.9 & 2.9 & 1.9 & 1.7 \\
\hline \multirow[t]{4}{*}{ Tall evergreen } & Current & 4.5 & 44.3 & 55.1 & 52.7 & 58.2 & 58.0 & 55.3 \\
\hline & Future & 4.5 & 46.0 & 58.1 & 53.7 & 61.1 & 59.5 & 57.4 \\
\hline & Current & 8.5 & 43.9 & 56.3 & 53.1 & 59.4 & 57.9 & 55.7 \\
\hline & Future & 8.5 & 46.9 & 59.5 & 55.5 & 61.4 & 60.1 & 58.0 \\
\hline
\end{tabular}

Abbreviation: RCP, representative concentration pathway. 

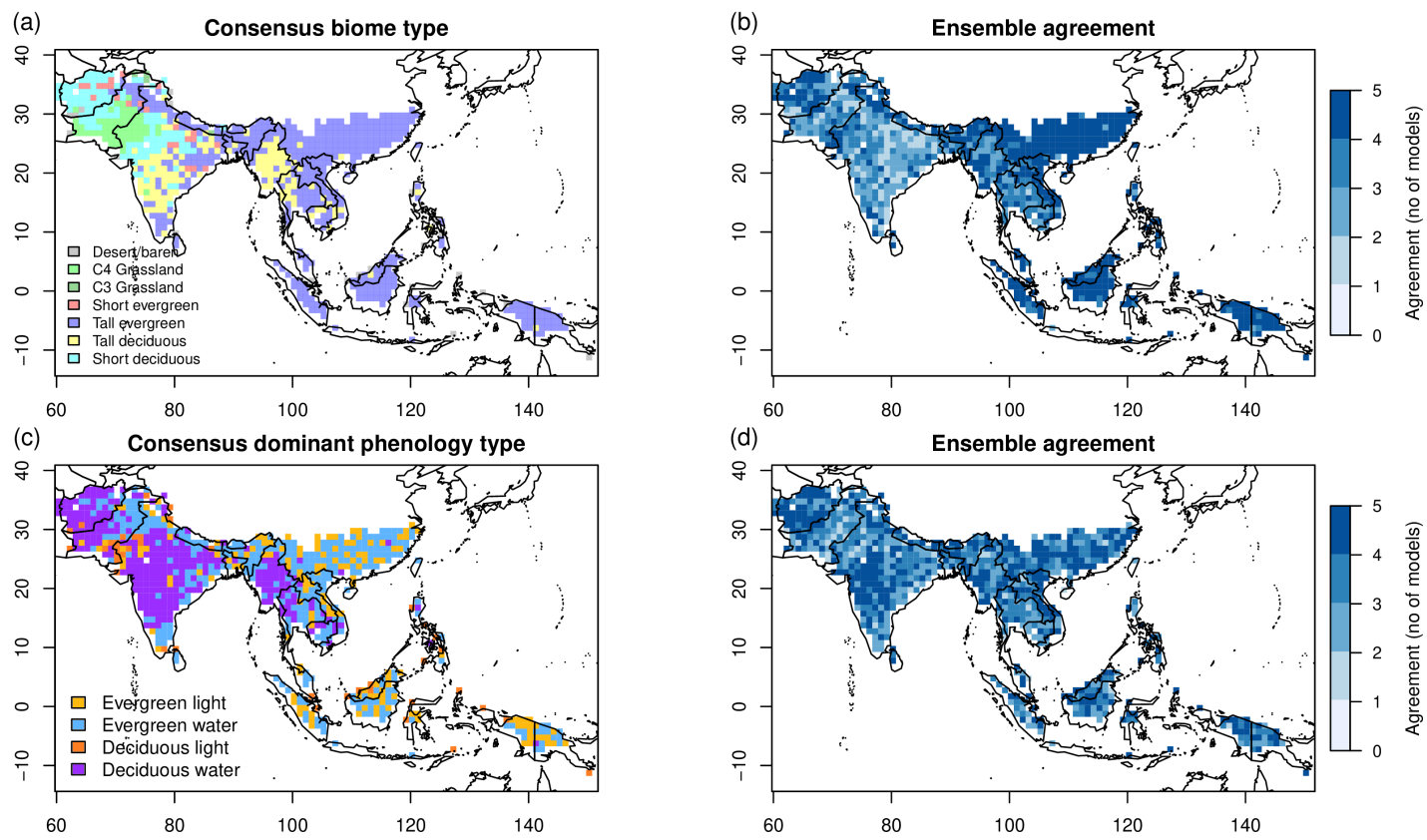

Figure 4.2 Consensus biome types (a) and dominant phenology types (c) simulated by adaptive dynamic global vegetation model version 2 under current conditions (year 2019). Panels (a, c) show consensus maps, $(b, d)$ show uncertainty, represented by the number of ensemble members that simulate the consensus type. Simulations were conducted for RCP8.5. Results for RCP4.5 are provided in Figure S4.6. RCP, representative concentration pathway

In RCP8.5, aboveground biomass changes by more than $10 \%$ between current and future climate were simulated in almost the entire study region, except for areas in tropical China (Figure 4.5a; Figure S10a-c). Vegetation height changed more than $10 \%$ in South Asia and western mainland Southeast Asia and less than 10\% in areas where the model simulated tall vegetation under current conditions (Figure 4.5b; Figure S10d-f). Decreases in aboveground biomass and height were only detected in Pakistan and Afghanistan (Figure 4.5b). $\mathrm{C}_{3}$ aboveground grass biomass showed decreases in the entire study region, except in Pakistan and Afghanistan (Figure 4.5c), where $\mathrm{C}_{3}$ aboveground grass biomass was low (Figure $\mathrm{S} 10 \mathrm{~g}-\mathrm{i}$ ). $\mathrm{C}_{4}$ grass biomass increased primarily in areas currently covered by deciduous vegetation and decreased in areas covered by evergreen vegetation (Figure 4.5d; Figure S10j-1). The area affected by changes was smaller when a $50 \%$ threshold was used to detect changes (Figures S4.8, S4.9). The broad patterns of change in aboveground biomass and vegetation height in RCP4.5 were similar to the patterns in RCP8.5, yet the areas of increase were smaller (primarily in tropical China) 
Chapter 4-Climate change promotes transitions to tall evergreen vegetation in tropical Asia

while the areas of decrease were larger (primarily in Pakistan and Afghanistan, Figures S4.7, S4.11).

Table 4.2 Aboveground vegetation biomass in the study region for different GCMs and RCPs and changes between different time periods (historic: 1950-1969; current: 2000-2019; future: 2080-2099). Biomass values for each ensemble member and the ensemble mean are provided. Models: 'M1' GFDL-ESM2M; 'M2' HadGEM2-ES; 'M3' IPSL-CM5A-LR; 'M4' MIROC-ESM; 'M5' NorESM1-M; 'Ens' ensemble mean; indicates percentage aboveground biomass changes between time periods

\begin{tabular}{|llllll|l|l|l|}
\hline Time & RCP & M1 & M2 & \multicolumn{1}{l}{ M3 } & M4 & M5 & Ens \\
\hline Historic (t/ha) & 4.5 & 117.8 & 116.5 & 112.0 & 133.8 & 125.2 & 121.1 \\
\hline Current (t/ha) & 4.5 & 125.1 & 128.9 & 122.0 & 143.7 & 140.0 & 131.9 \\
\hline Future (t/ha) & 4.5 & 145.7 & 142.8 & 134.4 & 159.0 & 161.7 & 148.7 \\
\hline$\Delta$ Historic to current (\%) & 4.5 & 6.2 & 10.6 & 8.9 & 7.4 & 11.8 & 8.9 \\
\hline$\Delta$ Current to future (\%) & 4.5 & 16.5 & 10.8 & 10.2 & 10.6 & 15.5 & 12.7 \\
\hline$\Delta$ Historic to future (\%) & 4.5 & 23.7 & 22.6 & 20.0 & 18.8 & 29.2 & 22.8 \\
\hline Historic (t/ha) & 8.5 & 118.0 & 116.1 & 111.2 & 134.3 & 124.7 & 120.9 \\
\hline Current (t/ha) & 8.5 & 126.4 & 129.9 & 121.2 & 148.2 & 137.8 & 132.7 \\
\hline Future (t/ha) & 8.5 & 159.1 & 156.6 & 142.9 & 179.1 & 177.7 & 163.0 \\
\hline$\Delta$ Historic to current (\%) & 8.5 & 7.1 & 11.9 & 9.0 & 10.3 & 10.5 & 9.8 \\
\hline$\Delta$ Current to future (\%) & 8.5 & 25.9 & 20.6 & 17.9 & 20.9 & 28.7 & 22.8 \\
\hline$\Delta$ Historic to future (\%) & 8.5 & 34.8 & 34.9 & 28.5 & 33.4 & 42.3 & 34.8 \\
\hline
\end{tabular}

Abbreviations: GCM, general circulation model; RCP, representative concentration pathway. 

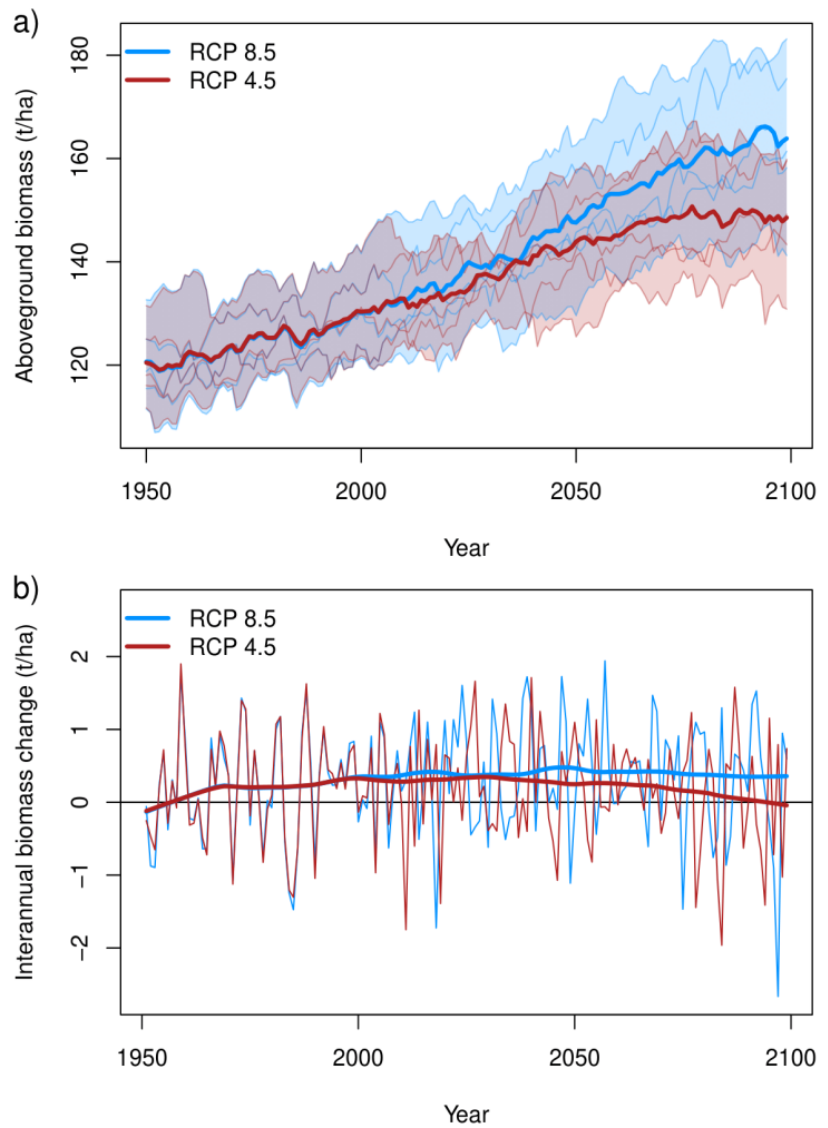

Figure 4.3 Aboveground vegetation biomass (a) and interannual biomass change between consecutive years (b) in model ensemble between 1950 and 2099 for tropical Asia. Thin lines in panel (a) represent mean annual aboveground biomass in simulations with different general circulation models, bold lines represent annual ensemble means for RCP4.5 and RCP8.5, and shaded areas represent the range (minimum and maximum) of the ensemble in both $R C P s$. Thin lines in panel (b) represent ensemble means, thick lines represent smoothed lines using 'lowess'. $R C P$, representative concentration pathway

Variation in absolute aboveground biomass and biomass change between different ensemble members was substantial between 1950 and 2099 (Table 4.2). In RCP8.5, mean aboveground biomass in the study region ranged between $142.9 \mathrm{t} / \mathrm{ha}$ for ISPL-CM5A-LR and 179.1 t/ha for MIROC-ESM in 2099. Biomass change between current and future conditions ranged between 10.2\% (IPSL-CM5A-LR) and 16.5\% (GFDL-ESM2M1) for RCP4.5, and between 17.9\% (IPSL-CM5A-LR) and 28.7\% (NorESM1-M) for RCP8.5 (Table 4.2). 
Chapter 4-Climate change promotes transitions to tall evergreen vegetation in tropical Asia

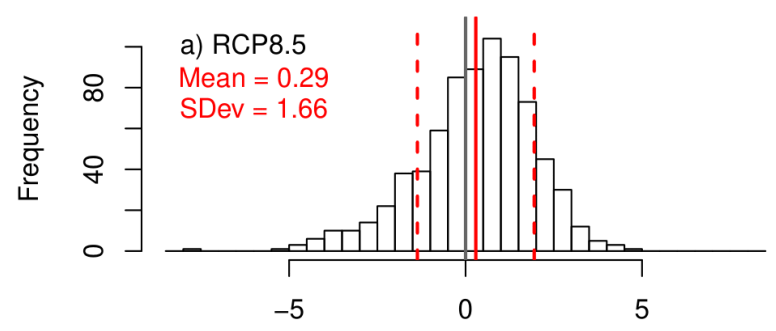

Interannual aboveground biomass change (t/ha)

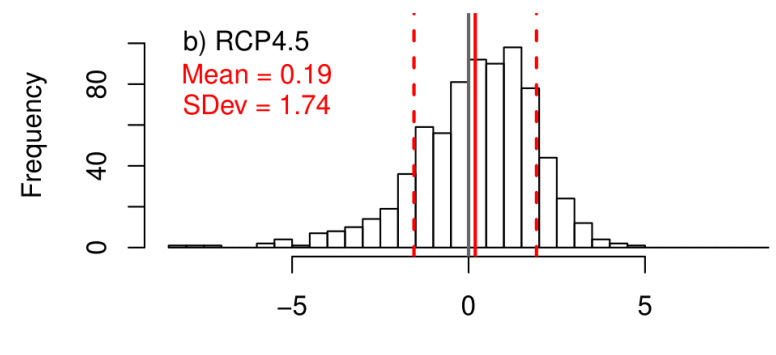

Interannual aboveground biomass change ( $\mathrm{t} / \mathrm{ha}$ )

Figure 4.4 Histograms of interannual aboveground biomass change between two consecutive years for (a) RCP8.5 and (b) RCP4.5. Histograms were plotted for all years between 1950 and 2099 for all ensemble members. The solid red line indicates the average of all changes, the dashed red lines indicate standard deviation. Time series of ensemble means of these changes are provided in Figure 4.3b. $R C P$, representative concentration pathway
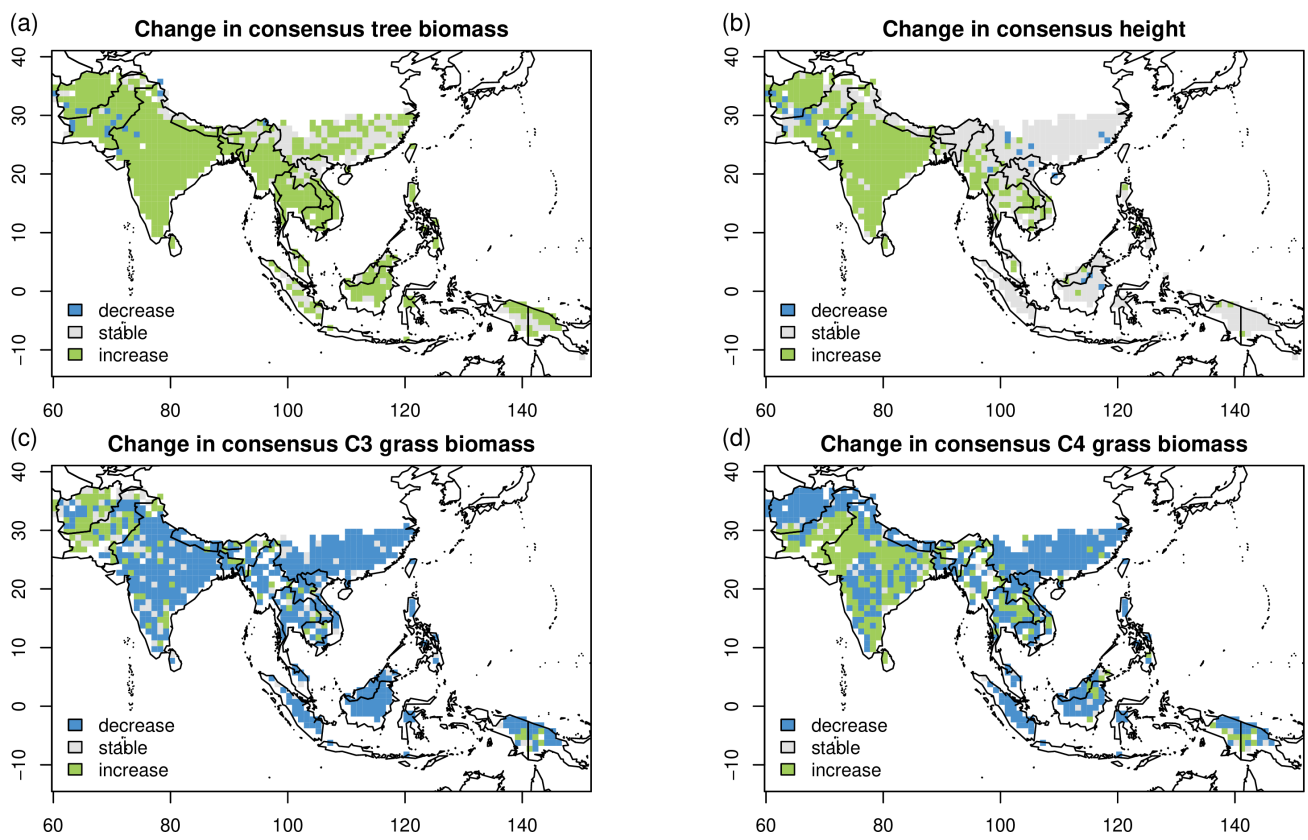

Figure 4.5 Areas where aboveground tree biomass and height change by more than $\pm 10 \%$ between current (year 2019) and future (year 2099) conditions in RCP8.5. For biomass, we used tree aboveground biomass (a), $C_{3}$ grass biomass (c) and $C_{4}$ grass biomass (d) in a grid cell, for vegetation height (b), we used the 90th percentile of all trees simulated in a grid cell. Results for RCP4.5 are provided in Figure S4.7. RCP, representative concentration pathway 


\subsubsection{Climate change impacts on phenology and biomes}

The aDGVM2 simulated changes in community composition under future climate conditions, specifically regarding the abundances of deciduous and evergreen vegetation (Figure 4.6). In RCP8.5, we found increases in the abundance of lighttriggered (Figure 4.6a-c) and water-triggered (Figure 4.6d-f) evergreen plants and decreases in the abundance of water-triggered deciduous plants in mainland Southeast Asia, central India and Pakistan (Figure 4.6g-i). In southern India, water-triggered evergreen plants decreased to the benefit of deciduous water-triggered plants. Similar patterns were simulated for RCP4.5 (Figure S4.12).

Changes in aboveground woody biomass and the abundances of phenological types caused biome transitions, predominantly from small to tall, and from deciduous to evergreen biome types (Figure 4.7a-b; Figure S4.13a,b). This trend was most pronounced in India and mainland Southeast Asia. Vegetation on the islands was stable, that is, aDGVM2 simulated tall evergreen vegetation for all ensemble members and time periods. The area affected by biome transitions varied within the ensemble (Table 4.1; Table S4.1). In the consensus biome map, aDGVM2 simulated biome transitions for $8.4 \%$ of the study region in RCP4.5 and $8.3 \%$ in RCP8.5, with values ranging between $7.9 \%$ and $10.0 \%$ among ensemble members (Table 4.3; Figure 4.7c). The area where at least one ensemble member projected a biome transition between current and future conditions was larger and $28.5 \%$ for RCP4.5 and $30.4 \%$ for RCP8.5, respectively (Table 4.3; Figure 4.7d). These areas covered most of India and Pakistan and large areas in mainland Southeast Asia.

When cultivated and managed land was considered (Figure S4.2; Tuanmu and Jetz, 2014), areas that were subject to biome transitions were smaller. These areas include grasslands and short vegetation in the west of the study region, tall vegetation in the east of the Indian peninsula and tall vegetation in mainland Southeast Asia (Figure 4.7e,f; Figure S4.13e,f).

Despite changes in the abundances of phenological strategies, we found that patterns of dominant phenological types were more stable between current and future climate conditions than the patterns of state variables and biome types (Figure 4.8; Figure S4.14). In the consensus map, only $2.7 \%$ and $3.5 \%$ of the simulated grid cells 
Chapter 4-Climate change promotes transitions to tall evergreen vegetation in tropical Asia

showed changes in the dominant phenological type in RCP4.5 and RCP8.5 respectively (Table 4.3).
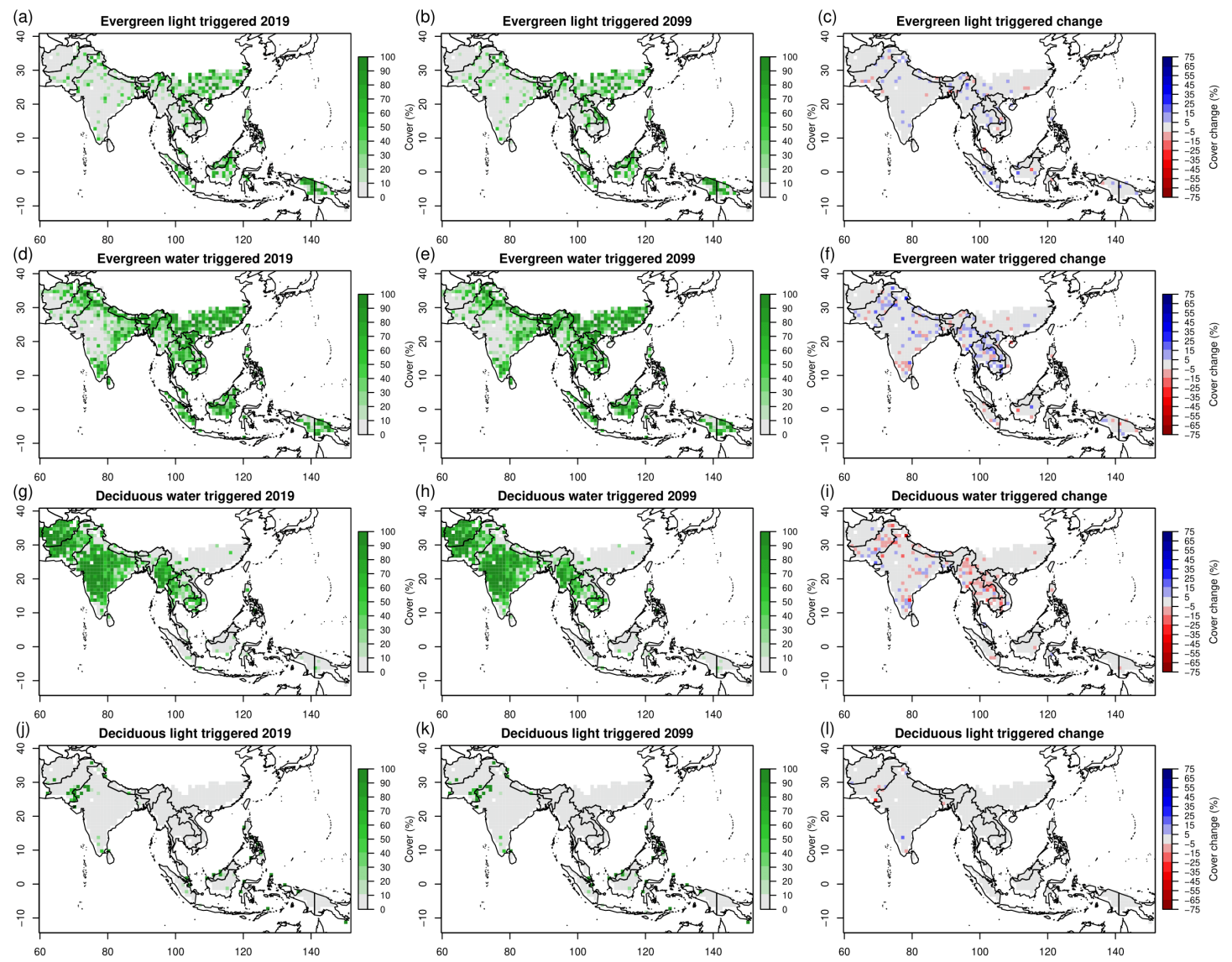

Figure 4.6 Relative abundance of different phenological strategies under current (year 2019) and future (year 2099) conditions, as well as change within this time period. Phenological strategies are evergreen light-triggered $(a-c)$, evergreen water-triggered $(d-f)$, deciduous water-triggered $(g-i)$ and deciduous lighttriggered $(j-l)$. Simulations for current conditions $(a, d, g$, $j$ ), future conditions $(b, e, h, k)$ and changes between current and future conditions $(c, f, i, l)$ are provided. The maps show ensemble means for RCP8.5. Results for RCP4.5 are provided in Figure $S 4$.12. RCP, representative concentration pathway

Values in ensemble members ranged between $1.7 \%$ and $5.0 \%$. Phenology changes in at least one ensemble member were predicted for $13.4 \%$ of the study area in RCP4.5 and $15.8 \%$ in RCP8.5. The most frequent type of phenology change was from deciduous water-triggered to evergreen water-triggered phenology, and these changes were mostly projected in warm areas with intermediate mean annual precipitation between ca. $500 \mathrm{~mm}$ and 2,000 $\mathrm{mm}$ (Figure 4.9; Figure S4.15). Masking of cultivated 
and managed land (Figure S4.2; Tuanmu and Jetz, 2014) reduced the area where transitions in dominant phenology occurred (Figure 4.8e,f; Figure S4.15e,f).
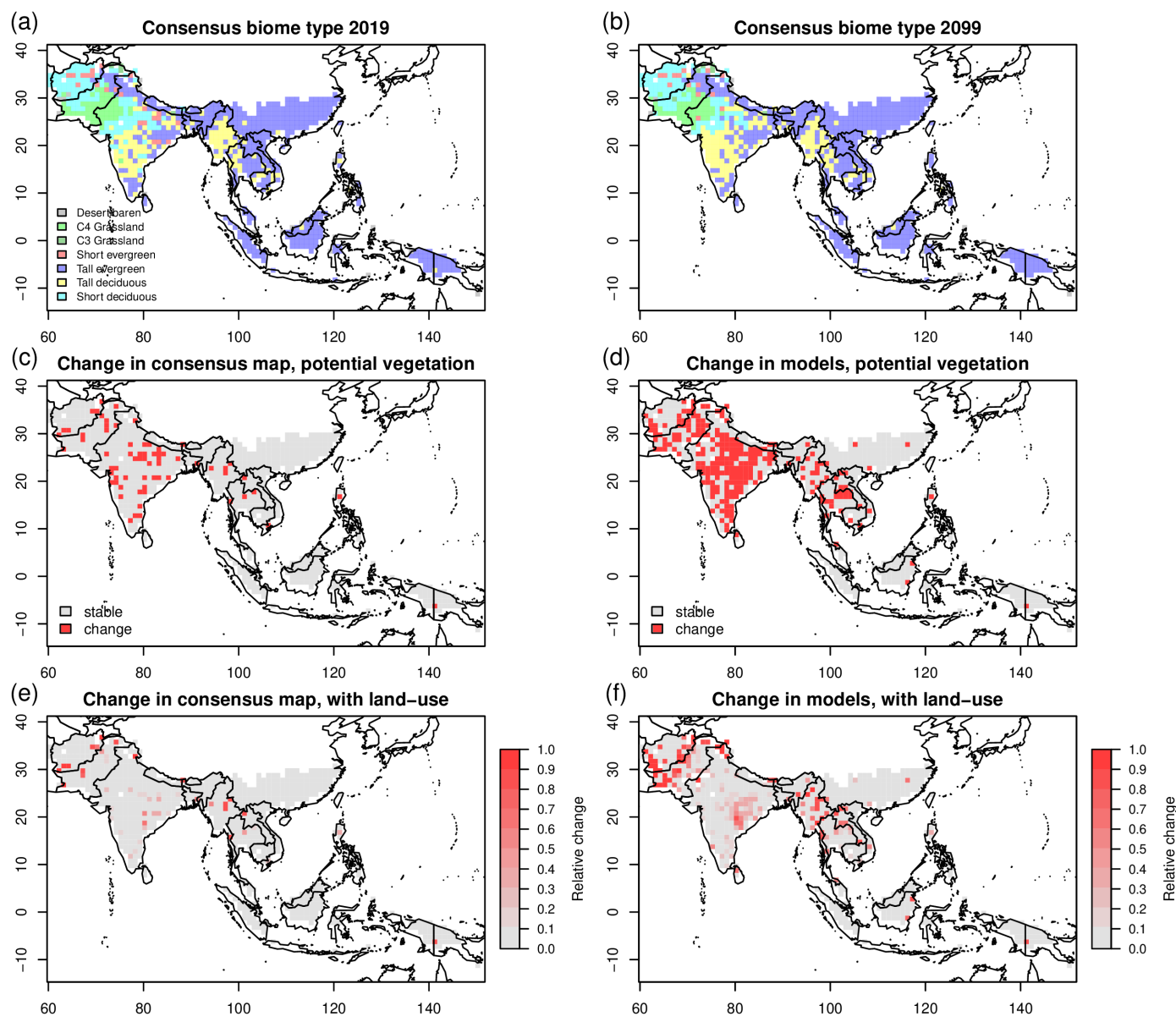

Figure 4.7 Consensus map of current (a, year 2019) and future (b, 2099) biome distribution in RCP8.5 for the ensemble. Areas where biome shifts between 2019 and 2099 were simulated for the consensus map $(c, e)$ and in at least one of the ensemble members $(d, f)$ are highlighted without land use impacts $(c, d)$ and with land use impacts (e, f). Land use was derived from Tuanmu and Jetz (2014). Results for RCP4.5 are provided in Figure S4.13. RCP, representative concentration pathway 
Chapter 4-Climate change promotes transitions to tall evergreen vegetation in tropical Asia

Table 4.3 Percentage of simulated grid cells in tropical Asia affected by transitions in biome type and in dominant phenology type for different GCMs and RCPs. Changes represent the period between current (year 2019) and future (year 2099) conditions. Models: 'M1' GFDL-ESM2M; 'M2' HadGEM2-ES; 'M3' IPSLCM5A-LR; 'M4' MIROC-ESM; 'M5' NorESM1-M; 'Ens' ensemble mean; 'Ova' overall change of all GCMs, that is, area where at least one GCM simulates a transition

\begin{tabular}{|c|c|c|c|c|c|c|c|c|}
\hline & RCP & M1 & M2 & M3 & M4 & M5 & Ens & Ova \\
\hline Biome type & 4.5 & 8.2 & 8.0 & 10.0 & 7.9 & 8.3 & 8.4 & 28.5 \\
\hline Biome type & 8.5 & 8.1 & 9.3 & 9.5 & 9.2 & 9.9 & 8.3 & 30.4 \\
\hline Phe & 4.5 & 2.9 & 3.6 & 1.7 & 3.1 & 3.6 & 2.7 & 13.4 \\
\hline Phenology & 8.5 & 3.5 & 3.6 & 1.9 & 5.0 & 3.5 & 3.5 & 15.8 \\
\hline
\end{tabular}

Abbreviations: GCM, general circulation model; RCP, representative concentration pathway.
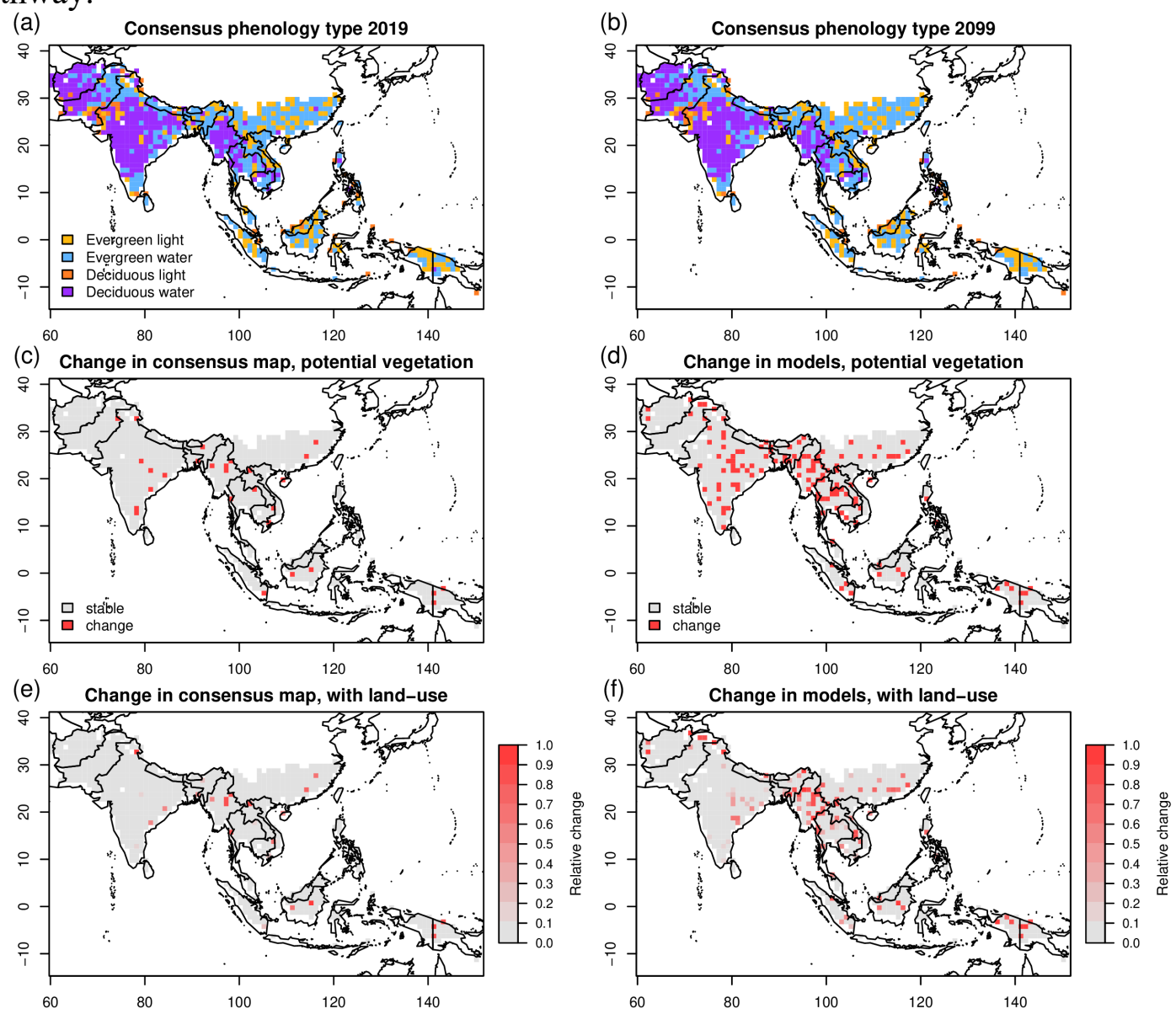

Figure 4.8 Consensus map of current (a, year 2019) and future (b, 2099) distribution of dominant phenological types in RCP8.5 for the ensemble. Areas where phenology shifts between 2019 and 2099 were simulated for the consensus map $(c, e)$ and in at least one of the ensemble members $(d, f)$ are highlighted without land use impacts $(c, d)$ and with land use impacts $(e, f)$. Land use was derived from Tuanmu \& Jetz, (2014). Results for RCP4.5 are provided in Figure S4.14. RCP, representative concentration pathway 
In the ensemble mean, transpiration showed a decrease of approximately $4 \%$ between 1950 and current conditions (Figure S4.16), despite increases in aboveground biomass. In RCP4.5, aDGVM2 simulated increases of transpiration to values similar to 1950 by the end of the century. In contrast, transpiration stabilized at the reduced value in RCP8.5.

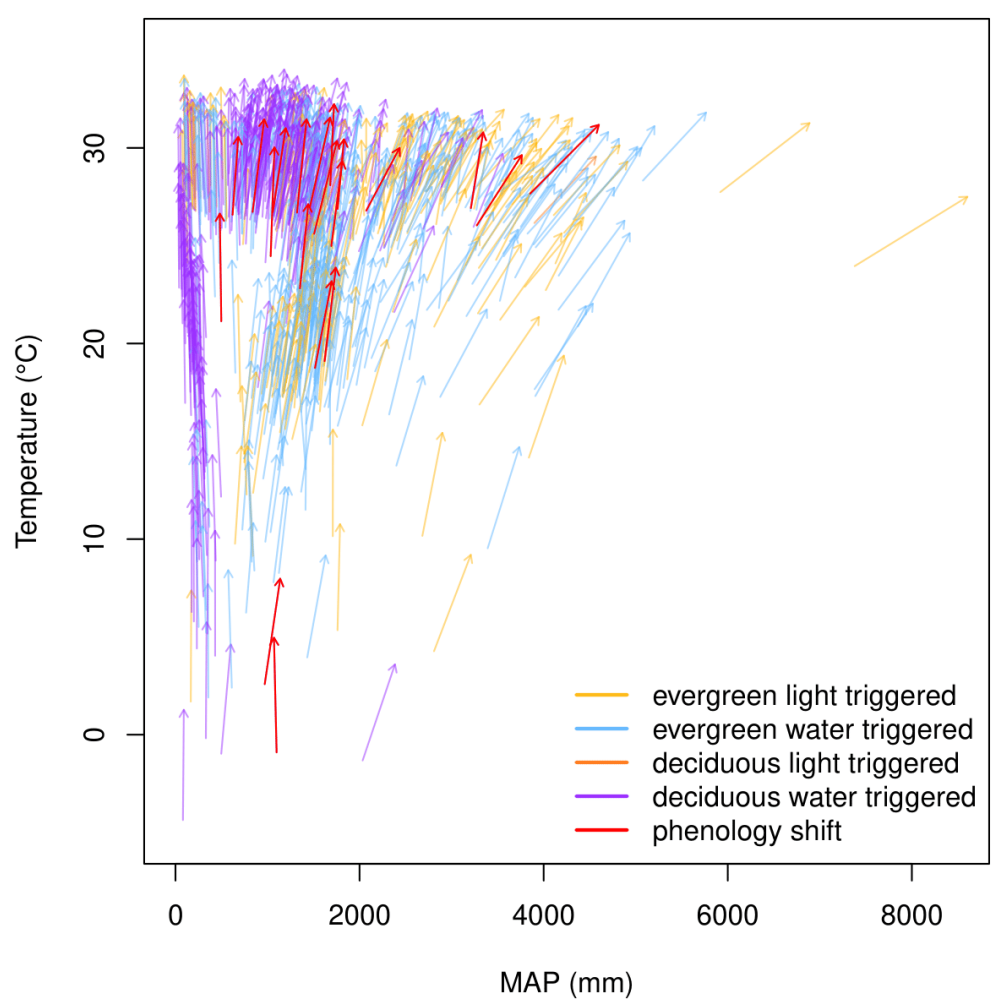

Figure 4.9 Transitions of dominant phenology in precipitationtemperature space for the RCP8.5 ensemble. Origin and end of arrows indicate location of a grid cell in climate space in 2019 and 2099; colours indicate different dominant phenological strategies and if a transition in the phenology was projected (red arrows) or not (other colours). Results for RCP4.5 are provided in Figure S4.15. $M A P$, mean annual precipitation; $R C P$, representative concentration pathway

\subsection{Discussion}

\subsubsection{Biomass increase and $\mathrm{CO}_{2}$ fertilization}

Previous modelling and remote sensing studies have shown increased vegetation productivity (Haverd et al., 2020) and greening trends (Piao et al., 2020) globally, and that the biosphere has acted as a carbon sink during recent decades (Le Quéré et al., 2018; Liu et al., 2019). Model simulations with aDGVM2 also showed increases in aboveground vegetation biomass for historic and future periods, indicating that regions 
covered by natural vegetation will remain a carbon sink until 2099. This trend was robust for an ensemble of two climate change scenarios and five GCMs. In RCP8.5, trends of interannual biomass changes between consecutive years remained almost constant until 2099 , indicating that the carbon uptake rate and the sink potential of natural vegetation remain stable. In contrast, in RCP4.5 interannual biomass change decreased between the 2030s and 2099. This result agrees with Hubau et al. (2020), who found sink saturation in tropical forests in Africa and Amazonia. However, our results indicate later saturation in RCP4.5 than reported by Hubau et al. (2020). In most of our study area, aboveground woody biomass increase exceeded $10 \%$. Exceptions were found for some patches of evergreen forest in tropical China and the islands of Indonesia, Malaysia, the Philippines and New Guinea, where aboveground biomass was already high under current climate conditions. Biomass decreases exceeding 10\% occurred only in arid areas with low aboveground biomass.

Simulated aboveground woody biomass increase is, in aDGVM2, primarily driven by $\mathrm{CO}_{2}$ fertilization effects of plant growth. We already found and quantified $\mathrm{CO}_{2}$ fertilization in the predecessor model version aDGVM (Scheiter and Higgins, 2009; Higgins and Scheiter, 2012; Scheiter et al., 2015; Martens et al., 2020). Kumar, Pfeiffer, Gaillard, Langan and Scheiter (2020) and Langan (2019) confirmed $\mathrm{CO}_{2}$ fertilization effects for aDGVM2 for South Asia and Amazonia, respectively, by conducting simulations with $\mathrm{CO}_{2}$ fertilization effects enabled or disabled.

Several lines of empirical evidence support these modelled effects of elevated $\mathrm{CO}_{2}$ on vegetation. First, open-top chamber experiments in different ecosystems showed increases in photosynthetic rates and water use efficiency at leaf or plant level (Kgope, Bond and Midgley, 2010; B. S. Ripley and S. Raubenheimer, personal communication, March 2019). Free air carbon enrichment (FACE) experiments in different ecosystems revealed ecosystem-level responses to elevated $\mathrm{CO}_{2}$. Ecosystem responses were ecosystem-specific (Hickler, Rammig and Werner, 2015) and variable over time, often with strong responses at the beginning of $\mathrm{eCO}_{2}$ treatments but weaker long-term responses. $\mathrm{CO}_{2}$ enrichment experiments in the study region are scarce. Deng et $a$. (2010) and Liu et al. (2008) used open-top chambers to study soil respiration and nutrient dynamics in tropical forests in China. FACE experiments are currently missing in the study region, and there is an urgent need for such experiments. 
Second, greening trends have been observed in tropical Asia and globally during recent decades (Piao et al., 2020). These have been attributed, among other drivers, to elevated $\mathrm{CO}_{2}$. Haverd et al. (2020) attributed $30 \%$ of the increase in gross primary productivity since 1990 to $\mathrm{CO}_{2}$ fertilization. Piao et al. (2015) used satellite-derived leaf area index (LAI) and modelling techniques to show greening trends in China, and identified elevated $\mathrm{CO}_{2}$ and nitrogen deposition as the most likely drivers. Yet, Piao et al. (2015) also included anthropogenic afforestation as a factor driving greening, and not only natural vegetation dynamics. Greening is typically quantified by remotely sensed indicators such as the normalized difference vegetation index or LAI. These indicators are proxies for leaf biomass and leaf productivity, but do not necessarily imply increases in carbon sequestration or sink potential. Chen et al. (2019) argued that increases in LAI and $\mathrm{CO}_{2}$ fertilization accounted for $12.4 \%$ and $47 \%$ of the terrestrial carbon sink since 1981, respectively, indicating links between greening and carbon sequestration.

Third, woody encroachment is observed in many savanna regions globally (Stevens et al., 2017). In South African savannas, encroachment has often been attributed to $\mathrm{CO}_{2}$ fertilization (Kgope, Bond and Midgley, 2010; Buitenwerf et al., 2012). Woody encroachment has also been observed in Indian savannas and the central dry zone of Myanmar, where alien shrub species such as Lantana camara, Chromolaena odorata and Prosopis juliflora rapidly invade native vegetation (Hiremath and Sundaram, 2005; Kannan, Shackleton and Uma Shaanker, 2013; Oo and Koike, 2015; Ratnam et al., 2016). These studies attributed encroachment to anthropogenic activities such as fire suppression or overgrazing rather than to elevated $\mathrm{CO}_{2}$. It remains to be tested to what degree $\mathrm{CO}_{2}$ effects reinforce other anthropogenic impacts or drive encroachment. Generally, $\mathrm{CO}_{2}$-induced woody encroachment has been less studied in tropical Asia than in southern Africa (e.g. Bond, Midgley and Woodward, 2003; Bond, 2008; Buitenwerf et al., 2012; Midgley and Bond, 2015). One explanation for the lack of study is that tropical Asia has a higher human population than other tropical regions. Human impacts associated with deforestation, or conversion of natural vegetation to cropland may override any $\mathrm{CO}_{2}$ or climate change effects on vegetation. Further, Asian savannas are often misinterpreted as degraded forest and management policies aim at afforestation rather than at the conservation of these landscapes (Ratnam et al., 2016; Kumar, Pfeiffer, Gaillard, Langan, Martens, et al., 2020). In this context, woody encroachment might be 
interpreted as a desired transitional stage towards forest expansion and as successful afforestation, rather than as a threat to biodiversity.

Our results largely agree with previous DGVM studies for tropical Asia that reported greening under future climate conditions. For instance, Sitch et al. (2008) compared different DGVMs for IPCC SRES A1F1 and showed that the models simulate stability or increases in vegetation carbon and woody cover in tropical Asia between 1860 and 2100. Yu et al. (2014) analysed a global ensemble run for RCP8.5 with 19 GCMs using CLM-CN-DV and found that net primary productivity is likely to increase in tropical Asia until the end of the century. Woody vegetation cover was projected to increase in most of the study area, except along the Himalayas and northern Indonesia (Yu et al., 2014). Using aDGVM, the predecessor of aDGVM2, we simulated substantial transitions from grasslands to savannas and from savannas to forests until 2100 in South Asia (Kumar and Scheiter, 2019).

While simulated aboveground biomass and vegetation height reflected broad patterns of remote sensing data, we also found areas where data and model disagree. For example, aDGVM2 underestimates biomass and height in areas highly affected by land use, such as the Indian peninsula. Further, aDGVM2 does not simulate some of the dipterocarp forests, with biomass of more than $400 \mathrm{t} / \mathrm{ha}$ and giant trees which can exceed $70 \mathrm{~m}$ in height and store large biomass. This mismatch can be explained by aDGVM2 not representing such giant trees, and by the coarse resolution of aDGVM2 simulations that ignores observed spatial heterogeneity. Conducting higher resolution simulations and replicate runs for model grid cells might capture heterogeneity and extremes of biomass and height at local scale. However, we expect that such additional simulations would not influence our general results.

\subsubsection{Ecological strategies, biomes and ecosystem functions}

The community assembly processes implemented in aDGVM2 allow the simulation of a diversity of distinct ecological strategies at local scale, as well as their responses to climate change (Scheiter, Langan and Higgins, 2013; Langan, Higgins and Scheiter, 2017). Thus, simulated vegetation at local scale was characterized by the coexistence of deciduous and evergreen plants, water- and light-triggered plants, singlestemmed trees and multi-stemmed shrubs, small and tall plants, as well as grasses and 
woody plants. The aDGVM2 selected for high grass biomass and dominance of watertriggered deciduous woody plants on the Indian peninsula, Pakistan and Afghanistan, and for tall evergreen woody vegetation in tropical China, the islands of Indonesia, the Philippines and New Guinea, as well as in the Himalayas. Interestingly, aDGVM2 simulated a mixture of light- and water-triggered phenology in most of the tall evergreen biomes of southern China, mainland Southeast Asia and the islands. We explain this mixture by high resource availability. While light-triggered evergreen plants are filtered out in more arid and seasonal regions, they can persist and coexist with water-triggered evergreen plants if water availability is high. Whether plants are triggered by water or light might not have substantial impacts on vegetation dynamics and ecosystem functions in these areas.

A representation of vegetation as a mixture of various ecological strategies with overlapping climatic envelopes in aDGVM2 agrees with reality. For instance, distributions of $\mathrm{C}_{3}$ and $\mathrm{C}_{4}$ grasses typically overlap rather than being disjoint (Still et al., 2003). Ge and Xie (2017) found overlapping distributions of evergreen and deciduous trees in tropical China, and open woody ecosystems such as savannas are mixtures of grasses, shrubs and trees (Ratnam et al., 2011, 2016), ranging from low to high tree cover (Sankaran et al., 2005).

Our simulations revealed climate change impacts on the relative abundance of different ecological strategies, the biome type and the dominant phenological type. As expected, aDGVM2 mainly simulated transitions from small to tall biome types and from deciduous to evergreen biome types. Changes in height structure can be explained by $\mathrm{CO}_{2}$ fertilization and associated increases in growth rates and aboveground biomass of woody plants. Changes in phenology from water-triggered to light-triggered types can be explained by increasing precipitation and reduced transpirational demand in $\mathrm{C}_{3}$ plants (Figure S4.16). A meta-analysis by Soh et al. (2019) showed that increases in intrinsic water use efficiency in response to elevated $\mathrm{CO}_{2}$ are higher in evergreen plants than in deciduous plants, which may explain a relative advantage of evergreen plants over deciduous plants under elevated $\mathrm{CO}_{2}$ in aDGVM2. Phenology of simulated vegetation in the Himalayas was predominantly evergreen (Ralhan et al., 1985) and not influenced by climate change. Whether future temperature increase will influence phenology in these regions remains unclear as temperature does not directly trigger phenology in aDGVM2. Temperature may influence phenological strategies indirectly via impacts on the carbon 
balance and mortality and associated selection for certain strategies. Predictive understanding of plant phenology is still challenging. Further model development is required to integrate triggers such as water, temperature, nutrients, radiation or day length (Adole, Dash and Atkinson, 2018; Piao et al., 2019), for example to account for the effects of temperature increase on phenology and growing season length in alpine vegetation in the Himalayas, or to predict widely observed pre-rain greening (Adole, Dash and Atkinson, 2018).

Transitions from deciduous to evergreen vegetation simulated by aDGVM2 agree with previous modelling studies. Ravindranath et al. (2006) used the BIOME4 model to simulate the responses of Indian forest to SRES A2 and B2 simulated by the Hadley Centre model (HadRM3). In addition to changes towards evergreen phenology, their study reported increases in savanna vegetation and decreases in more xeric vegetation types. The effects were attributed to $\mathrm{CO}_{2}$ fertilization and associated increases in net primary productivity (Ravindranath et al., 2006). Chaturvedi et al. (2011) found transitions towards evergreen forests using the IBIS model.

Modelled transition rates of biomes and dominant phenology types might be overestimated compared to real transition rates. While it has been shown that species and biomes might not be able to keep pace with climate change (Loarie et al., 2009; Scheiter, Moncrieff, et al., 2020), most DGVMs ignore seed dispersal and associated migration lags (Corlett and Westcott, 2013). Models assume that local seed pools contain all functional types or ecological strategies that persisted during model spin-up, and that climate change or other disturbances influence the relative abundance of these types. This modelling approach represents an establishment bottleneck that prevents or delays invasion of inferior ecological strategies or functional types into local communities, but at the same time it represents a full dispersal scenario (Thuiller et al., 2005). While this caveat is well known (Corlett, 2009; Corlett and Westcott, 2013; Blanco et al., 2014; Scheiter, Moncrieff, et al., 2020), it has rarely been addressed in DGVMs (but see Sato and Ise, 2012). Reasons include the mismatch between the coarse resolution of DGVM studies (typically $0.5^{\circ}$ or coarser) and shorter dispersal distances, and knowledge gaps about dispersal distances, probabilities and pathways (Corlett, 2009). Modelling dispersal and migration is particularly challenging in highly fragmented and heterogeneous landscapes (Nabel, Zurbriggen and Lischke, 2013) such as the Himalayas or the islands of tropical Asia. 


\subsubsection{The ensemble approach}

Simulated aboveground biomass, vegetation height and biome patterns differed between ensemble members under both current and future climate conditions. These differences can be attributed both to stochastic processes in aDGVM2 that cause differences between model runs even for similar environmental forcing, and to differences between environmental forcing data in the ISIMIP climate data ensemble (Warszawski et al., 2014; Figure S4.1). Deviation between aDGVM2 ensemble members was higher in more arid regions. In these regions, environmental conditions showed higher interannual variation and stochastic processes in aDGVM2, such as fire occurrence or demographic processes, had a greater effect on vegetation dynamics. This model behaviour confirms a previous aDGVM result indicating that fire-driven and open ecosystems are more variable and take longer to reach an equilibrium state with prevailing environmental conditions than forest (Scheiter, Moncrieff, et al., 2020).

Projecting future climate using GCMs, particularly patterns of precipitation, is challenging. Differences between GCMs explain variation in climate data within the ISIMIP ensemble. For instance, simulations of the monsoon and associated variability in precipitation are still uncertain in models. Raghavan et al. (2018) compared CMIP5 simulations of historical rainfall to observations for Southeast Asia and found that none of the models represented observations particularly well. The benefit of using ensembles of climate change scenarios is therefore that a wide range of potential climate change impacts is covered, and that most likely vegetation changes can be identified.

\subsubsection{Anthropogenic impacts and implications for management}

Our results have important implications for management and conservation under climate change. First, we showed that areas in tropical Asia covered by natural vegetation are likely to remain carbon sinks until 2099, when ignoring land use changes. This provides support for forest conservation and restoration as climate change mitigation strategies (Graham et al., 2016). However, the carbon sink potential also implies possible transitions from ancient grasslands and savannas into forests, both due to natural processes and due to deliberate afforestation. Transitions to forests may lead to conflicts of interest between stakeholder groups promoting carbon sequestration by afforestation, and those promoting conservation of biodiversity and traditional land use practices in 
grassland and savanna ecosystems (Bond et al., 2019). Reaching compromises between these interest groups and the resident communities will be challenging but necessary to balance biodiversity conservation against successful climate change mitigation and adaptation.

Second, we found substantial differences between RCPs and GCMs. This underlines that the ensembles of climate scenarios and vegetation models are necessary to cover a wide range of possibilities required for the development of sustainable management strategies. Relying on a single set of climate forcing data may constrain the range of possible vegetation states and lead to inappropriate management decisions. Utilization of regionally adapted vegetation models (Moncrieff, Bond and Higgins, 2016; Moncrieff et al., 2016) and high-resolution climate forcings that capture the local climate phenomena are highly recommended.

Third, our results indicate a trade-off between monitoring past and future vegetation changes by continuous state variables, such as aboveground biomass or tree cover, and classifying vegetation into biomes. The advantage of biome classification is that biomes reflect the status of multiple state variables and the associated ecosystem functions (Higgins, Buitenwerf and Moncrieff, 2016; Moncrieff, Bond and Higgins, 2016; Moncrieff et al., 2016). Biome transitions indicate simultaneous changes in multiple features of vegetation. Biomes are a compelling framework to understand largescale biogeographic patterns, and to communicate model results in an aggregated way. A caveat of using biomes is that biome transitions may suggest fundamental vegetation changes, species turnover or non-linear tipping-point behaviour. In fact, biome transitions might be triggered by smooth and moderate changes in variables used to define biome types.

The advantage of using continuous state variables is that even small changes in the vegetation state can be detected. Such changes might not necessarily modify the biome state but nonetheless influence the vegetation state and ecosystem functions. Keeping track of simultaneous changes in multiple state variables and interpreting the implications for ecosystem functioning might be more difficult than using a biome approach (Conradi et al., 2020). There is no single consensus biome classification scheme that adequately covers all biome types globally (Moncrieff, Bond and Higgins, 2016; Moncrieff et al., 2016; Mucina, 2019), and that can be applied in modelling studies, 
remote sensing and other observational studies. We argue that biome classification schemes should be tailored to specific research questions to ensure that they reflect targeted vegetation states and ecosystem functions. Inappropriate classification of vegetation may misguide decision-making (Kumar, Pfeiffer, Gaillard, Langan, Martens, et al., 2020).

Finally, we showed that areas with deciduous vegetation are most susceptible to climate change. They included grasslands in Afghanistan and Pakistan, as well as deciduous vegetation on the Indian peninsula and in mainland Southeast Asia. However, large proportions of these areas have already been transformed into managed land, and the areas not affected by direct anthropogenic effects are mostly small and scattered. This result highlights an urgent need to conserve and protect remaining patches of natural vegetation that are exposed to both anthropogenic pressure and climate change. Future high-resolution and region-specific modelling studies can help to identify migration corridors for different vegetation types and inform planning of protected areas, humanassisted migration (Corlett, 2009), and the establishment or restoration of habitat connectivity (Corlett and Westcott, 2013), while accounting for climate change impacts on vegetation. Here, we focused on natural vegetation and implications for remaining areas of undisturbed vegetation. Future studies should include more detailed land use scenarios to better account for historic and future land use change in the study region, including various scenarios for changes in plantations, crop production, urbanization or pollution and their impacts on vegetation growth. This can be achieved by using largescale products such as the harmonized land use scenarios (Hurtt et al., 2020), by considering Shared Socio-economic Pathways (Popp et al., 2017), and also by considering local-scale land use activities such as grazing, fire management or fuelwood harvesting. Some of these factors have been included into aDGVM and aDGVM2 previously, and their impacts on vegetation structure or regional-scale vegetation patterns have been investigated (Scheiter et al., 2015, 2019; Scheiter and Savadogo, 2016; Pfeiffer et al., 2019).

Despite recent developments in vegetation modelling, there is still a need to further improve our projections of future vegetation and biogeochemical cycles in order to provide reliable information for decision-making. First, we need an improved understanding of the effects of elevated $\mathrm{CO}_{2}$ on vegetation, and how $\mathrm{CO}_{2}$ fertilization is influenced by source or sink dynamics (Körner, 2015), microbial communities (Terrer et 
al., 2016), nutrient limitation and temperature or drought stress. Open-top chamber experiments or FACE experiments are required in the study region to enhance our knowledge. Second, the topography of tropical Asia is complex and heterogeneous in comparison to Africa or lowland rain forests of tropical South America. Tropical Asia includes numerous islands and the Himalayas. This complexity also implies high diversity of species and biome types (Kumar and Scheiter, 2019). Improving vegetation models by including, for example, slope and aspect, and associated impacts on radiation balance, hydrology, dispersal and migration, will improve our understanding of future vegetation. Third, high-resolution climate data from process-based downscaling and accurate soil data are required to account for environmental heterogeneity. Fourth, vegetation models require a capacity to represent the various vegetation types forming biomes of tropical Asia. Vegetation types such as bamboo thickets or mangroves are typically not included in DGVMs, and aDGVM2 does not simulate giant trees present in Asian forests. Kumar and Scheiter (2019) proposed concepts on how to model these vegetation types. Finally, changes of the land surface due to simulated vegetation and phenology change or land use change modify albedo, as well as the water and carbon cycle. These changes influence the climate system via complex feedbacks (Bonan, 2008). Assessments of such feedbacks require coupling of aDGVM2 with climate models.

\subsection{Conclusion}

We found that climate change and $\mathrm{CO}_{2}$ fertilization will likely increase woody biomass in tropical Asia until 2099. This trend was robust for an ensemble of different climate change scenarios and different climate models. Changes in aboveground biomass were associated with changes in phenology and vegetation structure, particularly with transitions from small deciduous vegetation to tall evergreen vegetation. These findings indicate that natural vegetation in tropical Asia will remain a carbon sink until 2099 with a high potential for carbon sequestration. Any human conversion of such natural vegetation into cropland might pose a threat to the carbon sink, as croplands and plantations typically store less carbon than natural vegetation. However, the trend towards more vegetation biomass also implies a risk for ecosystems with low woody cover, such as ancient grasslands or savannas. These ecosystems were most vulnerable to climate change impacts in our simulations, and a decrease in their extent and associated losses of biodiversity is likely. Conservation of these ecosystems is therefore required. 
Our results indicate a high potential for carbon sequestration initiatives, and at the same time indicate a high risk of vegetation change in ecosystems with low woody cover in protected areas. A careful balance of biodiversity conservation against carbon sequestration initiatives in the context of climate change adaptation and mitigation is mandatory.

\subsection{Acknowledgements}

S.S. and D.K. thank the Deutsche Forschungsgemeinschaft (DFG) for funding (Emmy Noether grant SCHE 1719/2-1). M.P. and C.M. acknowledge funding by the German Federal Ministry of Education and Research (BMBF, SPACES2 initiative, 'SALLnet' project, grant 01LL1802B and 'EMSAfrica' project, grant 01LL1801B). R.S.L. is sponsored by CAS-TWAS President's Fellowship for International Doctoral Students (grant 2016CTF096). This research was also supported by a joint Natural Science Foundation of China-Yunnan Government grant to K.W.T. and R.T.C. (U1502264).

\subsection{Conflict of Interest}

The authors declare that they have no conflict of interest. 


\section{SUPPLEMENTARY INFORMATION}

\section{aDGVM2 model description}

The following paragraphs provide a short description of the aDGVM2. A full description of the original model version is provided by Langan et al. (2017). We used an updated model version that (1) includes both $\mathrm{C}_{3}$ and $\mathrm{C}_{4}$ grasses (Kumar et al., 2020a; Kumar et al., 2020b), in contrast to previous versions that only included $\mathrm{C}_{4}$ grasses, (2) simulates plant-specific leaf-level photosynthetic rates based on leaf temperature and leaf traits such as the specific leaf area (Kumar, et al., 2020a, b), and (3) simulates both singlestemmed trees and multi-stemmed shrubs, where trees are better competitors in lightlimited environments whereas shrubs are better competitors in water-limited environments due to a trade-o between height and water uptake capacity (Gaillard et al., 2018).

The model simulates growth, reproduction, and mortality of individual plants while keeping track of state variables, such as biomass, height, and leaf area. Each plant in aDGVM2 is characterized by a plant-specific set of trait values. Traits describe growth form, leaf characteristics, hydraulic characteristics, resource allocation, architecture, reproduction, mortality, and response to disturbance. Most plant traits are linked by tradeo s to constrain possible trait combinations. Selection and trait inheritance assemble plant communities that are adapted to biotic and abiotic conditions. Plants with trait combinations that allow sufficient growth and reproduction rates, and that allow plants to cope with competition and disturbances can contribute their trait values to the community trait pool. Trait mutation and recombination may alter trait values in the community trait pool. Randomly drawn seeds from the trait pool are added to the plant population as seedlings. Plants that are not adapted to the prevailing disturbance regimes, biotic and abiotic conditions, or that do not allocate enough carbon to reproduction disappear from the population. Therefore, successful ecological strategies emerge dynamically from this community assembly process.

The aDGVM2 simulates four different phenological types: evergreen lighttriggered, ever-green water-triggered, deciduous light-triggered and deciduous watertriggered (Langan et al., 2017). Woody plants can adopt all four types whereas we assume that grasses are evergreen. Whether a plant is deciduous or evergreen and whether it is light- or water-triggered are two dynamic traits that are constant during the 
lifespan of a plant, but that can change between generations due to trait inheritance and community assembly processes in aDGVM2. Deciduous vegetation switches between a dormant and a metabolically active state once moving averages of soil matric potential (water-triggered) or solar radiation (light-triggered) exceed or fall below threshold values. Evergreen woody plants remain metabolically active during their entire life time. However, leaf flushing of evergreen plants is stimulated by water and light triggers, i.e., leaf flushing occurs once moving averages of soil matric potential (water-triggered) or solar radiation (light-triggered) exceed threshold values. The threshold values are plantspecific dynamic traits. They are constant during the lifespan of a plant but they can change between generations due to trait inheritance and the community assembly processes in aDGVM2. While our approach does not allow plants to switch between phenological strategies during their lifetime, growing season length can adjust to interannual variation of the climate, because the thresholds used to trigger phenology can be crossed earlier or later in the year.

The aDGVM2 simulates natural surface fire regimes (Langan et al., 2017). Grass biomass and leaf litter on the ground contribute to fuel biomass. Fuel biomass and fuel moisture are used to calculate the potential re intensity (Higgins et al., 2008). Fire spreads in a grid cell when fuel biomass is dry enough to carry fire and when the re intensity exceeds a threshold of $300 \mathrm{~kJ} \mathrm{~s}^{-1} \mathrm{~m}^{-1}$. To approximate the moisture status of fuel biomass, we use the matric potential of the upper soil layer. Fuel moisture is then used to calculate fire probability, and fire spreads if a random number is lower than the fire probability. Fire removes the total aboveground grass biomass and aboveground biomass of trees that are not well protected against fire. Specifically, we use a 'topkill' function characterized by tree height and bark thickness (Langan et al., 2017; Higgins et al., 2008) to simulate if fire damages a tree or not. Both grasses and trees can recover from are disturbance by re-allocating biomass from the storage pool to leaf and stem biomass. The size of the storage pool is thereby influences by a dynamic trait that defines the amount of carbon allocated to the storage biomass compartment. The community assembly processes and trait inheritance allow aDGVM2 to select for plants and communities that are well adapted to fire. Pathways are high allocation to bark for protection, high allocation to storage for reproduction, or low wood density and an architecture that allows rapid height growth and escaping from the flame zone. Anthropogenic fire is not considered in aDGVM2. 
Chapter 4-Climate change promotes transitions to tall evergreen vegetation in tropical Asia

Table S 4.1 Cover of aggregated biome types for current (2019) and future (2099) climate condi-tions for RCP4.5 and RCP8.5. Values were derived from Table 4.1. Cover is provided as percentage of grid cells covered by di erent aggregated biomes. Cover fractions for all ensemble members and the ensemble mean are provided. Values for cur-rent conditions are provided twice, because simulations slightly diverge between RCP4.5 and RCP8.5 due to model stochasticity and di erences in the climate data sets. Models: 'M1' GFDL-ESM2M; 'M2' HadGEM2-ES; 'M3' IPSL-CM5A-LR; 'M4' MIROC-ESM; 'M5' NorESM1-M; 'Ens' ensemble mean.

\begin{tabular}{|c|c|c|c|c|c|c|c|c|}
\hline Biome & Time & RCP & M1 & M2 & M3 & M4 & M5 & Ens \\
\hline \multirow{4}{*}{$\begin{array}{l}\text { Grassland } \\
\left(\mathrm{C}_{3} \text { and } \mathrm{C}_{4}\right)\end{array}$} & current & 4.5 & 5.6 & 9.8 & 6.6 & 10.2 & 7.5 & 7.8 \\
\hline & future & 4.5 & 6.9 & 8.9 & 7.2 & 9.3 & 7.3 & 7.9 \\
\hline & current & 8.5 & 6.3 & 9.7 & 7.1 & 9.5 & 7.6 & 7.7 \\
\hline & future & 8.5 & 5.4 & 8.4 & 6.6 & 8.1 & 6.9 & 7.1 \\
\hline \multirow{4}{*}{$\begin{array}{l}\text { Short } \\
\text { (deciduous and evergreen) }\end{array}$} & current & 4.5 & 16.7 & 19.7 & 23.5 & 14.4 & 18.6 & 18.4 \\
\hline & future & 4.5 & 13.9 & 17.9 & 19.3 & 11.7 & 14.4 & 13.8 \\
\hline & current & 8.5 & 16.3 & 19.8 & 23.0 & 14.0 & 18.1 & 17.5 \\
\hline & future & 8.5 & 14.7 & 16.7 & 19.4 & 11.3 & 13.8 & 14.3 \\
\hline \multirow{4}{*}{$\begin{array}{l}\text { Tall } \\
\text { (deciduous } \\
\text { and evergreen) }\end{array}$} & current & 4.5 & 72.3 & 67.7 & 66.9 & 72.8 & 71.0 & 71.1 \\
\hline & future & 4.5 & 75.3 & 70.2 & 69.4 & 76.3 & 75.3 & 75.6 \\
\hline & current & 8.5 & 72.7 & 67.8 & 66.8 & 73.7 & 71.1 & 71.6 \\
\hline & future & 8.5 & 74.9 & 72.0 & 70.4 & 77.7 & 76.5 & 75.7 \\
\hline \multirow{4}{*}{$\begin{array}{l}\text { Deciduous } \\
\text { (short and tall) }\end{array}$} & current & 4.5 & 42.8 & 27.9 & 33.1 & 23.9 & 28.3 & 31.5 \\
\hline & future & 4.5 & 41.8 & 25.3 & 32.1 & 23.9 & 28.1 & 30.6 \\
\hline & current & 8.5 & 43.4 & 27.2 & 32.0 & 24.0 & 27.8 & 30.6 \\
\hline & future & 8.5 & 41.6 & 25.0 & 31.4 & 24.7 & 28.3 & 30.3 \\
\hline \multirow{4}{*}{$\begin{array}{l}\text { Evergreen } \\
\text { (short and tall) }\end{array}$} & current & 4.5 & 46.2 & 59.5 & 57.3 & 63.3 & 61.3 & 58.0 \\
\hline & future & 4.5 & 47.4 & 62.8 & 56.6 & 64.1 & 61.6 & 58.8 \\
\hline & current & 8.5 & 45.6 & 60.4 & 57.8 & 63.7 & 61.4 & 58.5 \\
\hline & future & 8.5 & 48.0 & 63.7 & 58.4 & 64.3 & 62.0 & 59.7 \\
\hline
\end{tabular}



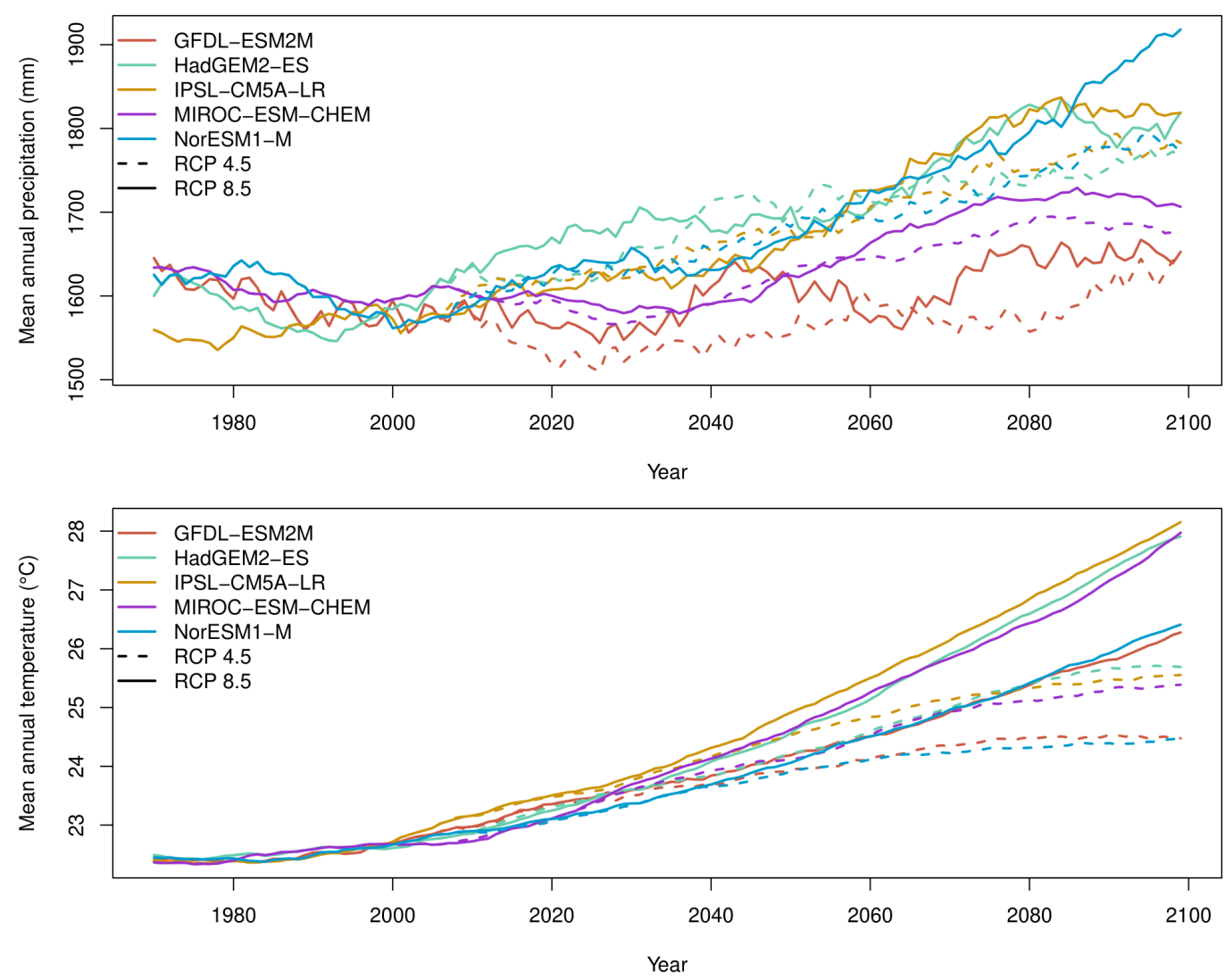

Figure S 4.1 Mean annual precipitation and mean annual temperature for the study region in different RCPs simulated with different GCMs. Time series represent 20 year sliding averages, i.e. the rest value in 1970 represents the average for the period 1951 to 1970, the last value in 2099 represents the period between 2080 and 2099.

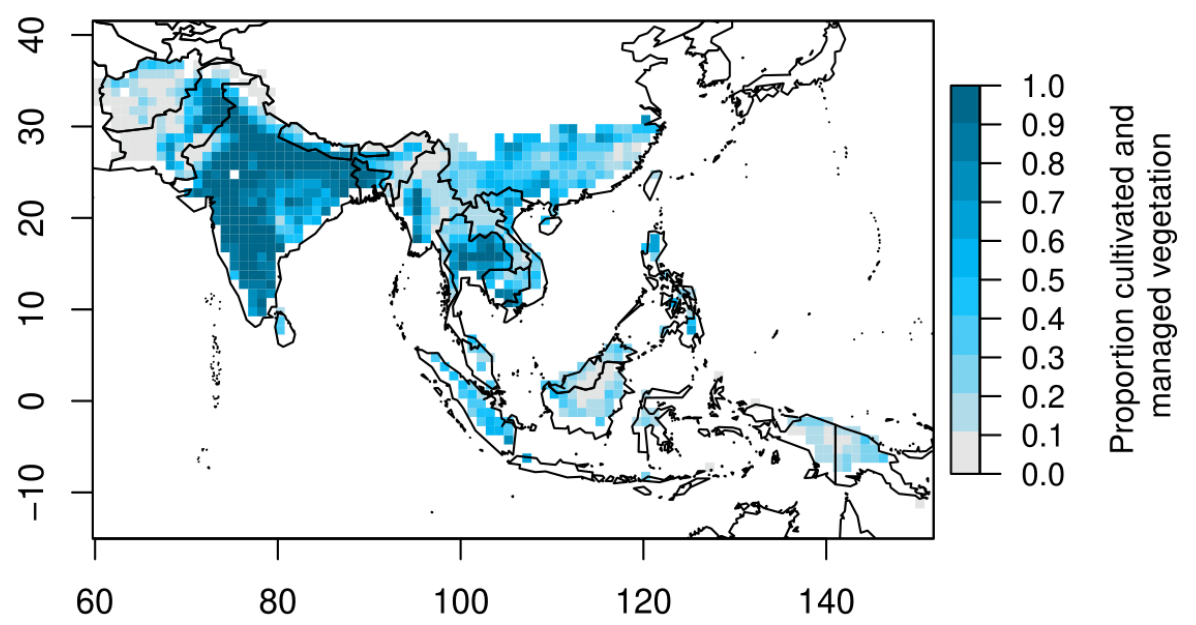

Figure $S 4.2$ Proportion of cultivated and managed vegetation in the study region. Data were obtained from Tuanmu \& Jetz (2014) and aggregated at 1 spatial resolution. The map includes 'cultivated and managed vegetation' (class 7) and 'Urban/Built-up' (class 9) of the Tuanmu \& Jetz (2014) data set. 

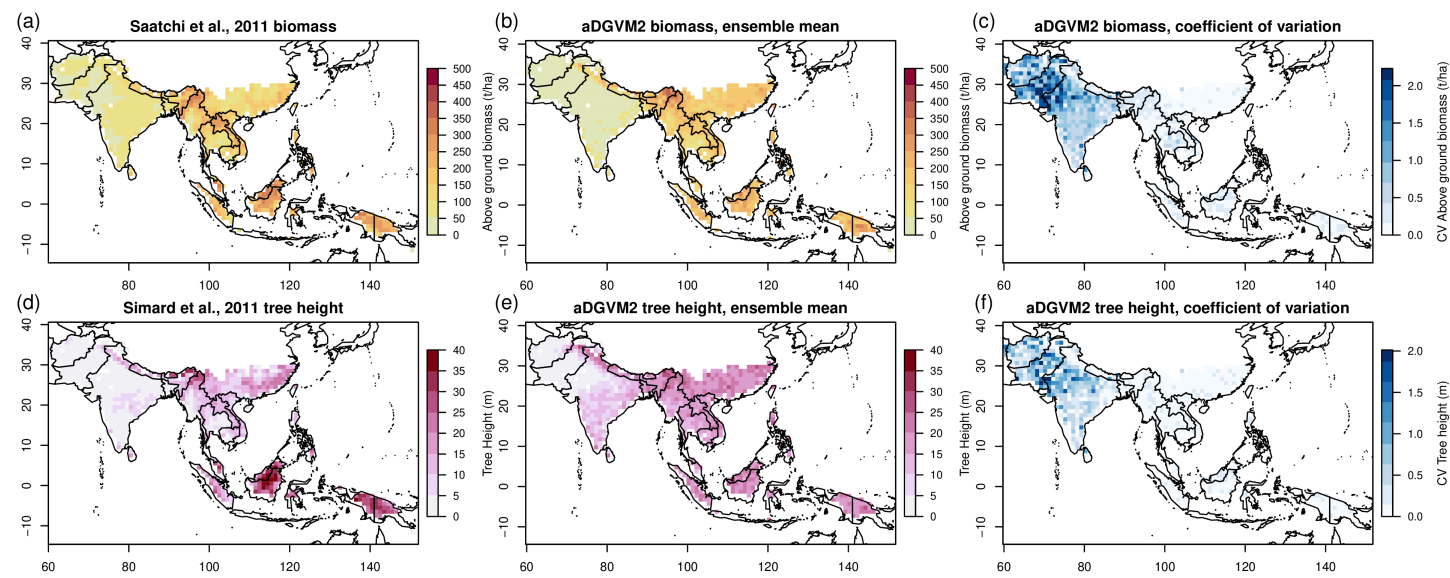

Figure $S 4.3$ Biomass $(a, b, c)$ and tree height $(d, e, f)$ derived from remote sensing $(a, d$, Saatchi et al. 2011; Simard et al. 2011) and simulated by aDGVM2 under current conditions (b, e, year 2019). Panels (c, f) show model uncertainty, represented by the coefficient of variation. For aboveground biomass and height, we calculated mean and coefficient of variation for the ensemble of very different GCMs for RCP4.5. Vegetation height of an ensemble member is represented by the $90^{\text {th }}$ percentile of all woody plants.
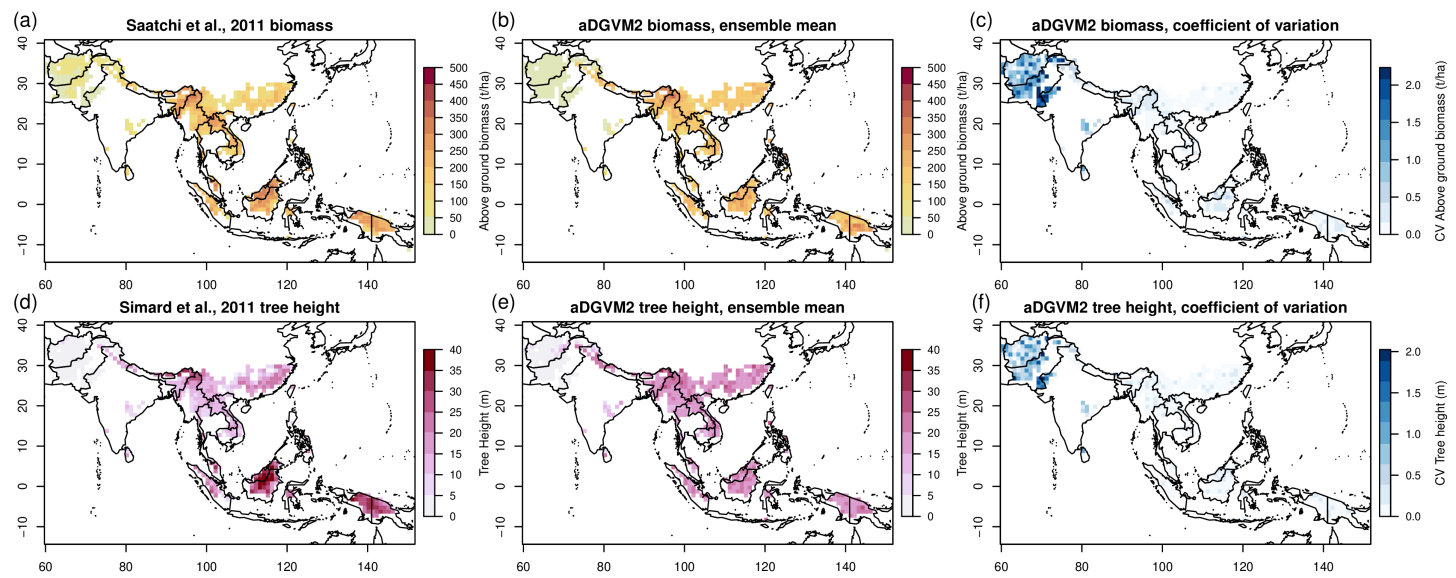

Figure $S 4.4$ Biomass $(a, b, c)$ and tree height $(d, e, f)$ derived from remote sensing $(a, d$, Saatchi et al. 2011; Simard et al. 2011) and simulated by aDGVM2 under current conditions (b, e, year 2019). Areas with more than 50\% cultivated and managed land (Tuanmu \& Jetz 2014) are excluded. Panels (c, f) show model uncertainty, represented by the coefficient of variation. For aboveground biomass and height, we calculated mean and coefficient of variation for the ensemble of very different GCMs for RCP8.5. Vegetation height of an ensemble member is represented by the $90^{\text {th }}$ percentile of all woody plants. 

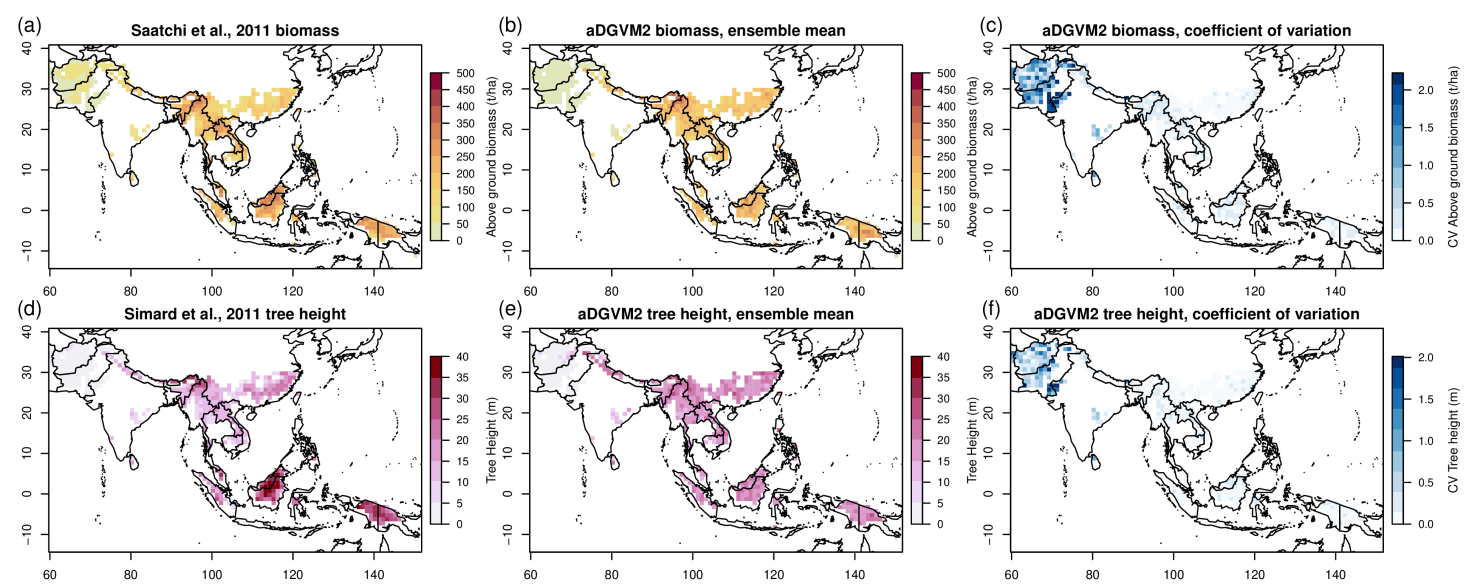

Figure $S 4.5$ Biomass $(a, b, c)$ and tree height $(d, e, f)$ derived from remote sensing $(a, d$, Saatchi et al. 2011; Simard et al. 2011) and simulated by aDGVM2 under current conditions (b, e, year 2019). Areas with more than 50\% cultivated and managed land (Tuanmu \& Jetz 2014) are excluded. Panels (c, f) show model uncertainty, represented by the coefficient of variation. For aboveground biomass and height, we calculated mean and coefficient of variation for the ensemble of very different GCMs for RCP4.5. Vegetation height of an ensemble member is represented by the $90^{\text {th }}$ percentile of all woody plants.
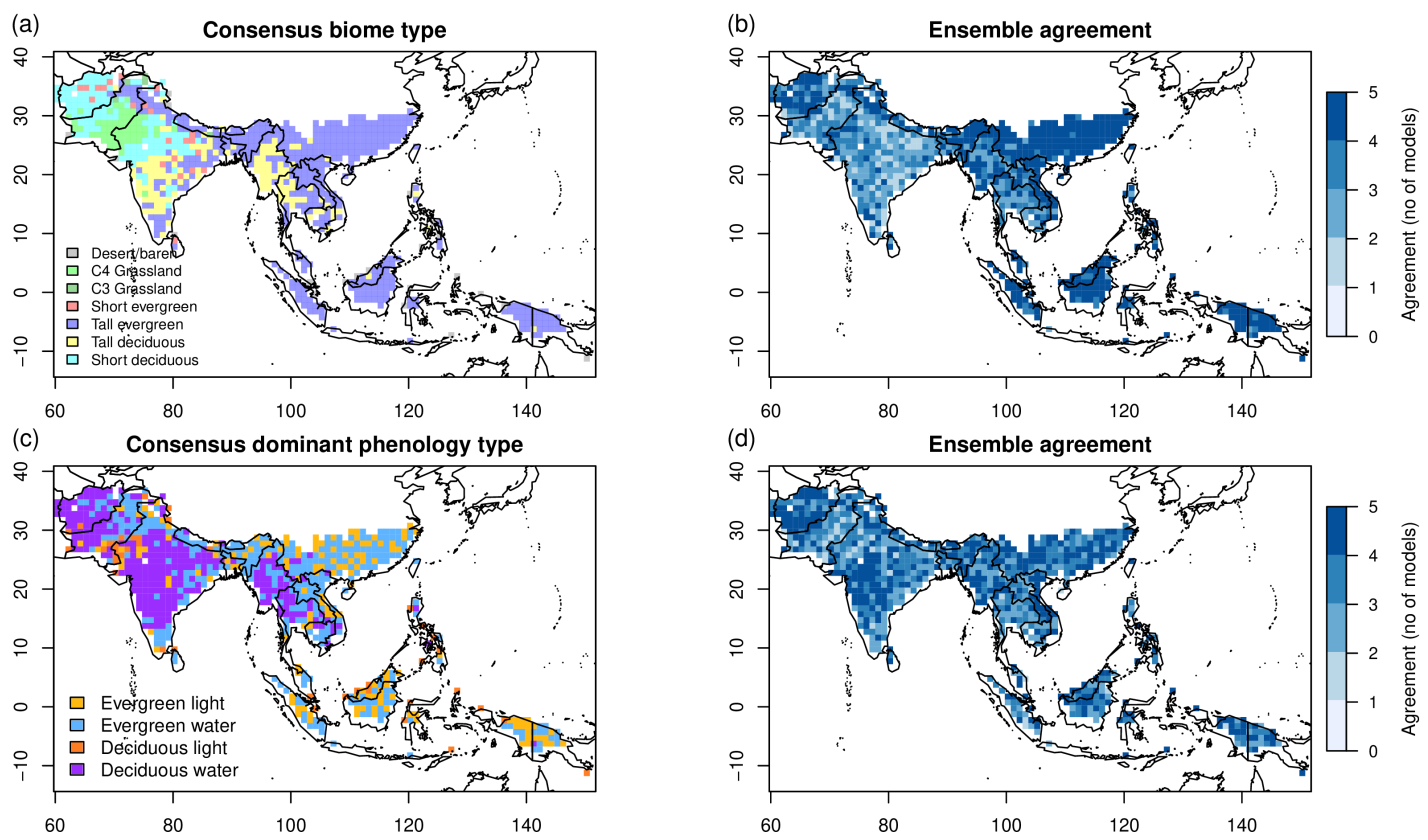

Figure S 4.6 Consensus biome types (a) and dominant phenology types (c) simulated by $a D G V M 2$ under current conditions (year 2019). (a, c) show consensus maps, (b, d) show uncertainty, represented by the number of ensemble members that simulate the consensus type. Simulations were conducted for RCP4.5. 
Chapter 4-Climate change promotes transitions to tall evergreen vegetation in tropical Asia
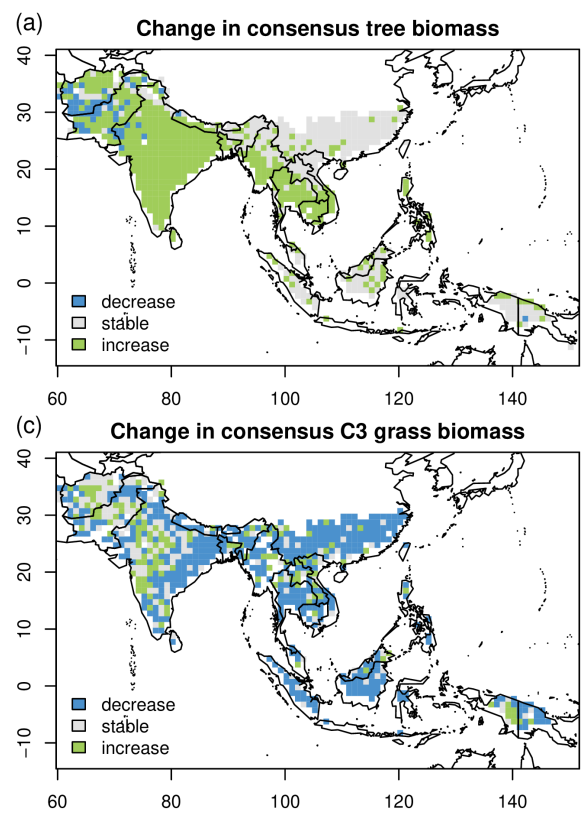
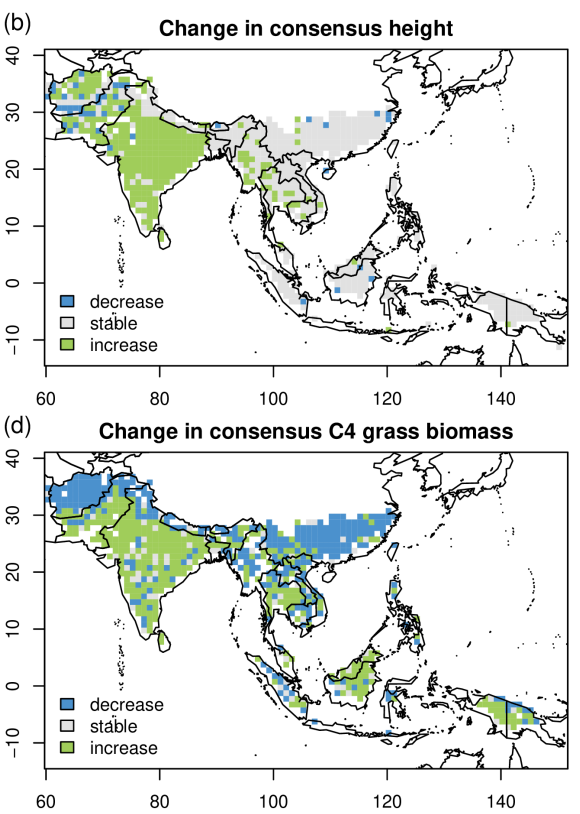

Figure S 4.7 Areas where aboveground tree biomass and height change by more than $10 \%$ between current (year 2019) and future (year 2099) conditions in RCP4.5. For biomass, we used aboveground tree biomass (a), C3 grass biomass (c) and $C_{4}$ grass biomass (d) in a grid cell, for vegetation height (b), we used the $90^{\text {th }}$ percentile of all trees simulated in a grid cell.
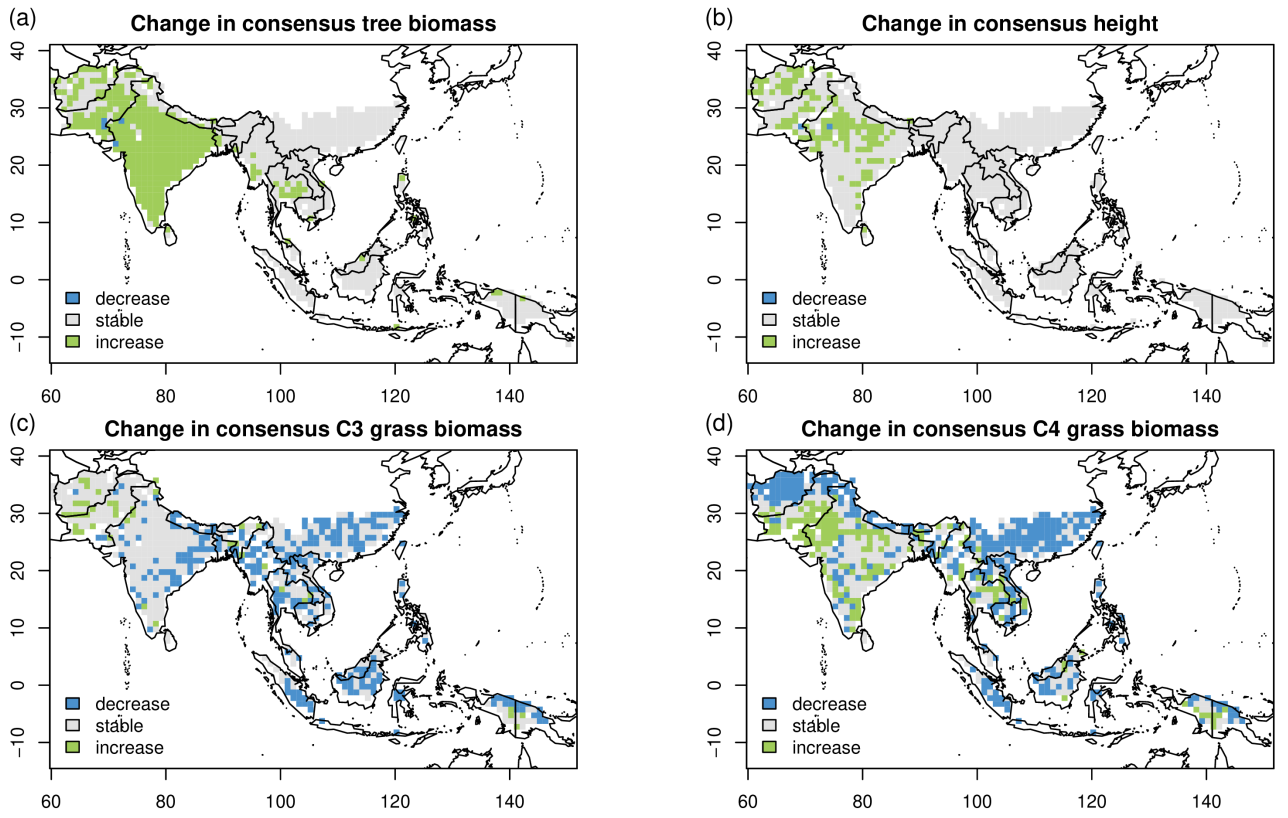

Figure S 4.8 Areas where aboveground tree biomass and height change by more than $50 \%$ between current (year 2019) and future (year 2099) conditions in RCP8.5. For biomass, we used aboveground tree biomass (a), $C_{3}$ grass biomass (c) and C4 grass biomass (d) in a grid cell, for vegetation height (b), we used the 90th percentile of all trees simulated in a grid cell. 

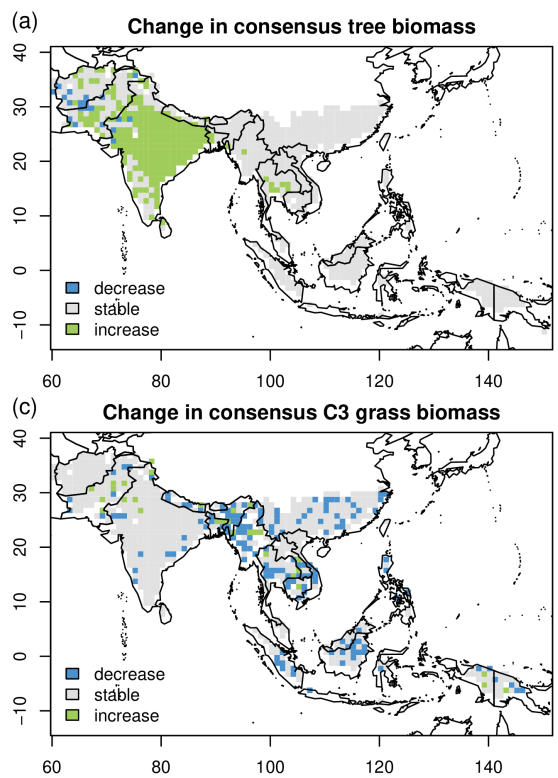
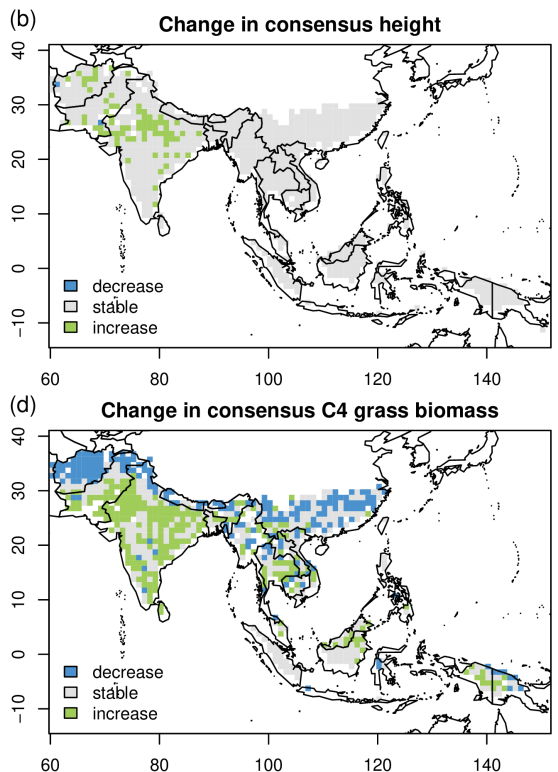

Figure S 4.9 Areas where aboveground tree biomass and height change by more than $\pm 50 \%$ between current (year 2019) and future (year 2099) conditions in RCP4.5. For biomass, we used aboveground tree biomass (a), $C_{3}$ grass biomass (c) and $C_{4}$ grass biomass (d) in a grid cell, for vegetation height (b), we used the 90th percentile of all trees simulated in a grid cell
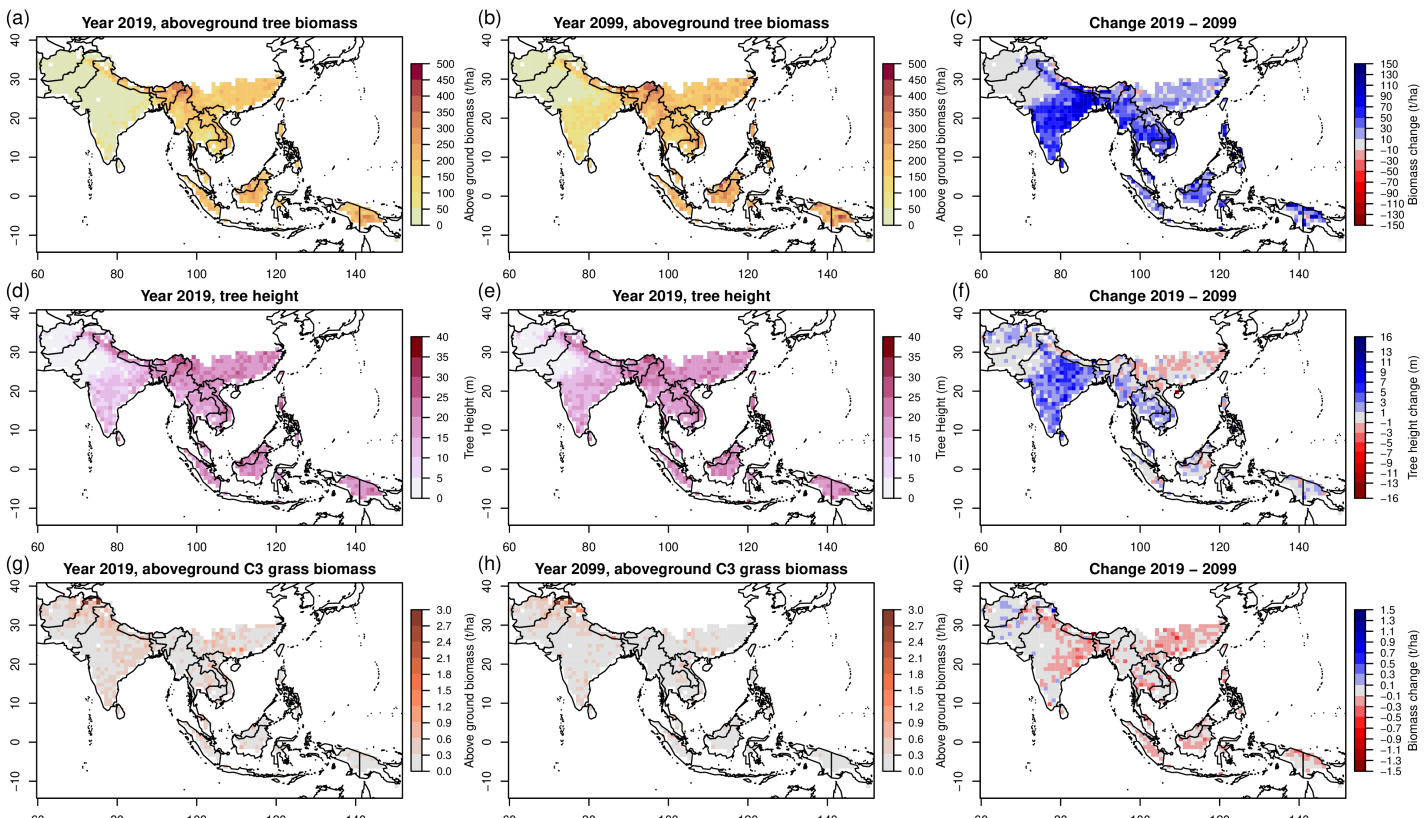

(j) ${ }^{60} \begin{array}{cccc}80 & 100 & 120 & 140 \\ & \text { Year 2019, aboveground } & \text { C4 } & \text { grass biomass }\end{array}$
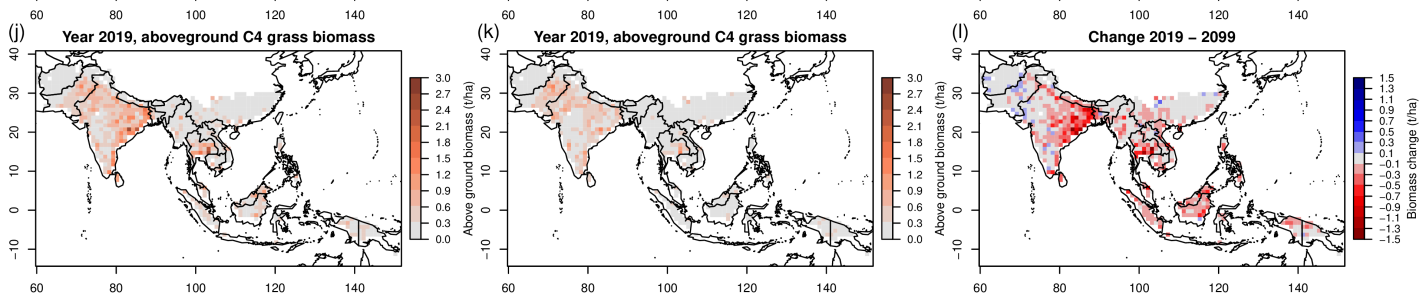

Figure $S 4.10$ Aboveground tree biomass $(a, b, c)$, tree height $(d, e, f), C_{3}$ grass biomass $(g, h, i)$ and $C_{4}$ grass biomass $(j, k, l)$ for current conditions (a,d,g,j, year 2019), future conditions (b,e,h,k, year 2099), as well as changes between current and future conditions $(c, f, i, l)$. Tree height is represented by the $90^{\text {th }}$ percentile of all trees simulated in a grid cell. Maps show results for RCP8.5. 
Chapter 4-Climate change promotes transitions to tall evergreen vegetation in tropical Asia

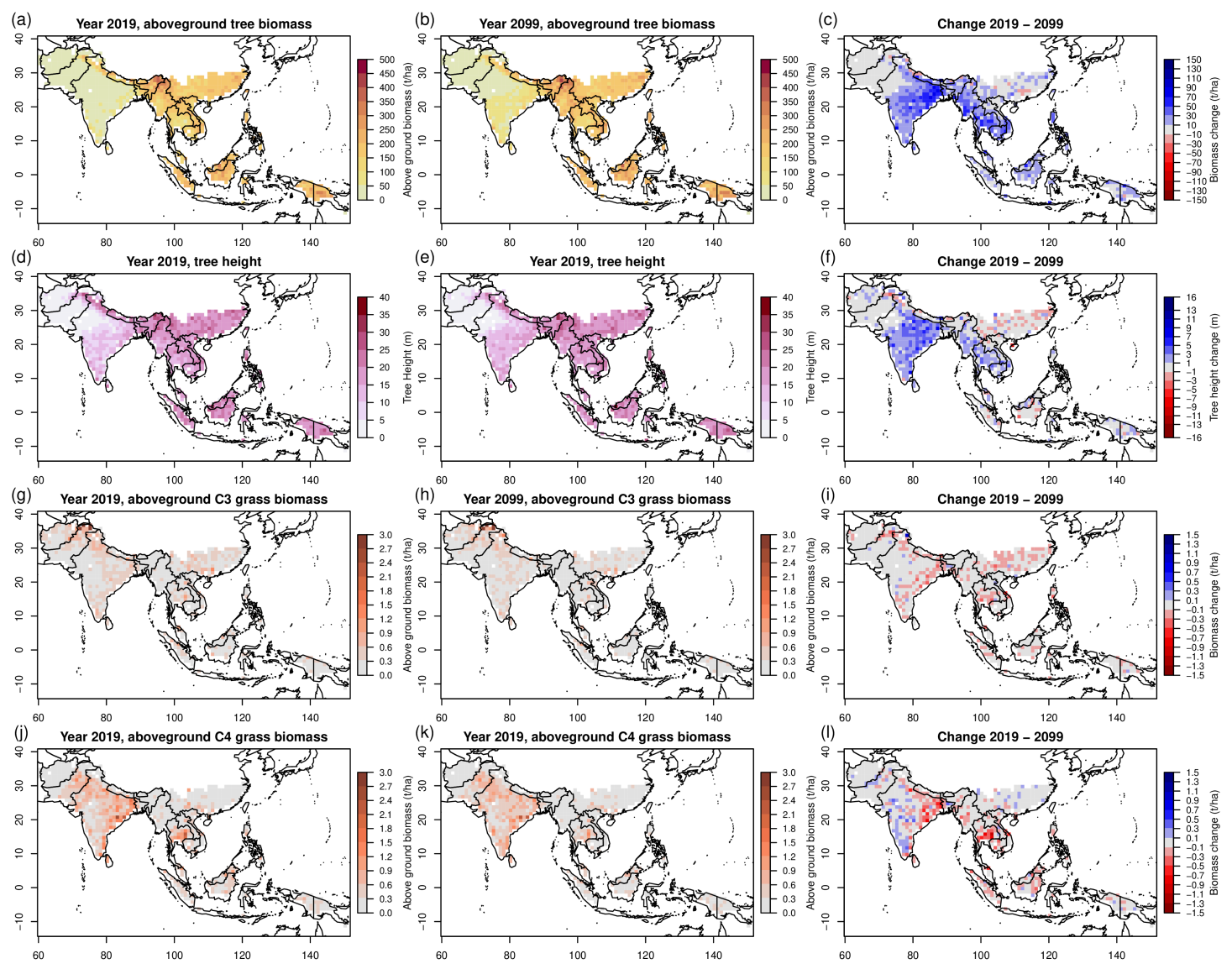

Figure S 4.11 Aboveground tree biomass (a,b,c), tree height (d,e,f), $C_{3}$ grass biomass $(g, h, i)$ and $C_{4}$ grass biomass $(j, k, l)$ for current conditions (a,d,g,j, year 2019), future conditions (b,e,h,k, year 2099), as well as changes between current and future conditions $(c, f, i, l)$. Tree height is represented by the $90 \%$-percentile of all trees simulated in a grid cell. Maps show results for RCP4.5. 

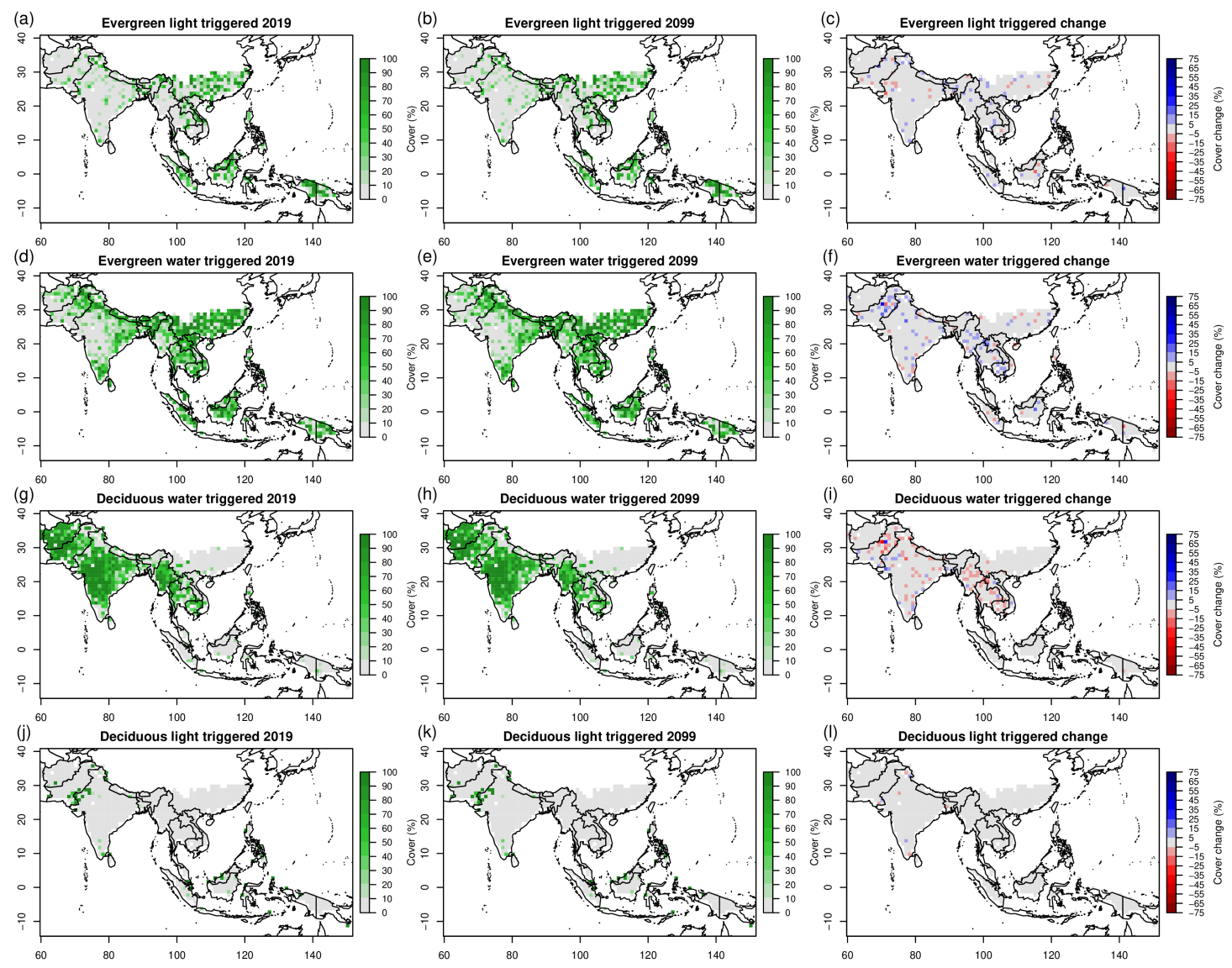

Figure S 4.12 Relative abundance of different phenological strategies under current (year 2019) and future (year 2099) conditions, as well as change within this time period. Phenological strategies are evergreen light-triggered $(a, b, c)$, evergreen water-triggered $(d, e, f)$, deciduous water triggered $(g, h, i)$, and deciduous lighttriggered $(j, k, l)$. Simulations for current conditions $(a, d, g, j)$, future conditions $(b, e, h, k)$ and changes between current and future conditions $(c, f, i, l)$ are provided. The maps show ensemble means for RCP4.5. 
Chapter 4-Climate change promotes transitions to tall evergreen vegetation in tropical Asia
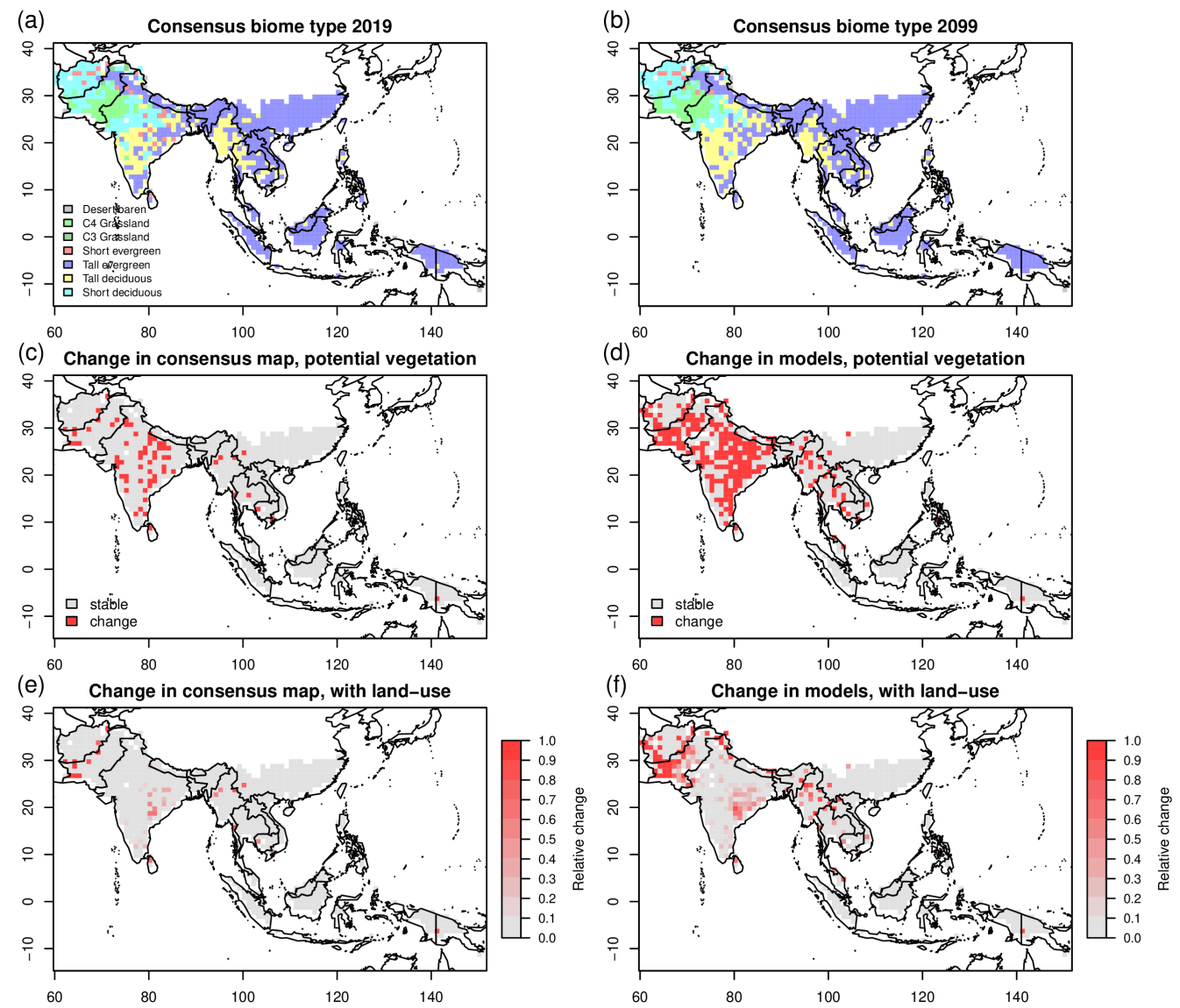

Figure S 4.13 Consensus map of current (a, year 2019) and future (b, 2099) biome distribution for the ensemble in RCP4.5. Areas where biomes shift between 2019 and 2099 were simulated for the consensus map (c,e) and in at least one ensemble members $(d, f)$ without land use impacts $(c, d)$ and with land use impacts $(e, f)$ are highlighted. Land use was derived from Tuanmu \& Jetz (2014). 

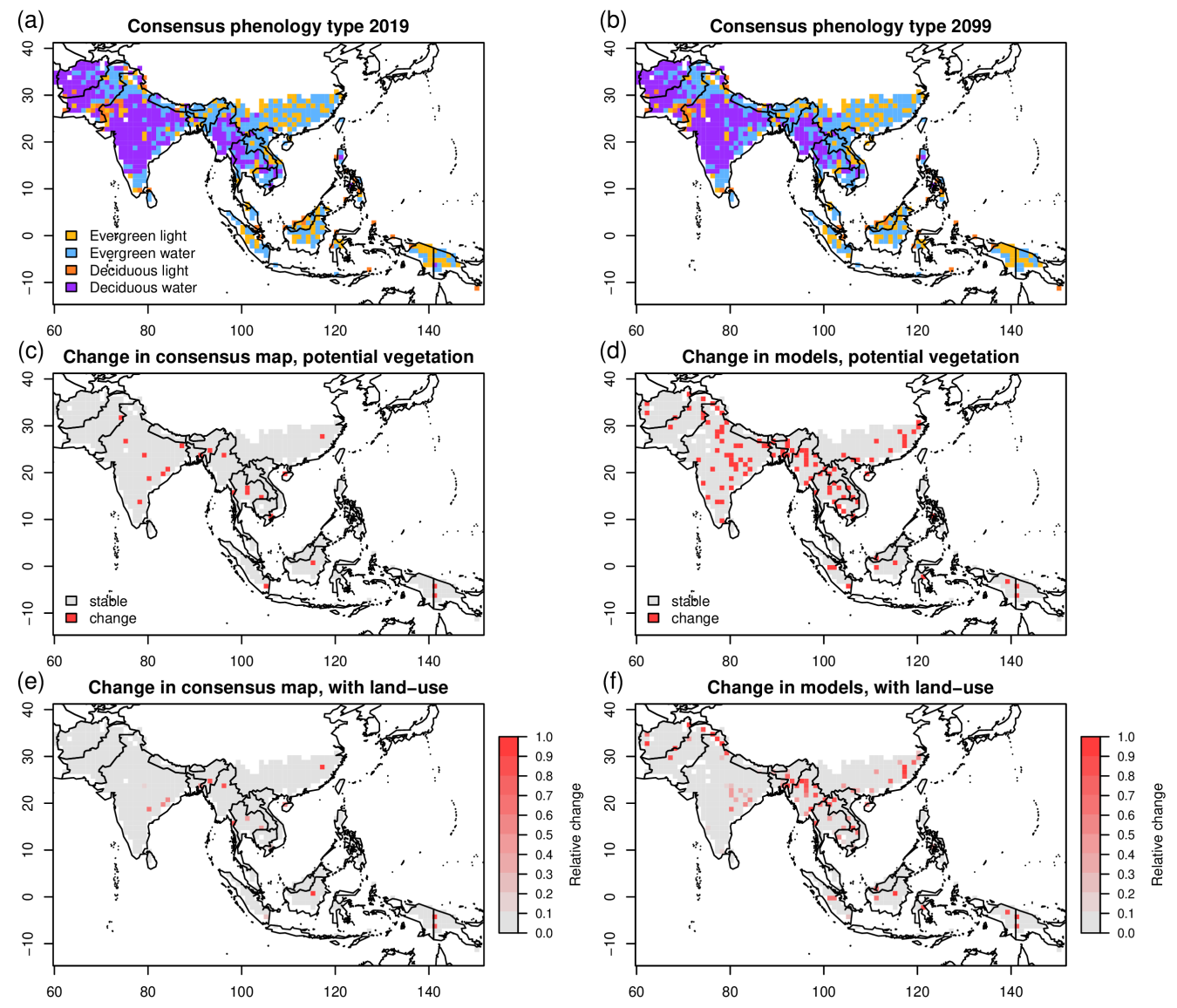

Figure S 4.14 Consensus map of current (a, year 2019) and future (b, 2099) distribution of dominant phenological types for the ensemble in RCP4.5. Areas where phenology shifts between 2019 and 2099 were simulated for the consensus map $(c, e)$ and for at least one ensemble members $(d, f)$ without land use impacts $(c, d)$ and with land use impacts (e,f) are highlighted. Land use was derived from Tuanmu \& Jetz (2014). 
Chapter 4-Climate change promotes transitions to tall evergreen vegetation in tropical Asia

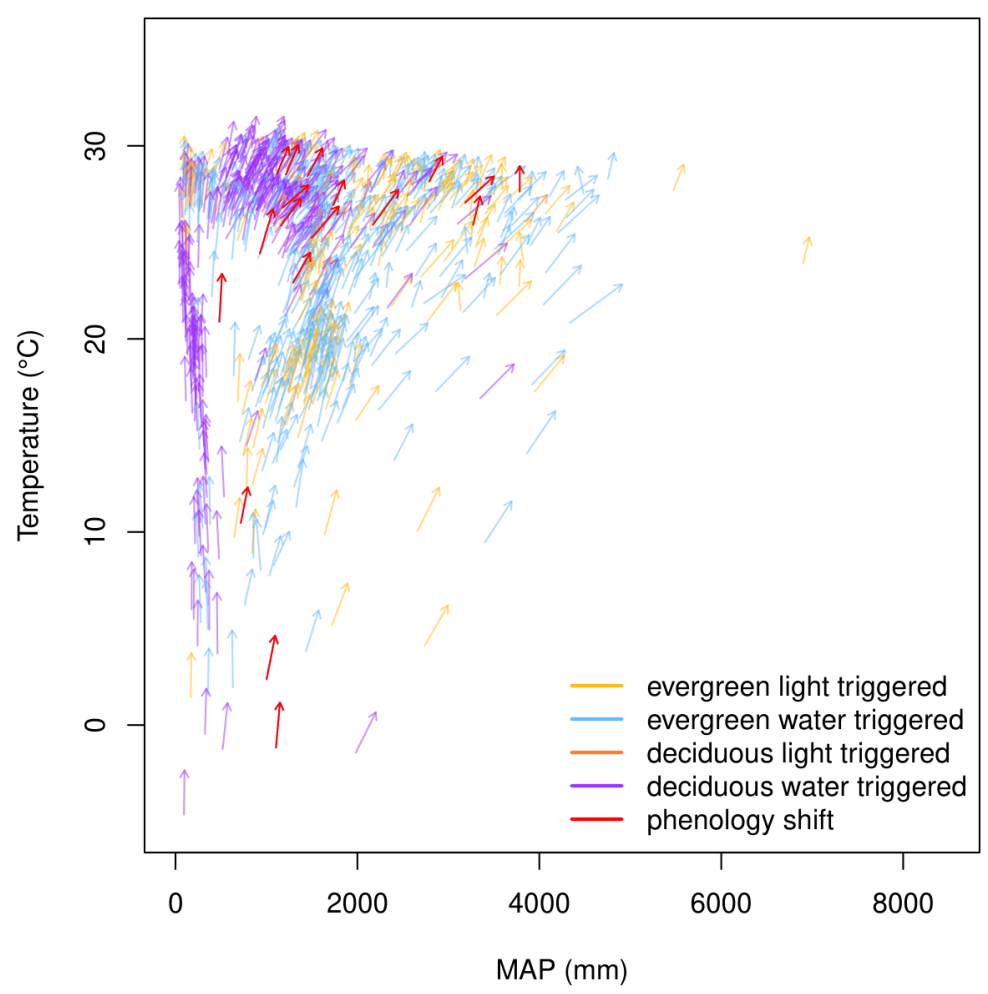

Figure S 4.15 Transitions of dominant phenology in precipitation-temperature space for RCP4.5 ensemble. Origin and end of arrows indicate location of each grid cell in the climate space in 2019 and 2099, colors indicate different dominant phenological strategies and if a transition in the phenology was projected (red arrows) or not (other colors).

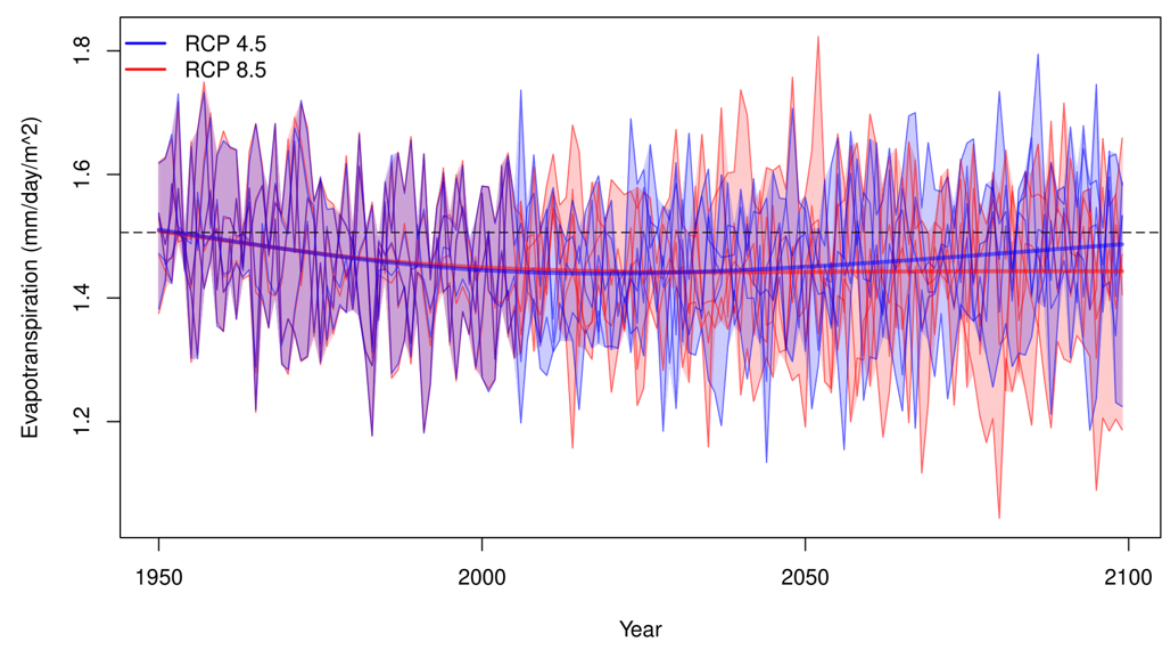

Figure S 4.16 Transpiration in the model ensemble between 1950 and 2099. Thin lines represent mean annual transpiration in simulations with different GCMs, bold lines represent annual ensemble means for RCP4.5 and RCP8.5, and shaded areas represent the range (minimum and maximum) of the ensemble in both RCPs. 


\title{
CHAPTER 5
}

\section{MISINTERPRETATION OF ASIAN SAVANNAS AS DEGRADED FOREST CAN MISLEAD MANAGEMENT AND CONSERVATION POLICY UNDER CLIMATE CHANGE}

Dushyant Kumar ${ }^{\mathrm{a}}$, Mirjam Pfeiffer ${ }^{\mathrm{a}}$, Camille Gaillard ${ }^{\mathrm{a}}$, Liam Langan ${ }^{\mathrm{a}}$, Carola Martens ${ }^{\mathrm{a}, \mathrm{b}}$, Simon Scheiter ${ }^{\text {a } * *}$

aSenckenberg Biodiversity and Climate Research Centre (SBiK-F), Senckenberganlage 25, 60325, Frankfurt am Main, Germany

'Institute of Physical Geography, Goethe University Frankfurt am Main, Altenhoeferallee 1, 60438, Frankfurt am Main, Germany

\begin{abstract}
Savannas cover large areas of tropical Asia. Yet, these ecosystems are threatened by intense land-use and governmental afforestation initiatives. They are vulnerable to woody encroachment due to fire suppression and climate change. Despite their ancient origins, Asian savannas have been misinterpreted as degraded forest since the colonial period. The consequences of this misinterpretation and climate change on ecosystem functions and diversity of savannas are highly uncertain. We used a dynamic vegetation model, the aDGVM2 to simulate vegetation state under different climate change scenarios to assess how different interpretations of simulated vegetation influence biome patterns in South Asia. Our results show that large areas in South Asia can be interpreted as woodland or degraded forest if we ignore the grassy component and as savanna if the grassy component is considered. The model projects woody encroachment in open savannas due to $\mathrm{CO}_{2}$-fertilization of woody plants and associated biome transitions towards forest by 2099 . Our analysis shows that $23.7 \%$ to $76.6 \%$ of the protected areas in the study region are at risk of change. Misclassifying grassy savannas as areas that are suitable for afforestation would lead to a $35-40 \%$ loss of these unique ecosystems. A
\end{abstract}

** This chapter and supplementary information were published in the journal Biological Conservation as "Kumar, D., Pfeiffer, M., Gaillard, et al., 2020. Misinterpretation of Asian savannas as degraded forest can mislead management and conservation policy under climate change. Biological Conservation, 241, 108293, doi; 10.1016/j.biocon.2019.108293."

Author contributions: DK and SS conceived the study, DK adjusted aDGVM2 for the study region, conducted model simulations, analysed results, created figures and led the writing. All authors contributed to the development of aDGVM2 and contributed ideas and comments to the text. 
grass-centric biome classification accounting for the grass component in addition to the woody component is necessary to correctly identify Asian savannas. We conclude that there is an urgent need for a correct interpretation of Asian savannas to allow sustainable management and conservation of biodiversity, which is already strongly threatened due to woody encroachment caused by climate change.

\section{Abbreviations:}

aDGVM2: adaptive dynamic global vegetation model version 2; RCP Representative Concentration pathways; ISIMIP: Inter-Sectoral Impact Model Intercomparison Project; SRTM: Shuttle Radar Topography Mission; GFDL-ESM2M: Geophysical Fluid Dynamics Laboratory Earth System Model

Keywords: aDGVM2, Asian savanna; biodiversity conservation; climate change; $\mathrm{CO}_{2}$ fertilization; degraded forest; woody encroachment.

\subsection{Introduction}

Ecosystems are globally affected by biodiversity loss due to intensification of land-use including deforestation and conversion of natural land to cropland, and due to climate change that shifts climatic envelopes of species and alters biotic interaction networks (Allan et al., 2015). Sustainable management policies are necessary both inside and outside conservation areas to protect biodiversity and ensure persistence of species, ecosystems, and associated ecosystem functions under future conditions (Chape et al., 2005). A robust knowledge of the target ecosystem is prerequisite for developing management policies (Holling, 2001). Yet, misinterpretation of ecosystem states may mislead management and result in policies that in fact promote biodiversity loss (TorelloRaventos et al., 2013). Understanding how misinterpretation of an ecosystem influences the capacity to develop management strategies is therefore critical.

Tropical savannas, mixed tree-grass systems with a discontinuous woody layer and a continuous $\mathrm{C}_{4}$ grass layer (Ratnam et al., 2011), are the most extensive biome in the sub-tropics and cover around $20 \%$ of the terrestrial area (Scholes and Archer, 1997). Early colonization of savanna regions has led to mismanagement (Moura et al., 2019). Fire suppression policies reduced fire frequency and enhanced woody encroachment (O'Connor et al., 2014), accumulation of flammable woody fuels, and occurrence of 
extreme wildfires (Ryan, Knapp and Varner, 2013). Despite intense research, knowledge gaps with respect to the ecology and conservation of savannas are pervasive (Veldman, 2016). These gaps can hamper savanna conservation efforts (Bond and Parr, 2010), obscure biodiversity losses (Veldman et al., 2015), and threaten livelihoods of people in savannas. Current conservation agendas in many tropical regions are tree-centric and largely focus on forests. Savanna management, however, requires a grass-centric perspective considering fire, herbivores, grass-tree co-dominance, as well as biodiversity and ecosystem services specific to savannas (Veldman et al., 2015). Tree-centric afforestation agendas are recently strongly advertised to increase carbon sequestration and foster climate change mitigation by withdrawing $\mathrm{CO}_{2}$ from the atmosphere (Bastin et al., 2019), but these agenda largely omit the potential negative consequences for biodiversity and conservation resulting from such carbon sequestration efforts. Moreover, Bright et al. (2015) showed that forests absorb more incoming radiation than grasslands, therefore afforestation may cause a net warming due to albedo effect, rather than the intended cooling ascribed to augmented carbon sequestration. The benefits and limitations of afforestation for reducing atmospheric $\mathrm{CO}_{2}$ are debated controversially (Baldocchi and Penuelas, 2019). Bond et al. (2019) argued that the continuation of continental-scale afforestation in open grassy biomes cause losses of biodiversity hosted by savannas. Global tree planting initiatives are based on the assumption that open woody vegetation formations are degraded forest (Bond et al. 2019). This is clearly a misconception because Africa's savannas and Asia's savannas (Ratnam et al., 2016) have existed alongside forests for millions of years prior to human induced forest degradation.

Management policies in Asian savannas exemplify such tree-centric agendas. A long history of misinterpreting Asian savannas as degraded forest created by anthropogenic activities is largely a colonial legacy (Ratnam et al., 2016). This misinterpretation has persisted among decision makers and resulting loss of savanna ecosystems and their biodiversity are ongoing (Ratnam et al., 2016).

Asian savannas feature greater woody cover than the more arid African savannas, which has been used to support their classification as forest (Ratnam et al., 2016). Yet, in ecosystems with dense woody cover, the ecological function of grasses is often neglected. Studies have documented the presence of endemic $\mathrm{C}_{4}$ grass communities in southern India, the Deccan region and central India, as well as different types of savanna vegetation on the Indian subcontinent (Ratnam et al., 2016). Palaeoecological evidence 
clearly supports that Asian savannas existed before human arrival (Cerling et al., 1997; Ratnam et al., 2016) and that they are an ancient, not man-made biome. Fossil records indicate savanna climates, high diversity of $\mathrm{C}_{4}$ grasses and presence of mammalian herbivores since the late Miocene (Ratnam et al., 2016). Diversity evolved in the presence of fire and herbivory, and evolution resulted in today's rich and endemic savanna flora and fauna (Cerling et al., 1997). The unique woody flora of Asian savannas is ancient and has evolved from local lineages (Dexter et al., 2015).

At present the development of management policies requires the consideration of climate change. Yet, assessing the individual impacts of climate change and land-use on savannas is challenging due to the complexity of grass-tree interactions (Scheiter et al., 2012). Vegetation shifts favoring woody plants can reduce grass biomass and fire activity, which may further accelerate shifts towards woody vegetation (Scheiter and Higgins, 2009; Stevens et al., 2017). Vegetation shifts favoring grasses can increase fire activity and inhibit tree recruitment (Scholes and Archer, 1997). Whether Asian savannas may undergo similar vegetation shifts as African savannas (Scheiter and Higgins, 2009) or Australian savannas (Scheiter et al., 2015) remains to be tested. Detailed studies of Asian savannas ranging from field inventories to long term monitoring plots are needed to understand their ecology, particularly as a unique biome type that contrasts dry deciduous forests, to prevent further biodiversity loss and to develop sustainable management policies. Dynamic global vegetation models (DGVMs) can serve this purpose. DGVMs simulate ecophysiological processes and provide a detailed representation of vegetation dynamics under prevailing biotic and abiotic conditions. In addition, DGVMs allow us to investigate multiple combinations of climate change and management scenarios (Kumar and Scheiter, 2019).

Here, we use the adaptive Dynamic Global Vegetation Model version 2 (aDGVM2, Scheiter, Langan and Higgins, 2013; Langan, Higgins and Scheiter, 2017) to assess how the interpretation of an ecosystem as savanna in a grass-centric view or as degraded forest in a tree-centric view influences vegetation projections for future conditions and affects management decisions. Using aDGVM2, we investigate the sensitivity of Asian savannas to changes in $\mathrm{CO}_{2}$ and climate until 2099 for the RCP4.5 and RCP8.5 scenarios. We investigate (a) the role of grass biomass in defining biome states, (b) how misinterpretation of savanna as degraded forests might mislead management efforts, and (c) how grassland-savanna-forest boundaries are influenced by 
RCP4.5 and RCP8.5, and whether Asian savannas exhibit similar shifts towards treedominated states as African savannas.

\subsection{Material and methods}

\subsubsection{Study area}

South Asia is bounded by the Himalayas in the north and Indian Ocean in the south. It includes four major biodiversity hotspots of the world (Myers et al., 2000), which are recognized as one of the centers of high plant diversity and high risk of biodiversity loss (Ganesh et al., 1996). South Asia covers approximately 5 Million km2 and spans an altitudinal gradient from about $0 \mathrm{~m}$ to $8500 \mathrm{~m}$ above mean sea level. South Asia's topography consists of different mountain ranges, plateaus, and river basins, resulting in a gradient from dry regions to humid regions. Climatic conditions vary from arid in the west to humid in the east and from temperate in the north to tropical in the south. The complexity of environmental conditions has resulted in a rich diversity in biome types (Ramankutty et al., 2010). Grasslands and savannas (both open and wooded) occur interspersed between forested areas throughout the region (Ratnam et al., 2016). Wooded savanna and grasslands are more common at low elevations, with open grasslands being restricted to small patches (Sankaran, 2009). Many of these habitats are likely anthropogenic in origin and associated with human settlement in the respective areas (Sankaran, 2009). Some areas are characterized by naturally occurring grasslandwoodland mosaics, and are ancient in origin (Ratnam et al., 2016).

\subsubsection{Description of aDGVM2}

The aDGVM2 is an individual-based dynamic vegetation model that implements a flexible trait approach (Scheiter, Langan and Higgins, 2013). It represents individual plants in the community with a plant-specific combination of trait values. Plant communities adapted to the biotic and abiotic environment evolve dynamically through competition for light, space and water, and through the principles of trait mutation, crossover and trait inheritance (Scheiter, Langan and Higgins, 2013; Langan, Higgins and Scheiter, 2017). The aDGVM2 simulates natural fire regimes. Dead leaf litter from trees combined with grass biomass serves as fuel load. When soil moisture content drops below a specified threshold, surface fire spreads in the vegetation stand. Fire removes all 
above ground grass biomass and, depending on plant height, above-ground biomass of woody individuals. Tree and grass individuals can re-sprout after fire by allocating carbon from a fire-protected storage pool to leaf and stem pools. Details are provided by Scheiter et al. (2013) and Langan et al. (2017). In this study, we do not account for herbivory (Pfeiffer et al., 2019) and anthropogenic effects (Scheiter et al., 2019).

\subsubsection{Environmental drivers and experimental model setup}

The aDGVM2 was forced with daily climate data of South Asia for RCP4.5 and RCP8.5. We used climate data simulated by GFDL-ESM2M, provided within ISIMIP2a (Warszawski et al., 2014). Data includes daily mean air temperature, minimum and maximum air temperature, incoming long and short wave radiation, relative humidity and precipitation at $0.5^{\circ}$ spatial resolution. Soil data was obtained from the Harmonized World Soil Database (FAO, Nachtergaele et al. 2009) and elevation data from SRTM (Jarvis et al., 2008). The soil and elevation data was resampled to match the $0.5^{\circ}$ spatial resolution of the climate data. We performed simulations with $\mathrm{CO}_{2}$ concentrations according to RCP4.5 and RCP8.5 (Vuuren et al., 2011). The climate projections used in the study show decreases in mean annual precipitation (MAP) for the western and northern part of the study region under RCP4.5 and RCP8.5, and drastic decreases over the entire southern and south eastern part of the region under RCP8.5 (see Supplementary Information).

Plants in aDGVM2 were initialized with random trait values sampled from a predefined range for each trait (Langan, Higgins and Scheiter, 2017). A 500-year spin-up period allows the aDGVM2 to reach a dynamic equilibrium with environmental conditions. After the spin-up period, historic and future climate data for the period 1950 to 2099 were applied.

\subsubsection{Model benchmarking}

We first conducted a data-model comparison for the entire study area assuming complete coverage by natural vegetation. Then we masked out areas with more than $50 \%$ managed land (land cover classes 7 'Cultivated and Managed Vegetation' and 9 'Urban and Built-up' in Tuanmu and Jetz, 2014) and repeated the comparison for remaining areas covered by natural vegetation. We compared simulated spatial patterns of biomass, 
tree height and canopy coverage to remote sensing products compiled by Saatchi et al. (2011), Simard et al. (2011) and DiMiceli et al. (2011). These remote sensing products were aggregated to the $0.5^{\circ}$ spatial resolution used in model simulations by calculating the mean of all values within each $0.5^{\circ}$ grid cell ("raster" package in R, Hijmans and van Etten, 2012). When considering natural vegetation in the entire study area, we obtain $\mathrm{R}^{2}$ values of $0.61,0.44$ and 0.60 for biomass, tree height and canopy coverage, respectively (Table S1). When masking out managed land, $\mathrm{R}^{2}$ values increase to $0.70,0.73$ and 0.75 , respectively. A large part of the data-model disagreement can hence be attributed to the fact that extensive areas in the study region are influenced by human activity (Kumar, Pfeiffer, Gaillard, Langan, Martens, et al., 2020). Model performance is generally better in areas with low human population density and high coverage of natural vegetation than in areas with high coverage of managed land. We have conducted a more detailed model benchmarking in Kumar et al. (2020b).

\subsubsection{Biome classification}

We used simulated tree canopy cover and annual mean grass biomass aggregated at plot level ( 1 hectare), to categorize vegetation into biome types. The presence of $\mathrm{C}_{4}$ grasses is one of the key characteristics of tropical savannas (Ratnam et al., 2011) and distinguishes woodland or forest from savanna (Torello-Raventos et al., 2013). Although savanna trees always use the $\mathrm{C}_{3}$ photosynthetic pathway and tropical savanna grasses mainly use the $C_{4}$ photosynthetic pathway (Ratnam et al. 2011), $C_{3}$ herbs and a few $C_{3}$ grasses may also occur in the savanna ground layer in subtropical and tropical regions (Medina et al., 1999; Lloyd et al., 2008). For example, in the South American Cerrado the understorey herbaceous layer is dominated by $\mathrm{C}_{3}$ grasses (Lloyd et al., 2008; Edwards et al., 2010; Sankaran and Ratnam, 2013; Lehmann et al., 2014). In order to simplify the biome categorization we merged the simulated $\mathrm{C}_{3}$ and $\mathrm{C}_{4}$ grasses into one common category. We used classification schemes with (grass-centric) and without (tree-centric) consideration of grasses to assess how misinterpretation of savannas as forests influences biome projections.

In the tree-centric biome scheme, areas with tree cover below 5\% are classified as barren if grass biomass is below $100 \mathrm{~kg} / \mathrm{ha}$ and as grassland if grass biomass is above $100 \mathrm{~kg} / \mathrm{ha}$. If tree cover is between $5 \%$ and $45 \%$, then vegetation is classified as woodland or degraded forest. Areas with canopy cover greater than $45 \%$ are classified as forest 
(Venter, Cramer and Hawkins, 2018), irrespective of grass biomass. In the grass-centric biome scheme, areas with tree cover between $5 \%$ and $45 \%$ are split into savannas if grass biomass is above $100 \mathrm{~kg} / \mathrm{ha}$ and into woodland if grass biomass is below $100 \mathrm{~kg} / \mathrm{ha}$. The definition of barren, grassland and forest in the grass-centric classification is identical to the tree-centric classification scheme.

\subsubsection{Risk of vegetation shift}

We quantified the risk of vegetation transitions to highlight areas that are most prone to biodiversity losses associated with increasing woody cover. Savannas and grasslands are open biomes that support a wide range of biotas (Bond and Parr, 2010; Murphy, Andersen and Parr, 2016). Conservation of these open grassy biomes would require protecting them from woody encroachment, increase in tree cover (Gray and Bond, 2013; Wilcox et al., 2018) and decrease in grass biomass. Here we used tree cover and grass biomass to classify biome types and biome transitions therefore indicate changes in these variables. However, a limitation of biome classification is that it used fixed thresholds to distinguish between biomes and that classification may hide or overestimate vegetation shifts. For example, a tree cover increase from $4 \%$ to $6 \%$ implies a biome transition from grassland to savanna, whereas a tree cover increase from $6 \%$ to $40 \%$ does not imply a biome transition despite being substantial.

To account for this caveat of biome classification, we used tree cover and grass biomass as indicators to derive categories for the risk of vegetation change between 2019 and 2099 in each grid cell. Specifically, we classified the risk of biome transition as high if tree cover change exceeded $10 \%$ and grass biomass change was less than $1 \mathrm{t} / \mathrm{ha}$. This reflects a situation where substantial woody encroachment occurs and characteristic grass-tree ratio change substantially. The risk was classified as intermediate if change in tree cover exceeded $10 \%$ and grass biomass increase exceeded $1 \mathrm{t} / \mathrm{ha}$. As both tree and grass biomass increases, the characteristic grass-tree ratio of savannas is maintained in this risk category. Risk is classified as low if change in tree cover was less than $10 \%$ and change in grass biomass exceeds $1 \mathrm{t} / \mathrm{ha}$. In this situation woody cover remains stable and only grass biomass changes. We combined these thresholds with a third indicator i.e., the change of biome type in each grid cell, to obtain maps indicating areas where tree cover, grass biomass and biome type change. Using thresholds for tree cover and grass biomass change was motivated by the concept of Threshold of Potential Concern (TPC). TPCs 
have been used in African savannas to warrant management action (Gillson and Duffin, 2007) as soon as pre-defined threshold in different indicators of the ecosystem state are exceeded. Yet, there is a lack of such information for Asian savannas.

We overlaid the boundaries of protected areas (IUCN) and the risk maps. We calculated the difference between the total number of protected areas and the number of protected areas at risk of vegetation transition until 2099 for the respective RCP scenarios. In addition, we also calculated the change in protected areas with natural vegetation cover by considering only areas with less than 50\% managed land (Tuanmu and Jetz, 2014).

\subsection{Results}

In aDGVM2 simulations, savannas occur primarily on the Indian peninsula (Figure 5.1a) and overlap with climate envelopes of Whittaker's tropical deciduous/savanna biomes (Ricklefs, 2008; based on Whittaker (1970), Figure 5.1b). The modeled savannas occupy the hot and arid envelopes of the climate space (Figure 5.1b). Large fractions of the study area can alternatively either be considered as woodland (treecentric scheme, Figure 5.1c, d) or as savanna (grass-centric scheme, Figures 5.1c, d), depending on the assumptions underlying biome classification. Using the tree-centric scheme, $41 \%$ of South Asia is classified as woodland under current climate conditions in both RCP4.5 and RCP8.5 (Table 5.1). When using the grass-centric scheme, only 5\% and $7 \%$ of the area is classified as woodland in RCP4.5 and RCP8.5, respectively. In the grass-centric scheme, $34 \%$ to $36 \%$ of the area is classified as savanna under both RCP scenarios. The extents of forest and grassland areas are similar in the grass-centric scheme and the tree-centric scheme (Table 5.1). 
Table 5.1 Proportion of area covered by each biome for present (2019) and future (2099) conditions, and percent change between 2019 and 2099 under both RCP 4.5 and RCP 8.5. Results for both the tree-centric and the grass-centric classification schemes are provided.

\begin{tabular}{|llllllll|}
\hline RCP & Year & Scheme & Barren & Grassland & Woodland & Savanna & Forest \\
\hline 4.5 & 2019 & tree-centric & 12.7 & 18.3 & 41.0 & - & 28.0 \\
4.5 & 2099 & tree-centric & 16.2 & 13.5 & 30.1 & - & 40.2 \\
Change & & & 27.4 & -26.4 & -26.5 & - & 43.6 \\
4.5 & 2019 & grass-centric & 12.7 & 18.3 & 5.5 & 35.5 & 28.0 \\
4.5 & 2099 & grass-centric & 16.2 & 13.5 & 9.2 & 21.0 & 40.2 \\
Change & & & 27.4 & -26.4 & 65.3 & -40.9 & 43.6 \\
8.5 & 2019 & tree-centric & 9.8 & 21.1 & 40.5 & - & 28.6 \\
8.5 & 2099 & tree-centric & 12.5 & 15.9 & 30.4 & - & 41.3 \\
Change & & & 27.3 & -24.5 & -25.1 & - & 44.2 \\
8.5 & 2019 & grass-centric & 9.8 & 21.1 & 7.2 & 33.3 & 28.6 \\
8.5 & 2099 & grass-centric & 12.5 & 15.9 & 8.8 & 21.5 & 41.3 \\
Change & & & 27.3 & -24.5 & 22.5 & -35.4 & 44.2 \\
\hline
\end{tabular}

Forest and woodland are projected to expand into regions currently covered by savanna by the year 2099 (Figures 5.2a, b, d, e). Forest area is projected to increase by $43.6 \%$ and $44.7 \%$ in RCP4.5 and RCP8.5, respectively (Table 5.1). In the grass-centric scheme, savanna cover is projected to decrease by $40.1 \%$ and $35.4 \%$ in RCP4.5 and RCP8.5, respectively (Figures 5.2; S5.3). Barren land is projected to increase and grassland area is projected to decline under both scenarios, causing desertification along the border of India and Pakistan (Figures 5.2; S5.3). Under both RCP scenarios, savanna areas in the north-western part transition into woodland by 2099 , although locations affected by biome transition vary (Figures $5.2 \mathrm{c}, \mathrm{f}$ ). Forest areas along the Western Ghats and the Himalayas are stable (Figures 5.2). 

management and conservation policy under climate change

(a) Biomes with savanna, grass-centric scheme

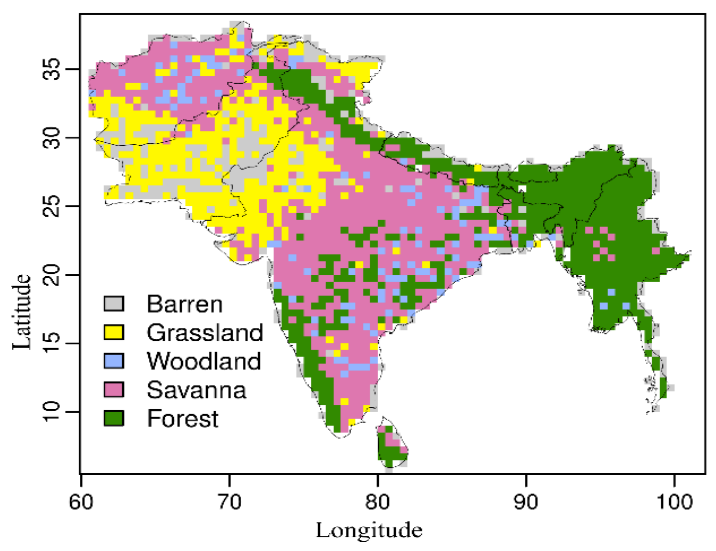

(c) Biomes without savanna, tree-centric scheme

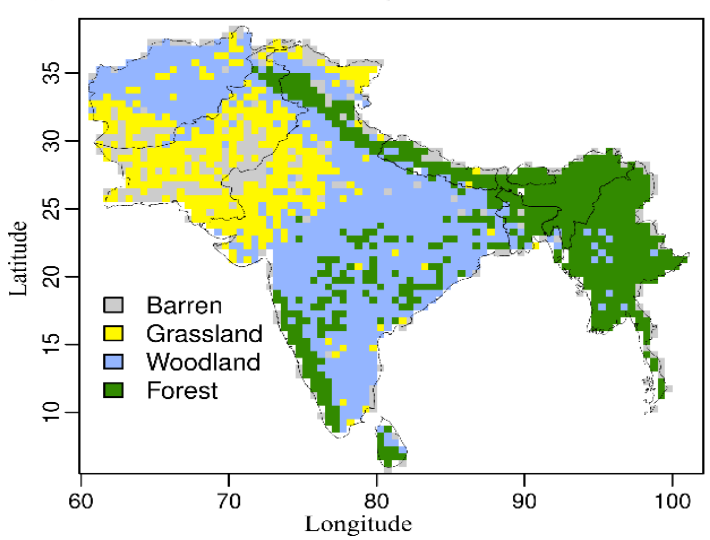

(b) Climatic niche for biomes, with grass-centric scheme

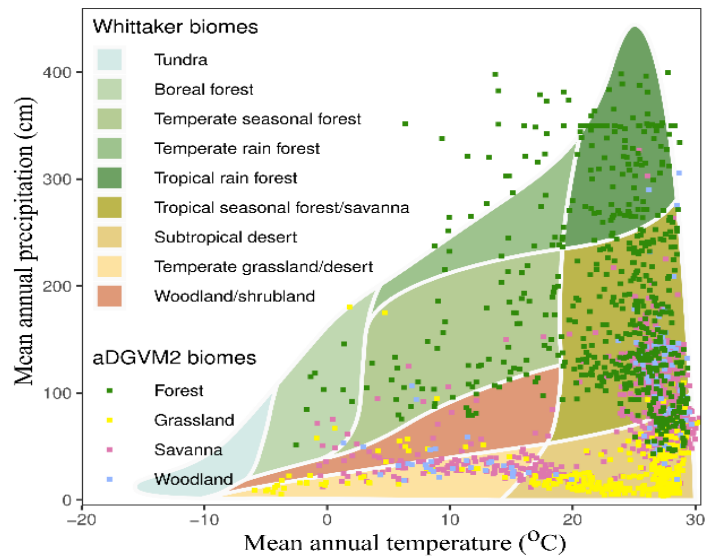

(d)

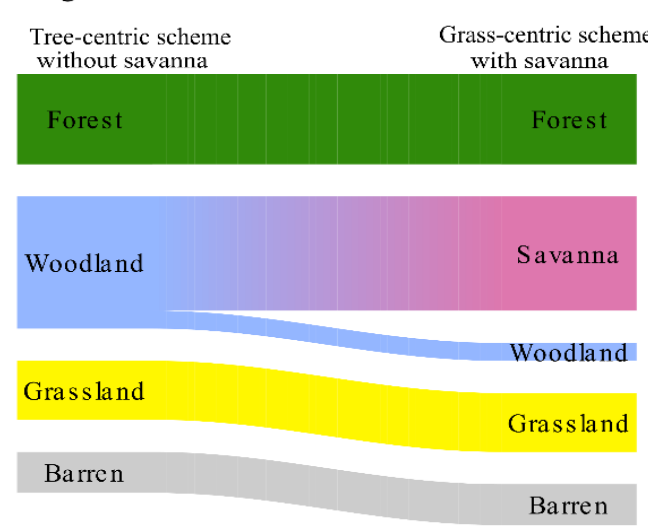

Figure 5.1 Biome patterns in South Asia simulated with aDGVM2 under current climate conditions (2019). (a) Biome distribution map when savannas are considered in a grass-centric scheme. (b) Location of simulated biomes (grass-centric scheme) in Whittaker's biome graph. (c) Biome distribution map when savannas are considered as woodland or dry deciduous forest in a tree-centric scheme. (d) Sankey graph illustrating overlap between biomes in tree-centric and grasscentric classification schemes. The width of lines represents the fractional cover of each biome in the study area.

Woody vegetation growth increases in RCP4.5 and RCP8.5, which explains most biome transitions (Figures 5.2; 5.3). Despite decreases in MAP, aDGVM2 simulates increases in woody biomass in the Deccan region under RCP8.5 (Figures 5.3a; S5.1). Above ground woody biomass, basal area and canopy area are projected to increase along the Western Ghats, as well as the eastern and central parts of south Asia (Figures 5.3a, b, c). Model projections show that grass biomass increases in central and southern India and decreases in other regions (Figure 5.3d). Simulation results indicate widespread 
Chapter 5-Misinterpretation of Asian savannas as degraded forest can mislead management and conservation policy under climate change

vulnerability of ecosystems to woody encroachment and associated biome transitions

(Figures 5.2, 5.4; S5.2).
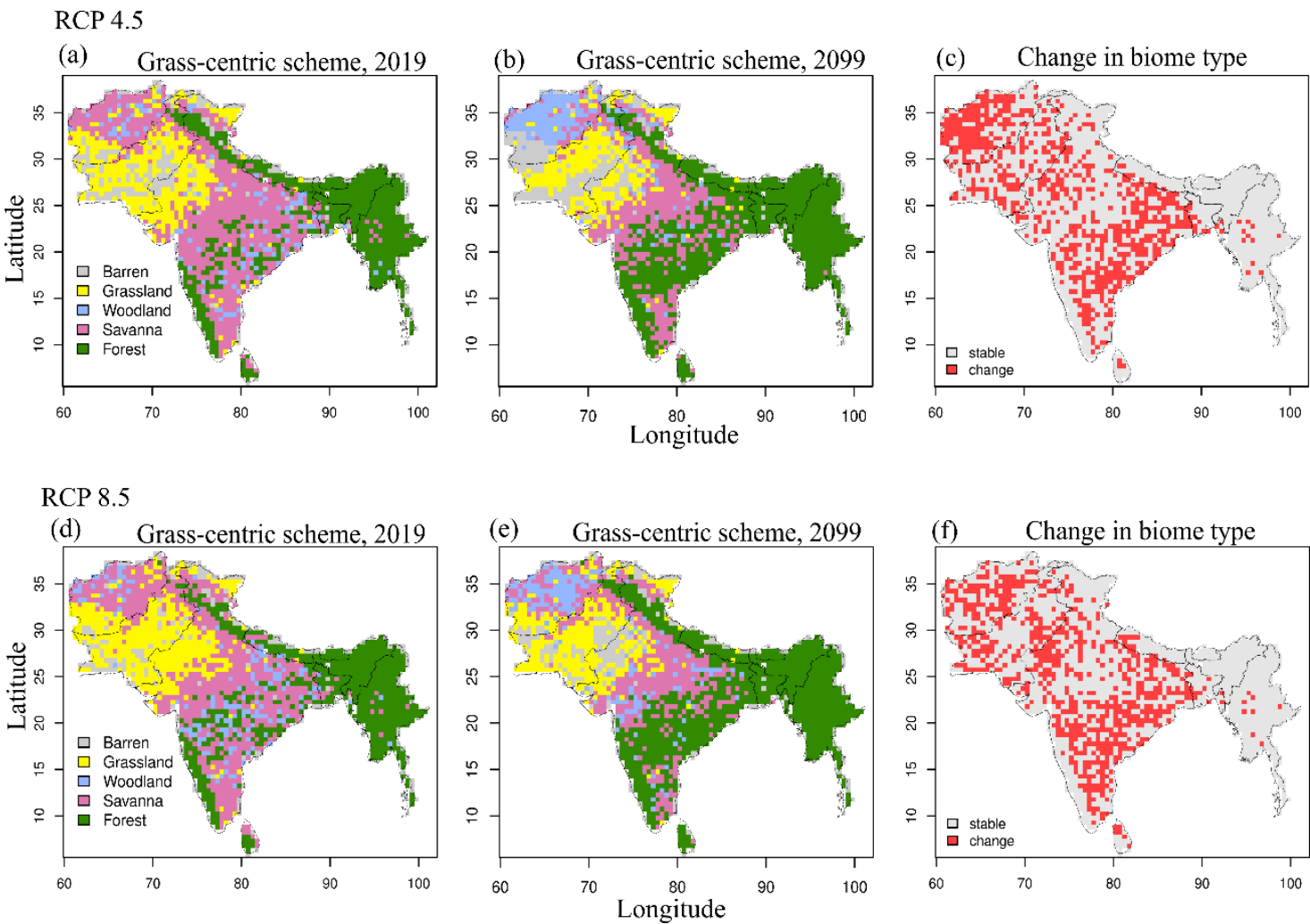

Figure 5.2 Simulated biome distributions under current and future conditions for RCP4.5 and RCP8.5. The figure shows current $(2019, a, d)$ and future $(2099, b, e)$ biomes and change in the biome distribution between 2019 and 2099 (c, f). Vegetation was classified using the grass-centric scheme, including savannas. See Figure S5.2 for simulations with tree-centric scheme.

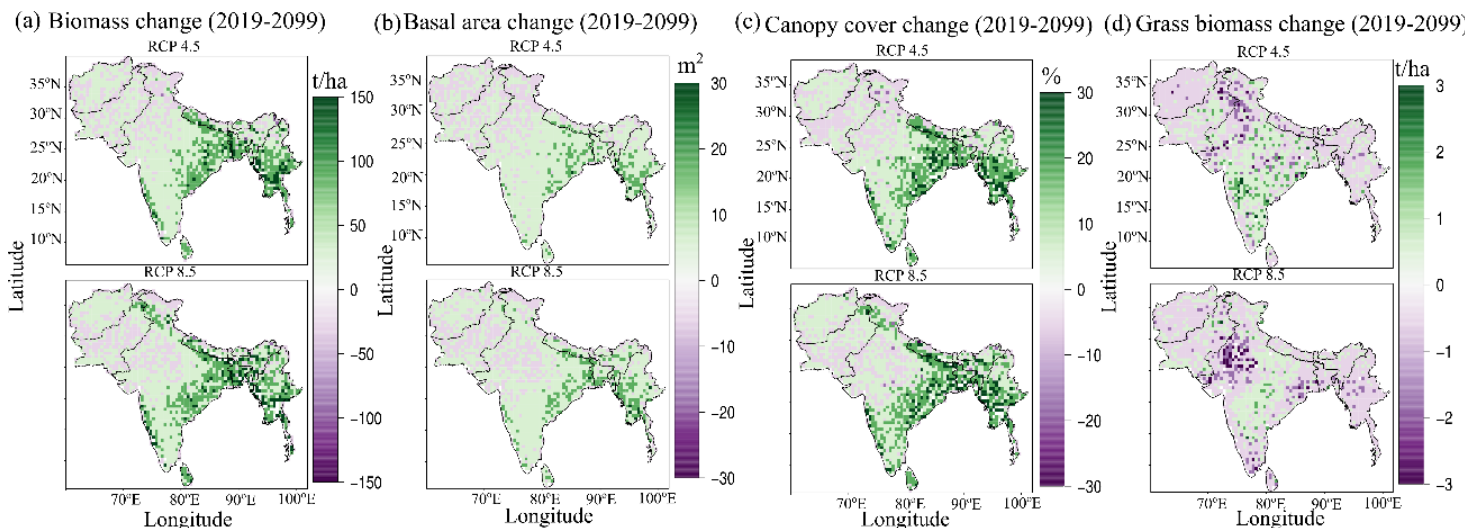

Figure 5.3 Simulated change in (a) biomass, (b) basal area, (c) canopy area and (d) grass biomass under RCP4.5 and RCP8.5 between 2019 and 2099. 

management and conservation policy under climate change

The risk assessment of potential vegetation transitions shows that the savanna regions in the eastern, central and southern parts of the study area are at high risk of transition for all used indicators (Figure 5.4). Areas with projected high risk of change in biome type and canopy cover are larger under RCP8.5 than under RCP4.5 (Figure 5.4). Most of these high-risk regions encompass protected areas (Figure 5.4). Specifically, $23.7 \%$ to $66.3 \%$ and $26.3 \%$ to $76.7 \%$ of the protected areas are at risk of change until 2099 for RCP4.5 and RCP8.5, respectively. However, after removing areas with a high proportion of managed land and applying three indicators to define vegetation transitions, results show that only $10.0 \%$ of the protected areas under natural vegetation cover under RCP4.5 and $12.7 \%$ under RCP8.5 are at high risk of change (Figure 5.4c, f).

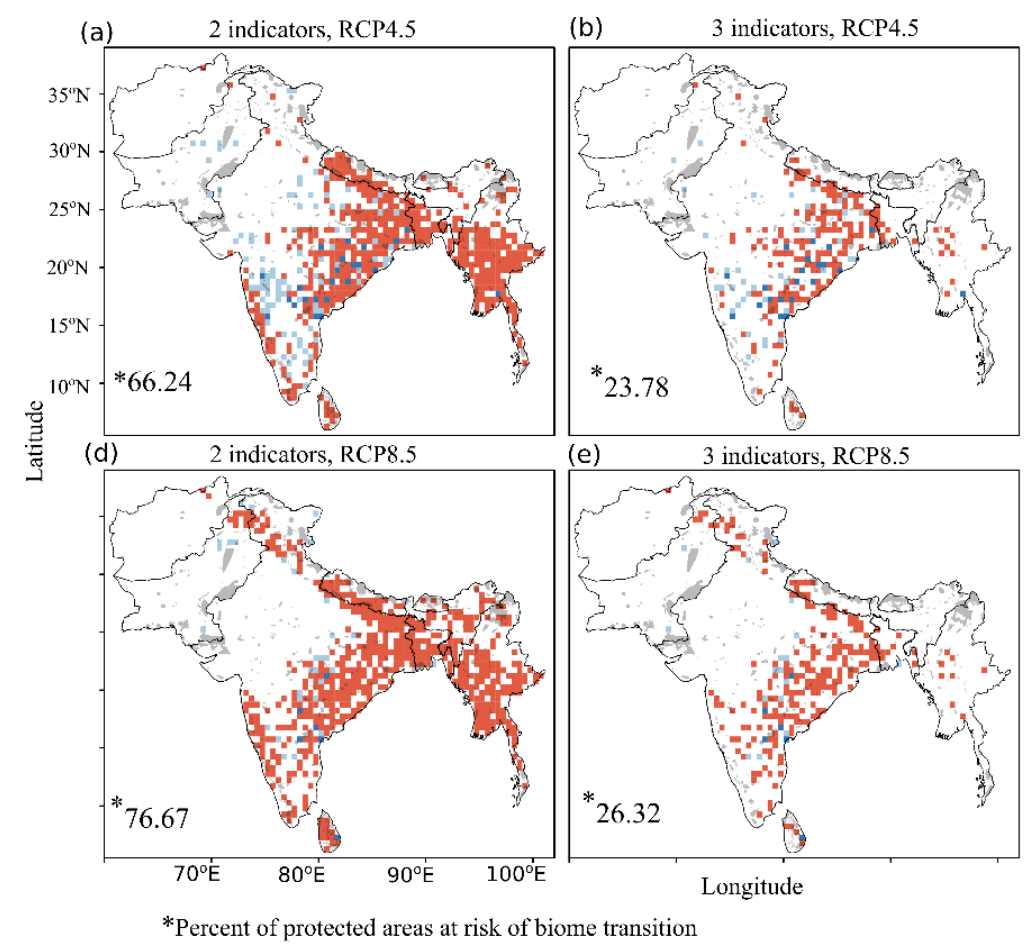

(c) 3 indicators and landcover, RCP4.5

Figure 5.4 Risk of vegetation shifts until 2099 in RCP4.5 and RCP8.5. Different indicators were used to assess the risk. $(a, d)$ Canopy cover and grass biomass (2-indicators), $(b, e)$ canopy cover, grass biomass and change in biome type (3 indicators) and (c, f) 3-indicators along with land cover mask to mask out managed land.

\subsection{Discussion}

Biome classification can lead to multiple interpretations of an ecosystem state depending on the focus and applied criteria. Classification is often study-specific and to some degree subjective (Torello-Raventos et al., 2013). Studies have highlighted 
uncertainty in recognizing vegetation states and resulting inappropriate management where the presence of grass has not been considered for biome classification (Putz and Redford, 2010). We illustrate that large areas in South Asia can be interpreted as woodland or savanna (Figures 5.1a, c) when adopting a grass-centric view for biome classification. A tree-centric classification scheme that ignores the presence of grasses identifies these areas as woodland or degraded forest. The tree-centric view has led to mismanagement of such mixed-vegetation formations (Ratnam et al., 2016).

For instance, woody encroachment might be seen as a positive sign toward forest regeneration and therefore encourage afforestation efforts, while ignoring the fate of the grassy component. However, inclusion of grass biomass in biome classification scheme clearly illustrates that the same vegetation formations can be interpreted as savanna (Figure 5.1d).

Woody encroachment and forest expansion into savannas are widespread across the savanna biome (Stevens et al., 2017). Our results show that some of the savanna regions in the Deccan region will likely disappear by the end of this century due to woody encroachment (Figure 5.2). It has been hypothesized that this change is mainly driven by increasing atmospheric $\mathrm{CO}_{2}$ concentrations and $\mathrm{CO}_{2}$ fertilization. Empirical evidence from free-air $\mathrm{CO}_{2}$ enrichment (FACE) experiments indicates that rising $\mathrm{CO}_{2}$ increases foliar cover and biomass (Norby and Zak, 2011). Yet, it remains unclear if such effects are persistent, and how interaction with other factors such as increasing temperatures and limited nutrient availability may counteract $\mathrm{CO}_{2}$ fertilization. We do not have any evidence from FACE experiments in Asian savanna ecosystem, however there is the OzFACE experiment in Australia's savanna. However, Buitenwerf et al. (2012) identified $\mathrm{CO}_{2}$ as the major driver of woody encroachment in African savanna. Elevated $\mathrm{CO}_{2}$ is expected to favor $\mathrm{C}_{3}$ woody plants and to promote woody encroachment by lowering stomatal conductance of grasses and thus increasing soil moisture availability for trees (Bond and Midgley, 2000). This increases the water use efficiency and productivity of $\mathrm{C}_{3}$ plants, even in drier regions (Bond and Midgley, 2000). As a result, biomass increases and tree canopy gets denser (Figures 5.3a, c). A dense canopy reduces the amount of light that reaches the ground, and inhibits grass growth (Dohn et al., 2013). Simulated patterns of woody encroachment into areas covered by savanna (Figures 5.2, 5.3a, c) agree with simulations for African savannas (Stevens et al., 2017) and Australian savannas (Scheiter et al., 2015). However, the positive effect of $\mathrm{CO}_{2}$ fertilization is still 
debated (eg. Körner et al., 2005), and nutrient limitation, which is ignored in our study, can constrain photosynthesis (Luo et al., 2004).

In savannas, woody encroachment is typically perceived as degradation, indicating changes in plant communities and loss of diversity (Ratajczak, Nippert and Collins, 2012). It may reflect a transition to a forest-dominated ecosystem state. Efforts to reverse encroachment often have limited success (Lett and Knapp, 2005). The continued expansion of woody vegetation due to fire suppression, increasing atmospheric $\mathrm{CO}_{2}$, increasing land-use intensity and change in mega-herbivory (Archibald et al., 2013) will likely lead to further changes in community structure of savannas. Afforestation in grasslands leads to the loss of biodiversity provided by herbaceous and endemic savanna species, which are lost from the system due to resource competition with trees (Brooks, Setterfield and Douglas, 2010). In South Asia, the continuous effort to afforest savanna areas poses major threats to their biodiversity (Veldman et al., 2015). Afforestation practices have introduced alien species such as Lantana camara, Prosopis juliflora and Cytisus scoparius, which have turned out to be highly invasive species (Hiremath and Sundaram, 2013). Conversion to forest is also problematic because semi-arid and mesic savannas provide habitats for a variety of endemic animal species (Krishna, Krishnaswamy and Kumar, 2008). In addition, ecosystem services such as savanna tourism or water availability may be affected. For instance, plantation of eucalypts increases the transpiration and influences water accessibility for other plants (Calder, Hall and Prasanna, 1993), which is a major issue in South Asia. Second, afforestation schemes imply conflicts of interest between various stakeholder groups aiming for economic benefits from plantations vs. carbon sequestration efforts or protection of biodiversity (Bond et al., 2019).

Reducing anthropogenic impacts is often sufficient for passive restoration (Meli et al., 2017). In contrast, active conservation and restoration of savannas requires management plans to establish and maintain the characteristic disturbance regimes of fire and herbivory. Within a short period of time, overgrazing, fire exclusion, and resulting woody encroachment can replace highly diverse old-growth grassland communities with low-diversity communities (e.g. Cava et al. 2018). Currently, protected areas represent a central component in attempts to preserve biodiversity and to conserve flora and fauna. Our simulation results show that without removing managed land from our analyses, $23.7 \%$ to $76.6 \%$ of the protected areas in the study region are at risk to experience a 
change in biome state. The variability in estimates depends on the criteria used in the estimation of risk. After removing managed land located within protected areas from the analyses, $10.0 \%$ to $12.7 \%$ of the protected areas are at risk of biome transitions.

Ecosystem management policies in South Asia should adopt a grass-centric perspective and prioritize grassland and savanna conservation through application of prescribed fires, careful management of natural wildfire, and control of herbivory. Transitions to low-diversity forests (Buisson et al., 2019) should be prevented through removal and control of invasive species, reintroduction of endemic grasses and prescribed fires. Conservation of savannas implies habitat protection for endemic wildlife such as Indian bustard, blackbuck, cheetah, sambar, gaur and Indian wolf(Prasad et al., 1978). We argue that more explorative studies are necessary to identify threatened savanna regions, and regions where conservation areas should be established to sustainably manage socio-economic activities while conserving the characteristic grasstree diversity.

\subsection{Conclusion}

In conclusion, this study shows that large areas in South Asia can be interpreted as woodland, degraded forest or as savanna. If we consider vegetation as woodland or degraded forest suitable for restoration within a tree-centric perspective, then we are at risk of losing $35 \%$ to $40 \%$ of a unique savanna biome. Adopting a grass-centric perspective for biome classification accounting for the grass component in addition to the woody component is necessary to correctly identify savannas. We assessed critical vegetation transitions with different indicators, and found that the savanna areas are most threatened by climate change. Differentiating savanna from woodland or degraded forest is essential for the development of knowledge-based management and conservation strategies aiming to preserve the integrity of ecosystems and foster their resilience toward climate change. We have shown that dynamic vegetation models can serve as tools to inform decision making for climate adaptation and mitigation. Yet, as long as the misinterpretation of savannas as degraded forest persists, the conservation of tropical grassy biomes will remain a challenge (Ratnam et al., 2016) and many savanna regions will experience biodiversity and habitat loss in the future. 

management and conservation policy under climate change

\section{SUPPLEMENTARY INFORMATION}

\section{Climate Projection}

The climate projections used in the study show decreases in MAP for the western and northern part of the study region under RCP4.5 and RCP8.5, and drastic decreases over the entire southern and south eastern part of the region under RCP8.5 (Figures S5.1a, b). An increase in MAP occurs in the north eastern Himalaya and the southern region of the Western Ghats in both scenarios (Figures S5.1a, b). MAT is projected to increase uniformly over the study region by $1-2^{\circ} \mathrm{C}$ under $\mathrm{RCP} 4.5$ and $5-6^{\circ} \mathrm{C}$ under $\mathrm{RCP} 8.5$ (Figures S5.1c, d).

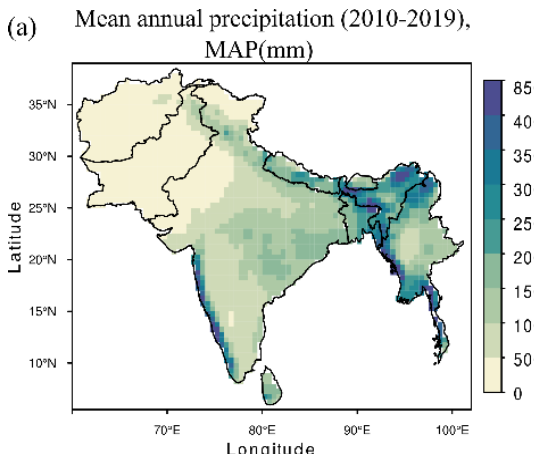

(c) Mean annual temperature (2010-2019),

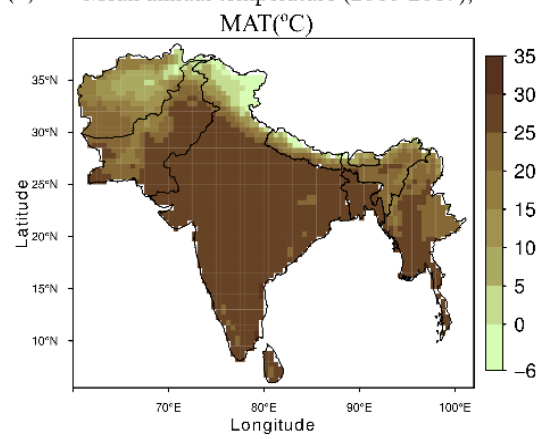

(b) Change in mean annual precipitation (2019-2099), MAP(mm)

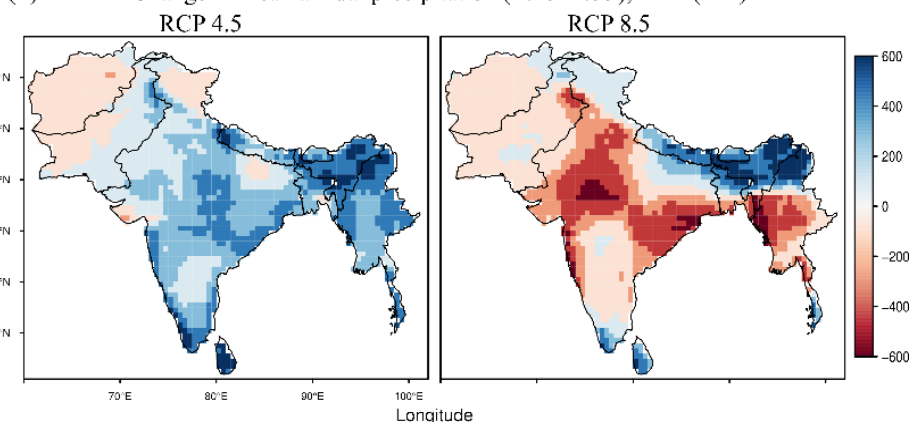

(d) Change in mean annual temperature (2019-2099), $\operatorname{MAT}\left({ }^{\circ} \mathrm{C}\right)$

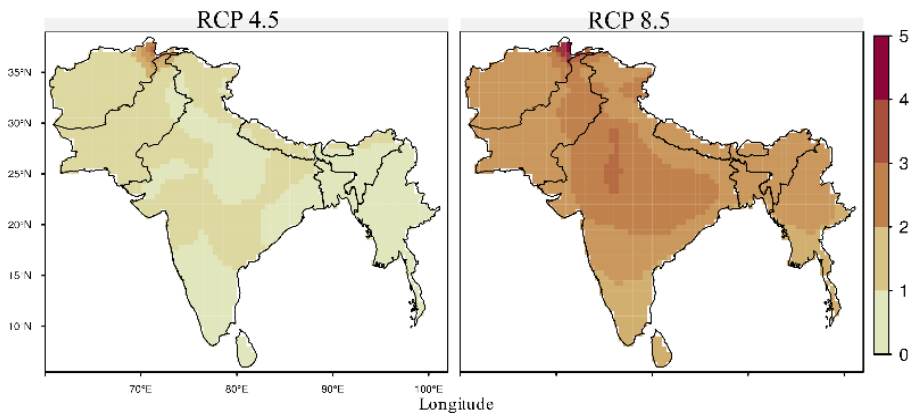

Figure S 5.1 Spatial distribution of (a) MAP averaged for period 2010-2019, (b) change in MAP under RCP4.5 and RCP8.5 until the period 2090-2099, (c) MAT averaged for period 2010-2019 and (d) change in MAT under RCP45 and RCP85 until the period 2090-2099 from GFDL-ESM2M of ISIMIP2a project. 
Chapter 5- Misinterpretation of Asian savannas as degraded forest can mislead management and conservation policy under climate change

(a) RCP 4.5
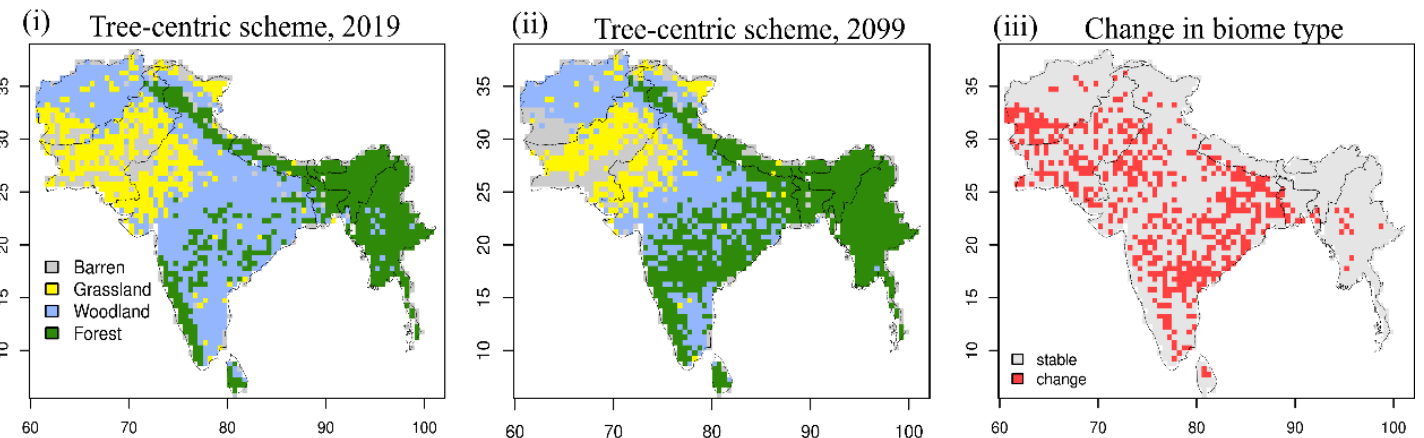

(b) RCP 8.5
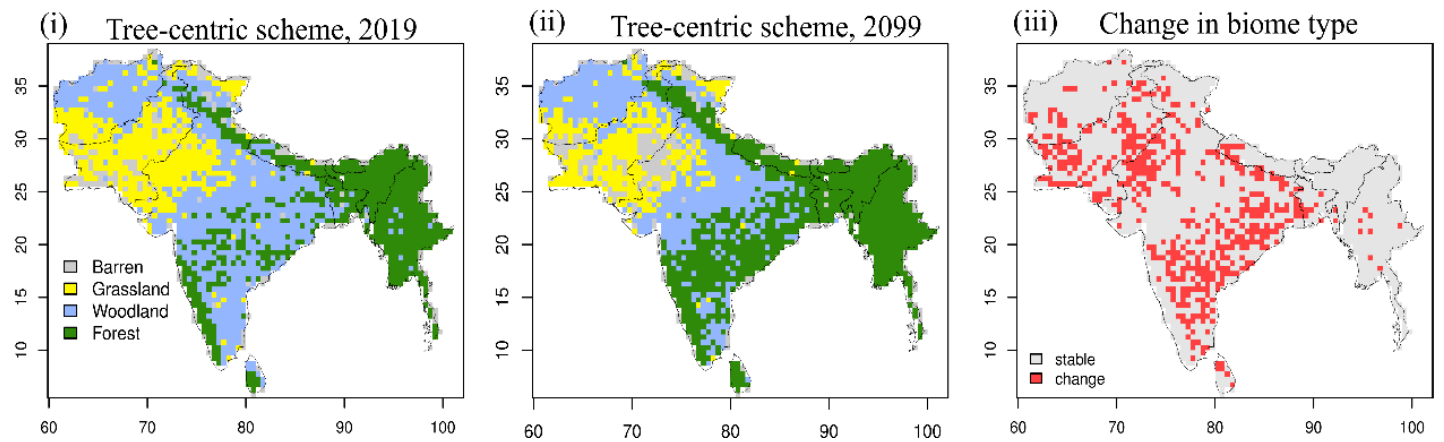

Figure S 5.2 Simulated biome distributions under current and future conditions for RCP4.5 and RCP8.5. The figure shows current (2019, a, d) and future (2099, b, e) biomes and change in biome distribution between 2019 and 2099 (c, f). Vegetation was classified using tree-centric scheme, without including savannas.

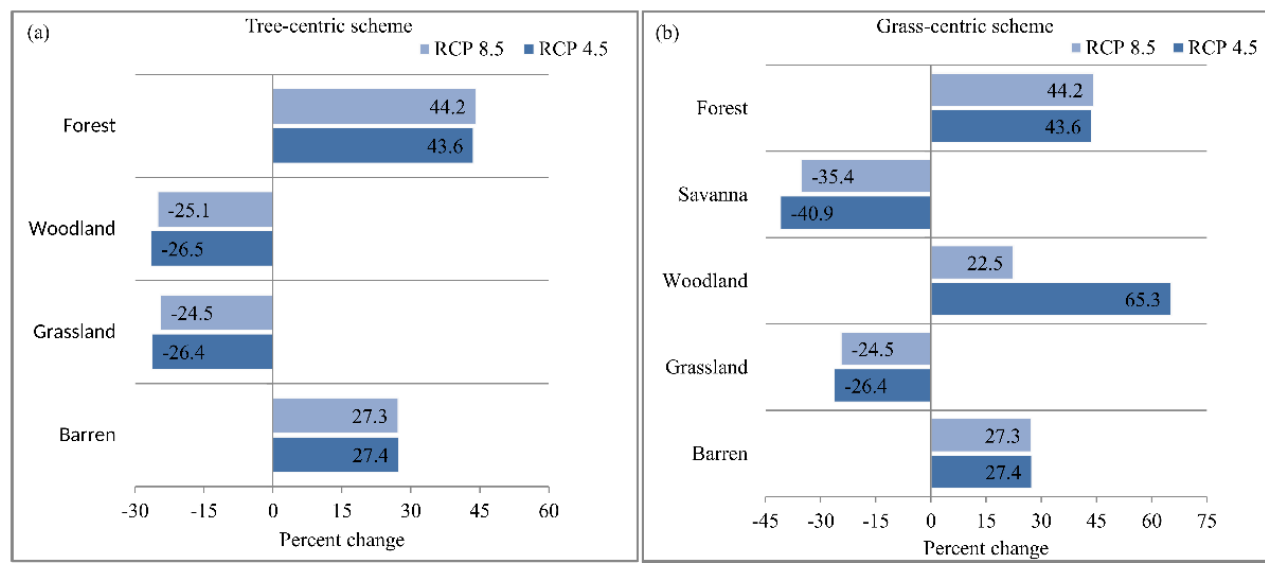

Figure S 5.3 Percent change in the area covered by each biome between 2019 and 2099 for (a) tree-centric scheme and (b) grass-centric scheme for biome classification schemes. 
Table S 5.1 Quantitative comparison between observed and simulated model biomass, canopy cover and tree height (NMSE: Normalized Mean Square Error, RMSE Root Mean Square Error). Number in bold font represent comparison when masking out the managed land, other numbers represent comparison including managed land

\begin{tabular}{|lllllll|}
\hline Variable & Model & Data & R $^{\mathbf{2}}$ & Pearson's $\boldsymbol{r}$ & NMSE & RMSE \\
\hline Biomass & aDGVM2 & Saatchi et. al., 2011 & 0.61 & 0.77 & 0.48 & 54.81 \\
& & & $\mathbf{0 . 7 0}$ & $\mathbf{0 . 8 3}$ & $\mathbf{0 . 4 1}$ & $\mathbf{6 3 . 9 3}$ \\
Height & aDGVM2 & Simard et. al., 2011 & 0.45 & 0.66 & 0.79 & 4.99 \\
& & & $\mathbf{0 . 7 2}$ & $\mathbf{0 . 8 5}$ & $\mathbf{0 . 5 8}$ & $\mathbf{4 . 9 2}$ \\
Canopy & aDGVM2 & DiMiceli et al., & 0.60 & 0.77 & 0.41 & 11.99 \\
Cover & & 2011 & $\mathbf{0 . 7 5}$ & $\mathbf{0 . 8 6}$ & $\mathbf{0 . 2 7}$ & $\mathbf{1 1 . 9 9}$ \\
& & & & & & \\
\hline
\end{tabular}




\section{CHAPTER 6}

\section{GENERAL OVERVIEW, OUTLOOK AND CONCLUSION}

\subsection{Overview}

Climate change and rising concentration of atmospheric $\mathrm{CO}_{2}$ alter the natural balance of ecosystems connected to biodiversity and hydrology of a region. This imbalance would further lead to the decline of ecosystem services. Most of these ecosystem services are indispensable for the survival of wildlife and the welfare of humans. Therefore, it is of utmost importance to understand plant-climate interactions, and the impact of climate change, rising $\mathrm{CO}_{2}$, land-use change, deforestation and fire on vegetation distribution. Over the past few decades, this has become a major concern in the field of ecology and biodiversity research. There is mounting evidence stressing the need to take timely action to minimize or mitigate the consequences of climate change on the health of ecosystem.

As highlighted in Chapter 1 and 2, studies investigating the impacts of climate change and rising $\mathrm{CO}_{2}$ explicitly in South Asia are rare and further constrained by the limitation of the models used. Many global-scale DGVMs have been used to represent the region. Still, most of them have failed to explicitly represent the savanna biome, and boundaries between deciduous and evergreen forest in the region. The lack of an accurate representation of different vegetation types and ecosystem processes at the regional scale is a main source of uncertainty in DGVMs. Therefore, developing the capacity to project vegetation change is critical to mitigate and efficiently adapt to climate change impacts.

Central to this thesis is the investigation of climate change impact, in time and space, on the distribution of vegetation patterns, phenology, vegetation structure and biome boundary shifts. For studying these processes and consequences of climate change on South and Southeast Asian vegetation, I have asked: How do rising $\mathrm{CO}_{2}$, rising temperature and changing precipitation regime affect biomes distribution and its boundaries? What are the consequences of such climate change on ecosystem productivity? How do the vegetation structure and phenology affected by these changes? How can the savanna biome be identified correctly for their conservation and protection? 
In this thesis, I have used a trait-based vegetation model, aDGVM2, with an improved ecophysiology sub-model to represent daily photosynthesis (Chapter 3) to simulate the impact of climate change on vegetation under different scenarios in the region. This reveals how an increase in atmospheric $\mathrm{CO}_{2}$, changed precipitation regime, and rising temperature influence the spatial and temporal distribution of vegetation patterns and structure. First, the contemporary state of vegetation, vegetation dynamics and limitations of DGVMs concerning South Asia are discussed in Chapter 2. I proposed a more realistic representation of different vegetation types and growth forms in DGVMs to better represent regional ecosystems with implications for a better understanding of climate-vegetation interaction future (Chapter 2). Second, I focused on the influence of climate change on vegetation distribution, structure and consequences on biome boundaries (South Asia in Chapter 3, and South and South-east Asia in Chapter 4). Lastly, I simulated savanna dynamics under climate change and discussed its implication on practical applications for savanna management in Chapter 5. Therein I have proposed a biome classification scheme to correctly distinguish between the most threatened and misinterpreted savanna biomes with deciduous forest.

The following sections summarize the main results of the different Chapters, and I discuss general aspects of model improvement, parameterizations and implications in the context of the regional vegetation. I synthesize here what was learned from simulations place it in the broader context of South and South-east Asian vegetation. Further, I outline future applications and perspectives for the presented study.

\subsubsection{Improving the representation of regional vegetation in DGVMs}

In Chapter 2, the contemporary state of vegetation modelling, limitation of DGVMs, and distinct vegetation types of the regions were reviewed and discussed in detail. Contrasting climatic conditions and diverse floral distributions in South Asia necessitate special attention to account for the different vegetation types and growth forms in vegetation models. I emphasized that current plant functional types schemes in DGVMs should be expanded to incorporate different plant communities and the ecophysiological process governing competition for resources. I made the case that many of the current limitations in DGVMs could be addressed by improving the representation of ecophysiological and biological processes via the improved representation of distinct vegetation types. I emphasized using either functional traits (FT) approach or using PFTs 
approach with variable traits derived as a function of environmental condition in DGVMs, to move away from the paradigm of fixed PFTs. First, to use an approach where the process of natural selection is modelled at the individual level, where the values of multiple traits determine individual fitness, and trade-offs between them, can indeed allow diverse communities of plants to emerge from the modelling framework such as in the aDGVM2 (Scheiter et al., 2013; Langan et al., 2017). For example, Gaillard et al. (2018) have shown that introducing fundamental trade-offs between height growths and hydraulic conductivity can mechanistically simulate biogeographical distribution shrubs, which is architecturally different from a tree. The second approach would be to vary parameters of PFTs as a function of environmental variables where the mean trait values of plant community directly related to environmental conditions resulting in trait convergence for the PFT. Trait-environment relationships have shown consistent patterns relating leaf functional traits to climate (Wright et al., 2005), soil fertility (Ordoñez et al., 2009), or both (Ordonez et al., 2009; van Ommen Kloeke et al., 2012). For example, implementing trait-environment relationships into JSBACH, a DGVM, indicated major consequences of trait variability on vegetation and carbon dynamics under the current climatic condition (Verheijen et al., 2013). In addition to a realistic representation of plant communities, our understanding of the regional ecosystem will improve, especially for less studied biomes such as Asian savannas. In chapter 5, the aDGVM2 was used to simulate the vegetation pattern, which is categorized into savanna and forest (deciduous forest in Chapter 3) using the state variable, i.e., grass biomass and tree cover.

Further improvement of realistic representation of the ecosystem in DGVMs is important because it has become the necessary tool for understanding water and carbon dynamics, and the underlying mechanisms in ecosystems. As these models represent the complex processes, ranging for example, from the leaf level (e.g., photosynthesis, transpiration), to the stand scale (e.g., plant resource competition), to the landscape (e.g., disturbances such as fire events) and beyond (Sato, Itoh and Kohyama, 2007; Sitch et al., 2008; Scheiter, Langan and Higgins, 2013). They can be used to explore the impact of climate change and management scenarios on the ecosystem. For instance, in South Asia, land-use change and mismanagement of savannas have resulted in the loss of biodiversity (Ratnam et al., 2016; Vlek et al., 2017; Kumar et al., 2020a). The potential impact of these factors on ecosystem health can be investigated with DGVMs. The model predicted trajectories can be used to decide further the best plausible management strategies for conservation to minimize or mitigate the adverse 
consequences on the ecosystem (Mason and Dzierzon, 2006; Halofsky et al., 2015; Scheiter et al., 2018). Various predictive models indicate that under a business-as-usual scenario, the Asia-Pacific region will continue to lose biodiversity, e.g., lose habitats and species at a similar pace to the global rate of extinction by 2050 (IPBES, 2019). Decisionmaking based on change scenarios, and models at different temporal and spatial scales can map plausible futures in diverse ecosystems in the region. The analysis of different scenarios can help policymakers to make better decisions on the most plausible futures for biodiversity and ecosystem services (Díaz et al., 2019; IPBES, 2019). At present, the development of dynamic vegetation models in the regions is still far behind western countries (Kumar et al., 2018). There is no doubt that building a new generation of dynamic vegetation models based on plant functional traits will be a challenge given the limitation of data availability in the region (Kumar and Scheiter, 2019). But at the same time, it is a good opportunity to fill the gaps. Development of DGVMs capable of representing regional vegetation would help integrate model results at the policy level to prioritize the management of conservation practices in a more justified scientific way. Therefore, the combined efforts of physiologists, ecologists, and modelers would be indispensable for improving the current and next generation of DGVMs globally and at a regional scale to understand the process explaining observed vegetation patterns.

Furthermore, it is utmost importance to set up long -term field experimental sites in different biomes to collect data for model parameterization. This would further advance our ecological understanding of ecosystems function and community structure in South Asia and beyond. A better understanding would pave the way to focus on various consequences on ecosystem services to integrate strategic management and operational planning across the ecosystem at different conservation levels (Costanza et al., 2017).

\subsubsection{Modelling the potential vegetation dynamics in South Asia, using trait-based vegetation model-aDGVM2}

In Chapter 3, I used the updated version of aDGVM2 to simulate the current and future vegetation distribution in South Asia under RCP4.5 and RCP8.5. I explored how the presence or absence of $\mathrm{CO}_{2}$ fertilization influences vegetation responses to climate change. The vegetation types are not defined in aDGVM2 as a priori, as it is done in PFT based DGVMs. I used the state variables and traits to categorize simulated vegetation 
properties into different dominant biome types. For example, the aDGVM2 allows the simulation of the extent of evergreen and deciduous vegetation for both shrubs and trees in response to the environment, and without predefining phenology and stem architecture. Under both RCPs, aDGVM2 predicted an increase in biomass, canopy cover, and tree height under $\mathrm{CO}_{2}$ fertilization, which triggered a transition towards treedominated biomes by the end of the 21 st century. This transition implies woody encroachment for the $21^{\text {st }}$ century. This has adverse implications for open biomes such as savanna and grassland, and threatens local biodiversity. However, the upside of this woody encroachment due to $\mathrm{CO}_{2}$ fertilization is that the region has the potential to remain a carbon sink given there is no other resource limitation (Kumar et al., 2020b; Scheiter, Kumar, et al., 2020). Although one needs to be cautious while interpreting these results, nutrient constraints on $\mathrm{CO}_{2}$ were not included in the study. I found that the biomes in the mountainous region, i.e., the Himalayas and the Western Ghats of the region, are more vulnerable and are susceptible to change in the future. I showed that the bioclimatic niches of biomes are not static but are specific for given $\mathrm{CO}_{2}$ concentration and climatic conditions. Therefore, the Whittaker plot used to illustrate the niches of biomes needs to be adjusted for future conditions.

Based on the projected biome transitions resulting from changing climate and rising $\mathrm{CO}_{2}$, I argue that the ecosystem management and mitigation strategies should be framed accordingly to allow for targeted long-term management for conservation of the protected areas and threatened biomes. These results demand an improvement in the current biological monitoring activities for tracking ecological responses to climate change. To achieve this, most vulnerable biomes identified (also in Chapter 5) by modelling results such as those presented in this study would be proposed as high-priority targets for programs that monitor vegetation-climate interactions, productivity and biodiversity.

Although the fire was included in all the simulations, the effect of fires on the biome distributions is not analyzed explicitly in this study. However, fire is very important for open biomes such as savanna and grassland (Sankaran, 2005). Fire management policy in the region still need to be informed based on savanna ecology as fire suppression is still practiced in some ecosystem in the region (Thekaekara et al., 2017). Proper management strategies for biomes would require investigating the impact of fire disturbance and land-use change in addition to climate change (Sannigrahi et al., 
2020). The current model setup can be used for exploring other tropical regions to study biosphere-atmosphere interactions under different future climate and management scenarios, e.g., elevated atmospheric $\mathrm{CO}_{2}$, fire (Scheiter et al., 2015), or herbivory (Pfeiffer et al., 2019). For instance, I extended it to Southeast Asia in Chapter 4 to focus on vegetation structure and phenology (Scheiter, Kumar, et al., 2020).

\subsubsection{Modelling the impact climate on vegetation structure and phenology}

In Chapter 4, the study region was extended to include Southeast Asia to verify if the current model configuration used in Chapter 3 can reproduce vegetation pattern in the region. It has been well established that climate change, for example, modifies plant phenology and vegetation structure, in turn influencing vegetation distribution, carbon storage and biodiversity. In this study, an ensemble of climate change scenarios was investigated to explore how it influences future biomass, vegetation height, and phenology in tropical Asia. Similar to the result obtained in Chapter 3, the model successfully reproduced the broad pattern of dominant biome types in the region. The study showed a robust trend of increasing vegetation biomass and transitions from small deciduous vegetation to taller evergreen vegetation where height changes of 5-10 m were predicted across most of tropical Asia (Scheiter, Kumar, et al., 2020). However, results were found to vary across individual ensemble members, demonstrating the need to consider a diversity of models when assessing future vegetation trends. The study showed that open ecosystems with deciduous vegetation such as grasslands and savannas are most susceptible to climate change.

The predicted phenological changes would reshape community structure within the biomes, affecting biodiversity and feedback to climate (Yang and Rudolf, 2010). Any alteration in the phenological synchrony of plant-animal interactions would greatly alter the structure and dynamics of plant communities, yet current understandings are still far from reaching general conclusions (Kharouba et al., 2018). The feedbacks between climate and vegetation can modify rates of global climate and vegetation change (Scheffer et al., 2005; Meir, Cox and Grace, 2006). Vegetation cover and structures define the surface albedo and the surface roughness, which influences the surface energy balance and convective precipitation (Laguë, Bonan and Swann, 2019). The predicted change in plant heights and phenology implies that coupling climate-vegetation models would better represent feedback between climate and vegetation (Piao et al., 2019). 
Although understanding the mechanisms of plant phenology responses to climate warming is still very limited, it is important to predict the future impact of phenological changes on ecosystem (Piao et al., 2019). Shifts in plant phenology also affect ecosystem carbon cycles and ecosystem feedback to climate, yet the quantification of such impacts remains challenging (Piao et al., 2019). Filling such knowledge gaps will enhance our capacity to understand and predict plant phenological changes under ongoing anthropogenic climate change (Piao et al., 2019). Schaphoff et al. (2006) found substantial differences in terrestrial carbon storage when a vegetation model was coupled to different general circulation models. Raddatz et al. (2007) observed positive feedbacks in the climate-carbon cycle by comparing coupled and uncoupled climate-carbon cycle simulations. The carbon storage potential under elevated $\mathrm{CO}_{2}$ can be better represented with coupled simulations than in uncoupled simulations.

Findings of vegetation responses to the changes have important implications for management policy because they suggest that large ensembles of climate models and scenarios are required to assess a wide range of potential future trajectories of vegetation change and develop robust management plans (Schindler and Hilborn, 2015). Since tropical Asia is host to 7 of the 36 global biodiversity hotspots (Myers et al., 2000; Mittermeier et al., 2004), effective management and policy recommendations would require an in-depth understanding of vegetation's response to climate change. I suggest that future studies should primarily focus on using new observation tools to improve the understanding of tropical plant phenology, on improving process-based phenology modelling, and on the scaling of phenology from species to landscape level.

\subsubsection{Conservation of threatened Asian savanna under climate change}

In Chapter 5, I showed how the same vegetation composition can be classified into entirely two different biomes based on the criteria considered for the biome classification. Misrepresentation of Asian savanna as the degraded forest has been a century-old problem because the ecosystem was managed from the perspective of forestry. This study showed that large areas in South Asia can be interpreted as woodland, degraded forest, or savanna. I proposed a biome classification scheme to distinguish between forest and savanna based on the abundance of grass biomass and tree density, i.e., canopy cover present in the system (Kumar et al., 2020a). I emphasized that adopting 
a grass-centric perspective for biome classification accounting for the grass component and the woody component is necessary to correctly identify savannas for conservation.

Savannas are the most vulnerable to woody encroachment due to climate, and a decrease in their extent and associated losses of biodiversity are very likely (Bond and Midgley, 2012; Stevens et al., 2017). Proper monitoring of savannas would help to detect any early warning for the actual encroachment (Pace, Carpenter and Cole, 2015; Marston et al., 2017). Woody encroachment implies transition toward the forest that has a benefit for climate mitigation. However, it also presents major conservational challenges because this transition might also threaten savanna biodiversity (Friedlingstein et al., 2019; Silveira et al., 2020). This also indicates potential conflicts of interest between biodiversity conservation in open ecosystems and active afforestation to enhance carbon sequestration (Fernandes et al., 2016; Banerjee et al., 2020; Haddad et al., 2020). The lack of recognition of Asian savannas as unique ecosystems distinct from forests and the common misperception of savannahs as degraded forests also pose significant conservation and management challenges (Sankaran and Ratnam, 2013; Ratnam et al., 2016).

Most Asian savannas usually receive more rainfall than some other iconic savannas of the tropics, i.e., South American Cerrado or African savanna, which are characterized by frequent burning and drought (Ratnam et al., 2016; Ratnam, Sheth and Sankaran, 2019). Similar to other savannas, Asian savannas are aslo bi-stable as simulations with fire show large extent of savannas (Figure 2.2e, f), whereas in the absence of fire, savanna regions are occupied by forest, woodland or grassland (Figure 2.2a, b; Chapter 2). Current fire management policy in Asian savanna is not well regulated, and understanding of forest fires has been skewed by colonial-era policy (Ratnam et al., 2016). There is a blanket fire-suppression policy in the region that is doing more harm than good to these tree-grass ecosystems. This policy affects the periodic small fire event which reducing the fuel load of the system. It ultimately leads to massive conflagrations that end up reaching the canopy and destroying the forest (Thekaekara et al., 2017). In addition to fire suppression, the invasive species Lantana has spread and has altered the understorey plant's structure and have detrimental effects on local biodiversity across trophic levels (Prasad, 2010; Sundaram and Hiremath, 2012). The suppression of the fires has an adverse effect as it paves the way for induced woody encroachment. For example, Lantana has completely taken over the understorey in the 
region's peninsula (Prasad, 2010; Thekaekara et al., 2017). I argue that urgent research is needed to understand the functional roles of fire disturbances in the ecosystems, and how the spread of Lantana and fire suppression have altered fire dynamics in the region, affecting diversity. Other disturbances include land-use change due to agriculture, tree plantations, and severe invasion by exotic woody species (Sankaran, 2005). All these factors increase the uncertainty of predicted trajectories under changing climatic regimes.

Savannas have been extensively investigated in other tropics (Lehmann et al., 2014; Stevens et al., 2017) but have not studied Asian tropics (Figure 1.2a; Ratnam et al., 2016; Kumar and Scheiter, 2019; Kumar et al., 2020a). It would be an opportunity to link the global savanna dynamics to Asian savanna dynamics, to bring the attention so that Asian Savanna can be well recognized and protected (Figure 1.2a). Protecting them would benefit the local wildlife and people dependent on the savannas landscape (Boone et al., 2018). As a large proportion of the population depends on savanna for their livelihood like bush meat, firewood, etc., (Twine, 2019). Intense land-use and climate change may degrade ecosystems and influence the provision of ecosystem services (Foley et al., 2005; Scheiter et al., 2019). This would affect the socio-economic life of the people. DGVMs have been used to explore the impact of ecosystem services (Scheiter et al., 2019). The aDGVM2 can serve as tools to inform decision making for climate adaptation and mitigation for savanna. Hence proper management strategies should be taken into account for carbon sequestration in the context of climate change adaptation without affecting biodiversity and their conservation in an open ecosystem.

\subsection{Limitation and model uncertainties}

All studies using DGVMs are based on certain assumptions to represent the complex natural system. Even an advanced trait-based dynamic vegetation model, such as aDGVM2, has some limitations and underlying assumptions. The model simulates observed biome or biomass patterns, and it does not necessarily mean that the model assumptions capture the underlying ecosystem dynamics (Oreskes and Belitz, 2001). Such limitations open up the scope of further research and model development.

\subsubsection{Inclusion of anthropogenic factors}

For a better representation of vegetation distribution, it is important to account for the land use pattern in addition to natural vegetation. Presented model simulations 
and predictions show potential vegetation dynamics in the region. However, it is important to account for anthropogenic factors like land-use for future studies given the region is heavily utilized for agricultural activities. It is important to consider anthropogenic activities such as deforestation, habitat conversion, urbanization, and ongoing management activities in modelling (Paul et al., 2019; Zaimes, Gounaridis and Symenonakis, 2019). These factors can modify the interactions between climate, plant communities, and biomes (Hansen et al., 2001). One way to account for anthropogenic land use would be to provide the gridded data on fractional land-use to DGVMs (Prestele et al., 2017; Quesada et al., 2018; Burton et al., 2019). Critical land change information enhances the understanding of the region's carbon balance because land use and land cover change (LULC) is an important perturbation of the regional and global carbon cycle (Quesada et al., 2018; Yue et al., 2020). DGVMs can model spatial and temporal ecosystem dynamic to represent carbon cycle and response to environmental conditions; however, they simulate the potential carbon cycle, which usually deviates from the observation (Houghton et al., 2012). The difference arises due to the lack of proper or simplified representation of processes related to LULC for the carbon cycle in DGVMs. Beside, DGVMs typically operate at coarse spatial resolutions with a limited representation of LULC (Arneth et al., 2017). DGVMs, including aDGVM2, should be enhanced to represent LULCC impact on the carbon cycle as done in studies by Sitch et al. (2015), Liu et al. ( 2016) and Schimel et al. (2016). DGVMs that can deal with fractional land cover change will be useful for large-scale, coarse-resolution regional and global simulations (Liu et al., 2020).

The impacts of various management scenarios can be considered using various Shared Socio-economic Pathways (SSPs) to predict the potential change. SSPs are scenarios of projected socio-economic global changes up to 2100 . They are used to derive greenhouse gas emissions scenarios with different climate policies (Riahi et al., 2017). SSPs set the scenarios on which reductions in emissions will - or will not - be achieved.

\subsubsection{Cold adapted biomes}

The biodiversity hotspots of the region harbor varieties of flora, including alpine vegetation communities in the Himalayas. The complex topography, diverse climatic conditions, and geodynamic processes give rise to the unique plant communities strongly influenced by gradients of precipitation and altitude in the region, as discussed in Chapter 
2. These communities are very sensitive to climate change and influence the species richness and community structure of the Himalayan flora (Gairola, Rawal and Todaria, 2008). Zobel and Singh (1997) concluded that Himalayan forests exhibit neither truly tropical nor temperate characteristics, are cold-adapted as discussed in detail in Chapter 2, are missing from the current study. These cold biomes at higher altitudes in the Himalayas are very dynamic biomes due to rising temperatures as the regions warm faster than the global average (Gonzalez et al., 2010). Knowledge of vegetation dynamics at a higher elevation on plant communities is crucial for understanding plant migration processes, their physiological limits, and diversity changes under the influence of climate change (Gottfried et al., 2012). Lack of knowledge about vegetation dynamics in response to climate change in cold and dry biomes is striking, especially in a dry region of Asia, where vascular plants grow in the highest elevations on earth (Dolezal et al., 2016). Therefore it requires the ecologist to also focus more on these cold-adapted biomes for their better representation in the vegetation model. A model like aDGVM2 potentially can be used to test the upward or multidirectional migration, which predicts an increase in absolute distributional limits, vegetation cover and abundance of alpine communities adapted to a warmer climate (Dolezal et al., 2016).

\subsubsection{Detailed representation of various carbon pools}

The aDGVM2 does not include the representation of carbon invested in defense mechanisms such as non-structural carbon (NSC). During harsh environmental conditions, plants respond by changing the allocation of available carbon among the different organs and synthesizing more functional metabolites such as NSC for defense mechanisms (Yang et al., 2018; Huang et al., 2020). The carbon allocation strategies are define by plant's responses to environmental condition, most of which are still not well understood in the context of climate change. Plants accumulate non-structural carbohydrates (NSC) under stress (Martínez-Vilalta et al., 2016). Increasing NSC in plants inhibits photosynthesis when growth is limited (Paul and Foyer, 2001). This indicates the potential for carbon sink strength to limit overall carbon assimilation into durable biomass and account for NSCs (Hartmann et al., 2020). The model currently also lacks carbon representation that plants invest in nutrient acquisition (e.g., mycorrhiza) or into defenses against predation and pathogens (Zemunik et al., 2015). Therefore, I 
suggest that it would be worthwhile to incorporate them into aDGVM2 framework to explore their implications for ecosystem carbon fluxes and community dynamics.

\subsubsection{Data availability}

The availability of plant physiological data for model parameterization is a major limitation for the region. There is insufficient ecophysiological data from the study region required for parameterization of trait ranges used in aDGVM2 to simulate plant communities (Kumar and Scheiter, 2019). Traits used to define the trade-offs are not easily measurable in the field, limiting the evaluation of simulated mechanisms. The complexity of the interactions between global change and biomes and biodiversity is difficult to model in the absence of such data (McMahon et al., 2011). However, the development of global trait databases (e.g. GLOPNET (Wright et al., 2004); TRY [http://www.try-db.org/]) can now redress this situation to some extent. Besides soil is an important factor defining vegetation distribution (Eyre, 2017; Langan et al., 2017), it would be necessary to have high-resolution soil data from the region. The low resolution of both soil and climate input data also limits the model's capability to capture the regional heterogeneity in vegetation distribution.

\subsubsection{Nutrient cycling}

Nutrient limitation is well known to exert negative feedback on photosynthesis via the amount of Rubisco, which is strongly controlled by nitrogen availability (Kattge et al., 2009). Nutrients directly control plant growth (Leuzinger and Hättenschwiler, 2013) and hence can affect $\mathrm{CO}_{2}$ fertilization in plants. FACE experiments have shown that progressive nitrogen limitation (Luo et al., 2004) has been demonstrated to limit plant growth (Norby et al., 2010). Further, the strength of $\mathrm{CO}_{2}$ fertilization modeled in aDGVM2 may be overestimated, given that the model does not include nutrients and nutrient cycling to represent the effect of nutrient limitation on productivity (Körner et al., 2005; Terrer et al., 2018). 


\subsection{Moving forward with aDGVM2}

\subsubsection{Building the way forward for biome-trait spectrum with aDGVM2}

Biomes have been defined based on the structural and functional similarity of vegetation characteristics (Moncrieff, Bond and Higgins, 2016; Mucina, 2019). Building on the ability of aDGVM2 to simulate different plant traits, I propose that the clustering of plant traits in trait-space would provide a useful approach for characterizing biomes. Various available biome maps are either derived from the expert opinion based on combinations of climatic data and observed vegetation maps (Olson et al., 2001) or remotely sensed vegetation types (Friedl et al., 2010). Different methods have been used to develop biome maps, for example, using the simulated plant attributes by mechanistic models (Prentice et al., 1992), climate-trait relationships (van Bodegom, Douma and Verheijen, 2014), or dominant biomes types using remote sensing (Higgins, Buitenwerf and Moncrieff, 2016). Here I suggest that the trait-space occupied by key plant functional traits can be used for defining and mapping distinct biome, i.e., "trait-biome diversity." I also suggest that the distinction between different biomes such as grassland, woodland or savanna, and deciduous or evergreen forest can be observed from the trait dominance in each biome. This is supported by the largely non-overlapping distributions of traits for different biomes (Figure 6.1). Building on the well-known traits-based studies focusing on plant structural economics (Díaz et al., 2016), I have decided to present the biometrait spectrum for simulated vegetation, plant forms, and function. Here I selected simulated traits to build the trait-spectrum, which is very close to Díaz et al's. (2016) trait spectrum. I performed a PCA using mean trait values of each grid cell simulated by aDGVM2 indicates the ecological sorting of different biomes in trait space (Figure 6.1). In Figure 6.1 the first PCA axis describes a trade-off between woody and grassy biomes and associated resource allocation strategies. The second PCA axis describes a trade-off between tall vegetation in forests and small vegetation with a high abundance of shrubs in grasslands and shrublands. These patterns emerge from the community assembly processes in aDGVM2, and they remain to be compared with patterns identified in observations (Díaz et al., 2016; Bruelheide et al., 2018). Performing PCA analysis on simulated traits shows the sorting of different biome types in South Asia and reveals different dominant ecological strategies characterizing these biomes. 
With the ability of aDGVM2 to simulate an individual's traits under a given environment, I propose that trait-based classification can open a new realm of questions for future research, such as

(a) Can aDGVM2 reproduce the observed trait pattern at the regional scale?

(b) Which traits does a combination explain the observed and future biome distribution?

(c) How do the projected climate and rising $\mathrm{CO}_{2}$ affect this "trait-biome diversity"?

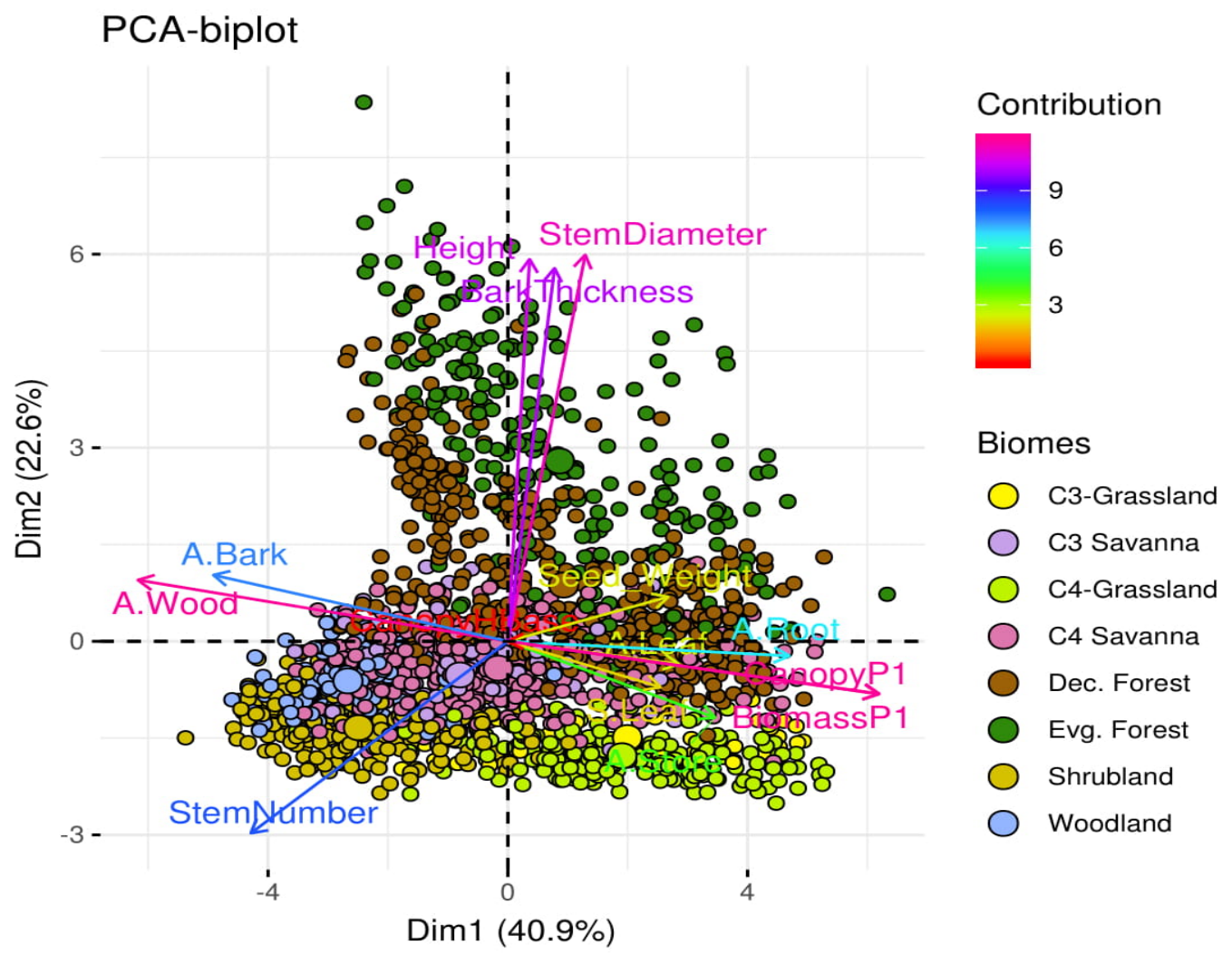

Figure 6.1 The two PCA axes represent grassy vs. woody biomes and plant size. The first two PCA axes explain $63.5 \%$ of the variation. Each point represents a simulated grid cell.

\subsubsection{Investigating lag-effects on diversity with aDGVM2}

During the entire Earth's history, the climatic condition and level of atmospheric $\mathrm{CO}_{2}$ have varied over time (Beerling and Royer, 2011). The change in Earth's terrestrial surface due to both anthropogenic, e.g., agricultural expansion, urbanization and natural processes, e.g., fires, drought, storms (Ellis, 2013; Song et al., 2018), have been shown to impact biodiversity (Newbold et al., 2015; Jung et al., 2019) and ecosystem services (Isbell et al., 2015). Previous studies by Gibson et al. (2011) and Newbold et al. (2015) 
have found that chance in terrestrial surface reduces local biodiversity globally but often ignored while studying biodiversity (Foster et al., 2003; Watson et al., 2014). Various studies using simulations and experiments have demonstrated that changes on terrestrial surface have larger impacts on biodiversity (Dornelas, 2010; Hautier et al., 2015; Santini et al., 2017). Moncrieff et al. (2014) indicated the importance of historic legacy effects for understanding future vegetation. Scheiter et al. (2020a) found that the cover of different biome types, biomass, and tree cover deviates substantially from the equilibrium vegetation state at given environmental conditions. The fire disturbance amplifies lag size that induces hysteresis and bi-stability between the savanna and forest system and changing the $\mathrm{CO}_{2}$ level can amplify the lag size (Higgins and Scheiter, 2012). However, the impact of such a lag effect between climate change and biodiversity still needs to be investigated.

The past land changes continue to affect biodiversity through various biotic lags that ecological processes such as extinction debt (Halley et al., 2016), colonization credit (Shackelford et al., 2017), and ecological memory effects (Ogle et al., 2015). These processes negatively affect plant communities and species present within ecosystem (Perring et al., 2018) and potentially reduce resilience of the communities (Hautier et al., 2015). Building on the work of Scheiter et al. (2020a) on the lag effect on biomes and biomass, it would be interesting to look into the lag effect on diversity. This lag effect can be due to either prolonged drought or major fire event. It has been shown that the predicted changes in biomass and biomes would also have consequences on diversity of the ecosystem (Langan, 2019). The flexibility of aDGVM2, makes it most suitable to study the lag effects on diversity of plant communities under projected climate change.

\subsection{Expansion of aDGVM2 for global scale}

The changes in traits influence ecosystem functioning (Lavorel and Garnier, 2002; Diaz et al., 2004) and the aDGVM2 can of simulate various plant functional traits under varying environmental condition. The model has been already tested for South America (Amazon Basin, Langan et al., 2017), Africa (Gaillard et al., 2018), and Topical Asia (South and South East Asia, i.e., this thesis, (Kumar et al., 2020a; Kumar et al., 2020b; Scheiter, Kumar, et al., 2020). The plan will be to expand the domain of aDGVM2 from tropical ecosystems to temperate and boreal ecosystems, making 
aDGVM2 capable of simulating the alpine communities of higher Himalayas and beyond.

\subsubsection{Including temperate and boreal vegetation communities}

A plant can adjust to the given environmental condition via changes in traits, and such changes by trait-driven interactions can be implemented in aDGVM2. One such trait-driven change is plants adaptation to a very cold environment. It can be implemented by including the plant low-temperature (LT) tolerance, also referred to as cold or frost tolerance or hardiness (Strimbeck et al., 2008). All plants found in cold climates such as in the higher Himalayas or Artic region have gone through a selection filter to resist local low-temperature extremes (Körner, 2016). Physiological studies have shown that maximum LT tolerance in temperate species ranges from -25 to $-35^{\circ} \mathrm{C}$, whereas in boreal species such as Abies, Picea, Pinus, and Larix, it is in the range of -40 to $-60{ }^{\circ} \mathrm{C}$ (Strimbeck et al., 2008). Some studies on boreal species in controlled environments have produced the depth of acclimation observed for the same species in nature (Sutinen, Palta and Reich, 1992). Temperate conifer species, e.g., Picea rubens, are known to fix carbon during mild winter weather (Hawkins et al., 1995), implying a plausible trade-off between LT tolerance and carbon balance (Ögren, 1997).

Extreme LT causes visible cell injury on some specific plant parts, e.g., leaf and young stems that cause loss of permeability of the plasma membrane resulting in the release of intracellular electrolytes (Strimbeck et al., 2008). The leakage is quantified by measuring the relative electrolyte leakage in affected plant tissues (Strimbeck et al., 2015). This technique is used to determine a minimum survival temperature or construct temperature response curves and interpolate the temperature resulting in 50\% plant or tissue death, LT 50 (Strimbeck et al., 2015; Lenz, Hoch and Vitasse, 2016). Plant adapted to LT, such as boreal or temperate conifers, sustain foliage cover even during winter months. Therefore, understanding the strength and mechanisms of how LT tolerance will be an important factor in predicting the effects of global warming.

Pescador et al. (2016) have established the relationships between freezing resistance, growth forms, and four key plant functional traits, i.e., plant height, specific leaf area, leaf dry matter content (LDMC), and seed mass. These morphological traits reflect plant's adaptations to stressful conditions like drought and freezing events that are common to mountains (Reich et al., 2003). Correlations between these freezing 
resistance traits can be critical for understanding the functional response to plant's LT tolerance. In particular, Squeo et al. (1991)found a negative correlation between plant height and freezing in plants from the high tropical Andes. Lopez-Iglesias et al. (2014) reported that plant species with a low specific leaf area (SLA) and a high leaf dry matter content (LDMC). These plants would have a reduced water loss area, more structural material, and increased resistance to physical stress such as drought or freezing (Cornelissen et al., 2003). Hekneby et al. (2006) found that cold acclimation in some Mediterranean legume species has decreased in the SLA and increased their freezing resistance. Verhoeven et al. (2004) found that the seed mass is positively correlated with the competitive ability and resistance to abiotic stress. Plant that produce larger seeds should be more resistant to freezing than those that produce smaller seeds (Sakai and Larcher, 2012).

Another essential aspect of plants adapted to extreme LT is that they have exhibited a persistent $\mathrm{Q}_{10}$ of 3-4, instead of the common $\mathrm{Q}_{10}$ of 2, i.e., a doubling of respiration for $10{ }^{\circ} \mathrm{C}$ rise in temperature (Larigauderie and Koerner, 1995). Empirical observations have shown that $\mathrm{Q}_{10}$ decreases with temperature (Tjoelker, Oleksyn and Reich, 2001), and models should treat $\mathrm{Q}_{10}$ as a temperature-dependent variable (Atkin and Tjoelker, 2003). These are the prime domains where future research on cold adaptation of plants needs to engage. By simulating variation in the plant trait responses to LT, it will be possible to simulate plant adaptation to the cold climate in aDGVM2.

\subsubsection{Including slope and aspect}

Topography in the region is very complex and heterogeneous compared to Africa or lowland rain forests of tropical South America, as it includes numerous hilly islands and the Himalayas. In DGVMs, topography mediated heterogeneities of the environment within simulation grids are often neglected (Pappas et al., 2015). Topography affects the radiation budget, climate, and hydrology (Stieglitz et al., 1997). It is necessary to represent topographical heterogeneity in the vegetation model (Rigon, Bertoldi and Over, 2006). Allen et al. (2006) showed to estimate daily solar radiation for inclined surfaces having specified slope and aspect for application with surface-energy balance models. Elevation can be used to derive heterogeneity within a grid and can be considered a way to implement within-grid heterogeneity for climate parameters such as air temperature (Kamoutsis, Chronopoulos and Matsoukis, 2017). The elevation is further tightly 
correlated with slope and soil depth profiles, which also control hydrology (Hoylman et al., 2018).

\subsubsection{Including temperature triggered phenology}

Onset and offset of growing season affect the productivity of forests, thus making phenology a critical component of ecosystem models (Jeong et al., 2012; Migliavacca et $a l ., 2012$ ). Available phenological models vary in their complexity (Richardson et al., 2013b). All models contain empirical components and have been developed to capture the processes of individual trees and are less able to capture the variability among trees over a larger region (Chuine, Cour and Rousseau, 1998). On a local scale, many studies have shown that simpler models often perform better than more complex models (Richardson and O'Keefe, 2009). Ecosystem models that incorporate phenology commonly use generalized phenological models, focusing on capturing large-scale vegetation patterns (Smith, Prentice and Sykes, 2001).

The aDGVM2 includes four different phenological types: evergreen lighttriggered, evergreen water-triggered, deciduous light-triggered and deciduous watertriggered (Langan et al., 2017) but does not explicitly define temperature-triggered phenology. The temperate and boreal plants, where temperature (as growing degree days, GDD) plays an essential role in phenology, need to be implemented in the model. Spring phenology of both boreal and temperate trees is mainly regulated by both temperature and length of day (Körner and Basler, 2010). However, the response to these factors varies among tree species, partly due to specific adaptations. Plants adapt different physiological mechanisms to escape or avoid or tolerate freezing temperatures (Guo, Liu and Chong, 2018). This mechanism includes a cold acclimation in autumn, a dormancy period during winter, and the maintenance of a certain freezing tolerance during dehardening in early spring (Polgar, Gallinat and Primack, 2014; Vitasse, Lenz and Körner, 2014). The change from one phase to the next is mediated by complex interactions between temperature and photoperiod that control the duration of chilling and time of budburst (Basler and Körner, 2014). This non-linear relationship between photoperiod and temperature may reflect the most prominent adaptation to escape frost injuries by regulating the appropriate timing for flushing (Lenz et al., 2013).

One of the main challenges today is truly understanding the effect of temperature and photoperiod on buds from the onset of dormancy to budburst and quantifying the 
freezing resistance of buds during the de-hardening period. Modelling the phenology of cold-adapted plants would help to predict the damaging effect of LT extremes.

\subsection{Significance of presented research}

This thesis contributes to a better understanding of potential vegetation dynamics in South and South-East Asia. I have conducted a detailed literature review to look into the knowledge gaps that exist in DGVMs when it comes to representing regional vegetation in South Asia. This study will encourage the modelling communities to focus on the heterogeneous vegetation types in the region. It will motivate them to develop a dynamic vegetation model to include biomes that are overlooked at the global scale of DGVM's studies. Most current known DGVMs, unfortunately, do not fully capture the distribution and ecosystem functioning of several vegetation types in the regions. I stress the fact that to build a vegetation model for the region will require improvement in the processes representing the interactions between the biotic and abiotic components in the regional ecosystem. These processes include representation of fire in savanna, better ecohydrology to distinguish between the wet and dry forest type both for deciduous and evergreen phenology, and alternative photosynthetic pathways (i.e., CAM for succulent plants) as well as an incorporation of temperature tolerance for cold-adapted vegetation. Future research should focus on improving the representation of these processes in models by setting up experimental field sites for collecting appropriate data. In recent years researches focusing on plant functional traits for understating the evolutionary and community aspects of vegetation have gain momentum. But there exists a problem related to the sharing of available data on a common platform. Ecosystem modellers working at various scales, e.g., local, regional or global levels, would require to bridge the existing gaps by sharing ecophysiological and site-specific data, e.g., climate and plant traits data for representing climate-vegetation interaction in a more realistic way. A better vegetation model can be a significant tool for determining suitable management strategies, enhancing ecosystem services, and alleviating future environmental change impacts.

Secondly, I showed how the biome boundaries, vegetation structure, and phenology would change under climate change and rising atmospheric $\mathrm{CO}_{2}$. The study identified the vulnerable biomes susceptible to change, and this way, these biomes could be the focus of conservation priorities and protection. Results showed a change in 
vegetation structure and phenology over the region that could modify albedo and alter both the water and carbon cycle. These changes influence the climate system via complex feedbacks (Bonan, 2008), and assessments of such feedbacks require the coupling of aDGVM2 with climate models.

Lastly, my thesis adds to the ongoing discussion about the conservation of ancient savannas, which are misinterpreted as degraded forests, which further contribute to mismanagement of conservation measures such as afforestation, fire management, etc. (Ratnam et al., 2016; Kumar et al., 2020a). Using the aDGVM2, I proposed a biome classification scheme to separate the simulated vegetation into forest and savanna. The study identified the regions for current savanna occurrences and predicted the probability of woody encroachment under the rising atmospheric concentration of $\mathrm{CO}_{2}$. This identified the threatened savanna region in South Asia under future climate change and should be brought under proper conservation through proper management plans such as regulating fires, removing alien plants, and controlling grazing.

I anticipate that the work presented here will fulfill at least two important functions: (1) drawing attention to the current gaps in our understanding of the role of climate change and rising $\mathrm{CO}_{2}$ on South and Southeast Asian biomes, especially savanna systems and (2) encourage modelling communities to focus more on tropical Asia which has very heterogeneous vegetation and home to 7 of the world biodiversity hotspot, to stimulate further research. In short, my Ph.D. research illustrates vegetation of tropical Asia would respond to future climate change and how it's possible to make better conclusions about these responses to mitigate any adverse consequences.

\subsection{Conclusion}

In this thesis, I investigated the impact of climate change and rising atmospheric $\mathrm{CO}_{2}$ concentration to understand the potential vegetation-climate interactions in South and South-East Asia, using a trait-based model, the aDGVM2. The advantage of aDGVM2 is that vegetation types are not predefined in the model but are inferred from the simulated results. This characteristic makes it unique as it increases realism and ability to improve the reliability of simulations under future climate scenarios. This is because, in aDGVM2, only plant communities with successful strategies, i.e., traitscombination, are dynamically assembled and emerges based on the prevailing 
environmental condition. Also, the spatial extent of vegetation type is not constraint by using bioclimatic limits in aDGVM2.

The study showed that the vegetation in South and South-East Asia will significantly shift towards tree dominated biome due to $\mathrm{CO}_{2}$-induced fertilization of $\mathrm{C}_{3}$ photosynthesis. I found that woodland and open biomes such as grassland and savanna will shift toward forest making savanna the most threatened biomes. The model further predicted taller evergreen vegetation and increasing aboveground biomass, suggesting that the region has the potential to remain as carbon sink till the end of this century.

I demonstrated that the Asian savanna could be distinguished from the forest with proposed grass-centric biome classifications schemes. I found that considering vegetation systems as woodland or degraded forest could easily be mistaken as a potential for forest restoration within a tree-centric perspective. This would put approximately $35 \%$ to $40 \%$ of a unique savanna biome at risk. It will encourage sustainable management strategies for the conservation of threatened savanna biomes to protect it from woody encroachment by regulating fire management and avoiding afforestation. The aDGVM2 can be used to explore these strategies for savannas and other threatened biomes (Scheiter et al., 2019).

The predicted increase in biomass due to woody encroachment may have been overestimated given the model did not account for nutrient limitation on $\mathrm{CO}_{2}$ fertilization. Therefore, it is important to include the effect of nutrient constraint on $\mathrm{CO}_{2}$ fertilization as well as the better representation of plant eco-hydrology and the edaphic process affecting vegetation dynamics. Improving vegetation models should also include slope and aspect for the better representation of mountainous regions such as the Himalayas, seed dispersal, and migration. I argue that the coupling climate and vegetation model would better represent the climate-vegetation interaction. This study is an important step towards understanding the South and Southeast ecosystems, specifically savannas, and thus contributes towards our ability to adapt better conservation strategies to mitigate the consequences of climate change. 


\section{REFERENCES}

Aber, J. et al. (2001) 'Forest processes and global environmental change: predicting the effects of individual and multiple stressors: we review the effects of several rapidly changing environmental drivers on ecosystem function, discuss interactions among them, and summarize predicted changes in productivity, carbon storage, and water balance', BioScience, 51(9), pp. 735-751.

Achard, F. et al. (2002) 'Determination of deforestation rates of the world's humid tropical forests', Science, 297(5583), pp. 999-1002.

Achard, F. et al. (2004) 'Improved estimates of net carbon emissions from land cover change in the tropics for the 1990s', Global Biogeochemical Cycles, 18(2).

Acharya, B. S. et al. (2018) 'Woody plant encroachment impacts on groundwater recharge: A review', Water, 10(10), p. 1466.

Addo-Fordjour, P., Rahmad, Z. B. and Shahrul, A. M. S. (2012) 'Effects of human disturbance on liana community diversity and structure in a tropical rainforest, Malaysia: implication for conservation', Journal of Plant Ecology, 5(4), pp. 391-399.

Adole, T., Dash, J. and Atkinson, P. M. (2018) 'Large-scale prerain vegetation green-up across Africa', Global Change Biology, 24, pp. 4054- 4068.

Agarwala, M. et al. (2016) 'Changes in the dry tropical forests in Central India with human use', Regional Environmental Change, 16(1), pp. 5-15.

Ahlstrom, A. et al. (2013) 'GCM characteristics explain the majority of uncertainty in projected 21 st century terrestrial ecosystem carbon balance', Biogeosciences, pp. 1517-1528.

Allan, E. et al. (2015) 'Land use intensification alters ecosystem multifunctionality via loss of biodiversity and changes to functional composition', Ecology letters, 18(8), pp. 834843.

Allen, M. R. et al. (2014) 'IPCC fifth assessment synthesis report-climate change 2014 synthesis report'.

Allen, R. G., Trezza, R. and Tasumi, M. (2006) 'Analytical integrated functions for daily solar radiation on slopes', Agricultural and Forest Meteorology, 139(1-2), pp. 55-73.

Alo, C. A. and Wang, G. (2008) 'Potential future changes of the terrestrial ecosystem based on climate projections by eight general circulation models', Journal of Geophysical Research: Biogeosciences, 113(G1).

Alongi, D. M. (2012) 'Carbon sequestration in mangrove forests', Carbon management, 3(3), pp. 313-322.

Annamalai, H. and Liu, P. (2005) 'Response of the Asian summer monsoon to changes in El Niño properties', Quarterly Journal of the Royal Meteorological Society: A journal of the atmospheric sciences, applied meteorology and physical oceanography, 131(607), pp. $805-831$.

Archibald, S. et al. (2013) 'Defining pyromes and global syndromes of fire regimes', Proceedings of the National Academy of Sciences, 110(16), pp. 6442-6447.

Arneth, A. et al. (2017) 'Historical carbon dioxide emissions caused by land-use changes are possibly larger than assumed', Nature Geoscience, 10(2), pp. 79-84.

Arora, V. (2002) 'Modeling vegetation as a dynamic component in soil-vegetation-atmosphere transfer schemes and hydrological models', Reviews of Geophysics, 40(2).

Ashmore, M. R. (2005) 'Assessing the future global impacts of ozone on vegetation', Plant, Cell \& Environment, 28(8), pp. 949-964.

Atkin, O. K. and Tjoelker, M. G. (2003) 'Thermal acclimation and the dynamic response of plant respiration to temperature', Trends in plant science, 8(7), pp. 343-351.

Bachelet, D. et al. (2001) 'Climate change effects on vegetation distribution and carbon budget in the United States', Ecosystems, 4(3), pp. 164-185. 
Bachelet, D. et al. (2018) 'Translating MC2 DGVM results into ecosystem services for climate change mitigation and adaptation', Climate, 6(1), p. 1.

Baithalu, S., Anbarashan, M. and Parthasarathy, N. (2012) 'Changes in tree diversity and stand structure of two tropical dry evergreen forests on the Coromandel coast of peninsular India over a decade (2001-2011)', International Journal of Ecology and Environmental Sciences, 38(2-3), pp. 87-96.

Baldocchi, D. and Penuelas, J. (2019) 'The physics and ecology of mining carbon dioxide from the atmosphere by ecosystems', Global change biology, 25(4), pp. 1191-1197.

Ball, J. T., Woodrow, I. E. and Berry, J. A. (1987) 'A model predicting stomatal conductance and its contribution to the control of photosynthesis under different environmental conditions', in Progress in photosynthesis research. Springer, pp. 221-224.

Ball, M. C. (2002) 'Interactive effects of salinity and irradiance on growth: implications for mangrove forest structure along salinity gradients', Trees, 16(2-3), pp. 126-139.

Banerjee, O. et al. (2020) 'Global socio-economic impacts of changes in natural capital and ecosystem services: State of play and new modeling approaches', Ecosystem Services, 46, p. 101202.

Bartlett, M. S., Vico, G. and Porporato, A. (2014) 'Coupled carbon and water fluxes in CAM photosynthesis: modeling quantification of water use efficiency and productivity', Plant and soil, 383(1-2), pp. 111-138.

Basler, D. and Körner, C. (2014) 'Photoperiod and temperature responses of bud swelling and bud burst in four temperate forest tree species', Tree physiology, 34(4), pp. 377-388.

Bastin, J.-F. et al. (2017) 'The extent of forest in dryland biomes', Science, 356(6338), pp. 635638.

Bastin, J.-F. et al. (2019) 'The global tree restoration potential', Science, 365(6448), pp. 76-79.

Bednarz, S. T. et al. (2001) 'Brush/water yield feasibility studies', Blackland Research Center, Temple, Texas, USA.

Beerling, D. J. and Royer, D. L. (2011) 'Earth's atmospheric CO2 history by proxy', Nature Geoscience, 4, pp. 1-2.

Bellard, C. et al. (2012) 'Impacts of climate change on the future of biodiversity', Ecology letters, 15(4), pp. 365-377.

Bera, S. K. et al. (2006) 'Conversion of forest land in Garo Hills, Meghalaya for construction of roads: A threat to the environment and biodiversity', Current Science, pp. 281-284.

Berger, U. et al. (2008) 'Advances and limitations of individual-based models to analyze and predict dynamics of mangrove forests: A review', Aquatic Botany, 89(2), pp. 260-274.

Berger, U. and Hildenbrandt, H. (2000) 'A new approach to spatially explicit modelling of forest dynamics: spacing, ageing and neighbourhood competition of mangrove trees', Ecological Modelling, 132(3), pp. 287-302.

Bhadouria, R., TRIPATHI, S. and Rao, K. S. (2018) 'Understanding plant community assemblage, functional diversity and soil attributes of Indian savannas through a continuum approach', Tropical Ecology, 59(4), pp. 545-554.

Bhowmick, M., Sahany, S. and Mishra, S. K. (2019) 'Projected precipitation changes over the south Asian region for every $0.5 \mathrm{C}$ increase in global warming', Environmental Research Letters, 14(5), p. 054005.

Blanco, C. C. et al. (2014) 'Feedbacks between vegetation and disturbance processes promote long-term persistence of forest-grassland mosaics in south Brazil', Ecological Modelling, 291, pp. 224- 232.

Blasco, F. and Legris, P. (1973) 'Dry evergreen forest of Point Calimere and Marakanam', Journal of Bombay Natural History Society, 70(2), pp. 279-294.

Blasco, F., Whitmore, T. C. and Gers, C. (2000) 'A framework for the worldwide comparison of tropical woody vegetation types', Biological Conservation, 95(2), pp. 175-189. 
Blois, J. L. et al. (2013) 'Climate change and the past, present, and future of biotic interactions', Science, 341(6145), pp. 499-504.

van Bodegom, P. M., Douma, J. C. and Verheijen, L. M. (2014) 'A fully traits-based approach to modeling global vegetation distribution', Proceedings of the National Academy of Sciences, 111(38), pp. 13733-13738.

Boit, A. et al. (2016) 'Large-scale impact of climate change vs. land-use change on future biome shifts in Latin America', Global change biology, 22(11), pp. 3689-3701.

Bonan, G. B. (2008) 'Forests and climate change: Forcings, feedbacks, and the climate benefits of forests', Science, 320, pp. 1444- 1449.

Bond, W. J. (2008) 'What limits trees in C4 grasslands and savannas?', Annual Review of Ecology Evolution and Systematics, 39, pp. 641-659.

Bond, W. J. et al. (2019) 'The trouble with trees: Afforestation plans for Africa', Trends in Ecology \& Evolution, 34, pp. 963-965.

Bond, W. J. and Midgley, G. F. (2000) 'A proposed CO2-controlled mechanism of woody plant invasion in grasslands and savannas', Global Change Biology, 6(8), pp. 865-869.

Bond, W. J. and Midgley, G. F. (2012) 'Carbon dioxide and the uneasy interactions of trees and savannah grasses', Philosophical Transactions of the Royal Society B: Biological Sciences, 367(1588), pp. 601-612.

Bond, W. J., Midgley, G. F. and Woodward, F. I. (2003) 'The importance of low atmospheric $\mathrm{CO} 2$ and fire in promoting the spread of grasslands and savannas', Global Change Biology, 9, pp. 973-982.

Bond, W. J. and Midgley, J. J. (2001) 'Ecology of sprouting in woody plants: the persistence niche', Trends in ecology \& evolution, 16(1), pp. 45-51.

Bond, W. J. and Parr, C. L. (2010) 'Beyond the forest edge: ecology, diversity and conservation of the grassy biomes', Biological conservation, 143(10), pp. 2395-2404.

Boone, R. B. et al. (2018) 'Climate change impacts on selected global rangeland ecosystem services', Global change biology, 24(3), pp. 1382-1393.

Bor, N. L. (1960) 'The Grasses of Burma, Ceylon, India and Pakistan (excluding Bambuseae).', The grasses of Burma, Ceylon, India and Pakistan (excluding Bambuseae).

Borchert, R. (1994) 'Soil and stem water storage determine phenology and distribution of tropical dry forest trees', Ecology, 75(5), pp. 1437-1449.

Boulangeat, I. et al. (2012) 'Improving plant functional groups for dynamic models of biodiversity: at the crossroads between functional and community ecology', Global change biology, 18(11), pp. 3464-3475.

Box, E. O. and Fujiwara, K. (2013) 'Vegetation types and their broad-scale distribution', Vegetation ecology. 2nd ed. Wiley-Blackwell, UK, pp. 455-485.

Brandis, D. (1906) Indian Trees: an account of trees, shrubs, woody climbers, bamboos and palms indigenous or commonly cultivated in the British Indian Empire. Constable.

Bremer, L. L. and Farley, K. A. (2010) 'Does plantation forestry restore biodiversity or create green deserts? A synthesis of the effects of land-use transitions on plant species richness', Biodiversity and Conservation, 19(14), pp. 3893-3915.

Brenes-Arguedas, T., Roddy, A. B. and Kursar, T. A. (2013) 'Plant traits in relation to the performance and distribution of woody species in wet and dry tropical forest types in Panama', Functional Ecology, 27(2), pp. 392-402.

Breshears, D. D. et al. (2005) 'Regional vegetation die-off in response to global-change-type drought', Proceedings of the National Academy of Sciences, 102(42), pp. 15144-15148.

Brienen, R. J. et al. (2015) 'Long-term decline of the Amazon carbon sink', Nature, 519(7543), pp. 344-348.

Bright, R. M. et al. (2015) 'Quantifying surface albedo and other direct biogeophysical climate forcings of forestry activities', Global Change Biology, 21(9), pp. 3246-3266. 
Brodie, J. F. et al. (2014) 'Secondary extinctions of biodiversity', Trends in Ecology \& Evolution, 29(12), pp. 664-672.

Brodribb, T. J., Holbrook, N. M. and Gutierrez, M. V. (2002) 'Hydraulic and photosynthetic coordination in seasonally dry tropical forest trees', Plant, Cell \& Environment, 25(11), pp. $1435-1444$.

Brooks, K. J., Setterfield, S. A. and Douglas, M. M. (2010) 'Exotic grass invasions: applying a conceptual framework to the dynamics of degradation and restoration in Australia's tropical savannas', Restoration Ecology, 18(2), pp. 188-197.

Brown, S., Gillespie, A. J. and Lugo, A. E. (1991) 'Biomass of tropical forests of south and southeast Asia', Canadian Journal of Forest Research, 21(1), pp. 111-117.

Bruelheide, H. et al. (2018) 'Global trait-environment relationships of plant communities', Nature Ecology \& Evolution, 2(12), pp.1906-1917

Budke, J. C., Jarenkow, J. A. and de Oliveira-Filho, A. T. (2010) 'Intermediary disturbance increases tree diversity in riverine forest of southern Brazil', Biodiversity and Conservation, 19(8), pp. 2371-2387.

Buisson, E. et al. (2019) 'Resilience and restoration of tropical and subtropical grasslands, savannas, and grassy woodlands', Biological Reviews, 94(2), pp. 590-609.

Buitenwerf, R. et al. (2012) 'Increased tree densities in S outh A frican savannas:> 50 years of data suggests $\mathrm{CO}_{2}$ as a driver', Global Change Biology, 18(2), pp. 675-684.

Buitenwerf, R., Rose, L. and Higgins, S. I. (2015) 'Three decades of multi-dimensional change in global leaf phenology', Nature Climate Change, 5(4), pp. 364-368.

Bunyavejchewin, S. (1999) 'Structure and dynamics in seasonal dry evergreen forest in northeastern Thailand', Journal of Vegetation Science, 10(6), pp. 787-792.

Burrows, G. E. (2002) 'Epicormic strand structure in Angophora, Eucalyptus and Lophostemon (Myrtaceae)-implications for fire resistance and recovery', New Phytologist, 153(1), pp. $111-131$.

Burton, C. et al. (2019) 'Representation of fire, land-use change and vegetation dynamics in the Joint UK Land Environment Simulator vn4. 9 (JULES)', Geoscientific Model Development, 12(1), pp. 179-193.

Bystriakova, N., Kapos, V. and Lysenko, I. (2004) 'Bamboo biodiversity', UNEP/Earthprint, United Kingdom.

Cadotte, M. W., Cardinale, B. J. and Oakley, T. H. (2008) 'Evolutionary history and the effect of biodiversity on plant productivity', Proceedings of the National Academy of Sciences, 105(44), pp. 17012-17017.

Calder, I. R., Hall, R. L. and Prasanna, K. T. (1993) 'Hydrological impact of Eucalyptus plantation in India', Journal of Hydrology, 150(2-4), pp. 635-648.

Canadell, J. G. (2002) 'Land use effects on terrestrial carbon sources and sinks', Science in China series C life sciences-english edition-, 45(SUPP), pp. 1-9.

Cao, L. et al. (2010) 'Importance of carbon dioxide physiological forcing to future climate change', Proceedings of the National Academy of Sciences, 107(21), pp. 9513-9518.

Castañeda-Moya, E., Rivera-Monroy, V. H. and Twilley, R. R. (2006) 'Mangrove zonation in the dry life zone of the Gulf of Fonseca, Honduras', Estuaries and Coasts, 29(5), pp. 751-764.

Castañeda-Moya, E., Twilley, R. R. and Rivera-Monroy, V. H. (2013) 'Allocation of biomass and net primary productivity of mangrove forests along environmental gradients in the Florida Coastal Everglades, USA', Forest Ecology and Management, 307, pp. 226-241.

Cava, M. G. et al. (2018) 'Abandoned pastures cannot spontaneously recover the attributes of old-growth savannas', Journal of applied ecology, 55(3), pp. 1164-1172.

Cerling, T. E. et al. (1997) 'Global vegetation change through the Miocene/Pliocene boundary', Nature, 389(6647), p. 153. 
Cervarich, M. et al. (2016) 'The terrestrial carbon budget of South and Southeast Asia', Environmental Research Letters, 11(10), p. 105006.

Champion, S. H. and Seth, S. K. (1968) 'A revised survey of the forest types of India.', A revised survey of the forest types of India.

Chape, S. et al. (2005) 'Measuring the extent and effectiveness of protected areas as an indicator for meeting global biodiversity targets', Philosophical Transactions of the Royal Society B: Biological Sciences, 360(1454), pp. 443-455.

Chapin, F. S. et al. (1997) 'Biotic control over the functioning of ecosystems', Science, 277(5325), pp. 500-504.

Charles-Dominique, T., Midgley, G. F. and Bond, W. J. (2017) 'Fire frequency filters species by bark traits in a savanna-forest mosaic', Journal of Vegetation Science, 28(4), pp. 728735.

Chaturvedi, R. K. et al. (2011) 'Impact of climate change on Indian forests: A dynamic vegetation modeling approach', Mitigation and Adaptation Strategies for Global Change, 16, pp. $119-142$

Chen, B. et al. (2014) 'Changes in vegetation photosynthetic activity trends across the AsiaPacific region over the last three decades', Remote Sensing of Environment, 144, pp. $28-41$.

Chen, I.-C. et al. (2011) 'Rapid range shifts of species associated with high levels of climate warming', Science, 333(6045), pp. 1024-1026.

Chen, J. M. et al. (2019) 'Vegetation structural change since 1981 significantly enhanced the terrestrial carbon sink', Nature Communications, 10, p. 4259.

Chen, R. and Twilley, R. R. (1998) 'A gap dynamic model of mangrove forest development along gradients of soil salinity and nutrient resources', Journal of ecology, 86(1), pp. 37-51.

Chesson, P. (2000) 'Mechanisms of maintenance of species diversity', Annual review of Ecology and Systematics, 31(1), pp. 343-366.

Chettri, N. et al. (2010) Biodiversity in the Eastern Himalayas: Status, trends and vulnerability to climate change. International Centre for Integrated Mountain Development (ICIMOD).

Chitale, V. S., Behera, M. D. and Roy, P. S. (2014) 'Future of Endemic Flora of Biodiversity Hotspots in India', PLoS ONE. Edited by D. Rocchini, 9(12), p. e115264.

Cho, M.-H. et al. (2015) 'The impact of land cover generated by a dynamic vegetation model on climate over east Asia in present and possible future climate', Earth System Dynamics, 6(1), p. 147.

Choat, B. et al. (2018) 'Triggers of tree mortality under drought', Nature, 558(7711), pp. 531539.

Choudhury, B. J. et al. (1998) 'A biophysical process-based estimate of global land surface evaporation using satellite and ancillary data II. Regional and global patterns of seasonal and annual variations', Journal of Hydrology, 205(3-4), pp. 186-204.

Christoffersen, B. O. et al. (2016) 'Linking hydraulic traits to tropical forest function in a sizestructured and trait-driven model (TFS v. 1-Hydro)', Geoscientific Model Development, 9, pp. 4227-4255.

Chuine, I., Cour, P. and Rousseau, D. D. (1998) 'Fitting models predicting dates of flowering of temperate-zone trees using simulated annealing,, Plant, Cell \& Environment, 21(5), pp. 455-466.

Cincotta, R. P., Wisnewski, J. and Engelman, R. (2000) 'Human population in the biodiversity hotspots', Nature, 404(6781), p. 990.

Clark, D. A. et al. (2001) 'Net primary production in tropical forests: an evaluation and synthesis of existing field data', Ecological applications, 11(2), pp. 371-384. 
Clark, J. S., Bell, D. M., Hersh, M. H. and Nichols, L. (2011) 'Climate change vulnerability of forest biodiversity: climate and competition tracking of demographic rates', Global Change Biology, 17(5), pp. 1834-1849.

Clark, J. S., Bell, D. M., Hersh, M. H., Kwit, M. C., et al. (2011) 'Individual-scale variation, species-scale differences: inference needed to understand diversity', Ecology Letters, 14(12), pp. 1273-1287.

Cleland, E. E. et al. (2007) 'Shifting plant phenology in response to global change', Trends in Ecology \& Evolution, 22, pp. 357- 365.

Clemente, A. S., Rego, F. C. and Correia, O. A. (1996) 'Demographic patterns and productivity of post-fire regeneration in Portuguese Mediterranean maquis', International Journal of Wildland Fire, 6(1), pp. 5-12.

Cochard, H. et al. (2002) 'Unraveling the effects of plant hydraulics on stomatal closure during water stress in walnut', Plant physiology, 128(1), pp. 282-290.

Cochard, H. et al. (2009) 'New insights into the mechanisms of water-stress-induced cavitation in conifers', Plant Physiology, 151(2), pp. 949-954.

Collatz, G. J. et al. (1991) 'Physiological and environmental regulation of stomatal conductance, photosynthesis and transpiration: a model that includes a laminar boundary layer', Agricultural and Forest meteorology, 54(2-4), pp. 107-136.

Collatz, G. J., Ribas-Carbo, M. and Berry, J. A. (1992) 'Coupled photosynthesis-stomatal conductance model for leaves of C4 plants', Functional Plant Biology, 19(5), pp. 519538.

Conradi, T. et al. (2020) 'An operational definition of the biome for global change research', New Phytologist.

Corlett, R. T. (2009) 'Seed dispersal distances and plant migration potential in tropical East Asia', Biotropica, 41, pp. 592- 598.

Corlett, R. T. and Westcott, D. A. (2013) 'Will plant movements keep up with climate change?', Trends in Ecology \& Evolution, 28, pp. 482- 488.

Cornelissen, J. H. et al. (2007) 'Global negative vegetation feedback to climate warming responses of leaf litter decomposition rates in cold biomes', Ecology letters, 10(7), pp. 619-627.

Cornelissen, J. H. C. et al. (2003) 'A handbook of protocols for standardised and easy measurement of plant functional traits worldwide', Australian journal of Botany, 51(4), pp. 335-380.

Costanza, R. et al. (2017) 'Twenty years of ecosystem services: how far have we come and how far do we still need to go?', Ecosystem services, 28, pp. 1-16.

Craine, J. M. and Dybzinski, R. (2013) 'Mechanisms of plant competition for nutrients, water and light', Functional Ecology, 27(4), pp. 833-840.

Cramer, W. et al. (2001) 'Global response of terrestrial ecosystem structure and function to CO2 and climate change: results from six dynamic global vegetation models', Global change biology, 7(4), pp. 357-373.

Curran, L. M. et al. (2004) 'Lowland forest loss in protected areas of Indonesian Borneo', Science, 303(5660), pp. 1000-1003.

Dadadghao,P.M \& K.A.Shankarnarayan (1973) ‘The Grass Cover of India. ICAR, NewDelhi'.

Dakshini, K. M. M. (1989) 'Shrublands of the Indian subcontinent', in The Biology and Utilization of Shrubs. Academic Press, pp. 177-197.

Daniels, R. R. et al. (2007) 'Dispelling the myth of tropical dry evergreen forests of India', Current science, 92(5), pp. 586-588.

Dawson, T. P. et al. (2011) 'Beyond predictions: biodiversity conservation in a changing climate’, science, 332(6025), pp. 53-58. 
Deb, J. et al. (2017) 'Summary of climate change impacts on tree species distribution, phenology, forest structure and composition for each of the 85 studies reviewed'.

Deb, J. C. (2017) 'Assessing species vulnerability to climate change in tropical Asia: Implications for biodiversity conservation and forest management'.

Deb, J. C. et al. (2018) 'Climate change impacts on tropical forests', Journal of Tropical Forest Science, 30(2), pp. 182-194.

Defries, R. S. and Townshend, J. R. G. (1994) 'NDVI-derived land cover classifications at a global scale', International Journal of Remote Sensing, 15(17), pp. 3567-3586.

Delpierre, N. et al. (2016) 'Temperate and boreal forest tree phenology: from organ-scale processes to terrestrial ecosystem models', Annals of forest science, 73(1), pp. 5-25.

Deng, Q. et al. (2010) 'Responses of soil respiration to elevated carbon dioxide and nitrogen addition in young subtropical forest ecosystems in China', Biogeosciences, 7, pp. 315328.

Deshingkar, P. et al. (1997) 'Adapting to climate change in a forest-based land use system: a case study of Himachal Pradesh, India', Atmospheric Environment Issues in Developing Countries Series (Sweden).

Dessler, A. E. and Parson, E. A. (2019) The science and politics of global climate change: A guide to the debate. Cambridge University Press.

Dexter, K. G. et al. (2015) 'Floristics and biogeography of vegetation in seasonally dry tropical regions', International Forestry Review, 17(2), pp. 10-32.

Diaz, S. et al. (2004) 'The plant traits that drive ecosystems: evidence from three continents', Journal of vegetation science, 15(3), pp. 295-304.

Díaz, S. et al. (2016) 'The global spectrum of plant form and function', Nature, 529, pp. 167171.

Díaz, S. and Cabido, M. (1997) 'Plant functional types and ecosystem function in relation to global change', Journal of vegetation science, 8(4), pp. 463-474.

Díaz, S. M. et al. (2019) 'The global assessment report on biodiversity and ecosystem services: Summary for policy makers'.

Doherty, R. M. et al. (2010) 'Implications of future climate and atmospheric CO2 content for regional biogeochemistry, biogeography and ecosystem services across East Africa', Global Change Biology, 16(2), pp. 617-640.

Dohn, J. et al. (2013) 'Tree effects on grass growth in savannas: competition, facilitation and the stress-gradient hypothesis', Journal of Ecology, 101(1), pp. 202-209.

Dolezal, J. et al. (2016) 'Vegetation dynamics at the upper elevational limit of vascular plants in Himalaya', Scientific Reports, 6(1), pp. 1-13.

Donato, D. C. et al. (2011) 'Mangroves among the most carbon-rich forests in the tropics', Nature geoscience, 4(5), p. 293.

Donato, D. C. et al. (2012) 'Whole-island carbon stocks in the tropical Pacific: Implications for mangrove conservation and upland restoration', Journal of environmental management, 97, pp. 89-96.

D'Onofrio, D., von Hardenberg, J. and Baudena, M. (2017) 'Evaluation of DGVMs in tropical areas: linking patterns of vegetation cover, climate and fire to ecological processes', EGUGA, p. 16367.

Dormann, C. F. and Woodin, S. J. (2002) 'Climate change in the Arctic: using plant functional types in a meta-analysis of field experiments', Functional Ecology, 16(1), pp. 4-17.

Dornelas, M. (2010) 'Disturbance and change in biodiversity', Philosophical Transactions of the Royal Society B: Biological Sciences, 365(1558), pp. 3719-3727.

Doyle, T. W. and Girod, G. F. (1997) 'The frequency and intensity of Atlantic hurricanes and their influence on the structure of south Florida mangrove communities', in Hurricanes. Springer, pp. 109-120. 
Doyle, T. W., Girod, G. F. and Books, M. A. (2003) 'Modeling mangrove forest migration along the southwest coast of Florida under climate change', Preparing for a changing climate: the potential consequence of climate variability and change: Gulf Coast region, pp. 211222.

Doyle, T. W., Smith III, T. J. and Robblee, M. B. (1995) 'Wind damage effects of Hurricane Andrew on mangrove communities along the southwest coast of Florida, USA', Journal of Coastal Research, pp. 159-168.

Drake, N. and Vafeidis, A. (2004) 'A review of European Union funded research into the monitoring and mapping of Mediterranean desertification', 1(4), pp. 1-51.

Duke, N. C. (2001) 'Gap creation and regenerative processes driving diversity and structure of mangrove ecosystems', Wetlands Ecology and Management, 9(3), pp. 267-279.

Eckstein, D., Hutfils, M. and Winges, M. (2018) Global climate risk index 2019: Who suffers most from extreme weather events? Weather-related loss events in 2017 and 1998 to 2017. Germanwatch, Bonn, Germany.

Edwards, E. J. et al. (2010) 'The origins of C4 grasslands: integrating evolutionary and ecosystem science', science, 328(5978), pp. 587-591.

Ehleringer, J. R. and Cerling, T. E. (2002) 'C3 and C4 photosynthesis', Encyclopedia of global environmental change, 2, pp. 186-190.

Ehleringer, J. R., Cerling, T. E. and Helliker, B. R. (1997) 'C4 photosynthesis, atmospheric CO2, and climate', Oecologia, 112(3), pp. 285-299.

Ellis, E. C. (2013) 'Sustaining biodiversity and people in the world's anthropogenic biomes', Current Opinion in Environmental Sustainability, 5(3-4), pp. 368-372.

Erfanian, A. et al. (2016) 'Multimodel ensemble simulations of present and future climates over W est A frica: Impacts of vegetation dynamics', Journal of advances in modeling Earth systems, 8(3), pp. 1411-1431.

Eyre, S. R. (2017) Vegetation and soils: a world picture. Routledge.

FA0 (2010) 'Global Forest Resources Assessment 2010 (FAO Forestry Paper 163) (Rome: Food and Agriculture Organization)'.

Farquhar, G. D., von Caemmerer, S. von and Berry, J. A. (1980) 'A biochemical model of photosynthetic CO2 assimilation in leaves of C3 species', Planta, 149(1), pp. 78-90.

Fatichi, S., Leuzinger, S. and Körner, C. (2014) 'Moving beyond photosynthesis: from carbon source to sink-driven vegetation modeling', New Phytologist, 201(4), pp. 1086-1095.

Favier, C. et al. (2012) 'Abrupt shifts in African savanna tree cover along a climatic gradient', Global Ecology and Biogeography, 21(8), pp. 787-797.

Feddema, J. J. et al. (2005) 'The importance of land-cover change in simulating future climates', Science, 310(5754), pp. 1674-1678.

Felzer, B. S. et al. (2007) 'Impacts of ozone on trees and crops', Comptes Rendus Geoscience, 339(11-12), pp. 784-798.

Felzer, B. S. et al. (2009) 'Importance of carbon-nitrogen interactions and ozone on ecosystem hydrology during the 21 st century', Journal of Geophysical Research: Biogeosciences, 114(G1).

Feng, H., Zou, B. and Luo, J. (2017) 'Coverage-dependent amplifiers of vegetation change on global water cycle dynamics', Journal of hydrology, 550, pp. 220-229.

Fernandes, G. W. et al. (2016) 'Afforestation of savannas: an impending ecological disaster.', Embrapa Recursos Genéticos e Biotecnologia-Artigo em periódico indexado (ALICE).

Feser, F. et al. (2011) 'Regional climate models add value to global model data: a review and selected examples', Bulletin of the American Meteorological Society, 92(9), pp. 11811192.

Fick, S. E. and Hijmans, R. J. (2017) 'WorldClim 2: new 1-km spatial resolution climate surfaces for global land areas', International Journal of Climatology, 37(12), pp. 4302-4315. 
Field, C. B. et al. (2007) 'Feedbacks of terrestrial ecosystems to climate change', Annu. Rev. Environ. Resour., 32, pp. 1-29.

Fischlin, A. et al. (2007) 'Ecosystems their properties goods and services. climate change 2007: Impacts adaptation and vulnerability. contribution of working group ii to the fourth assessment report of the intergovernmental panel on climate change ml parry of canziani jp palutikof pj van der linden and ce hanson eds. cambridge university press cambridge', Assessment Report of the Intergovernmental Panel on Climate Change, 4, pp. 211-272.

Fisher, J. B. et al. (2010) 'Carbon cost of plant nitrogen acquisition: A mechanistic, globally applicable model of plant nitrogen uptake, retranslocation, and fixation', Global Biogeochemical Cycles, 24(1).

Fisher, J. B., Whittaker, R. J. and Malhi, Y. (2011) 'ET come home: potential evapotranspiration in geographical ecology', Global Ecology and Biogeography, 20(1), pp. 1-18.

Flint, E. P. and Richards, J. F. (1994) 'Trends in carbon content of vegetation in South and Southeast Asia associated with changes in land use', in Effects of Land-Use Change on Atmospheric CO2 Concentrations. Springer, pp. 201-299.

Foley, J. A. et al. (2005) 'Global consequences of land use', science, 309(5734), pp. 570-574.

Forster, P. et al. (2007) 'Changes in atmospheric constituents and in radiative forcing. Chapter 2', in Climate Change 2007. The Physical Science Basis.

Foster, D. et al. (2003) 'The importance of land-use legacies to ecology and conservation', BioScience, 53(1), pp. 77-88.

Frank, Dorothea et al. (2015) 'Effects of climate extremes on the terrestrial carbon cycle: concepts, processes and potential future impacts', Global Change Biology, 21(8), pp. 2861-2880.

Franklin, J. (2010) Mapping species distributions: spatial inference and prediction. Cambridge University Press.

Franks, S. J., Wheeler, G. S. and Goodnight, C. (2012) 'Genetic variation and evolution of secondary compounds in native and introduced populations of the invasive plant Melaleuca quinquenervia', Evolution, 66(5), pp. 1398-1412.

Frasson, R. P. de M. et al. (2015) 'Modeling forest carbon cycle response to tree mortality: effects of plant functional type and disturbance intensity', Journal of Geophysical Research: Biogeosciences, 120(11), pp. 2178-2193.

Freschet, G. T. et al. (2010) 'Evidence of the 'plant economics spectrum'in a subarctic flora', Journal of Ecology, 98(2), pp. 362-373.

Freschet, G. T., Aerts, R. and Cornelissen, J. H. (2012) 'A plant economics spectrum of litter decomposability', Functional Ecology, 26(1), pp. 56-65.

Friedl, M. A. et al. (2010) 'MODIS Collection 5 global land cover: Algorithm refinements and characterization of new datasets', Remote sensing of Environment, 114(1), pp. 168-182.

Friedlingstein, P. et al. (2006) 'Climate-carbon cycle feedback analysis: results from the C4MIP model intercomparison', Journal of climate, 19(14), pp. 3337-3353.

Friedlingstein, P. et al. (2019) 'Comment on "The global tree restoration potential"', Science, 366(6463), p. eaay8060.

FSI (2011) India State of Forest Report 2011. Forest Survey of India Dehradun, India.

FSI (2017) 'STATE OF FOREST REPORT 2017'. Forest Survey of India, Ministry of Environment \& Forests. Available at: http://fsi.nic.in/forest-report-2017.

$\mathrm{Fu}$, J. (2001) 'Chinese moso bamboo: its importance', Bamboo, 22(5), pp. 5-7.

Gagnon, P. R. and Platt, W. J. (2008) 'Multiple disturbances accelerate clonal growth in a potentially monodominant bamboo', Ecology, 89(3), pp. 612-618.

Gaillard, C. et al. (2018) 'African shrub distribution emerges via height-Sapwood conductivity trade-off.' Journal of Biogeography, 45(12), pp.2815-2826. 
Gairola, S., Rawal, R. S. and Todaria, N. P. (2008) 'Forest vegetation patterns along an altitudinal gradient in sub-alpine zone of west Himalaya, India', African Journal of Plant Science, 2(6), pp. 042-048.

Gallardo-Cruz, J. A., Pérez-García, E. A. and Meave, J. A. (2009) ' $\beta$-Diversity and vegetation structure as influenced by slope aspect and altitude in a seasonally dry tropical landscape', Landscape Ecology, 24(4), pp. 473-482.

Ganesh, T. et al. (1996) 'Assessment of plant biodiversity at a mid-elevation evergreen forest of Kalakad-Mundanthurai Tiger Reserve, Western Ghats, India', Current Science, pp. 379392.

Gates, D. M. (1968) 'Transpiration and leaf temperature', Annual Review of Plant Physiology, 19(1), pp. 211-238.

Gautam, M. R., Timilsina, G. R. and Acharya, K. (2013) 'Climate change in the Himalayas: current state of knowledge'.

Ge, J. and Xie, Z. (2017) 'Geographical and climatic gradients of evergreen versus deciduous broad-leaved tree species in subtropical china: Implications for the definition of the mixed forest', Ecology and Evolution, 7, pp. 3636-3644.

Gentine, P. et al. (2016) 'An allometry-based model of the survival strategies of hydraulic failure and carbon starvation', Ecohydrology, 9(3), pp. 529-546.

Gianoli, E. et al. (2010) 'Distribution and abundance of vines along the light gradient in a southern temperate rain forest', Journal of Vegetation Science, 21(1), pp. 66-73.

Gibson, L. et al. (2011) 'Primary forests are irreplaceable for sustaining tropical biodiversity', Nature, 478(7369), pp. 378-381.

Gignoux, J., Clobert, J. and Menaut, J.-C. (1997) 'Alternative fire resistance strategies in savanna trees', Oecologia, 110(4), pp. 576-583.

Gillson, L. and Duffin, K. I. (2007) 'Thresholds of potential concern as benchmarks in the management of African savannahs', Philosophical Transactions of the Royal Society B: Biological Sciences, 362(1478), pp. 309-319.

Givnish, T. (1979) 'On the adaptive significance of leaf form', in Topics in plant population biology. Springer, pp. 375-407.

Gonzalez, P. et al. (2010) 'Global patterns in the vulnerability of ecosystems to vegetation shifts due to climate change', Global Ecology and Biogeography, 19(6), pp. 755-768.

Gopalakrishnan, R. et al. (2011) 'Sensitivity of terrestrial water and energy budgets to CO2physiological forcing: an investigation using an offline land model', Environmental Research Letters, 6(4), p. 044013.

Götmark, F., Götmark, E. and Jensen, A. M. (2016) 'Why be a shrub? A basic model and hypotheses for the adaptive values of a common growth form', Frontiers in plant science, 7, p. 1095.

Gottfried, M. et al. (2012) 'Continent-wide response of mountain vegetation to climate change', Nature climate change, 2(2), pp. 111-115.

Graham, V. et al. (2016) 'A comparative assessment of the financial costs and carbon benefits of REDD+ strategies in Southeast Asia', Environmental Research Letters, 11, p. 114022.

Gray, E. F. and Bond, W. J. (2013) 'Will woody plant encroachment impact the visitor experience and economy of conservation areas?', Koedoe, 55(1), pp. 00-00.

Greve, M. et al. (2011) 'Environmental and anthropogenic determinants of vegetation distribution across Africa', Global Ecology and Biogeography, 20(5), pp. 661-674.

Griffith, D. M. et al. (2017) 'Comment on "The extent of forest in dryland biomes", Science, 358(6365).

Gunatilleke, N., Pethiyagoda, R. and Gunatilleke, S. (2017) 'Biodiversity of Sri Lanka', Journal of the National Science Foundation of Sri Lanka, 36. 
Guo, X., Liu, D. and Chong, K. (2018) 'Cold signaling in plants: Insights into mechanisms and regulation', Journal of integrative plant biology, 60(9), pp. 745-756.

Halley, J. M. et al. (2016) 'Dynamics of extinction debt across five taxonomic groups', Nature communications, 7(1), pp. 1-6.

Halofsky, J. S. et al. (2015) 'Using a Dynamic Global Vegetation Model to Help Inform Management Decisions', in Global Vegetation Dynamics. Wiley Online Library, pp. 151-170.

Hannah, L. et al. (2020) 30\% land conservation and climate action reduces tropical extinction risk by more than $50 \%$. Ecography.

Hansen, A. J. et al. (2001) 'Global change in forests: responses of species, communities, and biomes: interactions between climate change and land use are projected to cause large shifts in biodiversity', BioScience, 51(9), pp. 765-779.

Hantson, S. et al. (2016) 'The status and challenge of global fire modelling', Biogeosciences, 13, pp. 3359- 3375 .

Harper, A. B. et al. (2016) 'Improved representation of plant functional types and physiology in the Joint UK Land Environment Simulator (JULES v4. 2) using plant trait information', Geoscientific Model Development, 9(7), pp. 2415-2440.

Harper, A. B. et al. (2018) 'Vegetation distribution and terrestrial carbon cycle in a carbon cycle configuration of JULES4. 6 with new plant functional types' Geoscientific Model Development, 11, 2857-2873 .

Harris, R. M. et al. (2016) 'Climate-vegetation-fire interactions and feedbacks: trivial detail or major barrier to projecting the future of the Earth system?', Wiley Interdisciplinary Reviews: Climate Change, 7(6), pp. 910-931.

Harrison, S. P. et al. (2010) 'Ecophysiological and bioclimatic foundations for a global plant functional classification', Journal of Vegetation Science, 21(2), pp. 300-317.

Harrison, S. P. and Prentice, C. I. (2003) 'Climate and $\mathrm{CO}_{2}$ controls on global vegetation distribution at the last glacial maximum: analysis based on palaeovegetation data, biome modelling and palaeoclimate simulations', Global Change Biology, 9(7), pp. 983-1004.

Hartmann, H. et al. (2018) 'Identifying differences in carbohydrate dynamics of seedlings and mature trees to improve carbon allocation in models for trees and forests', Environmental and experimental botany, 152, pp. 7-18.

Hartmann, H. et al. (2020) 'Plant carbon allocation in a changing world-challenges and progress: introduction to a Virtual Issue on carbon allocation', New Phytologist, 227(4), pp. 981988.

Hartzell, S. et al. (2015) 'Nonlinear dynamics of the CAM circadian rhythm in response to environmental forcing', Journal of theoretical biology, 368, pp. 83-94.

Hartzell, S., Bartlett, M. S. and Porporato, A. (2018) 'Unified representation of the C3, C4, and CAM photosynthetic pathways with the Photo3 model', arXiv preprint arXiv:1804.10667.

Hasnat, G. T., Kabir, M. A. and Hossain, M. A. (2018) 'Major environmental issues and problems of South Asia, Particularly Bangladesh', Handbook of environmental materials management, pp. 1-40.

Hasselquist, N. J., Allen, M. F. and Santiago, L. S. (2010) 'Water relations of evergreen and drought-deciduous trees along a seasonally dry tropical forest chronosequence', Oecologia, 164(4), pp. 881-890.

Hautier, Y. et al. (2015) 'Anthropogenic environmental changes affect ecosystem stability via biodiversity', Science, 348(6232), pp. 336-340.

Haverd, V. et al. (2020) 'Higher than expected CO2 fertilization inferred from leaf to global observations', Global Change Biology, 26, pp. 2390- 2402. 
Hawkins, B. J. et al. (1995) 'Frost hardiness and winter photosynthesis of Thuja piicata and Pseudotsuga menzlesll seedlings grown at three rates of nitrogen and phosphorus supply', Canadian Journal of Forest Research, 25(1), pp. 18-28.

Haxeltine, A. and Prentice, I. C. (1996) 'Biome3: An equilibrium terrestrial biosphere model based on ecophysiological constraints, resource availability, and competition among plant functional types', Global Biogeochemical Cycles, 10, pp. 693- 709.

He, M. et al. (2014) 'Bamboo: a new source of carbohydrate for biorefinery', Carbohydrate polymers, 111, pp. 645-654.

van der Heijden, G. M. et al. (2013) 'Liana Impacts on Carbon Cycling, Storage and Sequestration in Tropical Forests', Biotropica, 45(6), pp. 682-692.

Heimann, M. and Reichstein, M. (2008) 'Terrestrial ecosystem carbon dynamics and climate feedbacks', Nature, 451(7176), pp. 289-292.

Hekneby, M., Antolín, M. C. and Sánchez-Díaz, M. (2006) 'Frost resistance and biochemical changes during cold acclimation in different annual legumes', Environmental and experimental botany, 55(3), pp. 305-314.

Herring, S. C. et al. (2018) 'Explaining extreme events of 2016 from a climate perspective', Bulletin of the American Meteorological Society, 99(1), pp. S1-S157.

Hickler, T. et al. (2006) 'Implementing plant hydraulic architecture within the LPJ Dynamic Global Vegetation Model', Global Ecology and Biogeography, 15(6), pp. 567-577.

Hickler, T. et al. (2012) 'Projecting the future distribution of European potential natural vegetation zones with a generalized, tree species-based dynamic vegetation model', Global Ecology and Biogeography, 21(1), pp. 50-63.

Hickler, T., Rammig, A. and Werner, C. (2015) 'Modelling $\mathrm{CO}_{2}$ impacts on forest productivity', Current Forestry Reports, 1(2), pp. 69-80.

Higgins, S. I. et al. (2008) 'Physically motivated empirical models for the spread and intensity of grass fires', International Journal of Wildland Fire, 17(5), pp. 595-601.

Higgins, S. I., Bond, W. J. and Trollope, W. S. (2000) 'Fire, resprouting and variability: a recipe for grass-tree coexistence in savanna', Journal of Ecology, 88(2), pp. 213-229.

Higgins, S. I., Buitenwerf, R. and Moncrieff, G. R. (2016) 'Defining functional biomes and monitoring their change globally', Global Change Biology, 22, pp. 3583-3593.

Higgins, S. I. and Scheiter, S. (2012) 'Atmospheric $\mathrm{CO}_{2}$ forces abrupt vegetation shifts locally, but not globally', Nature, 488(7410), p. 209.

Hijioka, Y., Lin, E., Pereira, J. J., et al. (2014) 'Asia. Climate Change 2014: Impacts, Adaptation, and Vulnerability. Part B: Regional Aspects. Contribution of Working Group II to the Fifth Assessment Report of the Intergovernmental Panel on Climate Change', Cambridge University Press, Cambridge, United Kingdom and New York, pp. 13271370.

Hijmans, R. J. et al. (2005) 'Very high resolution interpolated climate surfaces for global land areas', International journal of climatology, 25(15), pp. 1965-1978.

Hijmans, R. J. (2020) raster: Geographic data analysis and modeling. R package version 3.0-12.

Hijmans, R. J. and van Etten, J. (2012) raster: Geographic analysis and modeling with raster data. R package version 2.0-12.

Hiremath, A. J. and Sundaram, B. (2005) 'The fire-lantana cycle hypothesis in Indian forests', Conservation and Society, pp. 26-42.

Hiremath, A. J. and Sundaram, B. (2013) 'Invasive plant species in Indian protected areas: conserving biodiversity in cultural landscapes', in Plant invasions in protected areas. Springer, pp. 241-266.

Hoffmann, W. A. et al. (2009) 'Tree topkill, not mortality, governs the dynamics of savannaforest boundaries under frequent fire in central Brazil’, Ecology, 90(5), pp. 1326-1337. 
Hoffmann, W. A. et al. (2012) 'Ecological thresholds at the savanna-forest boundary: how plant traits, resources and fire govern the distribution of tropical biomes', Ecology letters, 15(7), pp. 759-768.

Hoffmann, W. A., Orthen, B. and Franco, A. C. (2004) 'Constraints to seedling success of savanna and forest trees across the savanna-forest boundary', Oecologia, 140(2), pp. 252-260.

Hoffmann, W. A., Orthen, B. and Nascimento, P. K. V. do (2003) 'Comparative fire ecology of tropical savanna and forest trees', Functional Ecology, 17(6), pp. 720-726.

Hoffmann, W. A. and Solbrig, O. T. (2003) 'The role of topkill in the differential response of savanna woody species to fire', Forest ecology and management, 180(1-3), pp. 273-286.

Holbrook, N. M. and Putz, F. E. (1996) 'Physiology of tropical vines and hemiepiphytes: plants that climb up and plants that climb down', in Tropical forest plant ecophysiology. Springer, pp. 363-394.

Holling, C. S. (2001) 'Understanding the complexity of economic, ecological, and social systems', Ecosystems, 4(5), pp. 390-405.

Holmgren, M. and Scheffer, M. (2001) 'El Niño as a window of opportunity for the restoration of degraded arid ecosystems', Ecosystems, 4(2), pp. 151-159.

Holtum, J. A. et al. (2017) 'Facultative CAM photosynthesis (crassulacean acid metabolism) in four species of Calandrinia, ephemeral succulents of arid Australia', Photosynthesis research, 134(1), pp. 17-25.

Hongmao, L. et al. (2002) 'Practice of conserving plant diversity through traditional beliefs: a case study in Xishuangbanna, southwest China', Biodiversity \& Conservation, 11(4), pp. $705-713$.

Hooper, D. U. et al. (2012) 'A global synthesis reveals biodiversity loss as a major driver of ecosystem change', Nature, 486(7401), p. 105.

Houghton, R. A. (1999) 'The annual net flux of carbon to the atmosphere from changes in land use 1850-1990', Tellus B, 51(2), pp. 298-313.

Houghton, R. A. (2002) 'Temporal patterns of land-use change and carbon storage in China and tropical Asia', Science in china series c life sciences-english edition-, 45(SUPP), pp. 1017.

Houghton, R. A. et al. (2012) 'Carbon emissions from land use and land-cover change', Biogeosciences, (12), pp. 5125-5142.

House, J. I. et al. (2003) 'Conundrums in mixed woody-herbaceous plant systems', Journal of biogeography, 30(11), pp. 1763-1777.

Hoylman, Z. H. et al. (2018) 'Hillslope topography mediates spatial patterns of ecosystem sensitivity to climate', Journal of Geophysical Research: Biogeosciences, 123(2), pp. 353-371.

Huang, C.-W. et al. (2017) 'The effect of plant water storage on water fluxes within the coupled soil-plant system', New Phytologist, 213(3), pp. 1093-1106.

Huang, J. et al. (2016) 'Accelerated dryland expansion under climate change', Nature Climate Change, 6(2), pp. 166-171.

Huang, J. et al. (2020) 'Tree defence and bark beetles in a drying world: carbon partitioning, functioning and modelling', New Phytologist, 225(1), pp. 26-36.

Hubau, W. et al. (2020) 'Asynchronous carbon sink saturation in African and Amazonian tropical forests', Nature, 579, pp. 80-87.

Hughes, Alice C. (2017) 'Understanding the drivers of Southeast Asian biodiversity loss', Ecosphere, 8(1), p. e01624.

Hughes, C. E., Pennington, R. T. and Antonelli, A. (2013) 'Neotropical plant evolution: assembling the big picture', Botanical Journal of the Linnean Society, 171(1), pp. 1-18. 
Huntingford, C. et al. (2017) 'Implications of improved representations of plant respiration in a changing climate', Nature communications, 8(1), p. 1602.

Hurtt, G. C. et al. (2020) 'Harmonization of global land-use change and management for the period 850-2100 (LUH2) for CMIP6', Geoscientific Model Development Discussions, pp. 1-65.

Huston, M. A. (2005) 'The three phases of land-use change: implications for biodiversity', Ecological Applications, 15(6), pp. 1864-1878.

Huston, Michael A. and Huston, Michael Alan (1994) Biological diversity: the coexistence of species. Cambridge University Press.

Hüttich, C. et al. (2007) 'Indicators of Northern Eurasia's land-cover change trends from SPOTVEGETATION time-series analysis 1998-2005', International Journal of Remote Sensing, 28(18), pp. 4199-4206.

Ingwell, L. L. et al. (2010) 'The impact of lianas on 10 years of tree growth and mortality on Barro Colorado Island, Panama', Journal of Ecology, 98(4), pp. 879-887.

IPBES (2019) Summary for policymakers of the global assessment report on biodiversity and ecosystem services of the Intergovernmental Science-Policy Platform on Biodiversity and Ecosystem Services. S. Díaz, J. Settele, E. S. Brondízio E.S., H. T. Ngo, M. Guèze, J. Agard, A. Arneth, P. Balvanera, K. A. Brauman, S. H. M. Butchart, K. M. A. Chan, L. A. Garibaldi, K. Ichii, J. Liu, S. M. Subramanian, G. F. Midgley, P. Miloslavich, Z. Molnár, D. Obura, A. Pfaff, S. Polasky, A. Purvis, J. Razzaque, B. Reyers, R. Roy Chowdhury, Y. J. Shin, I. J. Visseren-Hamakers, K. J. Willis, and C. N. Zayas (eds.). IPBES secretariat, Bonn, Germany. 56 pages. Available at: https://doi.org/10.5281/zenodo.3553579.

IPCC (2013) IPCC: Climate Change 2013: The Physical Science Basis, Contribution of Working Group I to the Fifth Assessment Report of the Intergovernmental Panel on Climate Change, edited by: Stocker, T. F., Qin, D., Plattner, G.-K., Tignor, M., Allen, S. K., Boschung, J., Nauels, A., Xia, Y., Bex, V., and Midgley, P. M.: Cambridge University Press, Cambridge, United Kingdom and New York, NY, USA, 1535 pp., 2013. Cambridge University Press.

I.P.C.C. (2018) 'Global warming of 1.5C. An IPCC Special Report on the impacts of global warming of $1.5 \mathrm{C}$ above pre-industrial levels and related global greenhouse gas emission pathways, in the context of strengthening the global response to the threat of climate change, sustainable development, and efforts to eradicate poverty, chap', in MassonDelmotte, V. et al. (eds) Summary for policymakers. Geneva, Switzerland: World Meteorological Organization, pp. 1-24.

Isbell, F. et al. (2015) 'The biodiversity-dependent ecosystem service debt', Ecology letters, 18(2), pp. 119-134.

IUCN (2009) International Union for Conservation of Nature-Guidelines on biofuels and invasive species. IUCN.

Jarvis, A. et al. (2008) Hole-filled SRTM for the globe Version 4, available from the CGIARCSI SRTM $90 \mathrm{~m}$ Database.

Jenkins, M. and Adams, M. A. (2010) 'Vegetation type determines heterotrophic respiration in subalpine Australian ecosystems', Global Change Biology, 16(1), pp. 209-219.

Jensen, K. F. and Roberts, B. R. (1986) 'Changes in yellow poplar stomatal resistance with SO2 and $\mathrm{O} 3$ fumigation', Environmental Pollution Series A, Ecological and Biological, 41(3), pp. 235-245.

Jeong, S.-J. et al. (2012) 'Uncertainties in terrestrial carbon budgets related to spring phenology', Journal of Geophysical Research: Biogeosciences, 117(G1).

Jobbágy, E. G. and Jackson, R. B. (2000) 'The vertical distribution of soil organic carbon and its relation to climate and vegetation', Ecological applications, 10(2), pp. 423-436. 
Jones, C. et al. (2009) 'Committed terrestrial ecosystem changes due to climate change', Nature Geoscience, 2(7), pp. 484-487.

de Jong, R. et al. (2011) 'Analysis of monotonic greening and browning trends from global NDVI time-series', Remote Sensing of Environment, 115(2), pp. 692-702.

Joshi, P. K. et al. (2006) 'Vegetation cover mapping in India using multi-temporal IRS Wide Field Sensor (WiFS) data', Remote Sensing of Environment, 103(2), pp. 190-202.

Jucker, T. et al. (2018) 'Topography shapes the structure, composition and function of tropical forest landscapes', Ecology letters, 21(7), pp. 989-1000.

Jung, M. et al. (2019) 'Local species assemblages are influenced more by past than current dissimilarities in photosynthetic activity', Ecography, 42(4), pp. 670-682.

Kachina, P. et al. (2017) 'Effect of Forest fire on the regeneration of a bamboo species (Cephalostachyum pergracile Munro) at a mixed deciduous forest in Mae Klong Watershed Research Station, Thailand', Tropics, 26(2), pp. 37-48.

Kamoutsis, A., Chronopoulos, K. and Matsoukis, A. (2017) 'Altitude and Canopy Cover Effects on Air Temperature in a Mountainous Region of Ionian Islands, Greece', Current World Environment, 13(3), p. 292.

Kannan, R., Shackleton, C. M. and Uma Shaanker, R. (2013) 'Reconstructing the history of introduction and spread of the invasive species, lantana, at three spatial scales in India', Biological Invasions, 15, pp. 1287- 1302.

Karnosky, D. F. et al. (2003) 'Tropospheric O3 moderates responses of temperate hardwood forests to elevated $\mathrm{CO} 2$ : a synthesis of molecular to ecosystem results from the Aspen FACE project', Functional Ecology, 17(3), pp. 289-304.

Karnosky, D. F. et al. (2005) 'Scaling ozone responses of forest trees to the ecosystem level in a changing climate', Plant, Cell \& Environment, 28(8), pp. 965-981.

Karthik, T., Veeraswami, G. G. and Samal, P. K. (2009) 'Forest Recovery Following Shifting Cultivation: An Overview of Existing Research', Tropical Conservation Science, 2(4), pp. 374-387.

Kaskaoutis, D. G. et al. (2018) 'Impact of atmospheric circulation types on southwest Asian dust and Indian summer monsoon rainfall', Atmospheric Research, 201, pp. 189-205.

Katayama, N. et al. (2014) 'Landscape heterogeneity-biodiversity relationship: effect of range size', PloS one, 9(3), p. e93359.

Kattge, J. et al. (2009) 'Quantifying photosynthetic capacity and its relationship to leaf nitrogen content for global-scale terrestrial biosphere models', Global Change Biology, 15(4), pp. 976-991.

Kattge, J. et al. (2011) 'TRY - A global database of plant traits', Global Change Biology, 17, pp. $2905-2935$.

Kattge, J. and Knorr, W. (2007) 'Temperature acclimation in a biochemical model of photosynthesis: a reanalysis of data from 36 species', Plant, cell \& environment, 30(9), pp. 1176-1190.

Kaye, J. P. et al. (2004) 'Methane and nitrous oxide fluxes from urban soils to the atmosphere', Ecological Applications, 14(4), pp. 975-981.

Kearney, M. and Porter, W. (2009) 'Mechanistic niche modelling: combining physiological and spatial data to predict species' ranges', Ecology letters, 12(4), pp. 334-350.

Kehoe, L. et al. (2017) 'Biodiversity at risk under future cropland expansion and intensification', Nature Ecology \& Evolution, 1(8), pp. 1129-1135.

Kergoat, L. et al. (2002) 'Impact of doubled CO2 on global-scale leaf area index and evapotranspiration: Conflicting stomatal conductance and LAI responses', Journal of Geophysical Research: Atmospheres, 107(D24), p. ACL-30. 
Kergunteuil, A. et al. (2019) 'Plant adaptation to different climates shapes the strengths of chemically mediated tritrophic interactions', Functional Ecology, 33(10), pp. 18931903.

Kgope, B. S., Bond, W. J. and Midgley, G. F. (2010) 'Growth responses of African savanna trees implicate atmospheric $\mathrm{CO}_{2}$ as a driver of past and current changes in savanna tree cover', Austral Ecology, 35(4), pp. 451-463.

Kharouba, H. M. et al. (2018) 'Global shifts in the phenological synchrony of species interactions over recent decades', Proceedings of the National Academy of Sciences, 115(20), pp. $5211-5216$.

Kikuzawa, K. and Lechowicz, M. J. (2011) 'Quantifying Leaf Longevity', in Ecology of Leaf Longevity. Springer, pp. 23-39.

Kirschbaum, M. U. F. (2004) 'Direct and indirect climate change effects on photosynthesis and transpiration', Plant Biology, 6(03), pp. 242-253.

Kishwan, J., Pandey, R. and Dadhwal, V. K. (2009) 'India's forest and tree cover: contribution as a carbon sink', Technical paper, (130), pp. 1-12.

Kleidon, A. and Mooney, H. A. (2000) 'A global distribution of biodiversity inferred from climatic constraints: results from a process-based modelling study', Global Change Biology, 6(5), pp. 507-523.

Körner, C. (2003) 'Carbon limitation in trees', Journal of ecology, 91(1), pp. 4-17.

Körner, C. et al. (2005) 'Carbon flux and growth in mature deciduous forest trees exposed to elevated $\mathrm{CO}_{2}$ ', Science, 309(5739), pp. 1360-1362.

Körner, C. (2015) 'Paradigm shift in plant growth control', Current Opinion in Plant Biology, 25, pp. 107- 114 .

Körner, C. (2016) 'Plant adaptation to cold climates', F1000Research, 5.

Körner, C. and Basler, D. (2010) 'Phenology under global warming', Science, 327(5972), pp. 1461-1462.

Kotwal, P. C. and Pande, R. K. (1980) 'Ecological Studies on Grazing Pressure of Wild Herbivores on the Grasslands of Kanha National Park', ISTRE, Awadhesh Pratap Singh University, Rewa.

Krinner, G. et al. (2005) 'A dynamic global vegetation model for studies of the coupled atmosphere-biosphere system: DVGM for coupled climate studies', Global Biogeochemical Cycles, 19(1).

Krishna, Y. C., Krishnaswamy, J. and Kumar, N. S. (2008) 'Habitat factors affecting site occupancy and relative abundance of four-horned antelope', Journal of Zoology, 276(1), pp. 63-70.

Kristensen, E. et al. (2008) 'Organic carbon dynamics in mangrove ecosystems: a review', Aquatic Botany, 89(2), pp. 201-219.

Krupa, S. V. and Manning, W. J. (1988) 'Atmospheric ozone: formation and effects on vegetation', Environmental pollution, 50(1-2), pp. 101-137.

Kubiszewski, I. et al. (2020) 'The future value of ecosystem services: Global scenarios and national implications', in Environmental Assessments. Edward Elgar Publishing.

Kumar, D., Pfeiffer, M., Gaillard, C., Langan, L. and Scheiter, S. (2020) 'Climate change and elevated $\mathrm{CO} 2$ favor forest over savanna under different future scenarios in South Asia', Biogeosciences Discussions, pp. 1- 34 .

Kumar, D., Pfeiffer, M., Gaillard, C., Langan, L., Martens, C., et al. (2020) 'Misinterpretation of Asian savannas as degraded forest can mislead management and conservation policy under climate change', Biological Conservation, 241, p. 108293.

Kumar, D. and Scheiter, S. (2019) 'Biome diversity in South Asia - How can we improve vegetation models to understand global change impact at regional level?', Science of the Total Environment, 671, pp. 1001- 1016. 
Kumar, K. K. (2009) Climate sensitivity of Indian agriculture. Madras School of Economics Chennai.

Kumar, K. K. et al. (2011) 'Simulated projections for summer monsoon climate over India by a high-resolution regional climate model (PRECIS)', Current Science, 101(3), pp. 312326.

Kumar, M. et al. (2018) 'Dynamic forest vegetation models for predicting impacts of climate change on forests: an Indian perspective', Indian Journal of Forestry, 41(1), pp. 1-12.

Kumar, P. and Yashiro, M. (2014) 'The marginal poor and their dependence on ecosystem services: evidence from South Asia and Sub-Saharan Africa', in Marginality. Springer, Dordrecht, pp. 169-180.

Kumar, R. S. (2000) 'A review of biodiversity studies of soil dwelling organisms in Indian mangroves', Zoos' Print Journal, 15(3), pp. 221-227.

Kumar, S. et al. (2013) 'Evaluation of temperature and precipitation trends and long-term persistence in CMIP5 twentieth-century climate simulations', Journal of Climate, 26(12), pp. 4168-4185.

Kumar, S. P. et al. (2009) 'Response of the Arabian Sea to global warming and associated regional climate shift', Marine Environmental Research, 68(5), pp. 217-222.

Kumar, V., Jain, S. K. and Singh, Y. (2010) 'Analysis of long-term rainfall trends in India', Hydrological Sciences Journal-Journal des Sciences Hydrologiques, 55(4), pp. 484-496.

Kursar, T. A. et al. (2009) 'Tolerance to low leaf water status of tropical tree seedlings is related to drought performance and distribution', Functional Ecology, 23(1), pp. 93-102.

Laguë, M. M., Bonan, G. B. and Swann, A. L. (2019) 'Separating the impact of individual land surface properties on the terrestrial surface energy budget in both the coupled and uncoupled land-atmosphere system', Journal of Climate, 32(18), pp. 5725-5744.

Langan, L. (2019) Holism in Plant Biogeography-Improving the Representation Of, and Interactions Between, the Biosphere, Hydrosphere, Atmosphere and Pedosphere. $\mathrm{PhD}$ Thesis. Johann Wolfgang Goethe-Universität Frankfurt am Main.

Langan, L., Higgins, S. I. and Scheiter, S. (2017) 'Climate-biomes, pedo-biomes or pyro-biomes: Which world view explains the tropical forest - Savanna boundary in South America?', Journal of Biogeography, 44, pp. 2319-2330.

Lapola, D. M., Priess, J. A. and Bondeau, A. (2009) 'Modeling the land requirements and potential productivity of sugarcane and jatropha in Brazil and India using the LPJmL dynamic global vegetation model', Biomass and Bioenergy, 33(8), pp. 1087-1095.

Larigauderie, A. and Koerner, C. (1995) 'Does leaf dark respiration of alpine and lowland plants acclimate to temperature?', Bulletin of the Ecological Society of America, 76(CONF9507129-).

Lavorel, S. et al. (1997) 'Plant functional classifications: from general groups to specific groups based on response to disturbance', Trends in Ecology \& Evolution, 12(12), pp. 474-478.

Lavorel, S. et al. (2007) 'Plant functional types: Are we getting any closer to the Holy Grail?', in Canadell, J. G., Pataki, D. E., and Pitelka, L. F. (eds) Terrestrial Ecosystems in a Changing World. Berlin, Heidelberg, New York: Springer, pp. 149- 160.

Lavorel, S. and Garnier, E. (2002) 'Predicting changes in community composition and ecosystem functioning from plant traits: Revisiting the Holy Grail', Functional Ecology, 16, pp. $545-556$.

Le Quéré, C. et al. (2009) 'Trends in the sources and sinks of carbon dioxide', Nature geoscience, 2(12), pp. 831-836.

Le Quéré, C. et al. (2018) 'Global carbon budget 2018', Earth System Science Data, 10, pp. 2141- 2194.

Leakey, A. D. et al. (2009) 'Elevated $\mathrm{CO}_{2}$ effects on plant carbon, nitrogen, and water relations: six important lessons from FACE', Journal of experimental botany, 60(10), pp. 2859 2876. 
Lehmann, C. E. R. et al. (2011) 'Deciphering the distribution of the savanna biome', New Phytologist, 191(1), pp. 197-209.

Lehmann, C. E. R. et al. (2014) 'Savanna Vegetation-Fire-Climate Relationships Differ Among Continents', Science, 343(6170), pp. 548-552.

Lenz, A. et al. (2013) 'European deciduous trees exhibit similar safety margins against damage by spring freeze events along elevational gradients', New Phytologist, 200(4), pp. 11661175.

Lenz, A., Hoch, G. and Vitasse, Y. (2016) 'Fast acclimation of freezing resistance suggests no influence of winter minimum temperature on the range limit of European beech.', Tree Physiology, 36(4), pp. 490-501.

Letcher, S. G. and Chazdon, R. L. (2009) 'Lianas and self-supporting plants during tropical forest succession', Forest Ecology and Management, 257(10), pp. 2150-2156.

Lett, M. S. and Knapp, A. K. (2005) 'Woody plant encroachment and removal in mesic grassland: production and composition responses of herbaceous vegetation', The American Midland Naturalist, 153(2), pp. 217-232.

Leuzinger, S. and Hättenschwiler, S. (2013) 'Beyond global change: lessons from 25 years of $\mathrm{CO}_{2}$ research'.

Levy, P. E., Cannell, M. G. R. and Friend, A. D. (2004) 'Modelling the impact of future changes in climate, $\mathrm{CO} 2$ concentration and land use on natural ecosystems and the terrestrial carbon sink', Global Environmental Change, 14(1), pp. 21-30.

Li, Z. and Kobayashi, M. (2004) 'Plantation future of bamboo in China', Journal of Forestry Research, 15(3), pp. 233-242.

Lin, D., Xia, J. and Wan, S. (2010) 'Climate warming and biomass accumulation of terrestrial plants: a meta-analysis', New Phytologist, 188(1), pp. 187-198.

Linder, H. P. et al. (2012) 'Biotic modifiers, environmental modulation and species distribution models', Journal of Biogeography, 39(12), pp. 2179-2190.

Liu, J. et al. (2016) 'Estimating carbon sequestration in the piedmont ecoregion of the United States from 1971 to 2010', Carbon balance and management, 11(1), p. 10.

Liu, J. et al. (2020) 'Critical land change information enhances the understanding of carbon balance in the United States', Global Change Biology, 26(7), pp. 3920-3929.

Liu, J. X. et al. (2008) 'CO2 enrichment increases nutrient leaching from model forest ecosystems in subtropical China.' Biogeosciences Discussions, 5(3).

Liu, M. et al. (2008) 'Effects of Land-Use and Land-Cover Change on Evapotranspiration and Water Yield in China During 1900-2000 1', JAWRA Journal of the American Water Resources Association, 44(5), pp. 1193-1207.

Liu, M.-Z. and Osborne, C. P. (2008) 'Leaf cold acclimation and freezing injury in C3 and C4 grasses of the Mongolian Plateau', Journal of experimental Botany, 59(15), pp. 41614170 .

Liu, Y. et al. (2015) 'Spatial and temporal patterns of global NDVI trends: correlations with climate and human factors', Remote Sensing, 7(10), pp. 13233-13250.

Liu, Y. et al. (2019) 'Field-experiment constraints on the enhancement of the terrestrial carbon sink by CO2 fertilization', Nature Geoscience, 12, pp. 809-814.

Lloyd, J. et al. (2008) 'Contributions of woody and herbaceous vegetation to tropical savanna ecosystem productivity: a quasi-global estimate', Tree physiology, 28(3), pp. 451-468.

Lloyd, J. and Farquhar, G. D. (2008) 'Effects of rising temperatures and CO2 on the physiology of tropical forest trees', Philosophical Transactions of the Royal Society B: Biological Sciences, 363(1498), pp. 1811-1817.

Loarie, S. R. et al. (2009) 'The velocity of climate change', Nature, 462, pp. 1052- 1055.

Lohbeck, M. et al. (2015) 'Biomass is the main driver of changes in ecosystem process rates during tropical forest succession', Ecology, 96(5), pp. 1242-1252. 
Lombardozzi, D. L. et al. (2015) 'Temperature acclimation of photosynthesis and respiration: A key uncertainty in the carbon cycle-climate feedback', Geophysical Research Letters, 42(20), pp. 8624-8631.

Long, S. P. et al. (2004) 'Rising atmospheric carbon dioxide: plants FACE the future', Annu. Rev. Plant Biol., 55, pp. 591-628.

Lopez-Iglesias, B., Villar, R. and Poorter, L. (2014) 'Functional traits predict drought performance and distribution of Mediterranean woody species', Acta Oecologica, 56, pp. $10-18$.

Loreau, M. et al. (2001) 'Biodiversity and ecosystem functioning: current knowledge and future challenges', science, 294(5543), pp. 804-808.

Lucht, W. et al. (2006) 'Terrestrial vegetation redistribution and carbon balance under climate change', Carbon Balance and Management, 1(1), p. 6.

Lundholm, J. T. (2009) 'Plant species diversity and environmental heterogeneity: spatial scale and competing hypotheses', Journal of Vegetation Science, 20(3), pp. 377-391.

Luo, Y. et al. (2004) 'Progressive nitrogen limitation of ecosystem responses to rising atmospheric carbon dioxide', Bioscience, 54(8), pp. 731-739.

M Haddad, T. et al. (2020) 'Savannas after afforestation: Assessment of herbaceous community responses to wildfire versus native tree planting', Biotropica. 00:1-11.

Mabuchi, K., Sato, Y. and Kida, H. (2005) 'Climatic impact of vegetation change in the Asian tropical region. Part I: Case of the Northern Hemisphere summer', Journal of Climate, 18(3), pp. 410-428.

MacDonald, G. M. et al. (2008) 'Impacts of climate change on species, populations and communities: palaeobiogeographical insights and frontiers', Progress in Physical Geography, 32(2), pp. 139-172.

Malhi, Y. et al. (2020) Climate change and ecosystems: threats, opportunities and solutions. The Royal Society.

Mall, R. K. et al. (2006) 'Impact of climate change on Indian agriculture: a review', Climatic Change, 78(2-4), pp. 445-478.

Mani, M. S. (1974) 'Ecology and biogeography in India. Dr. W', W. Junk, Publishers, The Hague, pp. 1-773.

Mani, S. and Parthasarathy, N. (2006) 'Tree diversity and stand structure in inland and coastal tropical dry evergreen forests of peninsular India', Current Science, pp. 1238-1246.

Manzoni, S. (2014) 'Integrating plant hydraulics and gas exchange along the drought-response trait spectrum', Tree physiology, 34(10), pp. 1031-1034.

Mao, F. et al. (2016) 'Development of the BIOME-BGC model for the simulation of managed Moso bamboo forest ecosystems', Journal of environmental management, 172, pp. 2939.

Mao, J. et al. (2015) 'Disentangling climatic and anthropogenic controls on global terrestrial evapotranspiration trends', Environmental Research Letters, 10(9), p. 094008.

Marambe, B. and Silva, P. (2016) Impact of climate change on biodiversity: a challenge to agroecosystems in South Asia. National Institute for Agro-Environmental Sciences (NIAES).

Markesteijn, L. et al. (2011) 'Ecological differentiation in xylem cavitation resistance is associated with stem and leaf structural traits', Plant, Cell \& Environment, 34(1), pp. 137-148.

Marston, C. G. et al. (2017) 'Scrubbing up: multi-scale investigation of woody encroachment in a Southern African Savannah', Remote Sensing, 9(5), p. 419.

Martens, C. et al. (2020) 'Large uncertainties in future biome changes in Africa call for flexible climate adaptation strategies', 00: 1- 19 Global Change Biology.

Martínez-Vilalta, J. et al. (2016) 'Dynamics of non-structural carbohydrates in terrestrial plants: a global synthesis’, Ecological Monographs, 86(4), pp. 495-516. 
Mason, E. G. and Dzierzon, H. (2006) 'Applications of modeling to vegetation management', Canadian Journal of Forest Research, 36(10), pp. 2505-2514.

Matheny, A. M., Mirfenderesgi, G. and Bohrer, G. (2017) 'Trait-based representation of hydrological functional properties of plants in weather and ecosystem models', Plant Diversity, 39(1), pp. 1-12.

Mauzerall, D. L. et al. (2001) 'Asian, US, and European contributions to tropospheric O3 and its precursors in the Northern Hemisphere: a global photochemical model analysis.', in AGU Spring Meeting Abstracts.

Mcdowell, N. G. et al. (2016) 'Multi-scale predictions of massive conifer mortality due to chronic temperature rise', Nature Climate Change, 6(3), pp. 295-300.

McIntyre, B. D. (2009) East and South Asia and the Pacific (ESAP) report. Island Press.

McKinnon, M. C. et al. (2015) 'Impact evaluation to communicate and improve conservation non-governmental organization performance: the case of Conservation International', Philosophical Transactions of the Royal Society B: Biological Sciences, 370(1681), p. 20140282.

McLaughlin, S. B. et al. (2007) 'Interactive effects of ozone and climate on tree growth and water use in a southern Appalachian forest in the USA', New Phytologist, 174(1), pp. 109124.

McMahon, S. M. et al. (2011) 'Improving assessment and modelling of climate change impacts on global terrestrial biodiversity', Trends in Ecology \& Evolution, 26(5), pp. 249-259.

McSweeney, C. F. and Jones, R. G. (2016) 'How representative is the spread of climate projections from the 5 CMIP5 GCMs used in ISI-MIP?', Climate Services, 1, pp. 24-29.

Medina, E. et al. (1999) 'Natural abundance of $13 \mathrm{C}$ in tropical grasses from the INPA, Instituto Nacional de Pesquisas da Amazônia, herbarium', Revista Brasileira de Botânica.

Meinshausen, M. et al. (2011) 'The RCP greenhouse gas concentrations and their extensions from 1765 to 2300', Climatic change, 109(1-2), p. 213.

Meir, P., Cox, P. and Grace, J. (2006) 'Terrestrial carbon cycle feedbacks: a key uncertainty in climate projections', Trends in Ecology \& Evolution, 5(21), pp. 254-260.

Meli, P. et al. (2017) 'A global review of past land use, climate, and active vs. passive restoration effects on forest recovery', PloS one, 12(2), p. e0171368.

Méndez-Alonzo, R. et al. (2012) 'Coordinated evolution of leaf and stem economics in tropical dry forest trees', Ecology, 93(11), pp. 2397-2406.

Méndez-Alonzo, R. et al. (2013) 'Leaf phenology is associated with soil water availability and xylem traits in a tropical dry forest', Trees, 27(3), pp. 745-754.

Menon, S. et al. (2007) Couplings between changes in the climate system and biogeochemistry. Lawrence Berkeley National Lab.(LBNL), Berkeley, CA (United States).

Midgley, G. F. and Bond, W. J. (2015) 'Future of African terrestrial biodiversity and ecosystems under anthropogenic climate change', Nature Climate Change, 5, pp. 823-829.

Migliavacca, M. et al. (2012) 'On the uncertainty of phenological responses to climate change, and implications for a terrestrial biosphere model', Biogeosciences, 9(6), pp. 2063-2083.

Mirfenderesgi, G., Matheny, A. M. and Bohrer, G. (2017) 'Hydrodynamic Trait Coordination and Cost-Benefit Trade-offs throughout the Isohydric-Anisohydric Continuum in Trees', Ecohydrology, p. e2041.

Mitchell, T. D. et al. (2004) 'A comprehensive set of high-resolution grids of monthly climate for Europe and the globe: the observed record (1901-2000) and 16 scenarios (20012100)', Tyndall centre for climate change research working paper, 55(0), p. 25.

Mittermeier, R. A. et al. (2004) 'Hotspots Revisited: Earth's Biologically Richest and Most Endangered Terrestrial Ecoregions Cemex', Mexico City.

Moncrieff, G. R. et al. (2014) 'Increasing atmospheric CO2 overrides the historical legacy of multiple stable biome states in Africa', New Phytologist, 201(3), pp. 908-915. 
Moncrieff, G. R. et al. (2016) 'The future distribution of the savannah biome: Model-based and biogeographic contingency', Philosophical Transactions of the Royal Society B: Biological Sciences, 371.

Moncrieff, G. R., Bond, W. J. and Higgins, S. I. (2016) 'Revising the biome concept for understanding and predicting global change impacts', Journal of Biogeography, 43(5), pp. 863-873.

Mondal, N. and Sukumar, R. (2016) 'Fires in seasonally dry tropical forest: testing the varying constraints hypothesis across a regional rainfall gradient', PLoS One, 11(7), p. e0159691.

Montti, L., Campanello, P. I. and Goldstein, G. (2011) 'Flowering, die-back and recovery of a semelparous woody bamboo in the Atlantic Forest', Acta Oecologica, 37(4), pp. 361368.

Moorcroft, P. R., Hurtt, G. C. and Pacala, S. W. (2001) 'A method for scaling vegetation dynamics: the ecosystem demography model (ED)', Ecological monographs, 71(4), pp. 557-586.

Moura, L. C. et al. (2019) 'The legacy of colonial fire management policies on traditional livelihoods and ecological sustainability in savannas: Impacts, consequences, new directions', Journal of environmental management, 232, pp. 600-606.

Mucina, L. (2019) 'Biome: Evolution of a crucial ecological and biogeographical concept', New Phytologist, 222, pp. 97- 114.

Mucina, L. and Rutherford, M. C. (2006) The vegetation of South Africa, Lesotho and Swaziland. South African National Biodiversity Institute.

Murphy, B. P., Andersen, A. N. and Parr, C. L. (2016) 'The underestimated biodiversity of tropical grassy biomes', Philosophical Transactions of the Royal Society B: Biological Sciences, 371(1703), p. 20150319.

Murphy, B. P. and Bowman, D. M. (2012) 'What controls the distribution of tropical forest and savanna?', Ecology letters, 15(7), pp. 748-758.

Muthumperumal, C. and Parthasarathy, N. (2010) 'A large-scale inventory of liana diversity in tropical forests of South Eastern Ghats, India', Systematics and Biodiversity, 8(2), pp. 289-300.

Myers, N. et al. (2000) 'Biodiversity hotspots for conservation priorities', Nature, 403(6772), p. 853.

Nabel, J. E. M. S., Zurbriggen, N. and Lischke, H. (2013) 'Interannual climate variability and population density thresholds can have a substantial impact on simulated tree species' migration', Ecological Modelling, 257, pp. 88- 100.

Nachtergaele, F. et al. (2009) 'Harmonized world soil database (version 1.1)', FAO, Rome, Italy \& IIASA, Laxenburg, Austria.

Naveendrakumar, G. et al. (2019) 'South Asian perspective on temperature and rainfall extremes: A review', Atmospheric Research, 225, pp. 110-120.

Negi, G. C. S. et al. (2012) 'Impact of climate change on the western Himalayan mountain ecosystems: An overview', Tropical ecology, 53(3), pp. 345-356.

Newbold, T. et al. (2015) 'Global effects of land use on local terrestrial biodiversity', Nature, 520(7545), pp. 45-50.

Nguyen, T. T., Murphy, B. P. and Baker, P. J. (2019) 'The existence of a fire-mediated treerecruitment bottleneck in an Asian savanna', Journal of Biogeography, 46(4), pp. 745756.

Nolan, C. et al. (2018) 'Past and future global transformation of terrestrial ecosystems under climate change', Science, 361(6405), pp. 920-923.

Norby, R. J. et al. (2010) 'CO2 enhancement of forest productivity constrained by limited nitrogen availability', Proceedings of the National Academy of Sciences, 107(45), pp. 19368-19373. 
Norby, R. J. and Luo, Y. (2004) 'Evaluating ecosystem responses to rising atmospheric CO2 and global warming in a multi-factor world', New phytologist, 162(2), pp. 281-293.

Norby, R. J. and Zak, D. R. (2011) 'Ecological lessons from free-air CO2 enrichment (FACE) experiments', Annual review of ecology, evolution, and systematics, 42, pp. 181-203.

Novoa, A. et al. (2015) 'Introduced and invasive cactus species: a global review', AoB Plants, 7.

O'Connor, C. D. et al. (2014) 'Fire severity, size, and climate associations diverge from historical precedent along an ecological gradient in the Pinaleño Mountains, Arizona, USA', Forest Ecology and Management, 329, pp. 264-278.

Ogle, K. et al. (2015) 'Quantifying ecological memory in plant and ecosystem processes', Ecology letters, 18(3), pp. 221-235.

Ögren, E. (1997) 'Relationship between temperature, respiratory loss of sugar and premature dehardening in dormant Scots pine seedlings', Tree Physiology, 17(1), pp. 47-51.

Olson, D. M. et al. (2001) 'Terrestrial Ecoregions of the World: A New Map of Life on EarthA new global map of terrestrial ecoregions provides an innovative tool for conserving biodiversity', BioScience, 51(11), pp. 933-938.

Olson, J. S. (1994) 'Global ecosystem framework-definitions', USGS EROS Data Center Internal Report, Sioux Falls, SD, 37, p. 1994.

van Ommen Kloeke, A. E. E. et al. (2012) 'Global quantification of contrasting leaf life span strategies for deciduous and evergreen species in response to environmental conditions', Global Ecology and Biogeography, 21(2), pp. 224-235.

Oo, W. P. and Koike, F. (2015) 'Dry forest community types and their predicted distribution based on a habitat model for the central dry zone of Myanmar', Forest Ecology and Management, 358, pp. 108- 121.

Ordoñez, J. C. et al. (2009) 'A global study of relationships between leaf traits, climate and soil measures of nutrient fertility', Global Ecology and Biogeography, 18(2), pp. 137-149.

Ordonez, J. C. et al. (2009) 'Plant strategies in relation to resource supply in mesic to wet environments: does theory mirror nature?', The American Naturalist, 175(2), pp. 225239.

Oreskes, N. and Belitz, K. (2001) 'Philosophical issues in model assessment', Model validation: Perspectives in hydrological science, 23.

Ostendorf, B., Hilbert, D. W. and Hopkins, M. S. (2001) 'The effect of climate change on tropical rainforest vegetation pattern', Ecological modelling, 145(2-3), pp. 211-224.

Overpeck, J. et al. (1996) 'The southwest Indian Monsoon over the last 18000 years', Climate Dynamics, 12(3), pp. 213-225.

Overpeck, J. T., Rind, D. and Goldberg, R. (1990) 'Climate-induced changes in forest disturbance and vegetation', Nature, 343(6253), p. 51.

Owen, N. A. and Griffiths, H. (2013) 'A system dynamics model integrating physiology and biochemical regulation predicts extent of crassulacean acid metabolism (CAM) phases', New Phytologist, 200(4), pp. 1116-1131.

Ozanne, C. M. P. et al. (2003) 'Biodiversity meets the atmosphere: A global view of forest canopies', Science, 301, pp. 183- 186.

Pace, M. L., Carpenter, S. R. and Cole, J. J. (2015) 'With and without warning: managing ecosystems in a changing world', Frontiers in Ecology and the Environment, 13(9), pp. 460-467.

Pachauri, R. K. et al. (2014) Climate change 2014: synthesis report. Contribution of Working Groups I, II and III to the fifth assessment report of the Intergovernmental Panel on Climate Change. IPCC.

Pachzelt, A. et al. (2013) 'Coupling a physiological grazer population model with a generalized model for vegetation dynamics', Ecological Modelling, 263, pp. 92- 102. 
Panda, R. M., Behera, M. D. and Roy, P. S. (2017) 'Investigating the influence of environmental heterogeneity on plant species richness pattern of the Eastern Himalaya', Dim, 1, pp. 54 58.

Pandey, H. P. and Chauhan, S. K. (2012) 'Lantana camera: a journey from eradication to adaptive management.', Bioherald: International Journal of Biodiversity \& Environment, 2(2).

Pandey, R. K., Kandya, A. K. and Kotwal, P. C. (1985) 'Ecological studies of Kanha Wildlife National Park, India (I) History, distribution and structure of the grasslands', J. Trop For, 1, pp. 198-216.

Pandit, M. K. et al. (2007) 'Unreported yet massive deforestation driving loss of endemic biodiversity in Indian Himalaya', Biodiversity and Conservation, 16(1), pp. 153-163.

Pappas, C. et al. (2013) 'Sensitivity analysis of a process-based ecosystem model: Pinpointing parameterization and structural issues: Global sensitivity analysis of LPJ-GUESS', Journal of Geophysical Research: Biogeosciences, 118(2), pp. 505-528.

Pappas, C. et al. (2015) 'The role of local-scale heterogeneities in terrestrial ecosystem modeling', Journal of Geophysical Research: Biogeosciences, 120(2), pp. 341-360.

Parmesan, C. and Yohe, G. (2003) 'A globally coherent fingerprint of climate change impacts across natural systems', Nature, 421(6918), p. 37.

Parr, C. L. et al. (2014) 'Tropical grassy biomes: misunderstood, neglected, and under threat', Trends in ecology \& evolution, 29(4), pp. 205-213.

Parr, C. L., Gray, E. F. and Bond, W. J. (2012) 'Cascading biodiversity and functional consequences of a global change-induced biome switch', Diversity and Distributions, 18(5), pp. 493-503.

Parry, M. et al. (2007) Climate change 2007-impacts, adaptation and vulnerability: Working group II contribution to the fourth assessment report of the IPCC. Cambridge University Press.

Parthasarathy, N., Selwyn, M. A. and Udayakumar, M. (2008) 'Tropical dry evergreen forests of peninsular India: ecology and conservation significance', Tropical Conservation Science, 1(2), pp. 89-110.

Parton, W. J. et al. (1993) 'Observations and modeling of biomass and soil organic matter dynamics for the grassland biome worldwide', Global biogeochemical cycles, 7(4), pp. 785-809.

Patra, P. K. et al. (2013) 'The carbon budget of South Asia', Biogeosciences, 10(1), pp.513-527.

Paul, C. et al. (2019) 'Climate change and mixed forests: how do altered survival probabilities impact economically desirable species proportions of Norway spruce and European beech?', Annals of Forest Science, 76(1), pp. 1-15.

Paul, M. J. and Foyer, C. H. (2001) 'Sink regulation of photosynthesis', Journal of experimental Botany, 52(360), pp. 1383-1400.

Pavlick, R. et al. (2013) 'The Jena Diversity-Dynamic Global Vegetation Model (JeDi-DGVM): a diverse approach to representing terrestrial biogeography and biogeochemistry based on plant functional trade-offs', Biogeosciences, 10, pp. 4137-4177.

Pearson, R. G. and Dawson, T. P. (2003) 'Predicting the impacts of climate change on the distribution of species: are bioclimate envelope models useful?', Global ecology and biogeography, 12(5), pp. 361-371.

Peng, C. (2000) 'From static biogeographical model to dynamic global vegetation model: a global perspective on modelling vegetation dynamics', Ecological modelling, 135(1), pp. 33-54.

Perring, M. P. et al. (2018) 'Global environmental change effects on plant community composition trajectories depend upon management legacies', Global Change Biology, 24(4), pp. 1722-1740.

Pescador, D. S. et al. (2016) 'Summer freezing resistance: a critical filter for plant community assemblies in Mediterranean high mountains', Frontiers in plant science, 7, p. 194. 
Pfeiffer, M. et al. (2019) 'Grazing and aridity reduce perennial grass abundance in semi-arid rangelands-Insights from a trait-based dynamic vegetation model', Ecological Modelling, 395, pp. 11-22.

Piao, S. et al. (2006) 'Effect of climate and $\mathrm{CO} 2$ changes on the greening of the Northern Hemisphere over the past two decades', Geophysical Research Letters, 33(23).

Piao, S. et al. (2009) 'Spatiotemporal patterns of terrestrial carbon cycle during the 20th century', Global Biogeochemical Cycles, 23(4).

Piao, S. et al. (2015) 'Detection and attribution of vegetation greening trend in China over the last 30 years', Global Change Biology, 21, pp. 1601- 1609.

Piao, S. et al. (2019) 'Plant phenology and global climate change: Current progresses and challenges', Global Change Biology, 25, pp. 1922.

Piao, S. et al. (2020) 'Characteristics, drivers and feedbacks of global greening', Nature Reviews Earth \& Environment, 1, pp. 14- 27.

Pielke, R. A. (2005) 'Land use and climate change', Science, 310(5754), pp. 1625-1626.

Pierret, A. et al. (2016) 'Understanding deep roots and their functions in ecosystems: an advocacy for more unconventional research', Annals of botany, 118(4), pp. 621-635.

Pimm, S. L. et al. (1996) 'The future of biodiversity', Biological Conservation, 3(75), p. 310.

Polgar, C., Gallinat, A. and Primack, R. B. (2014) 'Drivers of leaf-out phenology and their implications for species invasions: insights from T horeau's C oncord', New Phytologist, 202(1), pp. 106-115.

Poorter, L. and Markesteijn, L. (2008) 'Seedling traits determine drought tolerance of tropical tree species’, Biotropica, 40(3), pp. 321-331.

Popp, A. et al. (2017) 'Land-use futures in the shared socio-economic pathways', Global Environmental Change, 42, pp. 331-345.

Prance, G. T. (2006) 'Tropical savannas and seasonally dry forests: an introduction', Journal of Biogeography, pp. 385-386.

Prasad, Ayesha E. (2010) 'Effects of an exotic plant invasion on native understory plants in a tropical dry forest', Conservation Biology, 24(3), pp. 747-757.

Prasad, A. E. (2010) 'Impact of Lantana camara, a major invasive plant, on wildlife habitat in Bandipur Tiger Reserve, southern India', Nature Conservation Foundation, Mysore, viewed on, 25.

Prasad, S. N. et al. (1978) 'On factors governing the distribution of wild mammals in Karnataka', J. Bombay Nat. Hist. Soc, 75, pp. 718-743.

Prentice, I. C. et al. (1992) 'Special Paper: A Global Biome Model Based on Plant Physiology and Dominance, Soil Properties and Climate', Journal of Biogeography, 19(2), p. 117.

Prentice, I. C. et al. (2007) 'Dynamic global vegetation modeling: quantifying terrestrial ecosystem responses to large-scale environmental change', in Terrestrial ecosystems in a changing world. Springer, pp. 175-192.

Prestele, R. et al. (2017) 'Current challenges of implementing anthropogenic land-use and landcover change in models contributing to climate change assessments', Earth System Dynamics, 8(2), pp. 369-386.

Proença, V. et al. (2017) 'Global biodiversity monitoring: from data sources to essential biodiversity variables', Biological Conservation, 213, pp. 256-263.

Purschke, O. et al. (2015) 'sPlot-the new global vegetation-plot database for addressing traitenvironment relationships across the world's biomes', in EGU General Assembly Conference Abstracts.

Putz, F. E. (1984) 'How trees avoid and shed lianas', Biotropica, pp. 19-23.

Putz, F. E. and Redford, K. H. (2010) 'The importance of defining "forest": Tropical forest degradation, deforestation, long-term phase shifts, and further transitions', Biotropica, 42(1), pp. 10-20. 
Qin, Z. S., Taylor, A. H. and Cai, X. S. (1993) 'Bamboo and forest dynamic succession in the ecological environment of Giant Panda in Wolong', Beijing: China Forestry Press, 13, pp. 30-57.

Quesada, B. et al. (2018) 'Potential strong contribution of future anthropogenic land-use and land-cover change to the terrestrial carbon cycle', Environmental Research Letters, 13(6), p. 064023.

Quillet, A., Peng, C. and Garneau, M. (2010) 'Toward dynamic global vegetation models for simulating vegetation-climate interactions and feedbacks: recent developments, limitations, and future challenges', Environmental Reviews, 18(NA), pp. 333-353.

Raddatz, T. J. et al. (2007) 'Will the tropical land biosphere dominate the climate-carbon cycle feedback during the twenty-first century?', Climate dynamics, 29(6), pp. 565-574.

Raghavan, S. V. et al. (2018) 'Assessment of CMIP5 historical simulations of rainfall over Southeast Asia', Theoretical and Applied Climatology, 132, pp. 989- 1002.

Rai, P. K. and Singh, M. M. (2015) 'Lantana camara invasion in urban forests of an Indo-Burma hotspot region and its ecosustainable management implication through biomonitoring of particulate matter', Journal of Asia-Pacific Biodiversity, 8(4), pp. 375-381.

Ralhan, P. K. et al. (1985) 'Phenological characteristics of the tree layer of Kumaun Himalayan forests', Vegetatio, 60, pp. 91- 101.

Ramakrishnan, P. S. (1992) Shifting agriculture and sustainable development: An interdisciplinary study from North-eastern India, UNESCO-MAP series, Paris. Oxford University Press, New Delhi, India.

Raman, T. S., Rawat, G. S. and Johnsingh, A. J. T. (1998) 'Recovery of tropical rainforest avifauna in relation to vegetation succession following shifting cultivation in Mizoram, north-east India', Journal of Applied Ecology, 35(2), pp. 214-231.

Ramankutty, N. et al. (2010) 'ISLSCP II Potential Natural Vegetation Cover', ORNL DAAC.

Ramaswami, G. and Sukumar, R. (2016) 'Invasive plants in the tropics and the case of lantana camara', Tropical Conservation: Perspectives on Local and Global Priorities, p. 154.

Randerson, J. T. et al. (2006) 'The impact of boreal forest fire on climate warming', science, 314(5802), pp. 1130-1132.

Ratajczak, Z., Nippert, J. B. and Collins, S. L. (2012) 'Woody encroachment decreases diversity across North American grasslands and savannas', Ecology, 93(4), pp. 697-703.

Ratnam, J. et al. (2011) 'When is a 'forest'a savanna, and why does it matter?', Global Ecology and Biogeography, 20(5), pp. 653-660.

Ratnam, J. et al. (2016) 'Savannahs of Asia: antiquity, biogeography, and an uncertain future', Philosophical Transactions of the Royal Society B: Biological Sciences, 371(1703), p. 20150305.

Ratnam, J., Sheth, C. and Sankaran, M. (2019) 'African and Asian Savannas: Comparisons of Vegetation Composition and Drivers of Vegetation Structure and Function', Savanna Woody Plants and Large Herbivores, pp. 25-49.

Ravindranath, N. H. et al. (2006) 'Impact of climate change on forests in India', Current Science, 90, pp. 354-361.

Ravindranath, N. H. et al. (2011) 'Climate change vulnerability profiles for North East India', Current Science, pp. 384-394.

Ravindranath, N. H. and Bhat, P. R. (1997) 'Monitoring of carbon abatement in forestry projects - Case study of Western Ghat Project', Mitigation and adaptation strategies for Global change, 2(2), pp. 217-230.

Ravindranath, N. H., Chaturvedi, R. K. and Murthy, I. K. (2008) 'Forest conservation, afforestation and reforestation in India: implications for forest carbon stocks', Current Science, 95(2), pp. 216-222. 
Ravindranath, N. H., Murali, K. S. and Sudha, P. (2006) 'Community forestry initiatives in Southeast Asia: a review of ecological impacts', International Journal of Environment and Sustainable Development, 5(1), pp. 1-11.

Ravindranath, N. H., Somashekhar, B. S. and Gadgil, M. (1997) 'Carbon flow in Indian forests', Climatic Change, 35(3), pp. 297-320.

Ravindranath, N. H. and Sukumar, R. (1996) 'Impacts of climate change on forest cover in India', The Commonwealth Forestry Review, pp. 76-79.

Ravindranath, N. H. and Sukumar, R. (1998) 'Climate change and tropical forests in India', in Potential Impacts of Climate Change on Tropical Forest Ecosystems. Springer, pp. 423441.

Reddy, C. S. et al. (2015) 'Nationwide classification of forest types of India using remote sensing and GIS', Environmental monitoring and assessment, 187(12), p. 777.

Reich, P. B. (1987) 'Quantifying plant response to ozone: a unifying theory', Tree physiology, 3(1), pp. 63-91.

Reich, P. B. (1995) 'Phenology of tropical forests: patterns, causes, and consequences', Canadian Journal of Botany, 73(2), pp. 164-174.

Reich, P. B. et al. (2003) 'The evolution of plant functional variation: traits, spectra, and strategies', International Journal of Plant Sciences, 164(S3), pp. S143-S164.

Reich, P. B. and Amundson, R. G. (1985) 'Ambient levels of ozone reduce net photosynthesis in tree and crop species', Science, 230(4725), pp. 566-570.

Reick, C. H. et al. (2013) 'Representation of natural and anthropogenic land cover change in MPI-ESM', Journal of Advances in Modeling Earth Systems, 5, pp. 459- 482.

Reid, D. G. and Jinchu, H. (1991) 'Giant panda selection between Bashania fangiana bamboo habitats in Wolong Reserve, Sichuan, China', Journal of Applied Ecology, pp. 228-243.

Reu, B. et al. (2014) 'Future no-analogue vegetation produced by no-analogue combinations of temperature and insolation', Global Ecology and Biogeography, 23(2), pp. 156-167.

Riahi, K. et al. (2017) 'The shared socioeconomic pathways and their energy, land use, and greenhouse gas emissions implications: an overview', Global Environmental Change, 42, pp. 153-168.

Richardson, A. D. et al. (2013) 'Climate change, phenology, and phenological control of vegetation feedbacks to the climate system', Agricultural and Forest Meteorology, 169, pp. 156-173.

Richardson, A. D. and O'Keefe, J. (2009) 'Phenological differences between understory and overstory', in Phenology of ecosystem processes. Springer, pp. 87-117.

Ricklefs, R. E. (2008) The economy of nature. Macmillan.

Rigon, R., Bertoldi, G. and Over, T. M. (2006) 'GEOtop: A distributed hydrological model with coupled water and energy budgets', Journal of Hydrometeorology, 7(3), pp. 371-388.

Rodgers, W. A. and Panwar, H. S. (1988) 'Planning a wildlife protected area network in India'.

Roman, D. T. et al. (2015) 'The role of isohydric and anisohydric species in determining ecosystem-scale response to severe drought', Oecologia, 179(3), pp. 641-654.

Root, T. L. et al. (2005) 'Human-modified temperatures induce species changes: joint attribution', Proceedings of the National Academy of Sciences of the United States of America, 102(21), pp. 7465-7469.

Ruangpanit, N. (1995) 'Tropical seasonal forests in monsson Asia: With emphasis on continental southeast Asia', Vegetatio, 121(1-2), pp. 31-40.

Rummukainen, M. (2010) 'State-of-the-art with regional climate models', Wiley Interdisciplinary Reviews: Climate Change, 1(1), pp. 82-96.

Running, S. W. and Hunt, E. R. (1993) 'Generalization of a forest ecosystem process model for other biomes, BIOME-BGC, and an application for global-scale models', Scaling physiological processes: Leaf to globe, pp. 141-158. 
Rustad, L. et al. (2001) 'A meta-analysis of the response of soil respiration, net nitrogen mineralization, and aboveground plant growth to experimental ecosystem warming', Oecologia, 126(4), pp. 543-562.

Ryan, K. C., Knapp, E. E. and Varner, J. M. (2013) 'Prescribed fire in North American forests and woodlands: history, current practice, and challenges', Frontiers in Ecology and the Environment, 11(s1), pp. e15-e24.

Saatchi, S. S. et al. (2011) 'Benchmark map of forest carbon stocks in tropical regions across three continents', Proceedings of the National Academy of Sciences of the United States of America, 108, pp. 9899-9904.

SACEP (2016) The 126th Meeting of the Consultative Committee of SACEP. 26 April 2016, Colombo, Sri Lanka. S.

Saenger, P. (2002) 'Introduction: The Mangrove Environment', in Mangrove Ecology, Silviculture and Conservation. Springer, pp. 1-10.

Saikia, P. et al. (2017) 'Plant diversity patterns and conservation status of eastern Himalayan forests in Arunachal Pradesh, Northeast India', Forest Ecosystems, 4(1), p. 28.

Sakai, A. and Larcher, W. (2012) Frost survival of plants: responses and adaptation to freezing stress. Springer Science \& Business Media.

Sakschewski, B. et al. (2015) 'Leaf and stem economics spectra drive diversity of functional plant traits in a dynamic global vegetation model', Global Change Biology, 21, pp. 27112725 .

Sala, O. E. et al. (2000) 'Global biodiversity scenarios for the year 2100', Science, 287(5459), pp. 1770-1774.

Sankaran, M. et al. (2005) 'Determinants of woody cover in African savannas', Nature, 438, pp. $846-849$.

Sankaran, M. (2005) 'Fire, grazing and the dynamics of tall-grass savannas in the KalakadMundanthurai Tiger Reserve, South India', Conservation and Society, pp. 4-25.

Sankaran, M. (2009) 'Diversity patterns in savanna grassland communities: implications for conservation strategies in a biodiversity hotspot', Biodiversity and Conservation, 18(4), pp. 1099-1115.

Sankaran, M. and Ratnam, J. (2013) 'African and Asian Savannas', in Encyclopedia of Biodiversity. Elsevier, pp. 58-74.

Sannigrahi, S. et al. (2020) 'Examining effects of climate change and land use dynamic on biophysical and economic values of ecosystem services of a natural reserve region', Journal of Cleaner Production, 257, p. 120424.

Santiago, L. S. et al. (2017) 'Functional strategies of tropical dry forest plants in relation to growth form and isotopic composition', Environmental Research Letters, 12(11), p. 115006.

Santini, L. et al. (2017) 'Assessing the suitability of diversity metrics to detect biodiversity change', Biological Conservation, 213, pp. 341-350.

Sarker, P. K., Rahman, M. S. and Giessen, L. (2018) 'Regional governance by the South Asia Cooperative Environment Program (SACEP)? Institutional design and customizable regime policy offering flexible political options', Land use policy, 77, pp. 454-470.

Sato, H. and Ise, T. (2012) 'Effect of plant dynamic processes on African vegetation responses to climate change: Analysis using the spatially explicit individual-based dynamic global vegetation model (SEIB-DGVM', Journal of Geophysical Research: Biogeosciences, 117, p. 03017.

Sato, H., Itoh, A. and Kohyama, T. (2007) 'SEIB-DGVM: A new Dynamic Global Vegetation Model using a spatially explicit individual-based approach', Ecological Modelling, 200(3-4), pp. 279-307. 
Scarano, F.R., 2017. Ecosystem-based adaptation to climate change: concept, scalability and a role for conservation science. Perspectives in Ecology and Conservation, 15(2), pp.6573.

Schaphoff, S. et al. (2006) 'Terrestrial biosphere carbon storage under alternative climate projections', Climatic change, 74(1-3), pp. 97-122.

Scheffer, M. et al. (2005) 'Synergy between small-and large-scale feedbacks of vegetation on the water cycle', Global change biology, 11(7), pp. 1003-1012.

Scheiter, S. et al. (2012) 'Fire and fire-adapted vegetation promoted C4 expansion in the Late Miocene', New Phytologist, 195(3), pp. 653-666.

Scheiter, S. et al. (2015) 'Climate change and long-term fire management impacts on Australian savannas', New phytologist, 205(3), pp. 1211-1226.

Scheiter, S. et al. (2018) 'How vulnerable are ecosystems in the Limpopo province to climate change?', South African journal of botany, 116, pp. 86-95.

Scheiter, S. et al. (2019) 'How does climate change influence the economic value of ecosystem services in savanna rangelands?', Ecological Economics, 157, pp. 342-356.

Scheiter, S., Moncrieff, G. R., et al. (2020) 'African biomes are most sensitive to changes in CO2 under recent and near-future CO2 conditions', Biogeosciences, 17(4), pp. 1147-1167.

Scheiter, S., Kumar, D., et al. (2020) 'Climate change promotes transitions to tall evergreen vegetation in tropical Asia', Global Change Biology, 26(9), 5106-5124.

Scheiter, S. and Higgins, S. I. (2009) 'Impacts of climate change on the vegetation of Africa: an adaptive dynamic vegetation modelling approach', Global Change Biology, 15(9), pp. 2224-2246.

Scheiter, S., Langan, L. and Higgins, S. I. (2013) 'Next generation dynamic global vegetation models: Learning from community ecology', New Phytologist, 198, pp. 957- 969.

Scheiter, S. and Savadogo, P. (2016) 'Ecosystem management can mitigate vegetation shifts induced by climate change in West Africa', Ecological Modelling, 332, pp. 19- 27.

Schenk, H. J. and Jackson, R. B. (2002) 'Rooting depths, lateral root spreads and belowground/above-ground allometries of plants in water-limited ecosystems', Journal of Ecology, 90(3), pp. 480-494.

Schenk, H. J. and Jackson, R. B. (2005) 'Mapping the global distribution of deep roots in relation to climate and soil characteristics', Geoderma, 126(1), pp. 129-140.

Schimel, D. et al. (2016) 'Observing the carbon-climate system', arXiv preprint arXiv:1604.02106.

Schimel, D., Stephens, B. B. and Fisher, J. B. (2015) 'Effect of increasing CO2 on the terrestrial carbon cycle', Proceedings of the National Academy of Sciences, 112(2), pp. 436-441.

Schindler, D. E. and Hilborn, R. (2015) 'Prediction, precaution, and policy under global change', Science, 347(6225), pp. 953-954.

Schleuning, M. et al. (2016) 'Ecological networks are more sensitive to plant than to animal extinction under climate change', Nature Communications, 7, p. 13965.

Schnitzer, S. A. and Bongers, F. (2002) 'The ecology of lianas and their role in forests', Trends in Ecology \& Evolution, 17(5), pp. 223-230.

Schnitzer, S. A. and Carson, W. P. (2010) 'Lianas suppress tree regeneration and diversity in treefall gaps', Ecology letters, 13(7), pp. 849-857.

Schnitzer, S. A., Dalling, J. W. and Carson, W. P. (2000) 'The impact of lianas on tree regeneration in tropical forest canopy gaps: evidence for an alternative pathway of gapphase regeneration', Journal of Ecology, 88(4), pp. 655-666.

Schnitzer, S. A., Kuzee, M. E. and Bongers, F. (2005) 'Disentangling above-and below-ground competition between lianas and trees in a tropical forest', Journal of Ecology, 93(6), pp. $1115-1125$. 
Scholes, R. J. and Archer, S. R. (1997) 'Tree-grass interactions in savannas', Annual review of Ecology and Systematics, 28(1), pp. 517-544.

Schuldt, A. et al. (2014) 'Woody plant phylogenetic diversity mediates bottom-up control of arthropod biomass in species-rich forests', Oecologia, 176(1), pp. 171-182.

Schutz, A. E. N., Bond, W. J. and Cramer, M. D. (2009) 'Juggling carbon: allocation patterns of a dominant tree in a fire-prone savanna', Oecologia, 160(2), p. 235.

Shackelford, N. et al. (2017) 'Isolation predicts compositional change after discrete disturbances in a global meta-study', Ecography, 40(11), pp. 1256-1266.

Shankarnarayan, K. A., Harsh, L. N. and Kathju, S. (1987) 'Agroforestry in the arid zones of India', Agroforestry Systems, 5(1), pp. 69-88.

Sharkey, T. D. et al. (2007) 'Fitting photosynthetic carbon dioxide response curves for C3 leaves', Plant, cell \& environment, 30(9), pp. 1035-1040.

Sharma, G. P., Raghubanshi, A. S. and Singh, J. S. (2005) 'Lantana invasion: An overview', Weed Biology and Management, 5(4), pp. 157-165.

Sharma, G. P., Singh, J. S. and Raghubanshi, A. S. (2005) 'Plant invasions: emerging trends and future implications', Current Science, 88(5), pp. 726-734.

Sharma, K. K. and Mehra, S. P. (2009) 'The Thar of Rajasthan (India): ecology and conservation of a desert ecosystem', in Faunal ecology and conservation of the Great Indian Desert. Springer, pp. 1-11.

Sharma, Y. M. L. (1980) 'Bamboos in the Asia Pacific Region', in Bamboo research in Asia: proceedings of a workshop held in Singapore, 28-30 May 1980. IDRC, Ottawa, ON, CA.

Sieck, M. et al. (2011) 'Current models broadly neglect specific needs of biodiversity conservation in protected areas under climate change', BMC ecology, 11(1), p. 12.

Silveira, F. A. et al. (2020) 'Myth-busting tropical grassy biome restoration', Restoration Ecology, 28(5), pp. 1067-1073.

Simard, M. et al. (2011) 'Mapping forest canopy height globally with spaceborne lidar', Journal of Geophysical Research: Biogeosciences, 116, p. 04021.

Simon, M. F. et al. (2009) 'Recent assembly of the Cerrado, a neotropical plant diversity hotspot, by in situ evolution of adaptations to fire', Proceedings of the National Academy of Sciences, 106(48), pp. 20359-20364.

Singh, J. S., Lauenroth, W. K. and Milchunas, D. G. (1983) 'Geography of grassland ecosystems', Progress in physical geography, 7(1), pp. 46-80.

Singh, J. S., Singh, K. P. and Agrawal, M. (1991) Environmental degradation of the ObraRenukoot-Singrauli area, India, and its impact on natural and derived ecosystems. Springer.

Singh, K. P. and Singh, J. S. (1988) 'Certain structural and functional aspects of dry tropical forest and savanna', International Journal of Ecology and Environmental Sciences.

Singh, R. et al. (2017) 'Herbaceous species diversity and soil attributes along a forest-savannagrassland continuum in a dry tropical region', Ecological Engineering, 103, pp. 226-235.

Sinha, S. et al. (2018) 'Effect of altitude and climate in shaping the forest compositions of Singalila National Park in Khangchendzonga Landscape, Eastern Himalaya, India', Journal of Asia-Pacific Biodiversity, 11(2), pp. 267-275.

Sitch, S. et al. (2003) 'Evaluation of ecosystem dynamics, plant geography and terrestrial carbon cycling in the LPJ Dynamic Global Vegetation Model', Global Change Biology, 9, pp. $161-185$.

Sitch, S. et al. (2008) 'Evaluation of the terrestrial carbon cycle, future plant geography and climate-carbon cycle feedbacks using five Dynamic Global Vegetation Models (DGVMs', Global Change Biology, 14, pp. 2015-2039. 
Sitch, Stephen et al. (2008) 'Evaluation of the terrestrial carbon cycle, future plant geography and climate-carbon cycle feedbacks using five Dynamic Global Vegetation Models (DGVMs)', Global Change Biology, 14(9), pp. 2015-2039.

Sitch, S. et al. (2015) 'Recent trends and drivers of regional sources and sinks of carbon dioxide', Biogeosciences, 12(3), pp. 653-679.

Sivakumar, M. V. and Stefanski, R. (2010) 'Climate change in South Asia', in Climate change and food security in South Asia. Springer, pp. 13-30.

Sloan, V. L. et al. (2013) 'Leaf and fine root carbon stocks and turnover are coupled across Arctic ecosystems', Global Change Biology, 19(12), pp. 3668-3676.

Smit, I. P. J. and Prins, H. H. T. (2015) 'Predicting the effects of woody encroachment on mammal communities, grazing biomass and fire frequency in African savannas', PLoS One, 10, p. 0137857.

Smith, B. et al. (2014) 'Implications of incorporating N cycling and N limitations on primary production in an individual-based dynamic vegetation model', Biogeosciences, 11, pp. 2027-2054.

Smith, B., Prentice, I. C. and Sykes, M. T. (2001) 'Representation of vegetation dynamics in the modelling of terrestrial ecosystems: comparing two contrasting approaches within European climate space', Global Ecology and Biogeography, 10(6), pp. 621-637.

Smith, M. and Nelson, B. W. (2011) 'Fire favours expansion of bamboo-dominated forests in the south-west Amazon', Journal of Tropical Ecology, 27(1), pp. 59-64.

Snell, R. S., Cowling, S. A. and Smith, B. (2013) 'Simulating Regional Vegetation-climate Dynamics for Middle America: Tropical Versus Temperate Applications', Biotropica, 45(5), pp. 567-577.

Snyder, P. K. (2010) 'The influence of tropical deforestation on the Northern Hemisphere climate by atmospheric teleconnections', Earth Interactions, 14(4), pp. 1-34.

Sobrado, M. A. (1993) 'Trade-off between water transport efficiency and leaf life-span in a tropical dry forest', Oecologia, 96(1), pp. 19-23.

Sodhi, N. S. et al. (2004) 'Southeast Asian biodiversity: an impending disaster', Trends in ecology \& evolution, 19(12), pp. 654-660.

Sodhi, N. S. et al. (2010) 'The state and conservation of Southeast Asian biodiversity', Biodiversity and Conservation, 19(2), pp. 317-328.

Soh, W. K. et al. (2019) 'Rising CO2 drives divergence in water use efficiency of evergreen and deciduous plants', Science Advances, 5, p. 7906.

Somers, G. L. et al. (1998) 'Empirical evidence of growth decline related to visible ozone injury', Forest Ecology and Management, 104(1-3), pp. 129-137.

Song, J. et al. (2019) 'A meta-analysis of 1,119 manipulative experiments on terrestrial carboncycling responses to global change', Nature ecology \& evolution, 3(9), pp. 1309-1320.

Song, X. et al. (2016) 'Dynamic allocation and transfer of non-structural carbohydrates, a possible mechanism for the explosive growth of Moso bamboo (Phyllostachys heterocycla)', Scientific reports, 6, p. 25908.

Song, X.-P. et al. (2018) 'Global land change from 1982 to 2016', Nature, 560(7720), pp. 639643.

Sperry, J. S. et al. (1998) 'Limitation of plant water use by rhizosphere and xylem conductance: results from a model', Plant, Cell \& Environment, 21(4), pp. 347-359.

Sperry, J. S. et al. (2019) 'The impact of rising CO2 and acclimation on the response of US forests to global warming', Proceedings of the National Academy of Sciences, 116(51), pp. 25734-25744.

Spicer, R. A. (2017) 'Tibet, the Himalaya, Asian monsoons and biodiversity-In what ways are they related?', Plant Diversity, 39(5), pp. 233-244. 
Squeo, F. A. et al. (1991) 'Freezing tolerance and avoidance in high tropical Andean plants: is it equally represented in species with different plant height?', Oecologia, 86(3), pp. 378382.

Squires, D. (2014) 'Biodiversity Conservation in Asia: Biodiversity Conservation in Asia', Asia $\&$ the Pacific Policy Studies, 1(1), pp. 144-159.

Staver, A. C., Archibald, S. and Levin, S. A. (2011) 'The Global Extent and Determinants of Savanna and Forest as Alternative Biome States', Science, 334(6053), pp. 230-232.

Stein, A. (2015) 'Environmental heterogeneity-species richness relationships from a global perspective', Frontiers of Biogeography, 7(4).

Stein, A., Gerstner, K. and Kreft, H. (2014) 'Environmental heterogeneity as a universal driver of species richness across taxa, biomes and spatial scales', Ecology letters, 17(7), pp. 866-880.

Stephenson, N. (1998) 'Actual evapotranspiration and deficit: biologically meaningful correlates of vegetation distribution across spatial scales', Journal of Biogeography, 25(5), pp. 855870.

Stevens, N. et al. (2017) 'Savanna woody encroachment is widespread across three continents', Global Change Biology, 23, pp. 235- 244.

Stieglitz, M. et al. (1997) 'An efficient approach to modeling the topographic control of surface hydrology for regional and global climate modeling', Journal of Climate, 10(1), pp. 118 137.

Still, C. J. et al. (2003) 'Global distribution of C3 and C4 vegetation: Carbon cycle implications', Global Biogeochemical Cycles, 17, p. 1006.

Strassburg, B. B. et al. (2012) 'Impacts of incentives to reduce emissions from deforestation on global species extinctions', Nature Climate Change, 2(5), pp. 350-355.

Strauss, S. Y. and Cacho, N. I. (2013) 'Nowhere to run, nowhere to hide: the importance of enemies and apparency in adaptation to harsh soil environments', The American Naturalist, 182(1), pp. E1-E14.

Strimbeck, G. R. et al. (2008) 'Dynamics of low-temperature acclimation in temperate and boreal conifer foliage in a mild winter climate', Tree physiology, 28(9), pp. 1365-1374.

Strimbeck, G. R. et al. (2015) 'Extreme low temperature tolerance in woody plants', Frontiers in plant science, 6, p. 884 .

Sundaram, B. and Hiremath, A. J. (2012) 'Lantana camara invasion in a heterogeneous landscape: patterns of spread and correlation with changes in native vegetation', Biological Invasions, 14(6), pp. 1127-1141.

Sutinen, M.-L., Palta, J. P. and Reich, P. B. (1992) 'Seasonal differences in freezing stress resistance of needles of Pinus nigra and Pinus resinosa: evaluation of the electrolyte leakage method', Tree Physiology, 11(3), pp. 241-254.

Svenning, J.-C. et al. (2015) 'The influence of paleoclimate on present-day patterns in biodiversity and ecosystems', Annual Review of Ecology, Evolution, and Systematics, 46.

Symes, W. S. et al. (2016) 'Why do we lose protected areas? Factors influencing protected area downgrading, downsizing and degazettement in the tropics and subtropics', Global Change Biology, 22, pp. 656- 665 .

Syvertsen, J. P. et al. (1976) 'Carbon reduction pathways and standing crop in three Chihuahuan Desert plant communities', The Southwestern Naturalist, pp. 311-320.

Tang, G. et al. (2010) 'Estimating potential forest NPP, biomass and their climatic sensitivity in New England using a dynamic ecosystem model', Ecosphere, 1(6), p. art18.

Tarnocai, C. et al. (2009) 'Soil organic carbon pools in the northern circumpolar permafrost region', Global biogeochemical cycles, 23(2). 
Taylor, A. H. and Zisheng, Q. (1988) 'Regeneration from seed of Sinarundinaria fangiana, a bamboo, in the Wolong Giant Panda Reserve, Sichuan, China', American Journal of Botany, pp. 1065-1073.

Team, R. C. (2018) R: A language and environment for statistical computing. Vienna, Austria: R Foundation for Statistical Computing.

Terrer, C. et al. (2016) 'Mycorrhizal association as a primary control of the $\mathrm{CO}_{2}$ fertilization effect', Science, 353(6294), pp. 72-74.

Terrer, C. et al. (2018) 'Ecosystem responses to elevated $\mathrm{CO}_{2}$ governed by plant-soil interactions and the cost of nitrogen acquisition', New Phytologist, 217(2), pp. 507-522.

Terrer, C. et al. (2019) 'Nitrogen and phosphorus constrain the $\mathrm{CO}_{2}$ fertilization of global plant biomass', Nature Climate Change, 9(9), pp. 684-689.

Tews, J. et al. (2004) 'Animal species diversity driven by habitat heterogeneity/diversity: The importance of keystone structures', Journal of Biogeography, 31, pp. 79-92.

Thekaekara, T. et al. (2017) 'Notes from the other side of a forest fire', Economic \& Political Weekly, 52(25-26), pp. 22-25.

Thompson, R. L. et al. (2016) 'Top-down assessment of the Asian carbon budget since the mid 1990s', Nature Communications, 7, p. 10724.

Thornes, J. (1996) 'Desertification in the Mediterranean', Mediterranean desertification and land use, pp. 1-12.

Thuiller, W. et al. (2005) 'Climate change threats to plant diversity in Europe', Proceedings of the National Academy of Sciences of the United States of America, 102, pp. 8245-8250.

Thuiller, W. et al. (2008) 'Predicting global change impacts on plant species' distributions: future challenges', Perspectives in Plant Ecology, Evolution and Systematics, 9(3), pp. 137152.

Tian, H. et al. (1999) 'The sensitivity of terrestrial carbon storage to historical climate variability and atmospheric $\mathrm{CO} 2$ in the United States', Tellus B: Chemical and Physical Meteorology, 51(2), pp. 414-452.

Tian, H. et al. (2003) 'Regional carbon dynamics in monsoon Asia and its implications for the global carbon cycle', Global and Planetary Change, 37(3-4), pp. 201-217.

Tian, H. Z. et al. (2010) 'Trend and characteristics of atmospheric emissions of $\mathrm{Hg}$, As, and Se from coal combustion in China, 1980-2007', Atmospheric Chemistry and Physics, 10(23), pp. 11905-11919.

Tjoelker, M. G., Oleksyn, J. and Reich, P. B. (2001) 'Modelling respiration of vegetation: evidence for a general temperature-dependent Q10', Global Change Biology, 7(2), pp. 223-230.

Torello-Raventos, M. et al. (2013) 'On the delineation of tropical vegetation types with an emphasis on forest/savanna transitions', Plant Ecology \& Diversity, 6(1), pp. 101-137.

Tripathi, P., Behera, M. D. and Roy, P. S. (2017) 'Optimized grid representation of plant species richness in India-Utility of an existing national database in integrated ecological analysis', PloS one, 12(3), p. e0173774.

Trugman, A. T. et al. (2018) 'Sensitivity of woody carbon stocks to bark investment strategy in Neotropical savannas and forests', Biogeosciences, 15(1), p. 233.

Tuanmu, M.-N. and Jetz, W. (2014) 'A global 1-km consensus land-cover product for biodiversity and ecosystem modelling', Global Ecology and Biogeography, 23(9), pp. 1031-1045.

Turetsky, M. R. et al. (2019) Permafrost collapse is accelerating carbon release. Nature Publishing Group.

Twine, W. (2019) 'Socioeconomic Value of Savannas', Savanna Woody Plants and Large Herbivores, pp. 151-179. 
UNEP (2003) United Nations Environment Programme Division of Early,GEO Year Book: 2003-2006. United Nations Environment Programme.

United Nations Statistics Division (2007) Demographic and social statistics.

Urban, J. et al. (2017) 'Stomatal conductance increases with rising temperature', Plant signaling \& behavior, 12(8), p. e1356534.

Valdes, P. J. et al. (2017) 'The BRIDGE HadCM3 family of climate models: HadCM3@ Bristol v1. 0', Geoscientific Model Development, 10, pp. 3715-3743.

Van Bodegom, P. M. et al. (2012) 'Going beyond limitations of plant functional types when predicting global ecosystem-atmosphere fluxes: exploring the merits of traits-based approaches', Global Ecology and Biogeography, 21(6), pp. 625-636.

Van der Werf, G. R. et al. (2010) 'Global fire emissions and the contribution of deforestation, savanna, forest, agricultural, and peat fires (1997-2009)', Atmospheric Chemistry and Physics, 10(23), pp. 11707-11735.

Van Nes, E. H. and Scheffer, M. (2007) 'Slow recovery from perturbations as a generic indicator of a nearby catastrophic shift', The American Naturalist, 169(6), pp. 738-747.

Van Vuuren, D. P. et al. (2011) 'A special issue on the RCPs', Climatic Change, 109(1-2), p. 1.

Veldman, J. W. et al. (2015) 'Where Tree Planting and Forest Expansion are Bad for Biodiversity and Ecosystem Services', BioScience, 65(10), pp. 1011-1018.

Veldman, J. W. (2016) 'Clarifying the confusion: old-growth savannahs and tropical ecosystem degradation', Philosophical Transactions of the Royal Society B: Biological Sciences, 371(1703), p. 20150306.

Venkataraman, K. and Sivaperuman, C. (2018) 'Biodiversity hotspots in India', in Indian Hotspots. Springer, pp. 1-27.

Venkateswaran, R. and Parthasarathy, N. (2005) 'Tree population changes in a tropical dry evergreen forest of south India over a decade (1992-2002)', Biodiversity \& Conservation, 14(6), pp. 1335-1344.

Venter, Z. S., Cramer, M. D. and Hawkins, H.-J. (2018) 'Drivers of woody plant encroachment over Africa', Nature communications, 9(1), p. 2272.

Veraart, A. J. et al. (2012) 'Recovery rates reflect distance to a tipping point in a living system', Nature, 481(7381), pp. 357-359.

Verbeeck, H. and Kearsley, E. (2016) 'The importance of including lianas in global vegetation models', Proceedings of the National Academy of Sciences, 113(1), pp. E4-E4.

Verheijen, L. M. et al. (2013) 'Impacts of trait variation through observed trait-climate relationships on performance of an Earth system model: a conceptual analysis'.

Verheijen, L. M. (2015) 'A plant traits-based approach in vegetation modeling'.

Verhoeven, K. J. et al. (2004) 'Can a genetic correlation with seed mass constrain adaptive evolution of seedling desiccation tolerance in wild barley?' International Journal of Plant Sciences, 165(2), pp. 281-288.

Verstraete, M. M., Scholes, R. J. and Smith, M. S. (2009) 'Climate and desertification: looking at an old problem through new lenses', Frontiers in Ecology and the Environment, 7(8), pp. 421-428.

Vicente-Serrano, S. M. et al. (2013) 'Response of vegetation to drought time-scales across global land biomes', Proceedings of the National Academy of Sciences, 110(1), pp. 52-57.

Vitasse, Y., Lenz, A. and Körner, C. (2014) 'The interaction between freezing tolerance and phenology in temperate deciduous trees', Frontiers in Plant Science, 5, p. 541.

Vitousek, P. M. et al. (1997) 'Human domination of Earth's ecosystems', Science, 277(5325), pp. 494-499.

Vivek, P. and Parthasarathy, N. (2015) 'Diversity and carbon stock assessment of trees and lianas in tropical dry evergreen forest on the Coromandel Coast of India', Trop. Plant Res, 2(3), pp. 2349-265. 
Vlek, P. L. et al. (2017) 'Trade-offs in multi-purpose land use under land degradation', Sustainability, 9(12), p. 2196.

Vuuren, D. P. et al. (2011) 'The representative concentration pathways: An overview', Climatic Change, 109, pp. 5- 31.

Walker, M. D. et al. (2006) 'Plant community responses to experimental warming across the tundra biome', Proceedings of the National Academy of Sciences, 103(5), pp. 13421346.

Walter, H. (1985) 'Vegetation of the earth and ecological systems of the geo-biosphere. SpringerVerlag', Berlin, Germany.

Walther, G. R. (2010) 'Community and ecosystem responses to recent climate change', Philosophical Transactions of the Royal Society B: Biological Sciences, 365, pp. 20192024.

Wang, T. et al. (2012) 'ClimateWNA-high-resolution spatial climate data for western North America', Journal of Applied Meteorology and Climatology, 51(1), pp. 16-29.

Wang, W. et al. (2013) 'Soil respiration and organic carbon dynamics with grassland conversions to woodlands in temperate China', PloS one, 8(8), p. e71986.

Wang, W. J. et al. (2019) 'Effects of rising atmospheric CO2, climate change, and nitrogen deposition on aboveground net primary production in a temperate forest', Environmental Research Letters, 14(10), p. 104005.

Wang, X. et al. (2017) 'Moisture-induced greening of the South Asia over the past three decades', Global change biology, 23(11), pp. 4995-5005.

Wang, Y. and Cao, S. (2011) Carbon sequestration may have negative impacts on ecosystem health. ACS Publications ,pp. 1759-1760.

Warren, J. M. et al. (2011) 'Ecohydrologic impact of reduced stomatal conductance in forests exposed to elevated CO2', Ecohydrology, 4(2), pp. 196-210.

Warszawski, L. et al. (2014) 'The inter-sectoral impact model intercomparison project (ISIMIP): project framework', Proceedings of the National Academy of Sciences, 111(9), pp. 3228-3232.

Watson, S. J. et al. (2014) 'Land-use change: incorporating the frequency, sequence, time span, and magnitude of changes into ecological research', Frontiers in Ecology and the Environment, 12(4), pp. 241-249.

Webb, C. T. et al. (2010) 'A structured and dynamic framework to advance traits-based theory and prediction in ecology', Ecology letters, 13(3), pp. 267-283.

Wei, Y. et al. (2014) 'The North American carbon program multi-scale synthesis and terrestrial model intercomparison project-Part 2: Environmental driver data', Geoscientific Model Development Discussions, 7, pp. 2875-2893.

White, M. A. et al. (2000) 'Parameterization and sensitivity analysis of the BIOME-BGC terrestrial ecosystem model: net primary production controls', Earth interactions, 4(3), pp. $1-85$.

Whittaker, R. H. (1970) 'Communities and ecosystems.', Communities and ecosystems.

Wigley, B. J., Bond, W. J. and Hoffman, M. T. (2009) 'Bush encroachment under three contrasting land-use practices in a mesic South African savanna', African Journal of Ecology, 47(s1), pp. 62-70.

Wilcove, D. S. et al. (2013) 'Navjot's nightmare revisited: logging, agriculture, and biodiversity in Southeast Asia', Trends in ecology \& evolution, 28(9), pp. 531-540.

Wilcox, B. P. et al. (2018) 'Emerging frameworks for understanding and mitigating woody plant encroachment in grassy biomes', Current Opinion in Environmental Sustainability, 32, pp. 46-52.

Williams, P. R. (2009) 'Contrasting demographics of tropical savanna and temperate forest eucalypts provide insight into how savannas and forests function. A case study using 
Corymbia clarksoniana from north-eastern Australia', Austral ecology, 34(2), pp. 120131.

Williams, R. J. et al. (1999) 'Fire regime, fire intensity and tree survival in a tropical savanna in northern Australia', Austral Ecology, 24(1), pp. 50-59.

Wingfield, J. C. (2013) 'Ecological processes and the ecology of stress: the impacts of abiotic environmental factors', Functional Ecology, 27(1), pp. 37-44.

Woodrow, I. E. and Berry, J. A. (1988) 'Enzymatic regulation of photosynthetic CO2, fixation in C3 plants', Annual Review of Plant Physiology and Plant Molecular Biology, 39(1), pp. 533-594.

Woodward, F. I. and Lomas, M. R. (2004) 'Simulating vegetation processes along the Kalahari transect', Global Change Biology, 10(3), pp. 383-392.

Woodward, F. I., Lomas, M. R. and Lee, S. E. (2001) 'Predicting the future productivity and distribution of global terrestrial vegetation', Terrestrial global productivity, pp. 521-541.

Wright, I. J. et al. (2004) 'The worldwide leaf economics spectrum', Nature, 428, pp. 821- 827.

Wright, I. J. et al. (2005) 'Modulation of leaf economic traits and trait relationships by climate', Global Ecology and Biogeography, 14(5), pp. 411-421.

Wright, I. J. et al. (2017) 'Global climatic drivers of leaf size', Science, 357, pp. 917-921.

Wullschleger, S. D. et al. (2014) 'Plant functional types in Earth system models: past experiences and future directions for application of dynamic vegetation models in high-latitude ecosystems', Annals of botany, 114(1), pp. 1-16.

Wuyts, B., Champneys, A. R. and House, J. I. (2017) 'Amazonian forest-savanna bistability and human impact', Nature Communications, 8, p. 15519.

Xiang, S. et al. (2013) 'Contrasting leaf trait scaling relationships in tropical and temperate wet forest species', Functional Ecology, 27(2), pp. 522-534.

$\mathrm{Xu}, \mathrm{L}$. and Baldocchi, D. D. (2003) 'Seasonal trends in photosynthetic parameters and stomatal conductance of blue oak (Quercus douglasii) under prolonged summer drought and high temperature', Tree physiology, 23(13), pp. 865-877.

$\mathrm{Xu}, \mathrm{X}$. et al. (2013) 'Implications of ice storm damages on the water and carbon cycle of bamboo forests in southeastern China', Agricultural and forest meteorology, 177, pp. 35-45.

$\mathrm{Xu}, \mathrm{X}$. et al. (2016) 'Diversity in plant hydraulic traits explains seasonal and inter-annual variations of vegetation dynamics in seasonally dry tropical forests', New Phytologist, 212(1), pp. 80-95.

Yadava, P. S. and Singh, J. S. (1977) 'Grassland vegetation; its structure, function, utilization and management' Progress in ecology. Volume 2. Grassland vegetation. Its structure, function, utilization and management. .

Yahara, T. et al. (2012) 'Strategies to observe and assess changes of terrestrial biodiversity in the Asia-Pacific regions', in The Biodiversity Observation Network in the Asia-Pacific Region. Springer, pp. 3-19.

Yang, B. et al. (2018) 'Allocation mechanisms of non-structural carbohydrates of Robinia pseudoacacia L. seedlings in response to drought and waterlogging', Forests, 9(12), p. 754.

Yang, L. H. and Rudolf, V. H. W. (2010) 'Phenology, ontogeny and the effects of climate change on the timing of species interactions', Ecology letters, 13(1), pp. 1-10.

Yang, Y. et al. (2015) 'From plant functional types to plant functional traits: A new paradigm in modelling global vegetation dynamics', Progress in Physical Geography, 39(4), pp. 514535.

Yang, Y. et al. (2016) 'A novel approach for modelling vegetation distributions and analysing vegetation sensitivity through trait-climate relationships in China', Scientific reports, 6 , p. 24110. 
Yuan, W. et al. (2019) 'Increased atmospheric vapor pressure deficit reduces global vegetation growth', Science advances, 5(8), p. eaax 1396.

Yue, C. et al. (2020) 'Contribution of land use to the interannual variability of the land carbon cycle', Nature communications, 11(1), pp. 1-11.

Zachos, F. E. and Habel, J. C. (eds) (2011) Biodiversity hotspots. Distribution and protection of conservation priority areas. Berlin and Heidelberg, Germany: Springer-Verlag.

Zaimes, G. N., Gounaridis, D. and Symenonakis, E. (2019) 'Assessing the impact of dams on riparian and deltaic vegetation using remotely-sensed vegetation indices and Random Forests modelling', Ecological Indicators, 103, pp. 630-641.

Zemunik, G. et al. (2015) 'Diversity of plant nutrient-acquisition strategies increases during longterm ecosystem development', Nature plants, 1(5), p. 15050.

Zeng, C. et al. (2013) 'Noise-and delay-induced regime shifts in an ecological system of vegetation', Journal of Statistical Mechanics: Theory and Experiment, 2013(10), p. P10017.

Zeng, Z. et al. (2017) 'Climate mitigation from vegetation biophysical feedbacks during the past three decades', Nature Climate Change, 7, pp. 432- 436.

Zhang, H., Henderson-Sellers, A. and McGuffie, K. (1996) 'Impacts of tropical deforestation. Part I: Process analysis of local climatic change', Journal of Climate, 9(7), pp. 14971517.

Zhang, K. et al. (2010) 'A continuous satellite-derived global record of land surface evapotranspiration from 1983 to 2006', Water Resources Research, 46(9).

Zhang, Yongqiang et al. (2016) 'Multi-decadal trends in global terrestrial evapotranspiration and its components', Scientific reports, 6, p. 19124.

Zhang, Y. et al. (2016) 'Seasonal and interannual changes in vegetation activity of tropical forests in Southeast Asia', Agricultural and Forest Meteorology, 224, pp. 1- 10.

Zhao, L., Dai, A. and Dong, B. (2018) 'Changes in global vegetation activity and its driving factors during 1982-2013', Agricultural and Forest Meteorology, 249, pp. 198-209.

Zhu, S. D. et al. (2013) 'Plant hydraulics and photosynthesis of 34 woody species from different successional stages of subtropical forests', Plant, cell \& environment, 36(4), pp. 879891.

Zizka, A., Govender, N. and Higgins, S. I. (2014) 'How to tell a shrub from a tree: A life-history perspective from a South African savanna', Austral ecology, 39(7), pp. 767-778.

Zobel, D. B. and Singh, S. P. (1997) 'Himalayan forests and ecological generalizations', BioScience, 47(11), pp. 735-745. 


\section{CURRICULUM VITAE}

DUSHYANT KUMAR

Current Address: Senckenberg Biodiversity and Climate Research Centre Frankfurt

Georg-Voigt-Straße 14-16

D-60325 Frankfurt am Main, Germany

E-mail: dushyantkumar.sbikf@gmail.com

Computer skills $\quad \mathrm{C}++$; Statistical \& Data: R ArcGIS; SWAT models

$\underline{\text { Education }}$

$2015-2021$

2014-2015

PhD Ecological Modelling, Biogeography

Senckenberg Biodiversity and Climate Research Center and Goethe University Frankfurt am Main.

Thesis Title: - Modelling vegetation-climate interactions in South and Southeast Asia using a trait-based dynamic vegetation model.

Research Assistant at Discipline of Earth Sciences Indian Institute of Technology Gandhinagar, Gujarat, India Project: - Impact of climate change and land -use change on stream flow and sediment generation.

$2012-2014$

M-Tech in Earth system Science \& Technology, Indian Institute of Technology Kharagpur, West Bengal, India Thesis Title: - Assessing Forests Carbon Dynamics using an ecosystem Model (LPJ-GUESS) in the Ganga River Basin, India.

2008-2012

B-Tech in Agricultural Engineering, College of Agricultural Engineering Raichur, Karnataka India Thesis Title: - Performance Evaluation of Solar Powered Refrigerator.

\section{Training and Workshops}

- Workshop on "Modelling challenges for mountain ecosystems", at Institute of Geography, Universität Hamburg, Feburary 2020.

- Workshop on Field Techniques by the Plant Environmental Physiology Group (PEPG)", Lisbon Portugal, September 2018.

- Workshop on "Geospatial Technologies in Hydrological Modelling" at IIT Kharagpur, 2013.

- Intensive Training on "Agricultural Mechanization at Central Farm Machinery Training and Testing Institute" Tractor Nagar, Budni Madhya Pradesh, India, 2011.

- Training on "Survey design, installation, operation and maintenance of micro irrigation systems" Jain Irrigation Systems Ltd. Jalgaon Maharashtra India, 2011.

\section{$\underline{\text { Awards and Scholarships }}$}

- Ministry of Human Resources Development of India Scholarship to pursue Master's degree in Indian Institute of Technology (2012- 2014).

- Indian council for Agricultural Research India Scholarship to pursue Bachelor's degree in University of Agricultural Sciences Raichur (2008- 20012).

- Awarded four Gold Medals by the University of Agriculture Sciences for the best performance in the field of Agricultural Engineering in Bachelor program. 


\section{Conference Presentations}

- Kumar D., Pfeiffer M., Gaillard C., Langan L., Martens C., and Scheiter S., (2020) Impact of climate change on biome distribution and productivity of the tropical ecosystems under RCP scenarios in South Asia. EGU General Assembly Conference (2020).

- Kumar, D., Pfeiffer, M., Langan, L., Gaillard, C., Martens, C., Scheiter, S. (2019). How does climate change shift the grassland-savanna-forest biome boundaries in South Asia? A dynamic vegetation modelling approach, International Savanna Science Network Meeting (2019), Skukuza, South Africa.

- Kumar, D., Langan, L., Pfeiffer, M., Scheiter, S. (2017). How do climate change and fire shift the grassland-savanna-forest biome boundaries in India? A dynamic vegetation modelling approach, International Biogeography Society Meeting (2017), Bengaluru, India.

- Kumar, D., Scheiter, S. (2017). Current and future vegetation dynamics in India's tropical ecosystems: insights from an adaptive dynamic vegetation model (aDGVM2), Student Conference on Conservation Science (2017), Bengaluru, India.

- Kumar, D., Langan, L., Scheiter, S. (2017). Future vegetation patterns in biodiversity hotspots in India under changing climate, European Conference of Tropical Ecology (2017), Brussels, Belgium.

\section{$\underline{\text { Publications }}$}

- Pfeiffer, M., Kumar, D., Martens, C., and Scheiter, S.: Climate change will cause non-analogue vegetation states in Africa and commit vegetation to long-term change, Biogeosciences, 2020, 17, 5829-5847, doi:10.5194/bg-17-5829-2020.

- Kumar, D., Pfeiffer, M., Gaillard, C., Langan, L., and Scheiter, S.: Climate change and elevated $\mathrm{CO}_{2}$ favor forest over savanna under different future scenarios in South Asia, Biogeosciences, 2021; 18, 2957-2979, doi: 10.5194/bg-18-2957-2021.

- Scheiter, S, Kumar, D, Corlett, RT, et al. Climate change promotes transitions to tall evergreen vegetation in tropical Asia. Global Change Biology, 2020; 26: 51065124, doi: $10.1111 / \mathrm{gcb} .15217$.

- Kumar, D., Pfeiffer, M., Gaillard, C., Langan, L., Martens, C., and Scheiter, S.: Misinterpretation of Asian savannas as degraded forest can mislead management and conservation policy under climate change. Biological Conservation, 2020; 241, 108293, doi: 10.1016/j.biocon.2019.108293.

- Kumar, D. \& Scheiter, S.: Biome diversity in South Asia-How can we improve vegetation models to understand global change impact at regional level? Science of The Total Environment, 2019; 671, 1001-1016, doi: 10.1016/j.scitotenv.2019.03.251.

- Gaillard, C., Langan, L., Pfeiffer, M., Kumar, D., Martens, C., Higgins, S.I. \& Scheiter, S.: African shrub distribution emerges via height-Sapwood conductivity trade-off. Journal of Biogeography, 2018; 45, 2815-2826, doi; 10.1111/jbi.13447. 